\title{
(4)
}

UNIVERSIDAD PERUANA DE CIENCIAS APLICADAS

FACULTAD DE INGENIERÍA

CARRERA DE INGENIERÍA DE SISTEMAS

\section{PROPUESTA DE UNA ARQUITECTURA \\ EMPRESARIAL PARA LA EMPRESA ERNST AND YOUNG}

TESIS

Para optar por el título profesional de Ingeniero de Sistemas

AUTORES:

GALDOS CORREA, ANDREE ALEJANDRO - 0000-0003-4927-0469 ARIAS EGÚSQUIZA, JOHAN ADOLFO - 0000-0003-4266-4502

ASESORES:

LÓPEZ PÉREZ SAMANTHA DEL CARMEN - 0000-0003-3707-4698

SUBAUSTE OLIDEN DANIEL ALEJANDRO - 0000-0003-1131-1384

Lima, Septiembre de 2018 
El presente trabajo se lo dedicamos a nuestros padres por ayudarnos en cada momento de nuestra vida profesional; Además, a los profesionales de esta carrera, que han ayudado a innovar el mundo donde vivimos. 


\section{(1)}

\section{AGRADECIMIENTOS}

El presente trabajo es en agradecimiento a los profesores y asesores, por enseñarnos y desarrollarnos como profesionales en virtud de sus conocimientos. 


\section{(1)}

\section{RESUMEN}

El trabajo de estudio propone implementar una arquitectura empresarial mediante TOGAF para la empresa Ernst and Young. Esta propuesta, se basará en un subproceso llamado Auditoría Interna de Riesgos del proceso de Consultoría que estará alineado a cumplir con los objetivos estratégicos asociados a la organización. Además, para el desarrollo de esta solución, se optará usar Scrum.

En esta solución se desarrollarán 4 Capítulos. El Capítulo 1, se establece el marco teórico del proyecto, objeto de estudio que contiene la organización objetivo como es la misión, visión, objetivos estratégicos, organigrama y alcance del proyecto. Además, los objetivos del proyecto tanto general como específicos. Por último, los beneficios del proyecto tanto tangibles e intangibles.

El Capítulo 2, tiene como contenido la arquitectura empresarial donde se ve la situación actual de la organización, para luego llegar a una propuesta de solución de arquitectura empresarial mediante TOGAF. El Capítulo 3, se definen las fortalezas y debilidades de la organización; además, se crean y trabajan los equipos de trabajo mediante el uso de Scrum a fin de brindar una solución tecnológica para EY, para reducir las brechas identificadas en el Capítulo 2. Por último, el Capítulo 4 muestra la estructura propuesta que se base sobre el Capítulo 1 de acuerdo al objeto de estudio para desarrollar un sistema tecnológico del subproceso de Auditoría Interna de Riesgos que este alienado a los objetivos de la organización. Adicionalmente, se brinda las conclusiones y recomendaciones para que EY vea la factibilidad de desarrollar esta solución propuesta.

\section{Palabras clave: Arquitectura Empresarial, Ernst and Young, Marco de trabajo ágil para el desarrollo de software.}




\title{
(1)
}

\begin{abstract}
The study work proposes to implement a business architecture through TOGAF for the company Ernst and Young. This proposal will be based on a sub-process called Internal Risk Auditing of the Consulting process that will be aligned to meet the strategic objectives associated with the organization. In addition, for the development of this solution, you will choose to use Scrum.
\end{abstract}

In this solution, 4 Chapters will be developed. Chapter 1 establishes the theoretical framework of the project, object of study that contains the objective organization such as the mission, vision, strategic objectives, organization chart and scope of the project. In addition, the project objectives both general and specific. Finally, the benefits of the project both tangible and intangible.

Chapter 2, has as its content the business architecture where the current situation of the organization is seen, to then arrive at a proposal of business architecture solution through TOGAF. Chapter 3, defines the strengths and weaknesses of the organization; In addition, work teams are created and work through the use of Scrum in order to provide a technological solution for EY, to reduce the gaps identified in Chapter 2. Finally, Chapter 4 shows the proposed structure based on the Chapter 1 according to the object of study to develop a technological system of the subprocess of Internal Audit of Risks that is alienated to the objectives of the organization. Additionally, the conclusions and recommendations are provided so that EY sees the feasibility of developing this proposed solution..

\section{Keywords: Business Architecture, Ernst and Young, Agile framework for software development.}




\section{(v)}

\section{TABLA DE CONTENIDO}

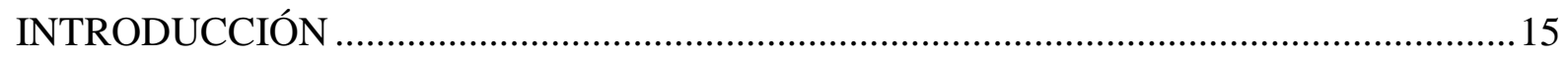

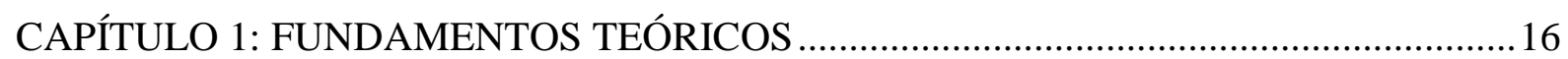

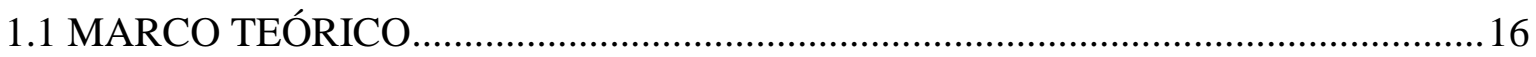

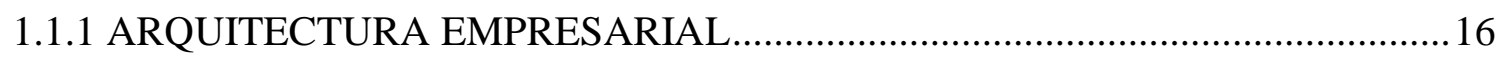

1.1.2 MÉTODOS ÁGILES PARA EL DESARROLLO DE SOFTWARE .....................23

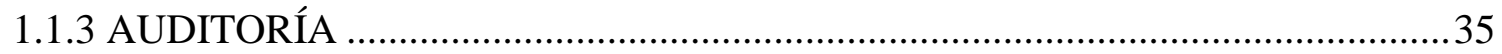

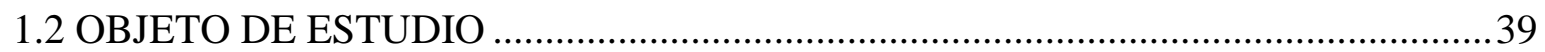

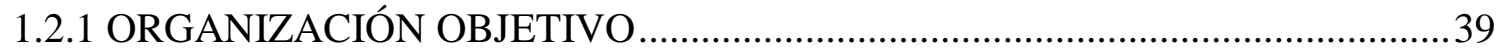

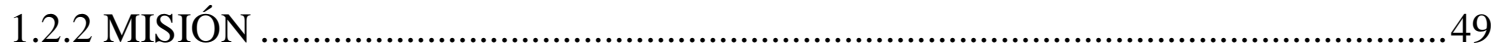

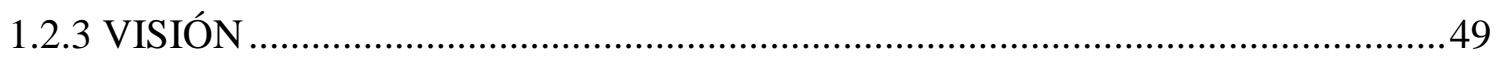

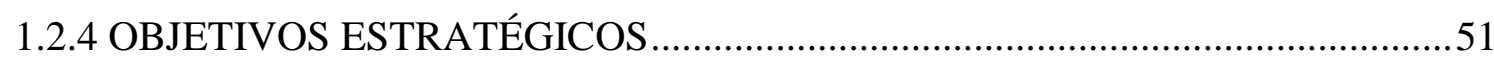

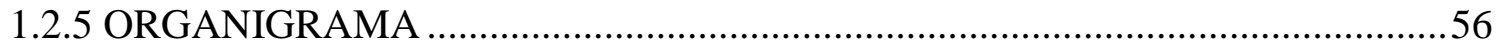

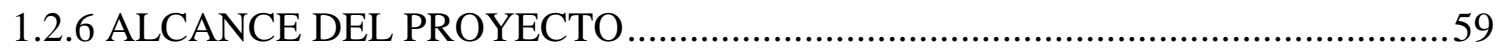

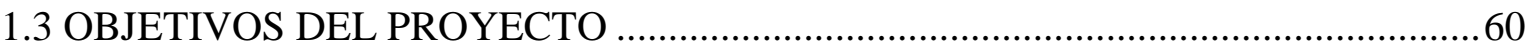

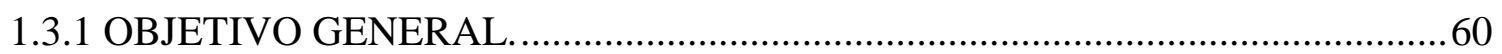

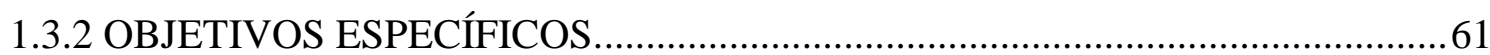

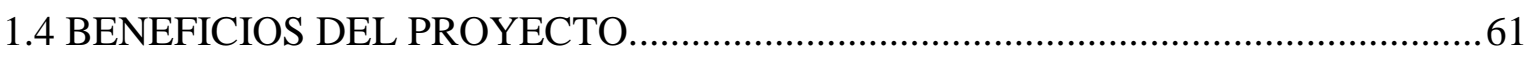

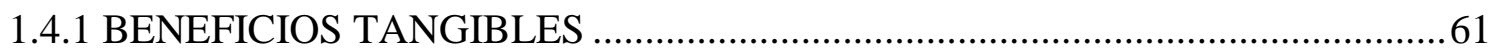

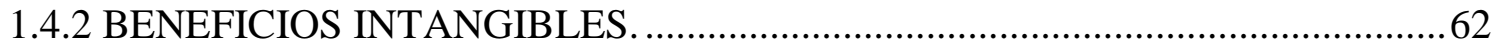

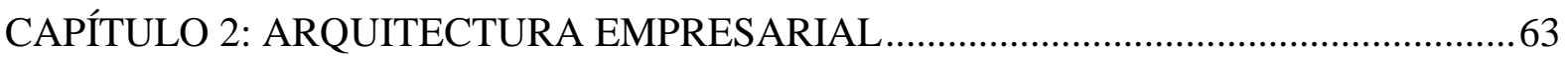

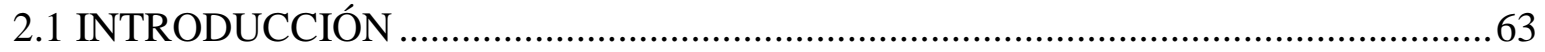

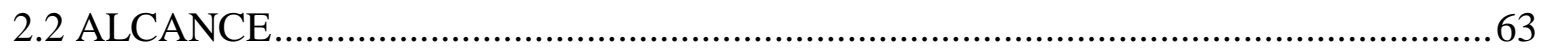

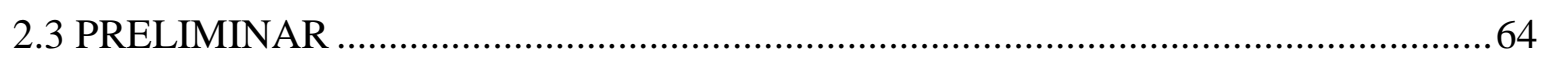

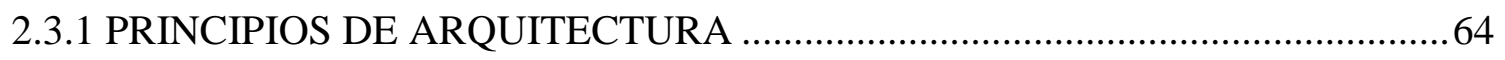

2.3.2 PETICIÓN DE TRABAJO DE ARQUITECURA ................................................. 70

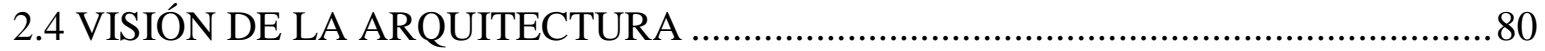




\section{(4)}

2.4.1 INTERESADOS Y SUS PREOCUPACIONES. 80

2.4.2 LISTA DE ASUNTOS / ESCENARIOS QUE DEBEN ABORDARSE................ 81

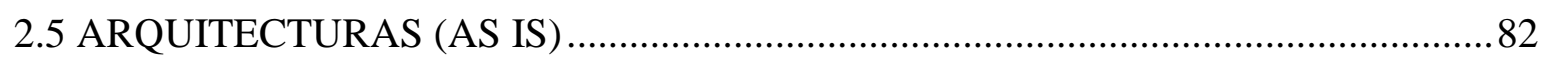

2.5.1 ARQUITECTURA DE NEGOCIO DE LA LÍNEA BASE ................................... 82

2.5.2 ESTRUCTURA DE LA ORGANIZACIÓN DE LA LÍNEA BASE ...................... 82

2.5.3 MAPA DE PROCESO Y FUNCIONES DE NEGOCIO DE LA LÍNEA BASE .. 84

2.5.4 MATRIZ DE OBJETIVOS ESTRATÉGICOS VERSUS PROCESOS DE LA

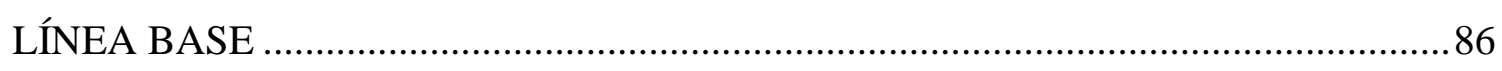

2.5.5 DESCRIPCIÓN DE PROCESO SELECCIONADO DE LA LÍNEA BASE .........89

2.5.6 ROLES DE NEGOCIO DE LA LÍNEA BASE......................................................92

2.5.7 MODELO DE DATOS DEL NEGOCIO DE LA LÍNEA BASE ..........................93

2.5.8 DIAGRAMA DE ACTIVIDADES DEL PROCESO DE LA LÍNEA BASE........96 2.5.9 ARQUITECTURA DE SISTEMAS DE INFORMACIÓN DE LA LÍNEA BASE .97

2.5.10 ARQUITECTURA DE DATOS DE LA LÍNEA BASE .......................................97

2.5.11 MODELO DE DATOS LÓGICO DE LA LÍNEA BASE....................................97

2.5.12 MATRIZ DE DATOS DE PROCESO SELECCIONADO VERSUS PROCESOS

DE NEGOCIO DE LA LÍNEA BASE .................................................................... 97

2.5.13 ARQUITECTURA DE APLICACIONES DE LA LÍNEA BASE ......................97

2.5.14 MATRIZ DE APLICACIONES VERSUS PROCESOS DE NEGOCIO DE LA

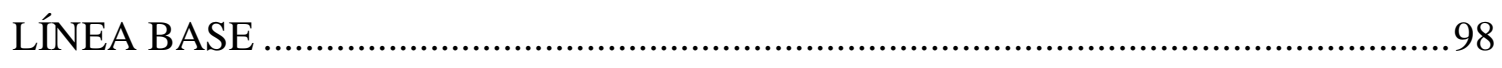

2.5.15 ARQUITECTURA TECNOLÓGICA DE LA LÍNEA BASE ............................ 100

2.5.16 MATRIZ TECNOLÓGICA VERSUS PROCESOS DE NEGOCIO DE LA LÍNEA

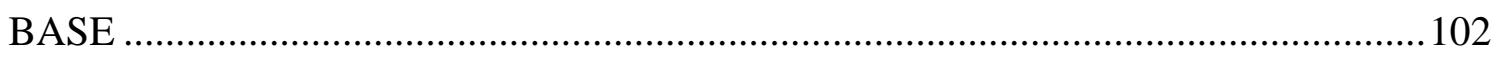

2.5.17 FUNDAMENTOS Y JUSTIFICACIÓN DEL ENFOQUE ARQUITECTÓNICO 103

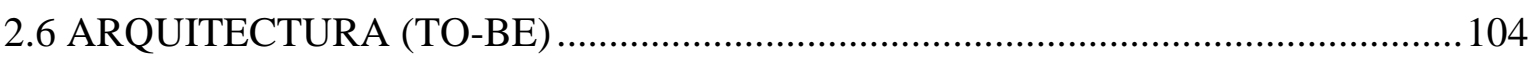

2.6.1 ARQUITECTURA DE NEGOCIO DE LA LÍNEA DESTINO ........................... 104

2.6.2 ESTRUCTURA DE LA ORGANIZACIÓN DE LA LÍNEA DESTINO ............. 105

2.6.3 MAPA DE PROCESO Y FUNCIONES DE NEGOCIO DE LA LÍNEA DE

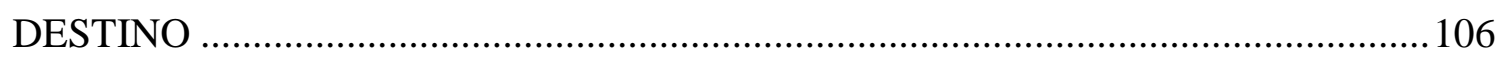




\section{(1)}

2.6.4 MATRIZ DE OBJETIVOS ESTRATÉGICOS VERSUS PROCESOS DE LA

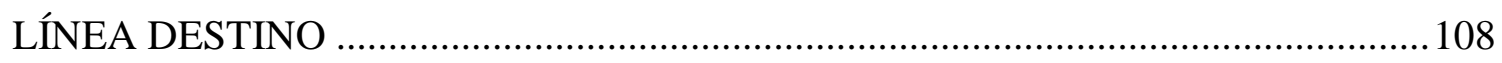

2.6.5 DESCRIPCIÓN DE PROCESO SELECCIONADO DE LA LÍNEA DESTINO 111 2.6.6 ROLES DE NEGOCIO DE LA LÍNEA DESTINO ............................................. 114

2.6.7 MODELO DE DATOS DEL NEGOCIO DE LA LÍNEA DESTINO ..................115 2.6.8 DIAGRAMA DE ACTIVIDADES DEL PROCESO DE LA LÍNEA DESTINO 118

2.6.9 ARQUITECTURA DE SISTEMAS DE INFORMACIÓN DE LA LÍNEA DESTINO 119

2.6.10 ARQUITECTURA DE DATOS DE LA LÍNEA DESTINO .............................119

2.6.11 MODELO DE DATOS LÓGICO DE LA LÍNEA DESTINO ............................119

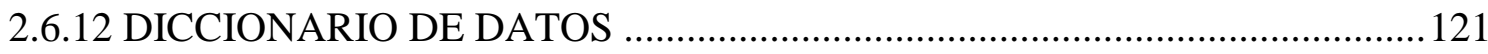

2.6.13 MATRIZ DE DATOS DE PROCESO SELECCIONADO VERSUS PROCESOS

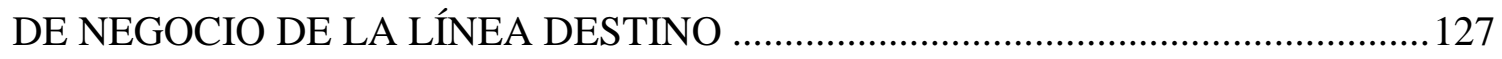

2.6.14 ARQUITECTURA DE APLICACIONES DE LA LÍNEA DESTINO .............. 128

2.6.15 MATRIZ DE APLICACIONES VERSUS PROCESOS DE NEGOCIO DE LA

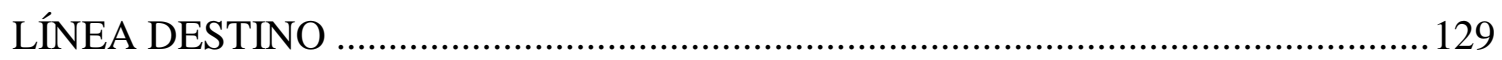

2.6.16 ARQUITECTURA TECNOLÓGICA DE LA LINEA DESTINO .....................130

2.6.17 MATRIZ TECNOLÓGICA VERSUS PROCESOS DE NEGOCIO DE LA LÍNEA

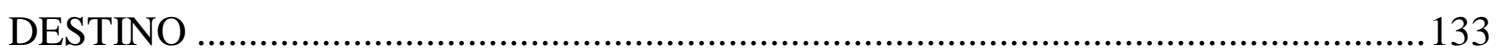

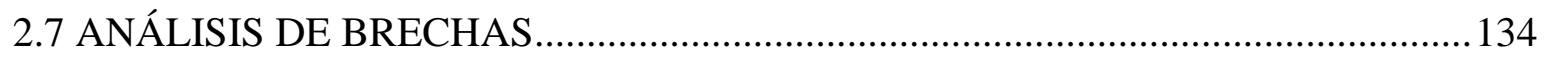

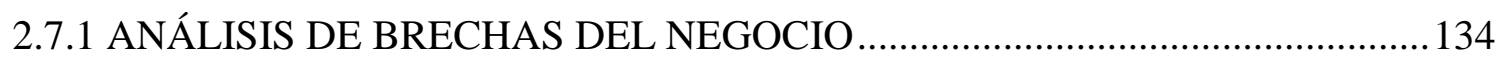

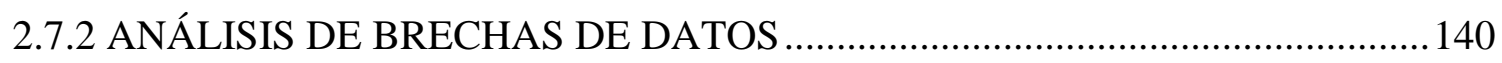

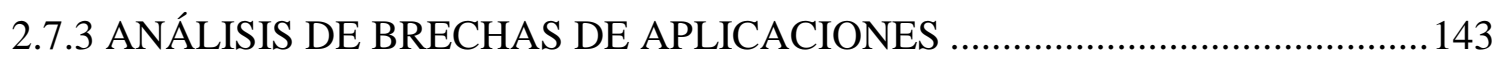

2.7.4 ANÁLISIS DE BRECHAS DE ARQUITECTURA TECNOLÓGICA................ 145

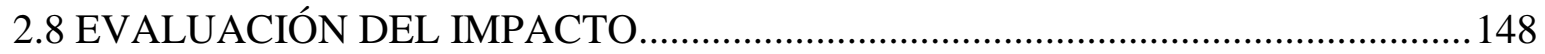

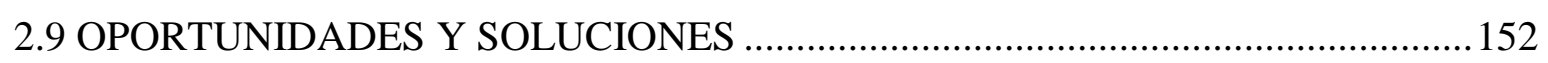

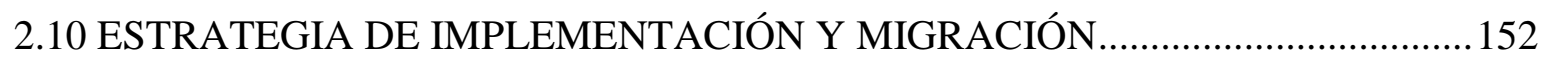

2.11 DIRECCIÓN DE LA IMPLEMENTACIÓN ESTRATÉGICA............................... 152

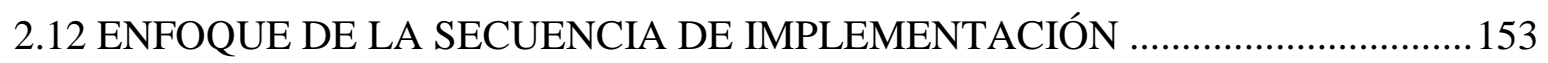

2.13 ESTRUCTURA DE DESGLOSE DEL TRABAJO ................................................ 155 
2.14 CUADRO DE RESUMEN DEL PLAN DE MIGRACIÓN...................................... 156

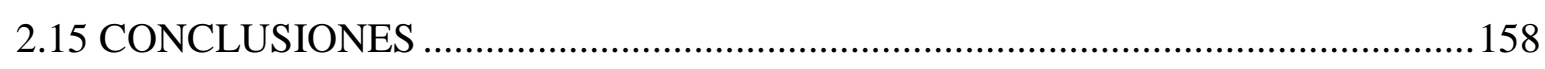

CAPÍTULO 3. MÉTODOS ÁGILES PARA EL DESARROLLO DE SOFTWARE ........... 160

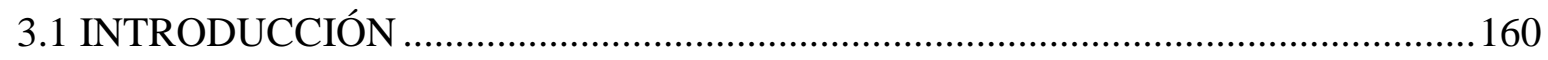

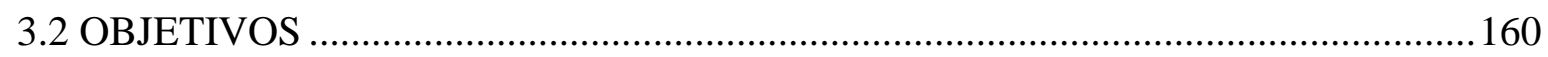

3.3 IDENTIFICACIÓN DE FORTALEZAS Y DEBILIDADES ................................... 161

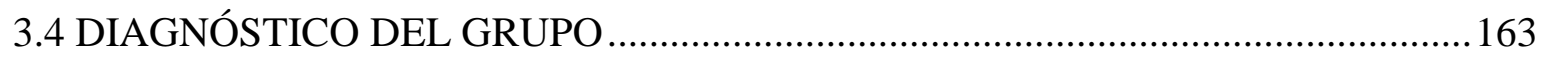

3.5 IDENTIFICACIÓN DE LAS DINÁMICAS PROPUESTAS...................................... 166

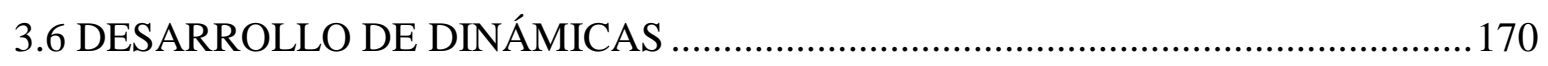

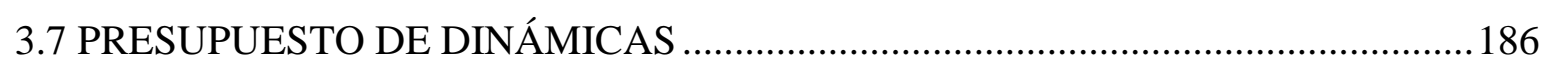

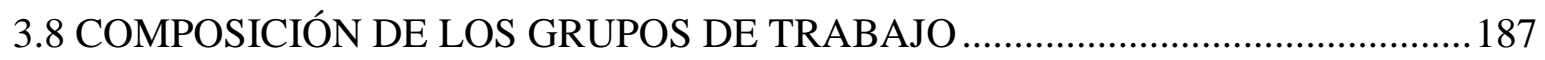

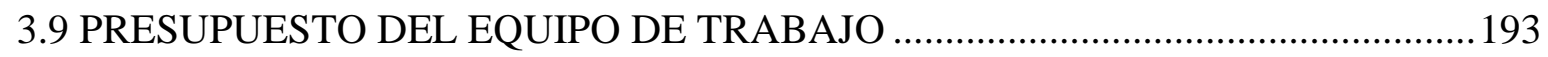

3.10 DEFINICIÓN DE LAS HERRAMIENTAS A UTILIZAR ..................................... 194

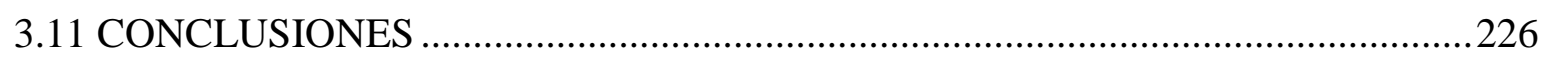

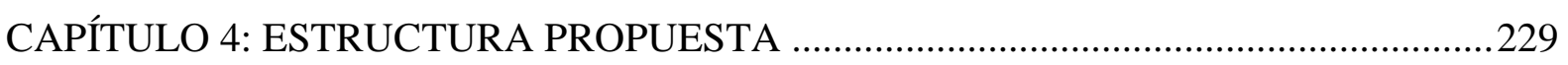

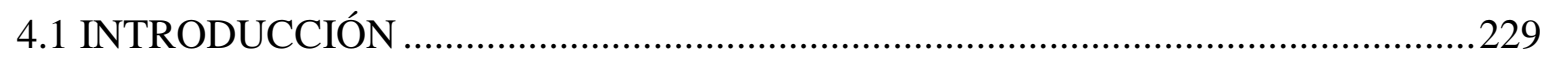

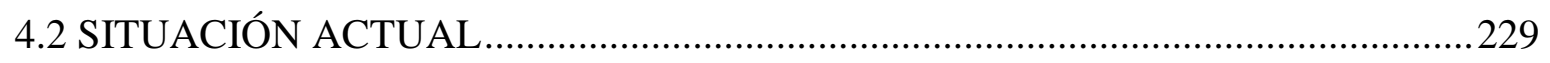

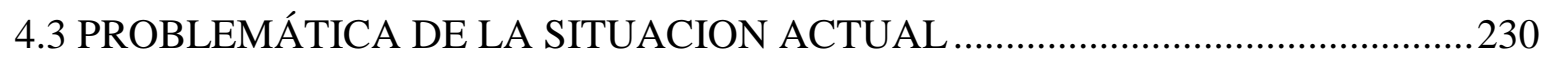

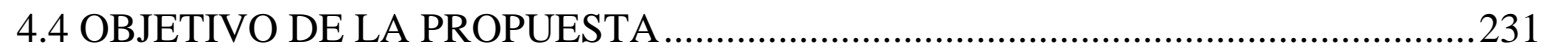

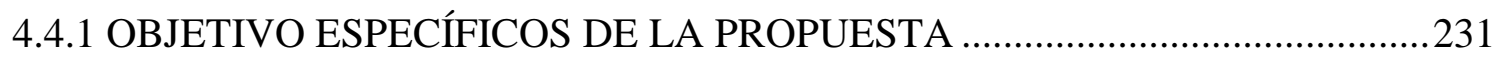

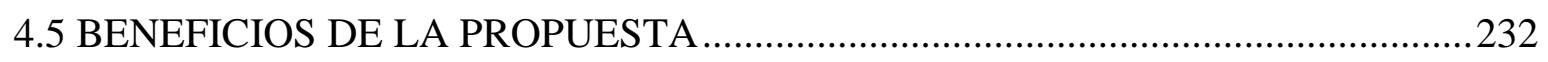

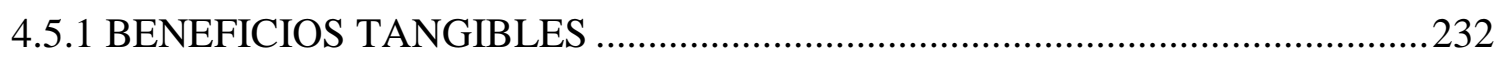

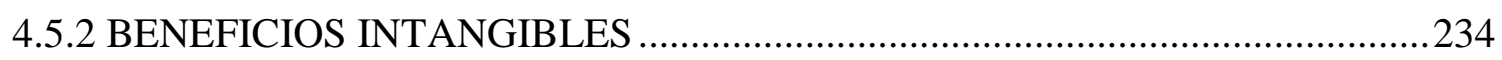

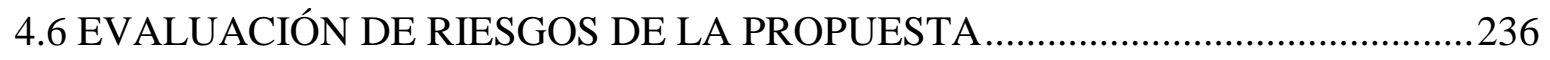

4.7 EVALUACIÓN FINANCIERA DE LA PROPUESTA ...........................................24

4.8 EVALUACIÓN DE MINIMIZAR EL TIEMPO DE TRABAJO SEGÚN LA

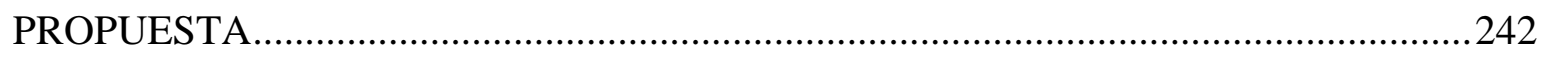

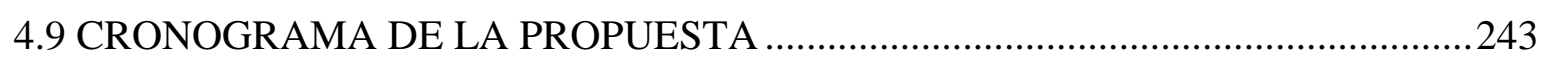

4.10 ESTRUCTURA DE DESGLOSE DE LA PROPUESTA .........................................249

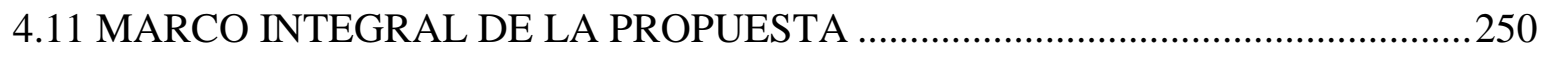

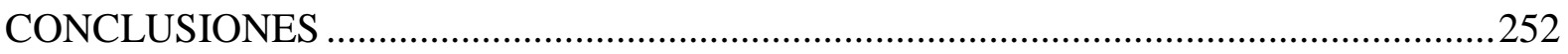




\section{$(1$}

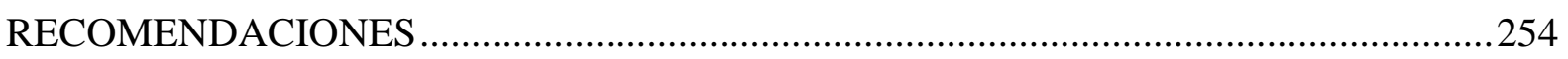

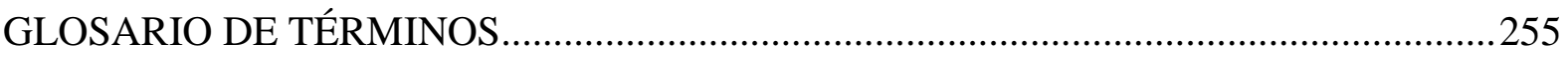

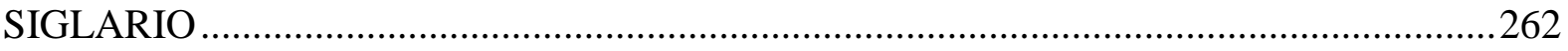

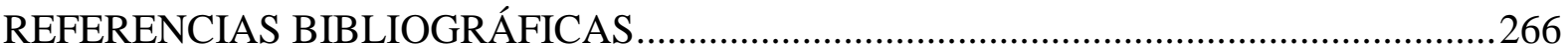

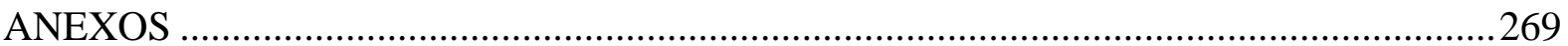




\section{(4)}

\section{ÍNDICE DE TABLAS}

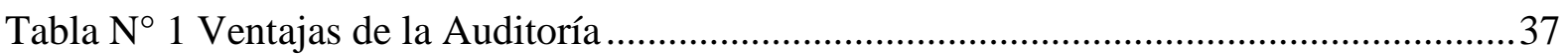

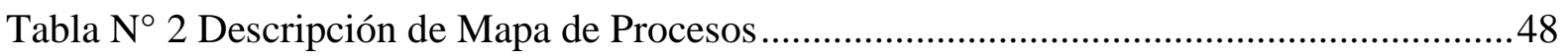

Tabla $\mathrm{N}^{\circ} 3$ Matriz de Objetivos Estratégicos Versus Procesos de Negocio............................53

Tabla N 4 Descripción de Cargos EY Perú ..........................................................................56

Tabla N ${ }^{\circ} 5$ Descripción de Participantes de la Gestión de Cambio..........................................77

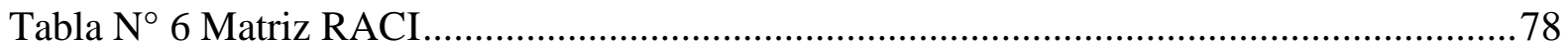

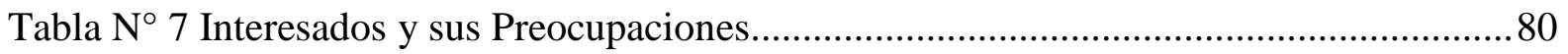

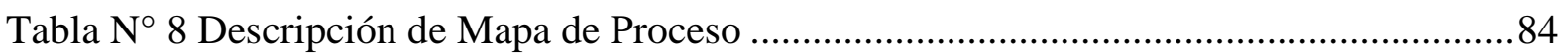

Tabla $\mathrm{N}^{\circ} 9$ Matriz de Objetivos Estratégicos Versus Procesos de la Línea Base.....................86

Tabla $\mathrm{N}^{\circ} 10$ Descripción de Actividades del Proceso Seleccionado de la Línea Base ............89

Tabla $\mathrm{N}^{\circ} 11$ Roles del Negocio de la Línea Base ..............................................................92

Tabla N 12 Descripción de los Datos del Negocio de la Línea Base .....................................94

Tabla $\mathrm{N}^{\circ} 13$ Arquitectura de aplicaciones de la Línea Base.................................................97

Tabla N 14 Matriz de Aplicación Versus Procesos del Negocio de la Línea Base.................98

Tabla N ${ }^{\circ} 15$ Descripción de los Dispositivos de la Arquitectura Tecnológica de la Línea Base

Tabla $\mathrm{N}^{\circ} 16$ Matriz de Aplicación Versus Procesos del Negocio de la Línea Base............... 102

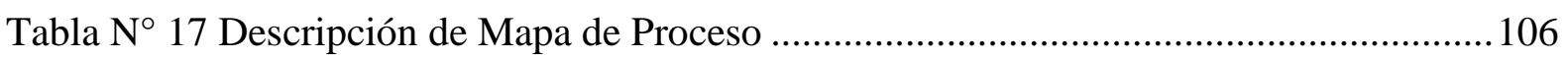

Tabla ํㅜ 18 Matriz de Objetivos Estratégicos Versus Procesos de la Línea Destino............ 108

Tabla N 19 Descripción de las Actividades del Proceso Seleccionado de la Línea Destino111

Tabla $N^{\circ} 20$ Roles del Negocio de la Línea Destino .............................................................. 114

Tabla $\mathrm{N}^{\circ} 21$ Descripción de los Datos del Negocio de la Línea Destino ............................... 116

Tabla $\mathrm{N}^{\circ} 22$ Diccionario de Datos de la Línea Destino...................................................... 121

Tabla N ${ }^{\circ} 23$ Entidades del Proceso Versus Procesos del Negocio de la Línea Destino......... 127

Tabla $\mathrm{N}^{\circ} 24$ Arquitectura de Aplicaciones de la Línea Destino ........................................... 128

Tabla N 25 Matriz de Aplicación Versus Procesos del Negocio de la Línea Destino ..........129

Tabla $\mathrm{N}^{\circ} 26$ Descripción de los Dispositivos de la Arquitectura Tecnológica de la Línea Destino

Tabla N ${ }^{\circ} 27$ Matriz de Aplicación Versus Procesos del Negocio de la Línea Destino .......... 133 


\section{(1)}

Tabla $\mathrm{N}^{\circ} 28$ Análisis de Brechas - Arquitectura de Negocio.............................................. 135

Tabla $\mathrm{N}^{\circ} 29$ Análisis de Brechas - Arquitectura de Datos ................................................... 140

Tabla N 30 Análisis de Brechas - Arquitectura de Aplicaciones ........................................ 143

Tabla N 31 Análisis de Brechas - Arquitectura Tecnológica ............................................ 145

Tabla N 32 Mapa de Riesgos de Probabilidad e Impacto ................................................... 148

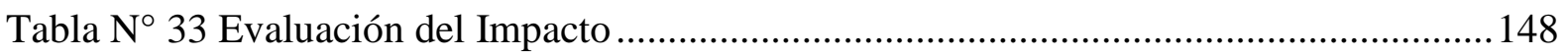

Tabla N $\mathrm{N}^{\circ} 34$ Cuadro de Resumen del Plan de Migración ....................................................... 156

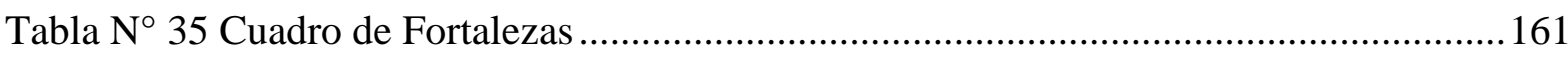

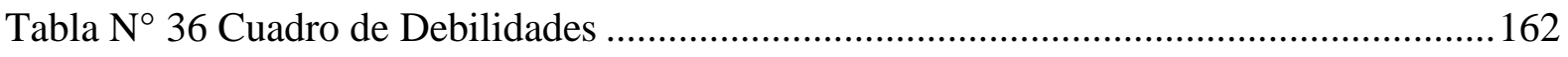

Tabla $\mathrm{N}^{\circ} 37$ Problema e Impacto de las Debilidades ............................................................ 165

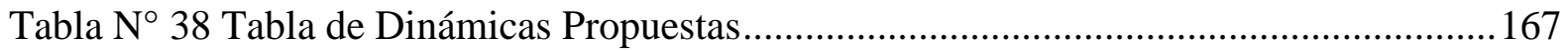

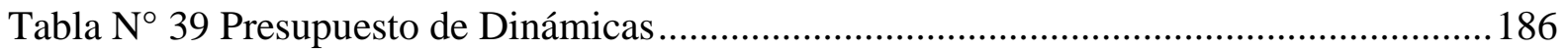

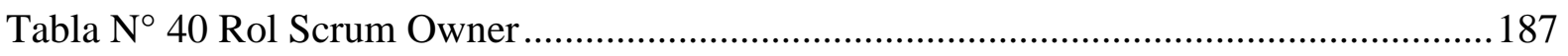

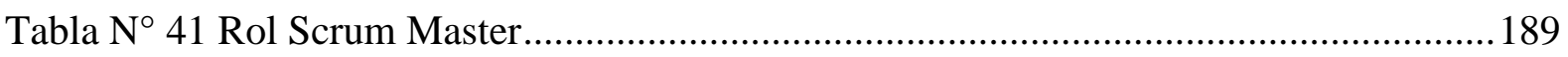

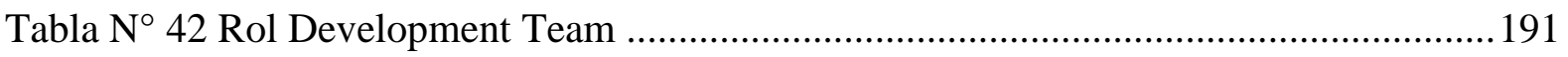

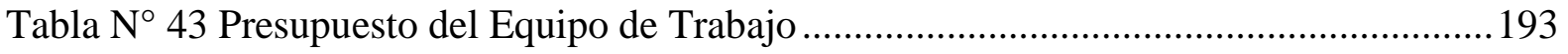

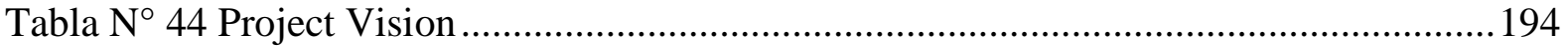

Tabla N ${ }^{\circ} 45$ Lista de User Stories del Sistema de Auditoría Interna de Riesgos .................. 199

Tabla N 46 Product Backlog Priorizado del Sistema de Auditoría Interna.........................206

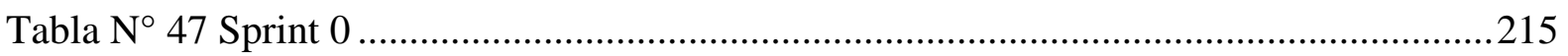

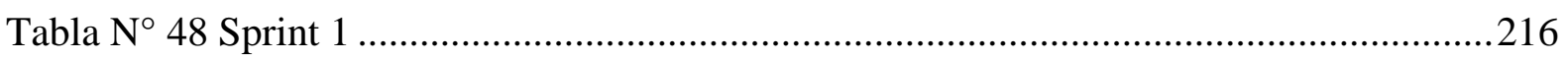

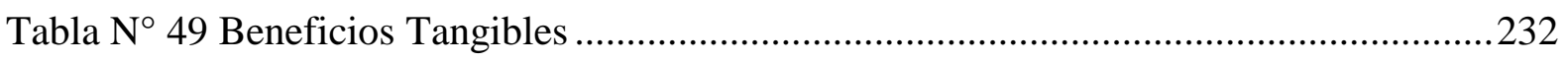

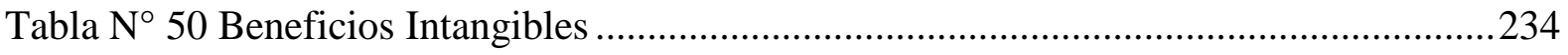

Tabla N ${ }^{\circ} 51$ Mapa de Riesgos de Probabilidad e Impacto ...................................................236

Tabla N ${ }^{\circ} 52$ Evaluación de Riesgos de la Propuesta .............................................................236

Tabla N ${ }^{\circ} 53$ Evaluación Financiera de la Propuesta.................................................................241

Tabla N $\mathrm{N}^{\circ} 54$ VAN y TIR de la Propuesta Financiera .......................................................241

Tabla $\mathrm{N}^{\circ} 55$ Horas Trabajadas de Forma Manual VS Automatizada...................................242

Tabla $\mathrm{N}^{\circ} 56$ Porcentaje Trabajo Minimizado ....................................................................242 


\section{(}

\section{ÍNDICE DE FIGURAS}

Figura $\mathrm{N}^{\circ} 1$ Componentes de la Arquitectura Empresarial ................................................. 18

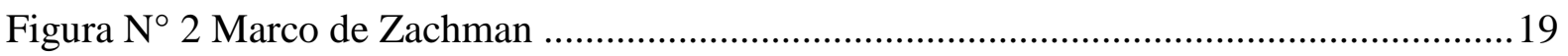

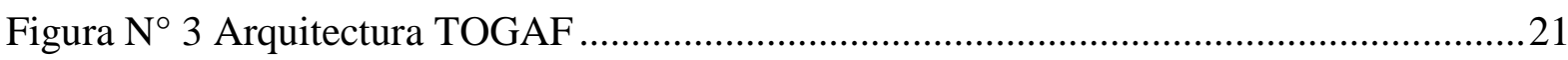

Figura $N^{\circ} 4$ Diferencias Entre Metodología Ágil Versus Metodología Tradicional ...............25

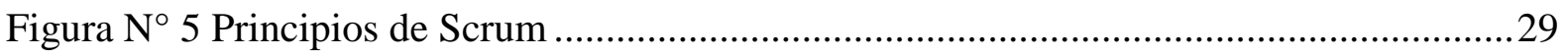

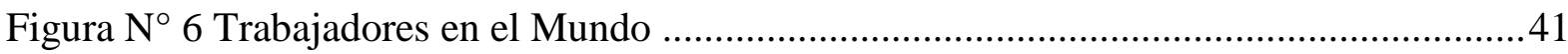

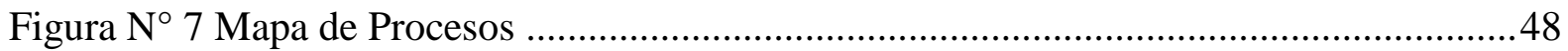

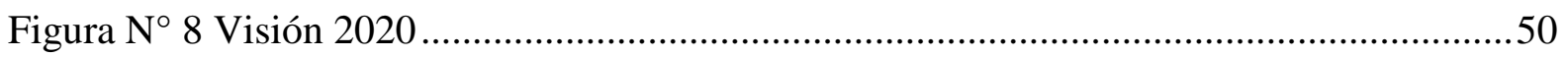

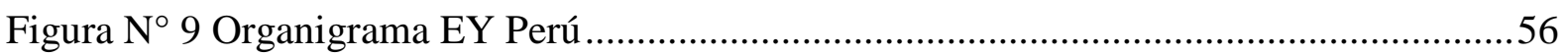

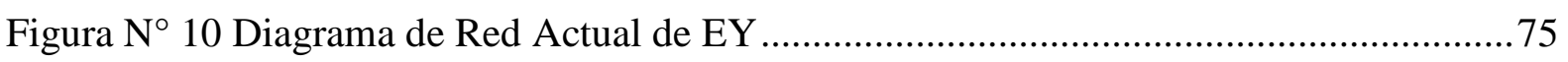

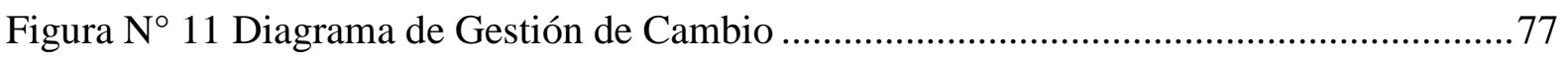

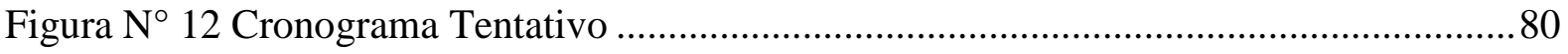

Figura $N^{\circ} 13$ Estructura de la Organización del Proceso Seleccionado de la Línea Base........83

Figura $N^{\circ} 14$ Mapa de Proceso del Proceso Seleccionado de la Línea Base............................84

Figura $\mathrm{N}^{\circ} 15$ Modelo de Datos de Negocio de la Línea Base ................................................93

Figura $\mathrm{N}^{\circ} 16$ Diagrama de Actividades de la Línea Base ....................................................96

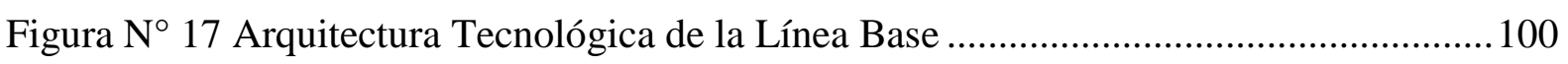

Figura $N^{\circ} 18$ Estructura de la Organización del Proceso Seleccionado de la Línea Destino 105

Figura $N^{\circ} 19$ Mapa de Proceso del Proceso Seleccionado de la Línea Destino ..................... 106

Figura $N^{\circ} 20$ Modelo de Datos del Negocio de la Línea Destino .......................................... 116

Figura $\mathrm{N}^{\circ} 21$ Diagrama de Actividades de la Línea Destino.................................................. 118

Figura $\mathrm{N}^{\circ} 22$ Modelo de Datos Lógico de la Línea Destino .................................................. 120

Figura $\mathrm{N}^{\circ} 23$ Arquitectura Tecnológica de la Línea Destino ..............................................131

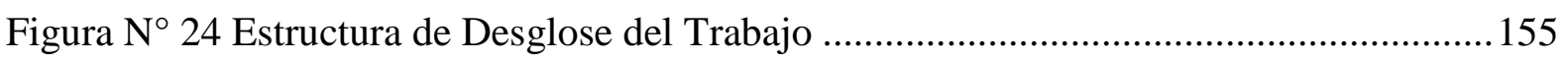

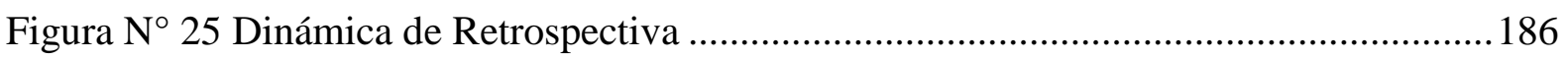

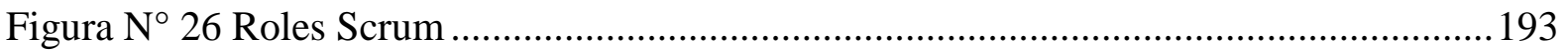

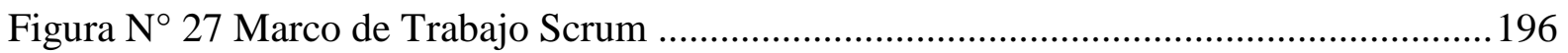




\section{(1)}

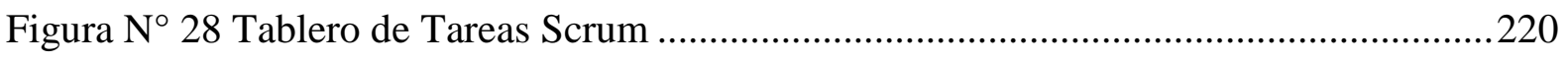

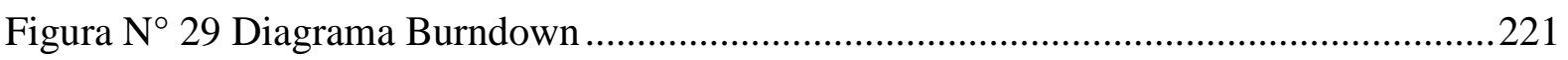

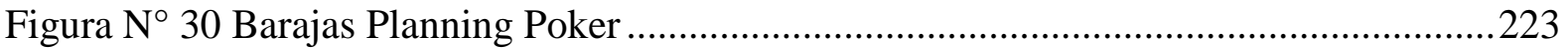

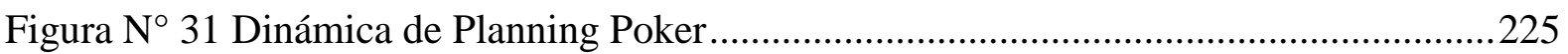

Figura $N^{\circ} 32$ Cronograma Tentativo Arquitectura Empresarial.........................................24

Figura $N^{\circ} 33$ Cronograma Tentativo Gestión de Proyecto....................................................248

Figura $N^{\circ} 34$ Estructura de Desglose de la Propuesta de Arquitectura Empresarial .............249

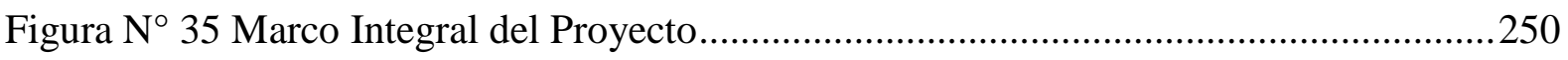




\section{(1)}

\section{INTRODUCCIÓN}

En este trabajo se realiza un análisis de la situación actual de la empresa de servicios llamada Ernst and Young, donde se pueden observar cuáles son los procesos de la empresa, objetivos estratégicos, misión, visión y los servicios que ofrece a sus clientes; además, como se conforma su estructura organizacional.

En la actualidad, muchas empresas están constantemente pensando cómo innovar y desarrollar mejores estrategias para alinearse con los objetivos de la organización. Para esto, el trabajo en los procesos del negocio deben estar automatizados mediante el uso de la tecnología.

El objeto de estudio del presente documento se basa en la empresa Ernst and Young, la cual brinda servicios a nivel mundial en consultoría sobre aseguramiento, asesoría, impuestos y transacciones. El campo de acción está dirigido al subproceso de Auditoría Interna de Riesgos, el cual se encuentra en la línea de servicio de consultoría que es uno de sus cuatro pilares de servicio que brinda la empresa.

El trabajo profesional que se propone en este documento, brinda una solución que permita cerrar las brechas en la búsqueda de una base de conocimiento para desarrollar proyectos por industria y automatizar la gestión del subproceso de Auditoría Interna de Riesgos desde la perspectiva de una arquitectura empresarial aplicando un marco de trabajo ágil mediante Scrum, esto ayudará a la alineación con los objetivos estratégicos de la organización. 


\section{(1) \\ CAPÍTULO 1: FUNDAMENTOS TEÓRICOS}

\subsection{MARCO TEÓRICO}

Este capítulo presenta conceptos con respecto al trabajo que se va a realizar mediante el uso de una Arquitectura Empresarial; además, de la utilización de un marco de referencia mediante el uso de TOGAF para cumplir con el alineamiento de los objetivos estratégicos de EY. Posteriormente, se muestra la ventaja del uso de un marco de trabajo ágil para el desarrollo de una propuesta tecnológico en comparación con metodologías tradicionales (cascada). Por último, se muestra los conceptos de Auditoría del trabajo que realiza la organización objetivo.

\subsubsection{ARQUITECTURA EMPRESARIAL}

Según Adriana Molano (Molano, 2015), una Arquitectura Empresarial es una metodología basada en una visión integral de las organizaciones, permite alinear procesos, datos, aplicaciones e infraestructura tecnológica con los objetivos estratégicos del negocio. En general, dentro de la Arquitectura Empresarial se identifican seis componentes: Estrategia, gobierno de TI, información, sistemas de información, servicios de tecnología, uso y apropiación. Su principal objetivo es garantizar la correcta alineación de la tecnología y los procesos de negocio en una organización, con el propósito de alcanzar el cumplimiento de sus objetivos estratégicos.

Según María Isabel Mejía (Mejía, 2013), la Arquitectura Empresarial señala un esquema o un mapa de navegación que incluye los procesos, componentes y políticas de una organización, y debe servir de apoyo en la toma de decisiones estratégicas. Y, en consecuencia, permite a la alta gerencia entender mejor el papel de la tecnología en su estrategia general, establecer el (ROI) de la inversión en TIC y revalorizar la importancia estratégica de las áreas de tecnología en la organización. 


\section{(1)}

Según Eva Maya Ortiz (ORTIZ, 2010) “Una arquitectura empresarial permite definir el entorno actual y/o deseado de una organización y el camino de transición entre ellos, lo cual ayuda a optimizar las interdependencias y las interrelaciones entre las operaciones de negocio de la empresa y las TI subyacentes que soportan esas operaciones. Sin una arquitectura empresarial completa y robusta se corre el riesgo de que las unidades de negocio de la empresa compren y construyan sistemas que ya existen, que son incompatibles y que son muy costosos de mantener e implementar. El objetivo de una arquitectura empresarial es entonces crear un entorno de TI unificado, es decir sistemas de hardware y software estandarizados, que se enlacen con el negocio de la organización y con su estrategia. Es de aclarar que el término negocio no implica la consecución de ganancias, sino que hace referencia a la meta, fin u objetivo de una organización de cualquier tipo. Adicionalmente, arquitectura empresarial no solamente se refiere a la infraestructura y a los sistemas de TI de una organización, ya que ella establece el Roadmap de la organización para cumplir su misión a través del desempeño óptimo de sus procesos de negocio dentro de un entorno de TI eficiente. De acuerdo con esto, una arquitectura empresarial tiene como meta contar con los recursos de TI necesarios para soportar una función o misión de negocio, promover estandarización y reúso de activos de TI existentes como también compartir métodos comunes para la gestión de proyectos y el desarrollo de software a través de la organización. En otras palabras, el propósito de una arquitectura empresarial es crear un mapa de activos de TI y de procesos de negocio y un conjunto de principios de gobernabilidad que orienten sobre la estrategia de negocio y cómo ella puede ser expresada a través de TI." 


\section{(9)}

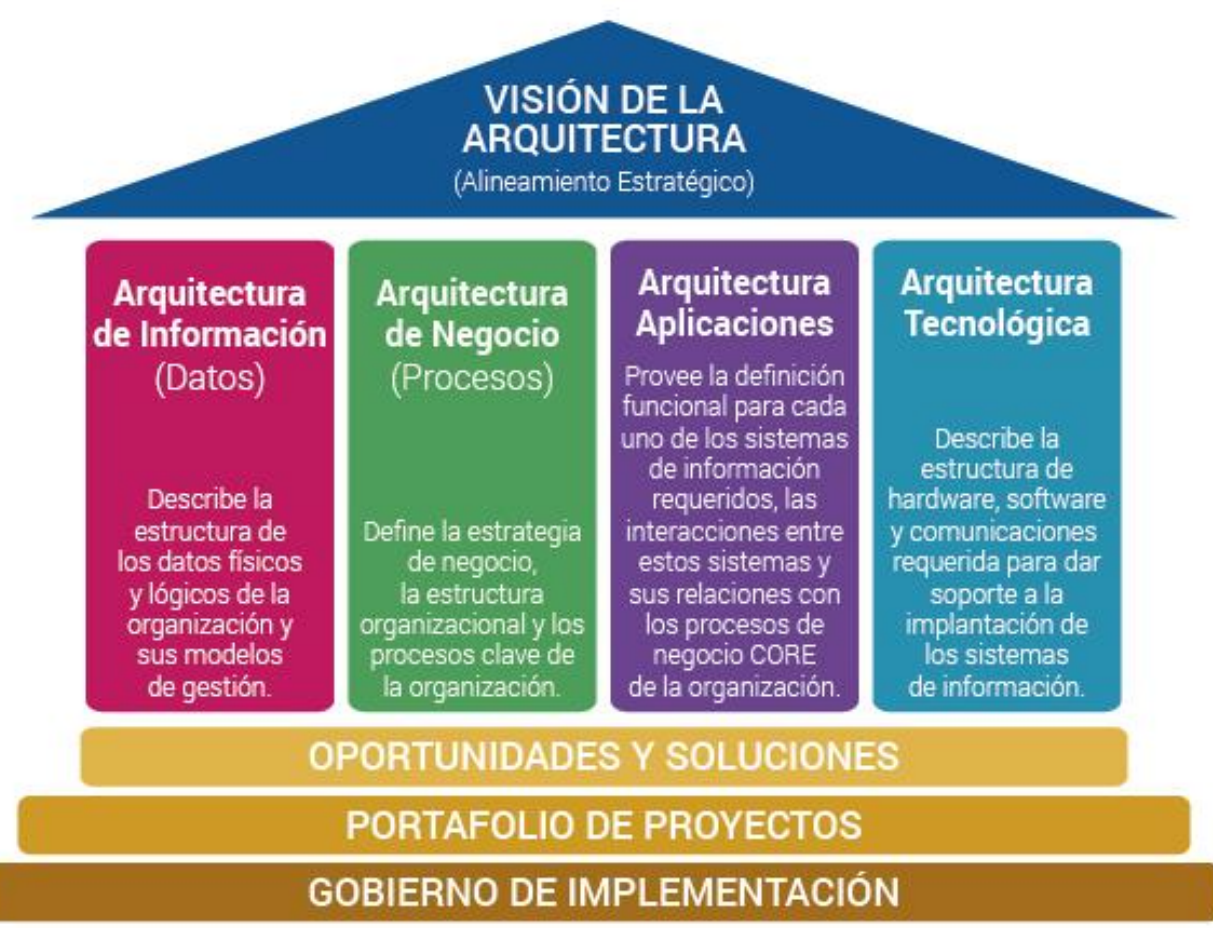

Figura $\mathrm{N}^{\circ} 1$ Componentes de la Arquitectura Empresarial

Fuente: Colombia Digital

\section{El marco de referencia de Zachman}

Según Adalberto Velázquez (Velázquez, 2006) "El Marco de Referencia de Zachman (Zachman, 1987) es una "herramienta de pensamiento" que permite organizar, clasificar y analizar las diferentes descripciones arquitecturales o artefactos de una empresa como son: los modelos de estrategia, organigramas, modelos de procesos, modelos de flujos de trabajo, modelos de datos, reglas de negocio, diagramas de aplicaciones, diagramas de redes, especificaciones de programas."

Zachman (Zachman, 1987) Sostiene que se representa típicamente como una matriz limitada de 6x6 con las interrogaciones de comunicación como columnas (¿Qué?, ¿Cómo?, ¿Dónde?, ¿Quién?, ¿Cuándo? y ¿Por qué?) y las Transformaciones como Filas. Las clasificaciones del Marco están representadas por las Células, es decir, la intersección entre las Interrogativas y las Transformaciones. Esta matriz necesariamente constituiría el conjunto total de 


\section{(4)}

representaciones descriptivas que son relevantes para describir algo, cualquier cosa; en particular una empresa.

Se observó empíricamente en la estructura de las representaciones descriptivas (la arquitectura) de edificios, aviones y otros productos industriales complejos, existen pruebas sustanciales para establecer que el Marco de referencia de Zachman es la estructura fundamental para la Arquitectura Empresarial y, proporciona el conjunto total de representaciones descriptivas relevantes para describir una empresa.

\section{The Zachman Framework for Enterprise Architecture"}
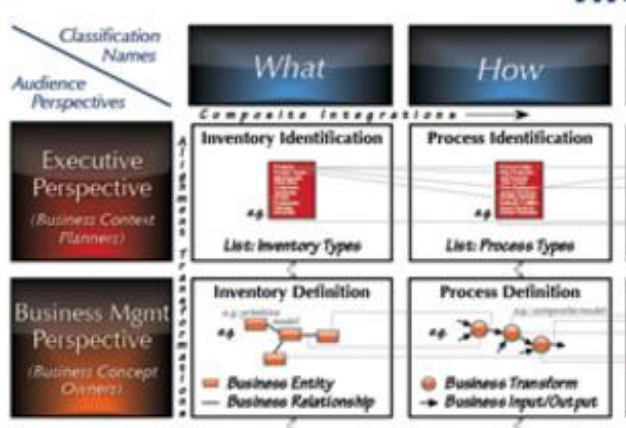

The Enterprise Ontology
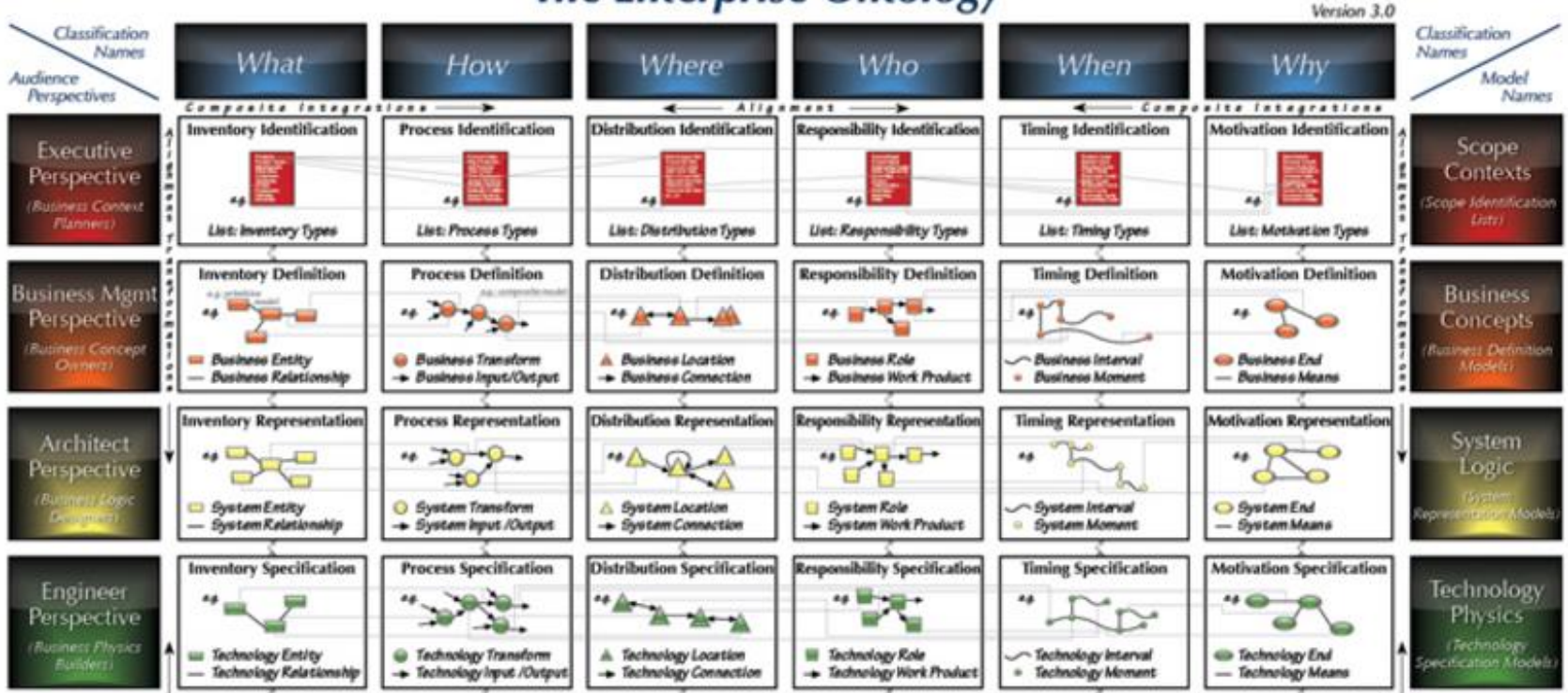

Business
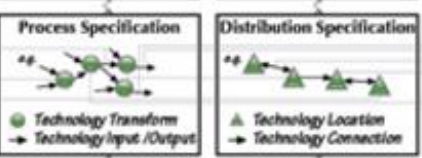

Respendidaty Specilication
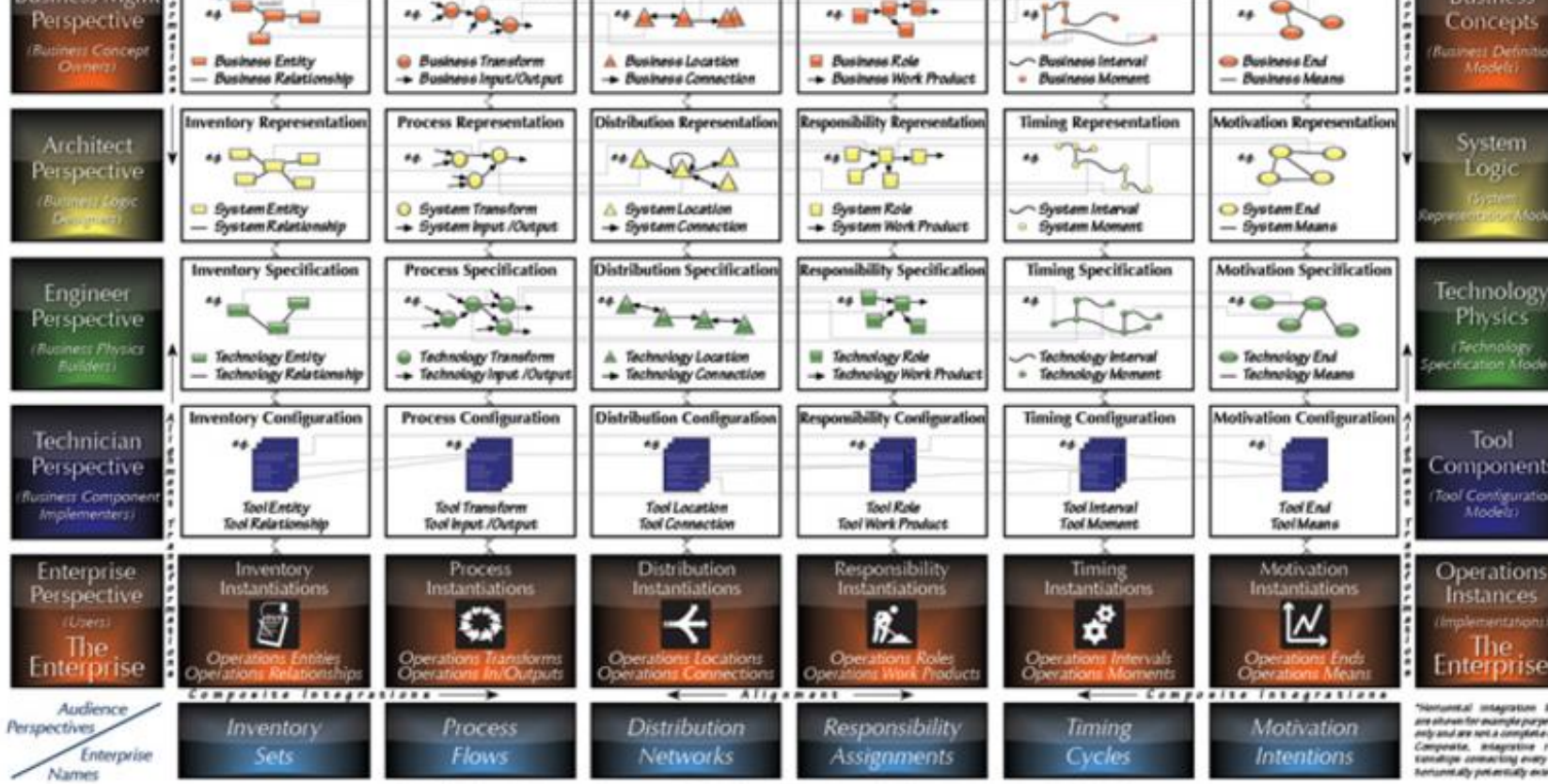

Figura $\mathrm{N}^{\circ} 2$ Marco de Zachman

Fuente: www.zachman.com 


\section{(1)}

\section{TOGAF}

Publicado por primera vez en 1995 (The open group, 2011), TOGAF se basó en el Departamento de Defensa de los Estados Unidos para la Arquitectura de Técnica de Gestión de la Información

Esta publicación indica lo siguiente: "Es un estándar de grupo abierto, una metodología y un marco de referencia de arquitectura empresarial probado y utilizado por las principales organizaciones del mundo para mejorar la eficiencia empresarial. Es el estándar de arquitectura empresarial más destacado y fiable, que garantiza estándares, métodos y comunicación consistentes entre los profesionales de arquitectura empresarial y ayuda a evitar meterse en métodos propietarios, utilizar los recursos de manera más eficiente, eficaz y obtener un mayor retorno de la inversión."

El marco TOGAF permite a las organizaciones abordar de manera efectiva las necesidades críticas del negocio:

- Asegurar que todos hablen el mismo idioma

- Evitar el bloqueo de soluciones propietarias mediante la estandarización de métodos abiertos para la arquitectura empresarial

- Ahorrar tiempo, dinero y utilizar recursos de manera más efectiva

- Obtención de ROI demostrable 


\section{(4)}

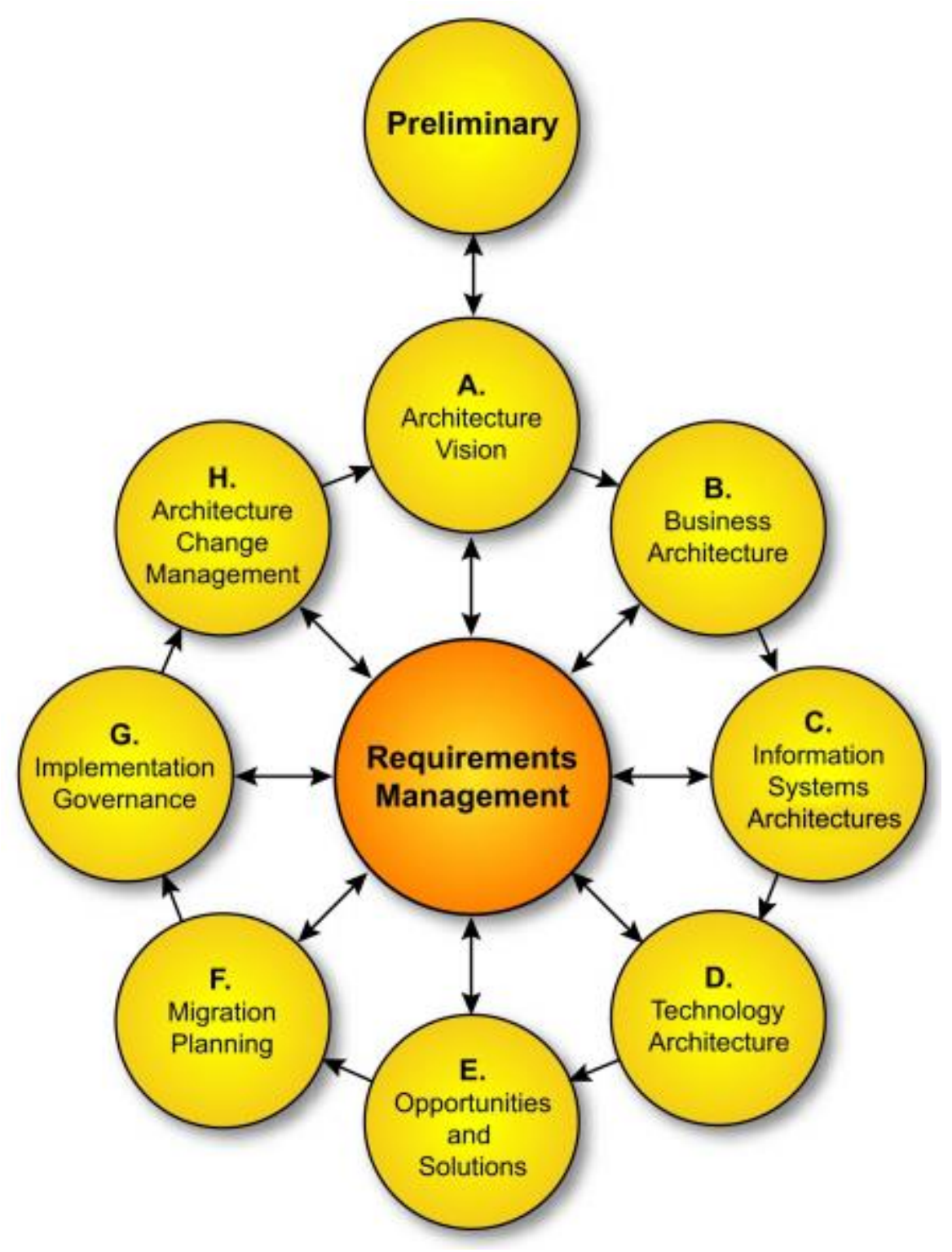

Figura $\mathrm{N}^{\circ} 3$ Arquitectura TOGAF

Fuente: TOGAF Standard Courseware V9.1 Edition

Según Javier Ares (ARES, 2014), el punto de partida del ciclo del método de desarrollo de la arquitectura (ADM) es la Fase Preliminar, seguido de la Fase A (Visión de Arquitectura) hasta la Fase H (Gestión de Cambios de Arquitectura). En todo momento, el ciclo ADM se desarrolla en paralelo a la actividad de gestión de requisitos. Para tener una idea más clara de que es lo que implica cada una de estas fases, se detallan a continuación: 


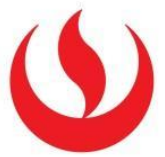

Fase Preliminar: En esta etapa se define el ámbito de la organización afectado por la iniciativa de $\mathrm{AE}$, así como el equipo de $\mathrm{AE}$ y los principios de la arquitectura aplicables. Además, dado que TOGAF es un marco estándar con el objetivo de adaptarse a cualquier organización y sector, debería ser adaptado a los requisitos específicos de la empresa. Por último, deben implementarse las herramientas necesarias para el desarrollo de la arquitectura.

Fase A - Visión de Arquitectura: En esta fase, se establece el proyecto de arquitectura junto con el alcance de la iniciativa de AE. Se deben identificar las partes interesadas, sus inquietudes y requerimientos de negocio. En esta fase, es el momento en el que también se deben confirmar los principios de arquitectura y desarrollar el documento de visión de arquitectura para poder proporcionar una visión general de los cambios que se llevarán a cabo en la organización como resultado de la iniciativa de $\mathrm{AE}$.

Fase B - Arquitectura de Negocios

Fase C - Arquitectura de Sistemas de Información

Fase D - Arquitectura de Tecnología: En estas tres fases, se desarrolla la línea base de arquitectura (AS-IS Architecture) y la arquitectura final (es decir, la arquitectura objetivo de la iniciativa de AE, TO-BE Architecture) para cada dominio de arquitectura (negocio, datos, aplicaciones y tecnología). Tras realizar las arquitecturas AS-IS y TO-BE, se debe realizar el gap analysis entre ambos para producir la hoja de ruta de arquitectura (Roadmap Architecture) para llegar a la arquitectura objetivo. El entregable principal de esta etapa es el documento de definición de arquitectura. Este documento contiene los artefactos arquitectónicos básicos creados durante el proyecto y toda la información importante relacionada. El documento de definición de arquitectura abarca todos los dominios de la arquitectura (negocios, datos, aplicaciones y tecnología) y también examina todos los estados relevantes de la arquitectura (línea base AS-IS, transición y destino TO-BE) 


\subsubsection{MÉTODOS ÁGILES PARA EL DESARROLLO DE SOFTWARE}

En febrero de 2001, tras una reunión celebrada en Utah-EEUU, nace el término "ágil” aplicado al desarrollo de software. En esta reunión participaron un grupo de 17 expertos de la industria del software, incluyendo algunos de los creadores o impulsores de metodologías de software. José H. Canós (Canós, 2003) sostiene que su objetivo fue esbozar los valores y principios que deberían permitir a los equipos desarrollar software rápidamente y respondiendo a los cambios que puedan surgir a lo largo del proyecto. Se pretendía ofrecer una alternativa a los procesos de desarrollo de software tradicionales, caracterizados por ser rígidos y dirigidos por la documentación que se genera en cada una de las actividades desarrolladas. Tras esta reunión se creó The Agile Alliance una organización, sin fines de lucro, dedicada a promover los conceptos relacionados con el desarrollo ágil de software y ayudar a las organizaciones para que adopten dichos conceptos. El punto de partida fue el Manifiesto Ágil, un documento que resume la filosofía "ágil".

Según el Manifiesto Ágil se valora:

- Al individuo y las interacciones del equipo de desarrollo sobre el proceso y las herramientas. La gente es el principal factor de éxito de un proyecto software. Es más importante construir un buen equipo que construir el entorno. Muchas veces se comete el error de construir primero el entorno y esperar que el equipo se adapte automáticamente. Es mejor crear el equipo y que éste configure su propio entorno de desarrollo en base a sus necesidades.

- Desarrollar software que funciona más que conseguir una buena documentación. La regla a seguir es "no producir documentos a menos que sean necesarios de forma inmediata para tomar una decisión importante". Estos documentos deben ser cortos y centrarse en lo fundamental.

- La colaboración con el cliente más que la negociación de un contrato. Se propone que exista una interacción constante entre el cliente y el equipo de desarrollo. Esta colaboración entre ambos será la que marque la marcha del proyecto y asegure su éxito.

- Responder a los cambios más que seguir estrictamente un plan. La habilidad de responder a los cambios que puedan surgir a lo largo del proyecto (cambios en los requisitos, en la 


\section{(1)}

tecnología, en el equipo, etc.) determina también el éxito o fracaso del mismo. Por lo tanto, la planificación no debe ser estricta sino flexible y abierta.

José H. Canós (Canós, 2003) Afirma que los valores anteriores inspiran los doce principios del manifiesto. Son características que diferencian un proceso ágil de uno tradicional. Los dos primeros principios son generales y resumen gran parte del espíritu ágil. El resto tienen que ver con el proceso a seguir y con el equipo de desarrollo, en cuanto metas a seguir y organización del mismo.

Los principios son:

- La prioridad es satisfacer al cliente mediante tempranas y continuas entregas de software que le aporte un valor.

- Dar la bienvenida a los cambios. Se capturan los cambios para que el cliente tenga una ventaja competitiva.

- Entregar frecuentemente software que funcione desde un par de semanas a un par de meses, con el menor intervalo de tiempo posible entre entregas.

- La gente del negocio y los desarrolladores deben trabajar juntos a lo largo del proyecto.

- Construir el proyecto en torno a individuos motivados. Darles el entorno y el apoyo que necesitan y confiar en ellos para conseguir finalizar el trabajo.

- El diálogo cara a cara es el método más eficiente y efectivo para comunicar información dentro de un equipo de desarrollo.

- El software que funciona es la medida principal de progreso.

- Los procesos ágiles promueven un desarrollo sostenible. Los promotores, desarrolladores y usuarios deberían ser capaces de mantener una paz constante.

- La atención continua a la calidad técnica y al buen diseño mejora la agilidad.

- La simplicidad es esencial.

- Las mejores arquitecturas, requisitos y diseños surgen de los equipos organizados por sí mismos.

- En intervalos regulares, el equipo reflexiona respecto a cómo llegar a ser más efectivo, y según esto ajusta su comportamiento. 


\begin{tabular}{|l|l|}
\hline \multicolumn{1}{|c|}{ Metodologías Ágiles } & \multicolumn{1}{|c|}{ Metodologías Tradicionales } \\
\hline $\begin{array}{l}\text { Basadas en heurísticas provenientes de prácticas de } \\
\text { producción de código }\end{array}$ & $\begin{array}{l}\text { Basadas en normas provenientes de estándares } \\
\text { seguidos por el entorno de desarrollo }\end{array}$ \\
\hline $\begin{array}{l}\text { Especialmente preparados para cambios durante el } \\
\text { proyecto }\end{array}$ & Cierta resistencia a los cambios \\
\hline Impuestas internamente (por el equipo) & Impuestas externamente \\
\hline Proceso menos controlado, con pocos principios & $\begin{array}{l}\text { Proceso mucho más controlado, con numerosas } \\
\text { políticas/normas }\end{array}$ \\
\hline $\begin{array}{l}\text { No existe contrato tradicional o al menos es } \\
\text { bastante flexible }\end{array}$ & Existe un contrato prefijado \\
\hline El cliente es parte del equipo de desarrollo & $\begin{array}{l}\text { El cliente interactúa con el equipo de desarrollo } \\
\text { mediante reuniones }\end{array}$ \\
\hline $\begin{array}{l}\text { Grupos pequeños (<10 integrantes) y trabajando en } \\
\text { el mismo sitio }\end{array}$ & Grupos grandes y posiblemente distribuidos \\
\hline Pocos artefactos & Más artefactos \\
\hline Pocos roles & Más roles \\
\hline Menos énfasis en la arquitectura del software & $\begin{array}{l}\text { La arquitectura del software es esencial y se } \\
\text { expresa mediante modelos }\end{array}$ \\
\hline
\end{tabular}

Figura $N^{\circ} 4$ Diferencias Entre Metodología Ágil Versus Metodología Tradicional

Fuente: www.avante.es

\section{$\underline{\text { SCRUM }}$}

Según la publicación (Slideshare, 2014) en el año 1986 Takeuchi y Nonaka publicaron el artículo "The New Product Development Game", el cual dio a conocer una nueva forma de gestionar proyectos en la que la agilidad, flexibilidad y la incertidumbre son los elementos principales.

Nonaka y Takeuchi se fijaron en empresas tecnológicas que, estando en el mismo entorno en el que se encontraban otras empresas, realizaban productos en menos tiempo, de buena calidad y menos costes. Observando a empresas como Honda, HP, Canon, se dieron cuenta de que el producto no seguía una fase en las que había un equipo especializado en cada una de ellas, si no que se partía de unos requisitos muy generales y el producto lo realizaba un equipo multidisciplinar que trabajaba desde el comienzo del proyecto hasta el final.

Se comparó esta forma de trabajo en equipo, con la colaboración que hacen los jugadores de Rugby y la utilización de una formación denominada Scrum. 


\section{(1)}

Scrum se ha convertido en los últimos tiempos en un estándar que muchas grandes empresas de tecnología están utilizando para acortar sus tiempos de desarrollo, y entregar un producto de calidad. Es así como a principios de los años noventa Ken Schwaber empleó una aproximación que lo llevó a poner en práctica el Scrum en su compañía. Jeff Sutherland desarrolló una aproximación similar en Easel Corporation y fue el primero en denominarla Scrum. Finalmente, en 1995 Schwaber y Sutherland, durante la conferencia OOPSLA 95 en Austin, Estados Unidos, presentaron en paralelo una serie de artículos describiendo Scrum, siendo ésta la primera aparición pública del marco de trabajo. Después ellos siguieron aportando con su experiencia y escribieron una serie de artículos y ambos colaboraron para sentar las bases de las mejores prácticas de la industria que hoy en día se conoce como Scrum.

\section{Scrum vs. Gestión tradicional de proyectos}

La estructura organizativa y la definición de roles y responsabilidades correspondientes son algunas de las áreas en las que Scrum difiere de manera importante de los métodos tradicionales de gestión de proyectos.

Como se menciona en la Guía para el cuerpo de conocimiento de Scrum (SBOK, 2017). En los métodos tradicionales de gestión de proyectos, la estructura de la organización es jerárquica y la autoridad para todos los aspectos del proyecto se delega desde el nivel superior al inferior (por ejemplo, el patrocinador, o espónsor del proyecto delega autoridad al Project Manager, y este, a su vez, la delega al Development Team ). Los métodos tradicionales de gestión de proyectos hacen énfasis en la responsabilidad individual respecto a las responsabilidades del proyecto, en vez de la responsabilidad colectiva. Cualquier desviación de la autoridad delegada se considera como una señal de problemas y puede ser llevada a un nivel más alto en la jerarquía de la organización. Por lo general, es el Project Manager, quien es responsable de la finalización con éxito del proyecto, así como de la toma de decisiones sobre diversos aspectos del proyecto, incluyendo el inicio, planificación, estimación, ejecución, seguimiento y control y cierre.

El énfasis en Scrum está en la auto-organización y la auto-motivación, donde el Development Team asume una mayor responsabilidad en lograr el éxito de un proyecto. Esto también garantiza la existencia de un sentido de compromiso y responsabilidad compartida. Esto, a su 


\section{(1)}

vez, da lugar a la motivación del Development Team que lleva a una optimización de su eficiencia. El Product Owner, el Scrum Master y el Development Team trabajan de cerca con el(los) Stakeholder(s) relevante(s) para ajustar los requisitos a medida que avanzan a través de los procesos de Desarrollar de épica(s), Crear el Backlog Priorizado del Producto y Crear User Stories. Esto asegura que no haya margen para la planificación aislada en Scrum. El conocimiento y las experiencias del Development Team sobre el desarrollo de productos que se utilizan para evaluar las entradas necesarias para planificar, calcular y ejecutar el trabajo del proyecto. La colaboración entre todo equipo asegura que el proyecto se lleve a cabo en un ambiente innovador y creativo propicio para el crecimiento y la armonía del equipo.

\section{Los principios de Scrum}

Tal como se define en la Guía para el cuerpo de conocimiento de Scrum (SBOK, 2017). Los principios de Scrum son las pautas básicas para aplicar el marco de trabajo de Scrum y deben implementarse en forma obligatoria en todos los proyectos Scrum. Los seis principios de Scrum son los siguientes:

- Control del proceso empírico (Empirical Process Control)

- Auto-organización (Self-organization)

- Colaboración (Collaboration)

- Priorización basada en valor (Value-based Prioritization)

- Time-boxing

- Desarrollo iterativo (Iterative Development)

Como se menciona en la Guía para el cuerpo de conocimiento de Scrum (SBOK, 2017), los principios de Scrum se pueden aplicar a cualquier tipo de proyecto en cualquier organización y deben cumplirse a fin de garantizar la aplicación efectiva del marco de trabajo de Scrum. Los principios de Scrum no están abiertos a la discusión ni pueden modificarse, y deben aplicarse tal como se especifica en el SBOK. El mantener los principios intactos y usarlos apropiadamente infunde confianza en el marco de trabajo de Scrum respecto al cumplimiento de los objetivos del proyecto. Los aspectos y procesos de Scrum, sin embargo, pueden modificarse para cumplir con los requisitos del proyecto o la organización. 


\section{(1)}

- Control del proceso empírico

Este principio enfatiza la filosofía central de Scrum con base a las tres ideas principales de transparencia, inspección y adaptación.

- Auto-organización

Este principio se enfoca en los trabajadores de hoy en día, que entregan un valor considerablemente mayor cuando se auto-organizan, lo cual resulta en equipos que poseen un gran sentido de compromiso y responsabilidad; a su vez, esto produce un ambiente innovador y creativo que es más propicio para el crecimiento.

- Colaboración

Este principio se centra en las tres dimensiones básicas relacionadas con el trabajo colaborativo: conocimiento, articulación y apropiación. También fomenta la gestión de proyectos como un proceso de creación de valor compartido con equipos que trabajan e interactúan conjuntamente para ofrecer el mayor valor.

- Priorización basada en valor

Este principio pone de relieve el enfoque de Scrum para ofrecer el máximo valor de negocio, desde el principio del proyecto hasta su conclusión.

- Time-boxing

Este principio describe cómo el tiempo se considera una restricción limitante en Scrum, y cómo este se utiliza para ayudar a manejar eficazmente la planificación y ejecución del proyecto. Los elementos del time boxing en Scrum incluyen Sprints, Daily Scrum, reuniones de Sprint Planning y reuniones de Sprint Review.

- Desarrollo iterativo

Este principio define el desarrollo iterativo y hace énfasis en cómo gestionar mejor los cambios y crear productos que satisfagan las necesidades del cliente. También alinea las responsabilidades del Product Owner y las de la organización relacionadas con el desarrollo iterativo. 


\section{()}

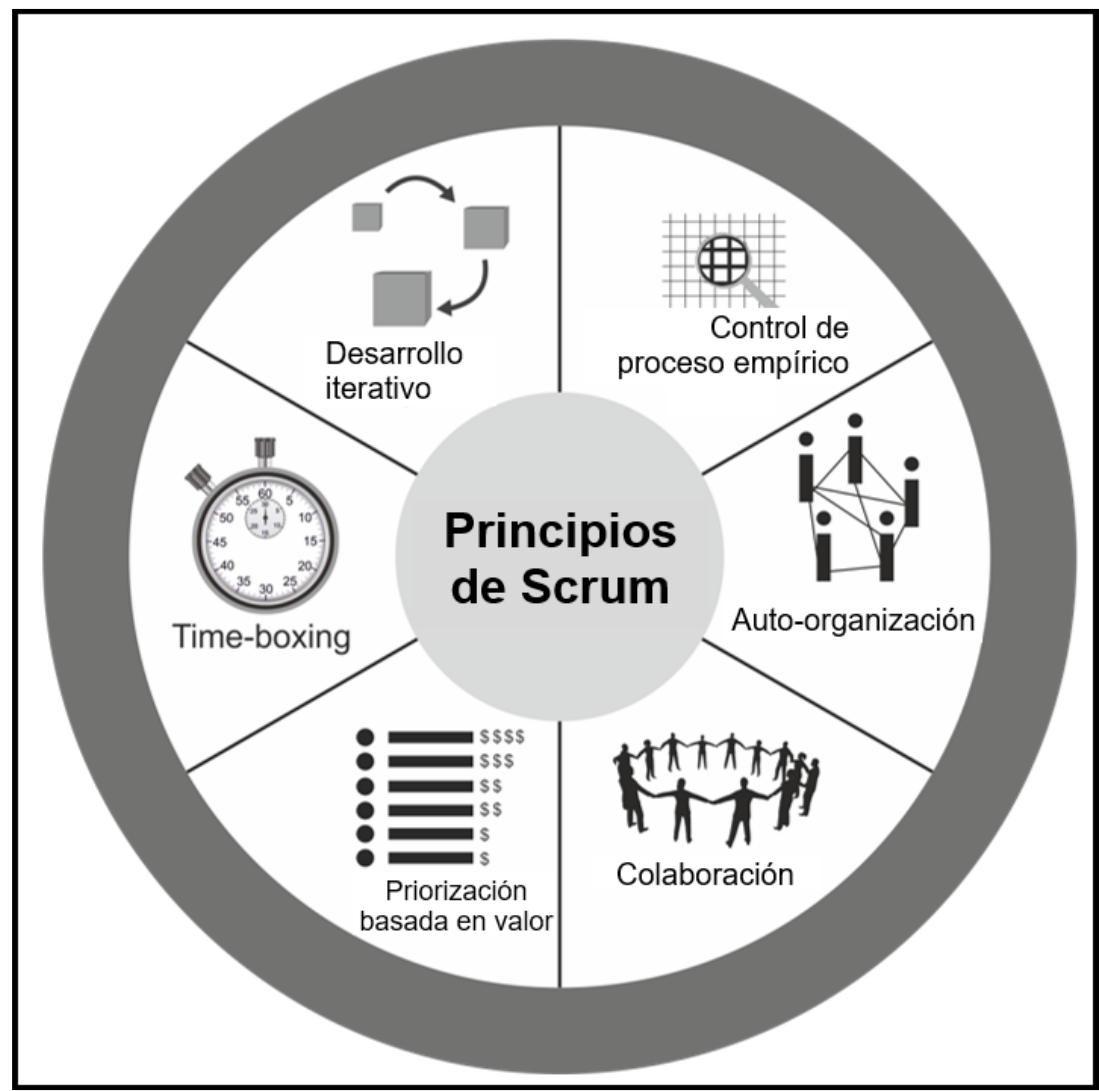

Figura $\mathrm{N}^{\circ} 5$ Principios de Scrum

Fuente: Guía para el cuerpo de conocimiento de Scrum SBOK

\section{Roles de Scrum}

Según la Guía para el cuerpo de conocimiento de Scrum (SBOK, 2017). Entender los roles y responsabilidades definidos en un proyecto Scrum es muy importante a fin de asegurar la implementación exitosa de Scrum.

Los roles de Scrum se dividen en dos amplias categorías:

\section{- Roles centrales}

Los roles centrales según la Guía para el cuerpo de conocimiento de Scrum (SBOK, 2017) son aquellos que se requieren obligadamente para crear el producto o servicio del proyecto. Las personas a quienes se les asignan los roles centrales están plenamente comprometidas con el proyecto y son las responsables del éxito de cada iteración del mismo, así como del proyecto en su totalidad.

Estos roles incluyen: 


\section{(1)}

- El Product Owner

Es la persona responsable de lograr el máximo valor empresarial para el proyecto. Este rol también es responsable de la articulación de requisitos del cliente y de mantener la justificación del negocio para el proyecto. El Product Owner representa la voz del cliente.

- El Scrum Master

Es un facilitador que asegura que el Development Team cuente con un ambiente propicio para completar el proyecto con éxito. El Scrum Master guía, facilita y enseña las prácticas de Scrum a todos los involucrados en el proyecto; elimina los impedimentos que pueda tener el equipo y se asegura de que se estén siguiendo los procesos de Scrum.

- El Development Team

Es el grupo o equipo de personas responsables de entender los requisitos especificados por el Product Owner y de crear los entregables del proyecto.

\section{- Roles no centrales}

Los roles no centrales según la Guía para el cuerpo de conocimiento de Scrum (SBOK, 2017) son los que no son necesariamente obligatorios para el proyecto Scrum, y estos pueden incluir a miembros de los equipos que estén interesados en el proyecto. No tienen ningún rol formal en el equipo del proyecto, y pueden interactuar con el equipo, pero pueden no ser responsables del éxito del proyecto. Los roles no centrales deben tenerse en cuenta en cualquier proyecto de Scrum.

Los roles no centrales incluyen los siguientes:

- Stakeholder(s)

- Es un término colectivo que incluye a clientes, usuarios y patrocinadores, que con frecuencia interactúan con el equipo de Scrum, e influyen en el proyecto a lo largo de su desarrollo. Lo más importante es que el proyecto produzca beneficios colaborativos para los Stakeholders.

- El Scrum Guidance Body

- Es un rol opcional, que generalmente consiste en un conjunto de documentos y/o un grupo de expertos que normalmente están involucrados en la definición de los objetivos relacionados con la calidad, las regulaciones gubernamentales, la seguridad y otros 


\section{(1)}

parámetros claves de la organización. El Scrum Guidance Body guía el trabajo llevado a cabo por el Product Owner, el Scrum Master y el Equipo Scrum.

- Los vendedores, incluyendo a individuos u organizaciones externas, ofrecen productos y/o servicios que no están dentro de las competencias centrales de la organización del proyecto.

\section{Herramientas de Scrum}

Según la Guía para el cuerpo de conocimientos de Scrum (SBOK, 2017) nos define las siguientes herramientas:

\section{- Product Backlog}

El Product Backlog es un solo documento de requisitos que define el alcance del proyecto, proporcionando una lista de prioridades de las características del producto o servicio a ser entregado.

En este proceso se elaboran y se refinan las épicas dándoles después prioridad. Durante este proceso también se establecen los criterios de terminado (Definition of Done).

\section{- User Stories}

Los User Stories se apegan a una estructura específica predefinida y son una forma simple de documentar los requerimientos y funcionalidades que desea el usuario final. Los requerimientos expresados en los User Stories son oraciones breves, sencillas y fáciles de entender. El formato estándar predefinido da como resultado en una comunicación mejorada entre los stakeholders, así como en mejores estimaciones por parte del equipo.

\section{- Sprint Backlog}

El Sprint Backlog es una lista de tareas a ser ejecutadas por el Development Team en el próximo sprint.

\section{- Incremento}


Al final de cada sprint se completa un incremento de producto o entregable. El entregable debe incluir todas las características y funcionalidades definidas en los User Stories que se incluyen en el sprint y deben haber sido evaluadas satisfactoriamente.

\section{Eventos principales en Scrum}

Según la Guía para el cuerpo de conocimientos de Scrum (SBOK, 2017) nos define los siguientes eventos:

\section{a. Sprint Planning}

Tal como se define en la Guía para el cuerpo de conocimiento de Scrum (SBOK, 2017). Esta reunión se lleva a cabo antes del Sprint, como parte de los procesos de comprometer User Stories, identificar tareas, estimar tareas y crear el Sprint Backlog. Se asigna a un tiempo de ocho horas durante un Sprint de un mes de duración.

La reunión de planificación del Sprint se divide en dos partes:

- Definición del objetivo

Durante la primera parte de la reunión, el Product Owner explica las User Stories de más alta prioridad o los requerimientos en el Backlog Priorizado del Producto al Development Team. Después, el Development Team en colaboración con el Product Owner se compromete con las User Stories, las cuales definen la meta del Sprint.

- Identificación y estimación de tareas

El Development Team decide "cómo" completar los elementos seleccionados en el Backlog Priorizado del Producto seleccionados para cumplir con la meta del Sprint. Las User Stories comprometidas y las Effort Estimated Tasks List se incluyen en el Backlog Priorizado del Producto al que se le dará seguimiento.

\section{b. Daily Scrum}

El Daily Scrum, según la Guía para el cuerpo de conocimiento de Scrum (SBOK, 2017). Es una breve reunión diaria con un tiempo de 15 minutos. El Development Team se reúne para dar un reporte sobre su progreso en el Sprint y planificar las actividades del día. La duración de la reunión es muy corta y se busca que todos los integrantes del Development Team estén 


\section{(1)}

presentes. Sin embargo, la reunión no se cancela o se retrasa si uno o más miembros no pueden asistir.

El Daily Scrum es organizado por el Scrum Master, donde cada miembro del Development Team brinda información en forma de respuesta a tres preguntas específicas:

- ¿Qué he hecho desde la última reunión?

- ¿Qué tengo planeado hacer antes de la siguiente reunión?

- ¿Qué impedimentos u obstáculos (si los hubiera) estoy enfrentando en la actualidad?

$\mathrm{Al}$ enfocarse en estas tres preguntas, todo el equipo puede tener una comprensión clara de la situación de trabajo. En ocasiones se pueden discutir otros elementos, pero se mantiene al mínimo en razón del tiempo asignado que tiene la reunión.

Es muy recomendable que, de ser posible, los miembros del Development Team den respuesta a las dos primeras preguntas en forma cuantificable en vez de dar largas respuestas cualitativas. Los miembros del equipo pueden organizar reuniones adicionales después del Daily Scrum a fin de abordar temas que requieran de mayor discusión.

\section{c. Sprint}

Según la Guía para el cuerpo de conocimiento de Scrum (SBOK, 2017). El Sprint es una iteración con un tiempo de una a cuatro semanas de duración durante el cual el Scrum Master guía, facilita y protege al Development Team de impedimentos tanto internos como externos durante el proceso de crear entregables. Esto ayuda a evitar una expansión de la visión más allá de su objetivo original, lo que podría afectar la meta del Sprint. Durante este tiempo, el equipo trabaja para convertir las necesidades del Backlog Priorizado del Producto en funcionalidades de productos fáciles de enviar. Para obtener los máximos beneficios de un proyecto Scrum, siempre se recomienda mantener el Sprint dentro de un Time-box de cuatro semanas, a menos que existan proyectos con requisitos muy estables, en los que los Sprints pueden extenderse hasta cuatro semanas.

\section{d. Sprint Review}




\section{(1)}

Tal como se define en la Guía para el cuerpo de conocimiento de Scrum (SBOK, 2017). Los miembros del equipo de Scrum y los Stakeholders relevantes participan en las reuniones de revisión del Sprint para aceptar los entregables que cumplan con los criterios de aceptación de las User Stories y rechazar los entregables no aceptables. Tales reuniones se convocan al final de cada Sprint. El Development Team demuestra los logros del Sprint, incluyendo las nuevas funcionalidades o los productos elaborados. Esto brinda una oportunidad para que el Product Owner y el(los) Stakeholder(s) inspeccionen lo que se ha completado hasta el momento y determinen si deben realizarse cambios en el proyecto o en los procesos en Sprints posteriores.

- Entregables aceptados

Los entregables que cumplen con los criterios de aceptación de las User Stories son aceptados por el Product Owner. El objetivo de un Sprint es crear e incrementar el producto, que cumplan con los criterios de aceptación definidos por el cliente y el Product Owner. Estos se consideran entregables aceptados que pudieran ser entregados al cliente y así se desea. Se mantiene una lista de entregables aceptados y se actualiza después de cada reunión de revisión del Sprint. Si un entregable no cumple con los criterios de aceptación definidos, no se considera aceptado y generalmente se llevará a un Sprint posterior para corregir cualquier problema. Esto no es muy recomendable, ya que el objetivo de cada Sprint es que los entregables cumplan con los criterios de aceptación.

- Entregables rechazados

Si los entregables no cumplen con los criterios de aceptación, tales entregables se rechazan. Las User Stories asociados a tales entregables rechazados se agregan al Backlog Priorizado del Producto para que tales entregables puedan ser considerados como parte de un Sprint posterior.

\section{e. Retrospectiva del Sprint}

Como se menciona en la Guía para el cuerpo de conocimiento de Scrum (SBOK, 2017), la retrospectiva del Sprint es un elemento importante del marco de trabajo de Scrum y es el 


\section{(1)}

último paso en un Sprint. Todos los miembros del Development Team asisten a la reunión, misma que organiza y modera el Scrum Master. Se recomienda que asista el Product Owner, aunque no es obligatorio. Un integrante del equipo se desempeña como secretario y documenta las discusiones y los elementos para acciones a futuro. Es esencial celebrar esta reunión es un entorno abierto y relajado a fin de fomentar la completa participación de todos los miembros del equipo. Las discusiones en la reunión de retrospectiva del Sprint abarcan tanto lo que salió mal como lo que salió bien. Los objetivos primordiales de la reunión son identificar tres elementos específicos:

- Las cosas que el equipo necesita seguir haciendo: mejores prácticas

- Las cosas que el equipo necesita empezar a hacer: mejoras en el proceso

- Las cosas que el equipo necesita dejar de hacer: problemas de proceso y embotellamiento.

Estas áreas se analizan y se crea una lista de mejoras accionables aceptadas.

\subsubsection{AUDITORÍA}

Según el manual Introduction to Auditing ó Introducción a la auditoría (INTRODUCTION TO AUDITING, s.f.). El termino Auditoría ha sido definido por diferentes autores:

- Spicer y Pegler: "La auditoría es un examinación de los libros contables y comprobantes de negocios, ya que permitirá a los auditores cerciorarse de que el balance se ha elaborado correctamente, por lo que da una visión verdadera y justa de la situación del negocio y que las cuentas de ganancias y pérdidas den una imagen fiel de la ganancias/pérdidas para el período financiero".

- El profesor L.R.Dicksee "la auditoría es una examinación de registros contables llevados a cabo con una visión de establecer si está correctamente y si reflejan completamente las transacciones a las cuales se relacionan".

- El libro "una introducción a las cuentas del gobierno indio y auditoría" emitida por el Contralor y Auditor General de la India, define la auditoría como "un instrumento de control financiero". Actúa como una protección en favor del propietario (ya sea un individuo o grupo de personas) contra la extravagancia, descuido o fraude de los servicios del 


\section{(1)}

propietario en la realización y utilización del dinero u otros activos, y garantiza en favor del propietario, que las cuentas mantenidas realmente representan hechos y que el gasto se ha incurrido con la debida regularidad y propiedad. La agencia empleada para este propósito es llamado auditor".

\section{Características:}

- La auditoría es una examinación sistemática y científica de los libros contables de un negocio.

- La auditoría es llevada a cabo por una persona independiente o grupo de personas que están debidamente calificados para el trabajo.

- La auditoría es una verificación de los resultados mostrados por las cuentas de ganancias y pérdidas y el estado de los resultados, tal como se muestra en el balance general.

- La auditoría es una revisión crítica del sistema de contabilidad y control interno.

- La auditoría se realiza con la ayuda de comprobantes, documentos, información y explicaciones recibidas de las autoridades.

- El auditor debe asegurarse de la autenticidad de los estados financieros e informar que muestran la verdad.

- El auditor debe inspeccionar, comparar, verificar, revisar, controlar los comprobantes que respaldan las transacciones y examinar la correspondencia, los libros de actas de los accionistas, los directores, el Memorando de Asociación y los Estatutos, etc., a fin de establecer la exactitud de los libros contables.

\section{Objetivos:}

Hay dos objetivos principales de la auditoría. El objetivo primario y el objetivo secundario o adicional. 


\section{(1)}

- Objetivo primario: según el artículo 227 de las compañías Act. 1956, el deber principal (objetivo) del auditor es informar a los propietarios si el balance proporciona una imagen fiel de la situación de la empresa y las cuentas de ganancias y pérdidas proporcionan una cifra correcta del beneficio de la pérdida para el año financiero.

- Objetivo secundaria: El objetivo de la auditoría secundaria es:

- Detección y prevención de fraudes, y

- Detección y prevención de errores

\section{Ventajas:}

Tabla $\mathrm{N}^{\circ} 1$ Ventajas de la Auditoría

\begin{tabular}{|l|l|l|}
\hline \multicolumn{1}{|c|}{$\begin{array}{c}\text { El punto de vista del } \\
\text { hombre de negocios }\end{array}$} & Punto de vista del inversor & \multicolumn{1}{|c|}{ Otras ventajas } \\
\hline $\begin{array}{l}\text { Detección de errores y } \\
\text { fraudes }\end{array}$ & Protege el interés & Evaluar estado financiero \\
\hline Préstamo de bancos & Control moral de \\
\hline Construye reputación & $\begin{array}{l}\text { Valoración adecuada de } \\
\text { inversiones }\end{array}$ & $\begin{array}{l}\text { Liquidaciones } \\
\text { reclamaciones }\end{array}$ \\
\hline $\begin{array}{l}\text { Valoración adecuada de los } \\
\text { activos }\end{array}$ & Buena Seguridad & Evidencia en la corte \\
\hline Aceptación del gobierno & & Liquidación de cuentas \\
\hline Actualizar cuentas & & Cálculo de compra \\
\hline Sugerencias para mejorar & & Facilitación de impuestos \\
\hline Útil para la agencia & & \\
\hline
\end{tabular}

Fuente: Introduction to Auditing

\section{Limitaciones:}

Según el manual Introduction to Auditing o Introducción a la auditoría (INTRODUCTION TO AUDITING, s.f.) se encuentran las siguientes limitaciones:

- No hay detección de errores y fraudes: El auditor puede no ser capaz de detectar ciertos fraudes que se cometen con intenciones maliciosas.

- Dependencia de la explicación por otros: El auditor debe depender de la explicación e información brindada por los funcionarios responsables de la compañía. El informe de 


\section{(1)}

auditoría se ve afectado negativamente si la explicación y la información demuestran ser falsas.

- Dependencia de las opiniones de los demás: El auditor debe basarse en los puntos de vista u opiniones de diferentes expertos (abogados, ingenieros, arquitectos, etc.). No puede ser un experto en todos los campos.

- Conflicto con los demás: El auditor puede tener diferencias de opinión con los contadores, la gerencia, los ingenieros, etc. En tal caso, el juicio personal juega un papel importante. Es diferente de persona a persona.

- Efecto de la inflación: Los estados financieros pueden no revelar una imagen verdadera incluso después de la auditoría debido a las tendencias inflacionarias.

- Prácticas corruptas para influir en los auditores: La gerencia puede usar prácticas corruptas para influenciar a los auditores y obtener un informe favorable sobre el estado de la organización.

- Sin garantía: El auditor no puede dar ninguna garantía sobre la rentabilidad futura y las perspectivas de la empresa.

- Limitaciones inherentes de los estados financieros: Los estados financieros no reflejan los valores actuales de los activos y pasivos. Muchos artículos se basan en el juicio personal de los propietarios. Ciertos hechos no monetarios no se pueden medir. Las declaraciones auditadas debido a estas limitaciones no pueden mostrar una posición verdadera.

- No es posible realizar una verificación detallada: El auditor no puede verificar todas y cada una de las transacciones. Es posible que se le solicite que haga una comprobación de prueba. 


\section{(1)}

\subsection{OBJETO DE ESTUDIO}

\subsubsection{ORGANIZACIÓN OBJETIVO}

Según la publicación en la página de la empresa (Ernst \& Young, 2017). Arthur Young nació en Glasgow, Escocia. Licenciado en Derecho, se interesó en la banca y las inversiones. En 1890, se mudó a los Estados Unidos para realizar estudios de contabilidad. En 1906, fundó una firma contable, Arthur Young \& Company, con su hermano Stanley.

Alwin C. Ernst nació en Cleveland, Estados Unidos. Al finalizar sus estudios, trabajó como asistente contable. En 1903 fundó, junto a su hermano Theodore, Ernst \& Ernst, una pequeña firma contable pública.

Arthur Young y Alwin C. Ernst eran innovadores y apreciaban la importancia de la calidad en su trabajo. Ernst fue precursor de la idea de que la información contable podría ser utilizada para tomar decisiones empresariales, lo que le diferenciaba ante las compañías clientes. Inspiró a su gente para ofrecer un mejor servicio. Arthur Young, por su parte, se posicionó tanto como contable como consejero empresarial.

Ambos comprendieron la importancia del capital humano. En 1920, la filosofía operativa de Ernst \& Ernst afirmaba que "el éxito de Ernst \& Ernst depende completamente del carácter, la habilidad y el esfuerzo de los hombres y mujeres que conforman la organización”. Young promovió activamente el desarrollo de los profesionales: en los años 20 fundó una escuela docente y, en la década de los años 30, su firma fue la primera organización en seleccionar empleados en campus universitarios.

Ambas compañías entraron rápidamente en el mercado global. En 1924, se asociaron con destacadas firmas británicas: Young lo hizo con Broads Paterson \& Co., y Ernst con Whinney Smith \& Whinney. Estas alianzas fueron las primeras de una larga lista para ambas corporaciones, que abrieron oficinas en todo el mundo para prestar servicios a sus clientes internacionales. 


\section{(1)}

Alwin C. Ernst y Arthur Young nunca llegaron a conocerse personalmente; ambos murieron en 1948 con tan sólo unos días de diferencia. Pero sus filosofías perduraron y, en 1989, Ernst \& Whinney y Arthur Young \& Co. se asociaron para crear EY. La nueva organización se posicionó rápidamente como una firma de vanguardia, caracterizada por una rápida globalización, nuevas tecnologías empresariales y continuas innovaciones.

Según la publicación (EY Vision, 2013), actualmente la empresa es una de las mayores firmas de servicios profesionales del mundo, que incluyen auditoría, impuestos, finanzas, contabilidad, servicios de cálculos y estudios actuariales y asesoramiento en la gestión para sus clientes.

La empresa está debido en cuatros regiones a nivel Global como son:

- Europa, Oriente Medio, India y África

- América

- Asia y el Pacífico

- Japón

La empresa brinda cuatro líneas de servicios principales como son:

- Servicio de auditoría (45\%): comprende Auditoría Financiera, Servicios Financieros Asesoría Contable, Servicios de Investigación de Fraude (Forensic) y Disputas, y los servicios de Sostenibilidad y Cambio Climático.

- Servicio de impuestos (26\%): incluye el cumplimiento del Impuesto Empresarial, Capital Humano, Aduanas, Impuestos Indirectos, Servicios de Impuestos internacionales, Contabilidad Tributaria y Servicios de asesoramiento de riesgos, Impuesto a las Transacciones.

- Servicio de consultoría (20\%): consta de cuatro líneas: Actuarial, IT Risk and Assurance, Risk y Performance Improvement.

- Servicio de consultoría de transacciones (TAS) (9\%): se ocupa de la agenda de las empresas de capital - la conservación, la optimización, la inversión, el aumento de capital, asesoramiento en fusiones y adquisiciones, así como en valoraciones 


\section{(1)}

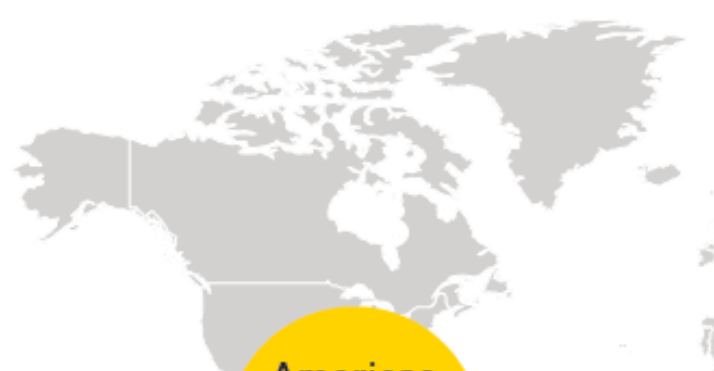

EMEIA

84,224

people

Americas
53,835

people

Figura $N^{\circ} 6$ Trabajadores en el Mundo

Fuente: Visión, Valores e Impacto EY Global (EY Vision, 2013)

\section{Consultoría / Advisory}

$\underline{\text { Servicios para mejorar el desempeño financiero }}$

En este servicio se encarga de mejorar el desempeño financiero y operativo, a través de la identificación, evaluación y diseño de las estrategias y soportes requeridos y aplicables al negocio, para lo cual se cuenta con los siguientes:

- Aseguramiento de ingresos

- Reducción de costos

- Análisis de productos, servicios y rentabilidad por unidad de negocio

- Balanced Scorecard

- Costeo ABC

- Diseño de modelo de costo

- Reportes financieros y operacionales

- Revisión de la gestión de call centers 


\section{(1)}

Servicios para mejorar el desempeño a través de la información

En este servicio se encarga de dar confianza en la información del cliente, en los sistemas que la contienen y en la organización que la administra, a través de los siguientes servicios:

- Diagnóstico de calidad de datos (Data Analytics)

- Apoyo en la planificación y gestión en la implementación de aplicaciones (ERP, CRM, SCM y BI)

- Diagnóstico de segregación de funciones (SOD)

- Evaluación y plan de seguridad de la información (ERP security)

- Cloud Computing

- Diseño de áreas de sistemas

- IT Effectiveness

- Optimización de costos de TI

- Optimización de portafolio de proyectos

- Plan estratégico de informática

- Revisión de la calidad de migración de los datos

- Selección de servicios de outsourcing

$\underline{\text { Servicios de soporte en la gestión de proyectos }}$

En este servicio se basa en obtener una mejora de resultados de los proyectos de transformación e integración, de innovación tecnológica y de despliegue de estrategias de la organización, a través de los siguientes servicios:

- Gestión de riesgos de procesos (Project Risk Management)

- Implantación de oficinas de proyectos (PMO)

- Asesoría en la gestión de inversión social

- Definición de portafolio de proyectos

- Diagnóstico de situación de proyectos

- Manejo de cambio y asistencia de proyectos de fusión o integración 


\section{(1)}

$\underline{\text { Servicios para la administración de riesgos }}$

Este servicio se basa en desarrollar políticas y mecanismos de control para el cliente pueda proteger sus activos y preservar el valor patrimonial, mediante los siguientes servicios:

- Auditoría Interna

- Control interno basado en COSO

- Asesoría en Basilea III y Solvencia II

- Asesoría en el cumplimiento de la ley de prevención de lavado de activos

- Asesoría en el cumplimiento de la ley Sarbanes - Oxley (SOX)

- Asesoría en el cumplimiento regulatorio

- Asesoría en la adecuación a la regulación FATCA

- Asesoría y evaluación del cumplimiento de la regulación de prácticas anticorrupción (FCPA y UK Bribery Act)

- Capacitación y aplicación de IFRS - NIIF

- Gestión de riesgos (ERM - Enterprise Risk Management)

- Informática forense - Análisis forense de datos electrónicos

- Investigación de fraudes

- Línea de reporte de actos irregulares - Ethics Line (Call Center)

- Mejora de Gobierno Corporativo

- Programa de prevención de fraudes

- Responsabilidad social empresarial

- Revisión de prácticas de control interno

Servicios de seguridad de la información para la administración de pagos

- Auditoría de sistemas (COBIT - ISO 27000 - ITIL) y cumplimiento regulatorio de normas SBS y Sarbanes - Oxley

- Definición del modelo de gobierno de TI

- Evaluación de la eficiencia en el soporte informático (ERP Effectiveness)

- Plan de continuidad de negocios

- Plan de recuperación de sistemas en caso de desastres (DRP) 


\section{(1)}

- Plan de seguridad de información

- SSAE16, ISAE3402 - Reporte sobre servicios tercerizados (ex SAS70)

\section{Auditoría / Assurance}

- Auditoria de estados financieros y revisiones especiales

Tiene un enfoque de riesgos, procesos y controles; para garantizar que no existen errores o irregularidades en los estados financieros del cliente. Además de considerar los aspectos del negocio y sector que tienen incidencia en la información financiera. Este enfoque permite identificar oportunidades de mejora en los controles internos y riesgos no controlados por el cliente, por lo que permite brindar recomendaciones para mejorar los procesos, controles y calidad general de la información que utiliza gerencia, directorio y los accionistas.

- Asesoría en Normas Internacionales de Información Financiera (NIIF - IFRS)

Al implementar NIIF / IFRS es la oportunidad de contar con información financiera de calidad de un lenguaje que permite a las empresas acceder tanto al mercado local como internacional, inclusive si se desea sólo obtener líneas de crédito con bancos internacionales, por lo que es considerado "el pasaporte para que las empresas tengan acceso al mundo financiero".

- Revisión de la información financiera en procesos de fusiones y adquisiciones Para la entidad que realiza alguna compra, se apoya en revisar los activos y pasivos de la empresa si estas están soportadas adecuadamente y con criterios contables aceptables, informando al comprador de ajustes que deben realizar a los saldos contables, además de brindar información sobre deficiencias en los proceso y controles, así como de otros elementos en la empresa sujeta a la revisión.

- Auditoría y revisión de informes de sostenibilidad

Estas revisiones se realizan considerando el sector económico particular del cliente, e incluyen los aspectos financieros y no financieros relacionados, brindando confianza a 


\section{(1)}

quienes requieren esta información sobre el compromiso que tienen las empresas para garantizar la sostenibilidad de sus operaciones.

\section{Asesoría tributaria / Tax}

- Asesoría en impuestos

En este servicio es para ayudar a las compañías a implementar correctamente las regulaciones fiscales que afectan las actividades de su negocio, a través de los servicios:

- Consultoría tributaria

- Planificación fiscal

- Cumplimiento tributario

Este servicio ofrece asesoramiento al cumplimiento de las obligaciones tributarias y en los procesos de revisión por parte de la auditoría tributaria, identificando áreas de reducción de riesgos y mejora de control.

- Precios de transferencia

Este servicio ofrece ayuda a las compañías a revisar, documentar, administrar y defender sus procesos y políticas de precios de transferencia entre entidades vinculadas y alinearlas con su estrategia de negocios. El enfoque se da en tres frentes:

- Consultoría y planificación estratégica

- Cumplimiento

- Controversia

- Aduanas, Comercio Exterior y Procedimientos Especiales

Este servicio ofrece a las compañías el desarrollo e implementación de procedimientos efectivos vinculados con operaciones con el exterior. Los servicios que ofrece son:

- Asesoría aduanera

- Conformidad en temas aduaneros incluyendo el soporte en fiscalizaciones iniciadas por la autoridad administrativa 


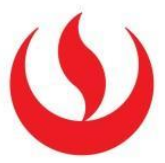

- Asesoría laboral y tributaria individual

Este servicio ofrece a las compañías a cumplir con las obligaciones laborales y fiscales, así como a alinearse a los cambios regulatorios, con el fin de administrar eficazmente su capital humano.

- Litigios

Este servicio brinda los siguientes procedimientos:

- Asesorar en las fiscalizaciones iniciadas por la administración tributaria

- Procedimientos de reclamación y apelación de en sede administrativa

- Procesos judiciales ante el Poder Judicial y el Tribunal Constitucional

- Procedimientos no contenciosos

- Impuestos en transacciones

Este servicio ayuda a mitigar los riesgos asociados a las transacciones que efectué un cliente, comprendiendo y planificando las implicancias fiscales.

- Impuestos internacionales

Este servicio ayuda en la asesoría tributaria relacionada con la inversión extranjera en el Perú, así como con la inversión peruana en el extranjero.

- Outsourcing Contable

- Tercerización de la contabilidad contable y fiscal

- Tercerización de planillas o nóminas

- Revisión de contratos

\section{Transacciones y Finanzas Corporativas / Transactions Advisory Services (TAS)}

- Diligencia comercial, contable, tributario, laboral y de TI

Este servicio ayuda a los clientes a alcanzar sus objetivos estratégicos, tanto en procesos de adquisición como de desinversión. La revisión puede comprender también la evaluación 
de procedimientos, sistemas de información y organización involucrada en la preparación de la información financiera.

- Valuación y modelamiento de negocio

Este servicio ayuda al cliente a estimar el valor de mercado de empresas, negocios y activos con fines transaccionales, de gestión, contables y fiscales.

- Fusiones y adquisiciones

Este servicio ayuda al cliente en materia de fusiones y adquisiciones tanto al momento de efectuar la compra como realizar la venta.

- Financiamiento de proyectos

Este servicio ofrece asesoramiento profesional e independiente a clientes tanto en el sector privado como público en materia de infraestructura. En donde, se evalúa la factibilidad de los proyectos, como análisis de riesgos, asesoramiento sobre las alternativas de mitigación, desarrollar estrategia financiera, y en búsqueda y negociación de financiamiento. 


\section{(1)}

MAPA DE PROCESOS

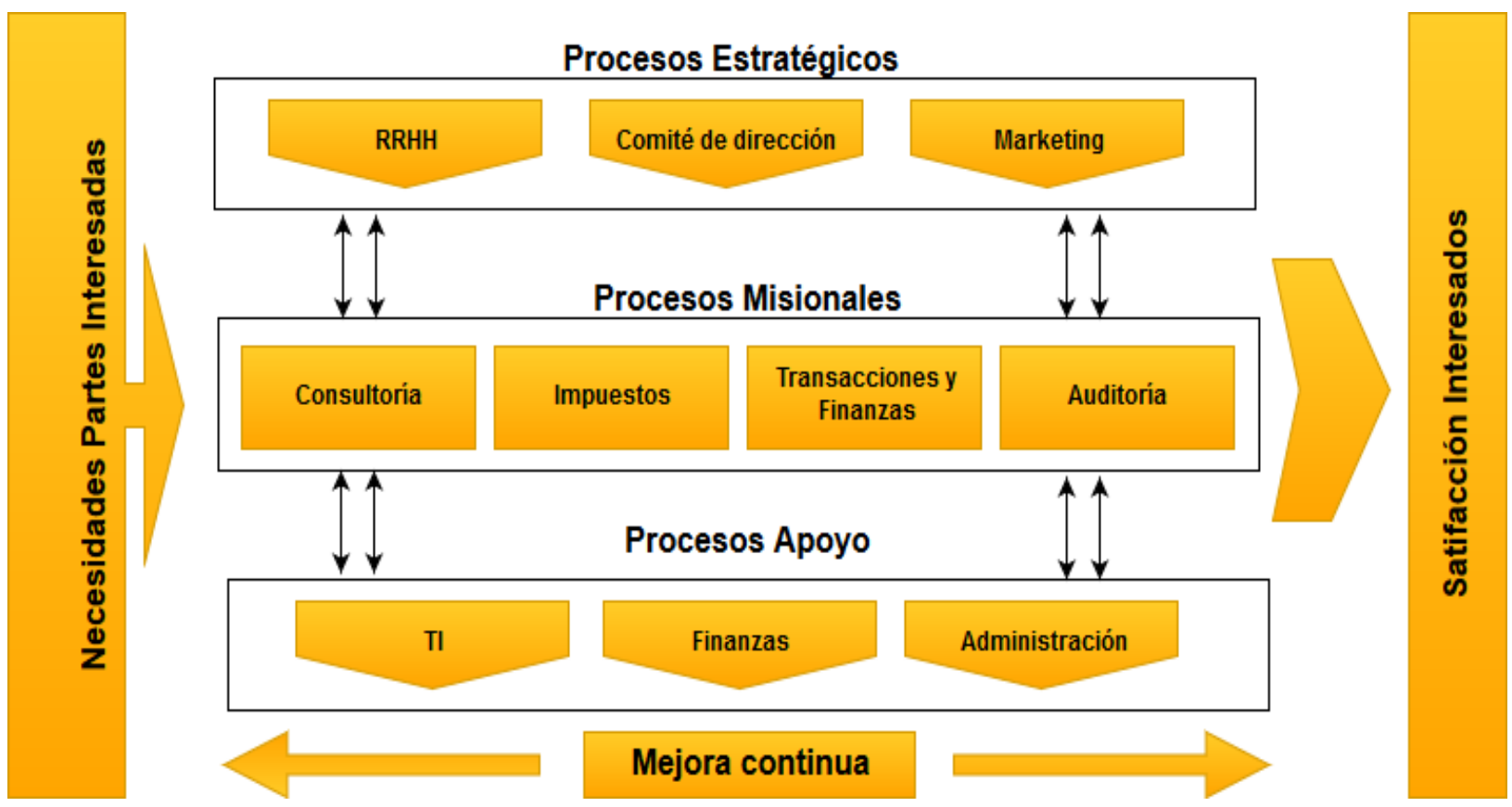

Figura $\mathrm{N}^{\circ} 7$ Mapa de Procesos

Fuente: Elaboración Propia

Tabla N 2 Descripción de Mapa de Procesos

\begin{tabular}{|l|l|}
\hline \multicolumn{1}{|c|}{ Proceso } & \multicolumn{1}{|c|}{ Descripción } \\
\hline RRHH & $\begin{array}{l}\text { Este proceso es el pilar de la organización, ya } \\
\text { que se encarga de gestionar y coordinar la } \\
\text { aplicación de las normas y los } \\
\text { procedimientos de los recursos humanos. Las } \\
\text { cuales desarrollan y aplican en los sistemas } \\
\text { de información en la gestión del talento } \\
\text { humano. }\end{array}$ \\
\hline Comité de dirección & $\begin{array}{l}\text { Es el proceso que se encarga de garantizar la } \\
\text { viabilidad del negocio, asegurar la } \\
\text { supervivencia, buscar crecimiento, fija el } \\
\text { marco estratégico y asegurar su compresión } \\
\text { en toda la organización }\end{array}$ \\
\hline Marketing & $\begin{array}{l}\text { Es el proceso que se encarga de desarrollar } \\
\text { estrategias de marketing a corto y largo plazo } \\
\text { de la organización. Estas estrategias pueden }\end{array}$ \\
\hline
\end{tabular}




\section{$(1$}

\begin{tabular}{|c|c|}
\hline & $\begin{array}{l}\text { ser: desarrollo de la marca, inteligencia } \\
\text { competitiva y relaciones públicas }\end{array}$ \\
\hline Consultoría & $\begin{array}{l}\text { Es el proceso que se encarga de gestionar la } \\
\text { línea de servicio de Consultoría hacia los } \\
\text { clientes de la organización }\end{array}$ \\
\hline Impuestos & $\begin{array}{l}\text { Es el proceso que se encarga de gestionar la } \\
\text { línea de servicio de Impuestos hacia los } \\
\text { clientes de la organización }\end{array}$ \\
\hline Transacciones y Finanzas & $\begin{array}{l}\text { Es el proceso que se encarga de gestionar la } \\
\text { línea de servicio de Transacciones y } \\
\text { Finanzas hacia los clientes de la organización }\end{array}$ \\
\hline Auditoría & $\begin{array}{l}\text { Es el proceso que se encarga de gestionar la } \\
\text { línea de servicio de Auditoría hacia los } \\
\text { clientes de la organización }\end{array}$ \\
\hline $\mathrm{TI}$ & $\begin{array}{l}\text { Es el proceso que se encarga de planificar, } \\
\text { diseñar, ejecutar y monitorear la estrategia de } \\
\text { las tecnologías de la información. Además, } \\
\text { de supervisar y evaluar el alineamiento de los } \\
\text { sistemas de información a los procesos de la } \\
\text { organización }\end{array}$ \\
\hline Finanzas & $\begin{array}{l}\text { Es el proceso que se encarga de la eficiencia } \\
\text { administrativa del capital de trabajo dentro } \\
\text { de un criterio de riesgos y rentabilidad; } \\
\text { además, de orientar la estrategia financiera } \\
\text { para garantizar la disponibilidad de fuentes } \\
\text { de financiación. }\end{array}$ \\
\hline Administración & $\begin{array}{l}\text { Es el proceso que se encarga de la aplicación } \\
\text { de herramientas gerenciales que respondan a } \\
\text { las necesidades estratégicas, competitivas e } \\
\text { innovadoras para la organización en el } \\
\text { mercado }\end{array}$ \\
\hline
\end{tabular}

Fuente: Elaboración Propia

\subsubsection{MISIÓN}

"Prestar servicios de auditoría, impuestos, transacciones y asesoría a negocios para cada cliente en todo el mundo".

\subsubsection{VISIÓN}

“La visión 2020 establece el propósito de construir un mundo laboral mejor”. 
(1)

Desk research

(2)

Input stakeholder consultation (internal and external) regarding materiality and value creation

\begin{tabular}{l} 
MATERIAL TOPICS \\
Strong brand \\
Independence \\
Innovative and creative services \\
Insight into client sector, business and needs \\
Recruiting and retaining top talents \\
Attractive employer (including diversity) \\
Human / personal development and on-the-job training \\
Quality \\
Audit firm rotation, services switch (audit vs. non-audit) and Vio \\
Client satisfaction \\
Transparency \\
Integrity and ethical standards \\
Stakeholder relations \\
\hline Sustainability (transport, energy, resources)
\end{tabular}

Figura Nº 8 Visión 2020
Vision \& Strategy EY - Vision 2020

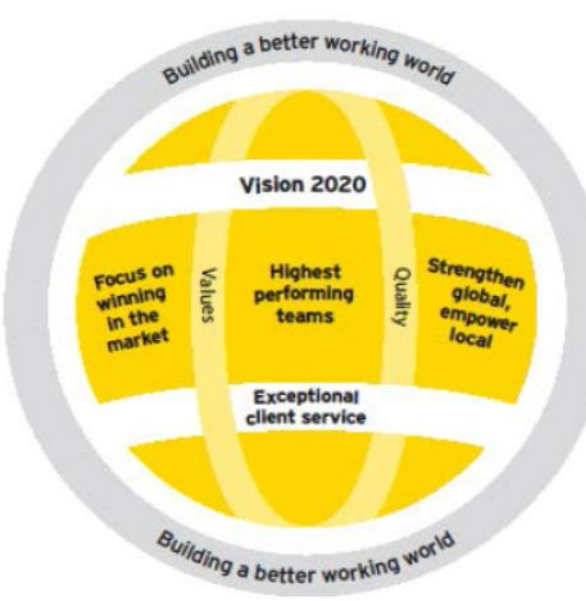

4.

Validation Regional Partner Forum

5 Finalization combined Leadership Team/ Board of Directors
Materiality 2014/2015

\begin{tabular}{|c|c|c|}
\hline \multicolumn{2}{|c|}{ Material topics } & \multirow[t]{2}{*}{ Topics include } \\
\hline \multicolumn{2}{|c|}{ Markets } & \\
\hline 1 & Innovation & $\begin{array}{l}\text { - Use of technology and data analytics } \\
\text { Develop innovative, sustainable and creative } \\
\text { services }\end{array}$ \\
\hline 2 & Quality of service & $\begin{array}{l}\text { Safeguarding and further improving the } \\
\text { quality of our servive by delivering } \\
\text { exceptional client service: connected, } \\
\text { responsive and insightful } \\
\text { - Full insight into the sectors, businesses and } \\
\text { needs of our clients }\end{array}$ \\
\hline 3 & Stakeholder relations & $\begin{array}{l}\text { Positive and strong relations with all EY's } \\
\text { stakeholders } \\
\text { EY's position in the public debate } \\
\text { Knowledge transfer to society and other } \\
\text { stakeholders }\end{array}$ \\
\hline \multicolumn{2}{|c|}{ Talent } & \\
\hline 4 & $\begin{array}{l}\text { Recruiting and retaining } \\
\text { top talent }\end{array}$ & $\begin{array}{l}\text { - Diverse and inclusive teams } \\
\text { Personal career design }\end{array}$ \\
\hline 5 & Learning and development & $\begin{array}{l}\text { - Investing in personal development } \\
\text { Training on the job }\end{array}$ \\
\hline \multicolumn{2}{|c|}{ Operations } & \\
\hline 6 & $\begin{array}{l}\text { Sustainable financial } \\
\text { performance }\end{array}$ & $\begin{array}{l}\text { - Leading growth and competitive earnings } \\
\text { - Investment in innovation and quality }\end{array}$ \\
\hline 7 & $\begin{array}{l}\text { Independence, integrity } \\
\text { and ethical standards }\end{array}$ & $\begin{array}{l}\text { Integrity and independence are hallmarks of } \\
\text { our opinions, services and ethical standards }\end{array}$ \\
\hline
\end{tabular}

Einancial capital 9 Human Capital

Intellectual Capital

Fuente: Visión, Valores e Impacto EY Global (EY Vision, 2013) 


\section{(1)}

\subsubsection{OBJETIVOS ESTRATÉGICOS}

Según la publicación de Ernst and Young (EY Vision, 2013), se define a la empresa como organización de servicios profesionales, su éxito depende de la calidad y el compromiso de la gente y de cómo se unen. Es por eso que la creación de los equipos de mayor rendimiento se desarrolla e inspiran a las mejores personas y promueven la cultura que los apoya en el trabajo conjunto. Esto es fundamental para la estrategia de la firma.

La empresa tiene como objetivo la consigna de que la gente brillante y talentosa, que está dispuesta a desarrollarse de forma personal y profesionalmente. Por lo que lo más relevante es ayudar a la gente a alcanzar sus metas y asegurar que su tiempo en EY sea valioso en términos de lo que aprenden, las experiencias que obtienen y en la construcción de su propia marca personal.

Como reflejo de esto, la empresa brinda una propuesta de desarrollo única para sus empleados que dura toda la vida.

La empresa se compromete con sus empleados a:

- Crear una valiosa experiencia de reclutamiento a través de iniciativas tales como programas de pasantías globales.

- Proporcionar el mejor aprendizaje y desarrollo a través de la formación, tutoría y experiencia en el trabajo.

- Promover una cultura inclusiva que celebre la diversidad en el lugar de trabajo.

- Dar a la gente flexibilidad y elección en su plan de trabajo.

- Asegurar la seguridad, la salud y el bienestar de la gente.

Por otro lado, la empresa se compromete a brindar un servicio excepcional a sus clientes, para satisfacer sus necesidades tanto para ellos como del interés público con transparencia y profesionalismo. Además, tiene el compromiso de construir un mundo laboral mejor que se refleja con la visión de que los servicios que ofrece la firma, ayudan a crear confianza en los 


\section{(1)}

mercados de capitales, lo que en última instancia conduce a un crecimiento económico más sostenible.

Bajo estos esfuerzos para apoyar a sus clientes, el mercado de la empresa se basa en la colaboración. En trabajo en conjunto con las partes interesadas como son: los gobiernos, formuladores de políticas, organizaciones sin fines de lucro o reguladores, se puede crear un cambio positivo. También se cree poder ayudar a apoyar el crecimiento económico y la creación de empleo impulsado por los empresarios y la mayor participación de las mujeres en los negocios. 


\section{(4)}

\section{MATRIZ DE OBJETIVOS ESTRATÉGICOS VERSUS PROCESOS DE NEGOCIO}

Tabla N ${ }^{\circ} 3$ Matriz de Objetivos Estratégicos Versus Procesos de Negocio

\begin{tabular}{|c|c|c|c|c|c|c|c|c|c|c|c|}
\hline & \multicolumn{11}{|c|}{ Objetivo } \\
\hline Proceso & Subproceso & $\begin{array}{l}\text { Innovar } \\
\text { en toda } \\
\text { la } \\
\text { organiz } \\
\text { ación }\end{array}$ & $\begin{array}{l}\text { Crear } \\
\text { modelos } \\
\text { de } \\
\text { negocios } \\
\text { alternativ } \\
\text { os }\end{array}$ & $\begin{array}{l}\text { Gestio } \\
\text { nar } \\
\text { servici } \\
\text { os de } \\
\text { mayor } \\
\text { escala }\end{array}$ & $\begin{array}{l}\text { Consider } \\
\text { ar la } \\
\text { agenda } \\
\text { digital a } \\
\text { los } \\
\text { clientes }\end{array}$ & $\begin{array}{l}\text { Usar la } \\
\text { tecnología } \\
\text { en las } \\
\text { líneas de } \\
\text { servicio }\end{array}$ & $\begin{array}{l}\text { Desarrollar } \\
\text { un } \\
\text { ecosistema } \\
\text { de alianzas } \\
\text { y recursos }\end{array}$ & $\begin{array}{l}\text { Adoptar } \\
\text { una visión } \\
\text { a futuro } \\
\text { acerca del } \\
\text { trabajo }\end{array}$ & $\begin{array}{l}\text { Seguir } \\
\text { una ruta } \\
\text { de } \\
\text { diversida } \\
\text { d e } \\
\text { inclusión }\end{array}$ & $\begin{array}{l}\text { Optimizar } \\
\text { costos y } \\
\text { mejor } \\
\text { márgenes }\end{array}$ & $\begin{array}{l}\text { Contro } \\
1 \text { de } \\
\text { costos } \\
\text { indirec } \\
\text { tos }\end{array}$ \\
\hline Comité de Dirección & & $\mathrm{X}$ & $X$ & $\mathrm{X}$ & & $\mathrm{X}$ & $\mathrm{X}$ & $X$ & $X$ & $X$ & $\mathrm{X}$ \\
\hline RRHH & & $\mathrm{X}$ & & & & & $\mathrm{X}$ & $\mathrm{X}$ & $\mathrm{X}$ & & \\
\hline Marketing & & $\mathrm{X}$ & & & & & & $\mathrm{X}$ & & & \\
\hline Auditoría & & & $\mathrm{X}$ & $\mathrm{X}$ & $\mathrm{X}$ & $\mathrm{X}$ & $\mathrm{X}$ & $\mathrm{X}$ & $\mathrm{X}$ & $\mathrm{X}$ & \\
\hline Transacciones y Finanzas & & & $\mathrm{X}$ & $\mathrm{X}$ & $\mathrm{X}$ & $\mathrm{X}$ & $\mathrm{X}$ & $\mathrm{X}$ & $\mathrm{X}$ & $\mathrm{X}$ & \\
\hline Impuestos & & & $\mathrm{X}$ & $\mathrm{X}$ & $\mathrm{X}$ & $\mathrm{X}$ & $\mathrm{X}$ & $\mathrm{X}$ & $\mathrm{X}$ & $\mathrm{X}$ & \\
\hline Consultoría & $\begin{array}{l}\text { Auditoría Interna } \\
\text { Control interno } \\
\text { basado en COSO } \\
\text { Asesoría en } \\
\text { Basilea III y } \\
\text { Solvencia II }\end{array}$ & & $\mathrm{X}$ & $\mathrm{X}$ & $\mathrm{X}$ & $\mathrm{X}$ & $\mathrm{X}$ & $\mathrm{X}$ & $\mathrm{X}$ & $\mathrm{X}$ & \\
\hline
\end{tabular}




\begin{tabular}{|c|c|c|c|c|c|c|c|c|c|c|c|}
\hline & $\begin{array}{l}\text { Análisis forense } \\
\text { de datos } \\
\text { electrónicos }\end{array}$ & & & & & & & & & & \\
\hline TI & & $\mathrm{X}$ & & & & $\mathrm{X}$ & & & & $\mathrm{X}$ & \\
\hline Finanzas & & & & & & & & & & $\mathrm{X}$ & $\mathrm{X}$ \\
\hline Administración & & & & & & & & & & $\mathrm{X}$ & $\mathrm{X}$ \\
\hline & & 4 & 5 & 5 & 4 & 6 & 6 & 7 & 6 & 8 & 3 \\
\hline
\end{tabular}

Fuente: Elaboración propia 


\section{(}

\subsubsection{ORGANIGRAMA}

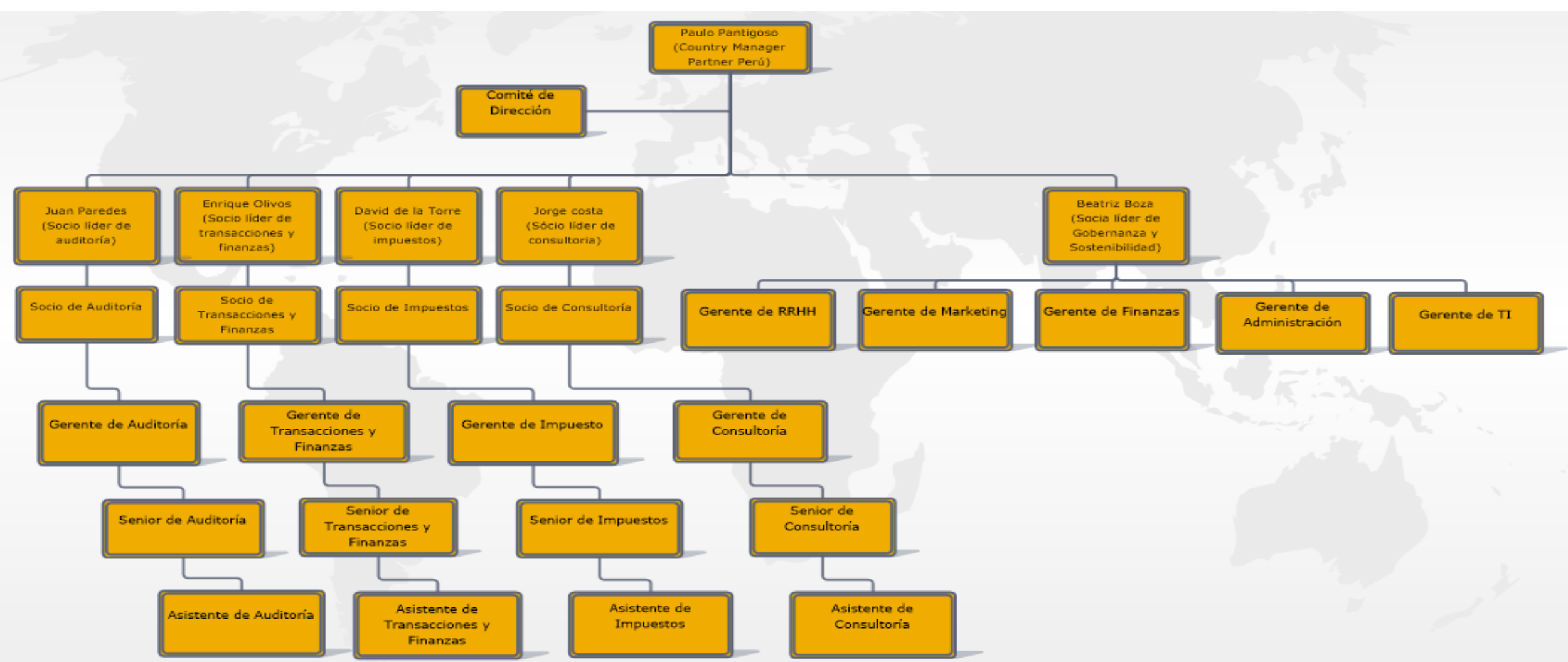

Figura $\mathrm{N}^{\circ} 9$ Organigrama EY Perú

Fuente: Elaboración Propia

Tabla Nº 4 Descripción de Cargos EY Perú 


\begin{tabular}{|c|c|}
\hline Cargo & Descripción \\
\hline Country Manager Partner Perú & $\begin{array}{l}\text { Encargado de representar a la firma en el país y en } \\
\text { gestionar las operaciones, desarrollo del negocio y } \\
\text { aumentar la rentabilidad de la empresa en la país }\end{array}$ \\
\hline Comité de Dirección & $\begin{array}{l}\text { Son los miembros encargados de garantizar la viabilidad } \\
\text { del negocio, asegurar la supervivencia, buscar } \\
\text { crecimiento, fija el marco estratégico y asegurar su } \\
\text { compresión en toda la organización }\end{array}$ \\
\hline Socio Líder de Auditoría & $\begin{array}{l}\text { Es el encargado principal de ver toda la línea de servicio } \\
\text { de auditoría. Busca nuevas sub líneas de servicio como } \\
\text { oportunidades de negocio y del aumento de la cartera de } \\
\text { clientes }\end{array}$ \\
\hline $\begin{array}{l}\text { Socio Líder de Transacciones y } \\
\text { Finanzas }\end{array}$ & $\begin{array}{l}\text { Es el encargado principal de ver toda la línea de servicio } \\
\text { de transacciones y finanzas. Busca nuevas sub líneas de } \\
\text { servicio como oportunidades de negocio y del aumento } \\
\text { de la cartera de clientes }\end{array}$ \\
\hline Socio Líder de Impuestos & $\begin{array}{l}\text { Es el encargado principal de ver toda la línea de servicio } \\
\text { de impuestos. Busca nuevas sub líneas de servicio como } \\
\text { oportunidades de negocio y del aumento de la cartera de } \\
\text { clientes }\end{array}$ \\
\hline Socio Líder de Consultoría & $\begin{array}{l}\text { Es el encargado principal de ver toda la línea de servicio } \\
\text { de consultoría. Busca nuevas sub líneas de servicio como } \\
\text { oportunidades de negocio y del aumento de la cartera de } \\
\text { clientes }\end{array}$ \\
\hline $\begin{array}{l}\text { Socio Líder de Gobernanza y } \\
\text { Sostenibilidad }\end{array}$ & $\begin{array}{l}\text { Es el encargado de ver los procesos propios del negocio } \\
\text { como RRHH, Marketing, Finanzas, Administración y TI }\end{array}$ \\
\hline Socio de Auditoría & $\begin{array}{l}\text { Es el encargado de supervisar el trabajo de sus gerentes } \\
\text { en cada cliente. Da seguimiento y control de los } \\
\text { proyectos de su cartera de clientes. }\end{array}$ \\
\hline Socio de Transacciones y Finanzas & $\begin{array}{l}\text { Es el encargado de supervisar el trabajo de sus gerentes } \\
\text { en cada cliente. Da seguimiento y control de los } \\
\text { proyectos de su cartera de clientes. }\end{array}$ \\
\hline Socio de Impuestos & $\begin{array}{l}\text { Es el encargado de supervisar el trabajo de sus gerentes } \\
\text { en cada cliente. Da seguimiento y control de los } \\
\text { proyectos de su cartera de clientes. }\end{array}$ \\
\hline Socio de Consultoría & $\begin{array}{l}\text { Es el encargado de supervisar el trabajo de sus gerentes } \\
\text { en cada cliente. Da seguimiento y control de los } \\
\text { proyectos de su cartera de clientes }\end{array}$ \\
\hline Gerente de RRHH & $\begin{array}{l}\text { Es el encargado de gestionar y coordinar la aplicación de } \\
\text { las normas y los procedimientos de RRHH. Desarrollar y } \\
\text { aplicar sistemas de información en la gestión del talento } \\
\text { humano }\end{array}$ \\
\hline
\end{tabular}




\section{()}

\begin{tabular}{|c|c|}
\hline Gerente de Marketing & $\begin{array}{l}\text { Es el encargado de desarrollar estrategias de marketing a } \\
\text { corto y largo plazo de la organización. Entre las cuales } \\
\text { están como estrategias como son: desarrollo de la marca, } \\
\text { inteligencia competitiva y relaciones públicas }\end{array}$ \\
\hline Gerente de Finanzas & $\begin{array}{l}\text { Es el encargado de la eficiencia administrativa del capital } \\
\text { de trabajo dentro de un criterio de riesgos y rentabilidad; } \\
\text { además, de orientar la estrategia financiera para } \\
\text { garantizar la disponibilidad de fuentes de financiación. }\end{array}$ \\
\hline Gerente de Administración & $\begin{array}{l}\text { Es el encargado de la aplicación de herramientas } \\
\text { gerenciales que respondan a las necesidades estratégicas, } \\
\text { competitivas e innovadoras para la organización en el } \\
\text { mercado }\end{array}$ \\
\hline Gerente de TI & $\begin{array}{l}\text { Es el encargado de planificar, diseñar, ejecutar y } \\
\text { monitorear la estrategia de las tecnologías de la } \\
\text { información. Además, de supervisar y evaluar el } \\
\text { alineamiento de los sistemas de información a los } \\
\text { procesos de la organización }\end{array}$ \\
\hline Gerente de Auditoría & $\begin{array}{l}\text { Es el encargado de liderar los proyectos de cada cliente } \\
\text { de la línea de servicio de auditoría. Además, realiza el } \\
\text { presupuesto del proyecto como también de la selección } \\
\text { del equipo que tendrá por proyecto. Por último, se } \\
\text { encarga del seguimiento y control de su equipo de trabajo } \\
\text { hasta la finalización del proyecto. }\end{array}$ \\
\hline Gerente de Transacciones y Finanzas & $\begin{array}{l}\text { Es el encargado de liderar los proyectos de cada cliente } \\
\text { de la línea de servicio de transacciones y finanzas. } \\
\text { Además, realiza el presupuesto del proyecto como } \\
\text { también de la selección del equipo que tendrá por } \\
\text { proyecto. Por último, se encarga del seguimiento y } \\
\text { control de su equipo de trabajo hasta la finalización del } \\
\text { proyecto. }\end{array}$ \\
\hline Gerente de Impuesto & $\begin{array}{l}\text { Es el encargado de liderar los proyectos de cada cliente } \\
\text { de la línea de servicio de impuesto. Además, realiza el } \\
\text { presupuesto del proyecto como también de la selección } \\
\text { del equipo que tendrá por proyecto. Por último, se } \\
\text { encarga del seguimiento y control de su equipo de trabajo } \\
\text { hasta la finalización del proyecto. }\end{array}$ \\
\hline Gerente de Consultoría & $\begin{array}{l}\text { Es el encargado de liderar los proyectos de cada cliente } \\
\text { de la línea de servicio de consultoría. Además, realiza el } \\
\text { presupuesto del proyecto como también de la selección } \\
\text { del equipo que tendrá por proyecto. Por último, se } \\
\text { encarga del seguimiento y control de su equipo de trabajo } \\
\text { hasta la finalización del proyecto. }\end{array}$ \\
\hline
\end{tabular}




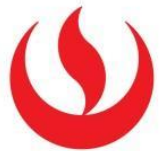

\begin{tabular}{|l|l|}
\hline Senior de Auditoría & $\begin{array}{l}\text { Es el encargado del trabajo directo que se realiza en un } \\
\text { proyecto del cliente de la línea de servicio de auditoría, } \\
\text { tiene mayor experiencia en trabajo de campo que un } \\
\text { asistente. Además, supervisa a los asistentes que } \\
\text { pertenecen al equipo de proyecto }\end{array}$ \\
\hline Senior de Transacciones y Finanzas & $\begin{array}{l}\text { Es el encargado del trabajo directo que se realiza en un } \\
\text { proyecto del cliente de la línea de servicio de } \\
\text { transacciones y finanzas, tiene mayor experiencia en } \\
\text { trabajo de campo que un asistente. Además, supervisa a } \\
\text { los asistentes que pertenecen al equipo de proyecto }\end{array}$ \\
\hline Senior de Impuestos & $\begin{array}{l}\text { Es el encargado del trabajo directo que se realiza en un } \\
\text { proyecto del cliente de la línea de servicio de impuestos, } \\
\text { tiene mayor experiencia en trabajo de campo que un } \\
\text { asistente. Además, supervisa a los asistentes que } \\
\text { pertenecen al equipo de proyecto }\end{array}$ \\
\hline Senior de Consultoría & $\begin{array}{l}\text { Es el encargado del trabajo directo que se realiza en un } \\
\text { proyecto del cliente de la línea de servicio de consultoría, } \\
\text { tiene mayor experiencia en trabajo de campo que un } \\
\text { asistente. Además, supervisa a los asistentes que } \\
\text { pertenecen al equipo de proyecto }\end{array}$ \\
\hline Asistente de Consultoría & $\begin{array}{l}\text { Es un miembro de la organización que no cuenta con } \\
\text { mucha experiencia en la línea de servicio de auditoría. } \\
\text { Trabaja directamente en el desarrollo del proyecto con } \\
\text { supervisión de un Senior }\end{array}$ \\
\hline Asistente de Auditoría & $\begin{array}{l}\text { Es un miembro de la organización que no cuenta con } \\
\text { mucha experiencia en la línea de servicio de } \\
\text { transacciones y finanzas. Trabaja directamente en el } \\
\text { desarrollo del proyecto con supervisión de un Senior }\end{array}$ \\
\hline Asistente de Transacciones y Finanzante de Impuestos & $\begin{array}{l}\text { Es un miembro de la organización que no cuenta con } \\
\text { mucha experiencia en la línea de servicio de impuestos. } \\
\text { Trabaja directamente en el desarrollo del proyecto con } \\
\text { supervisión de un Senior }\end{array}$ \\
\hline $\begin{array}{l}\text { Es un miembro de la organización que no cuenta con } \\
\text { mucha experiencia en la línea de servicio de consultoría. } \\
\text { Trabaja directamente en el desarrollo del proyecto con } \\
\text { supervisión de un Senior }\end{array}$ \\
\hline
\end{tabular}

Fuente: Elaboración Propia

\subsubsection{ALCANCE DEL PROYECTO}

El presente alcance propone construir una arquitectura empresarial para la empresa Ernst and Young. Para ello, se tomará sólo un proceso dentro de todos los que conformados dentro de las 


\section{(1)}

líneas de servicios de la organización; en este caso, se tomará el subproceso de Auditoría Interna de Riesgos que se encuentra dentro del servicio de consultoría. Posteriormente, se realizará un análisis de la situación actual de la arquitectura empresarial de la organización mediante el $A S-I S$, revisando sus tres componentes como son: arquitectura de negocio, arquitectura de sistemas de información y arquitectura tecnológica. Para luego, realizar una nueva propuesta de la arquitectura empresarial mediante el TO-BE. En la cual, se evidenciará el detalle de sus tres componentes definidos anteriormente en el marco de referencia, que estará basado en TOGAF. En esta, se trabajarán las siguientes fases como son: preliminar, visión de la arquitectura, arquitectura de negocio, arquitectura de sistemas de información, arquitectura tecnológica, oportunidades y soluciones, y se concluirá con la planificación de la migración.

Además, se desarrollará un marco de trabajo ágil para el proyecto. Previamente, se hará la identificación de fortalezas y debilidades del equipo de trabajo, con el fin de realizar un diagnóstico para identificar sus habilidades blandas y duras. Posteriormente, se harán dinámicas para fortalecer las habilidades del equipo y convertir en oportunidades las debilidades identificadas. Para luego, conformar el equipo y trabajar el proyecto que de valor al negocio de forma productiva.

\subsection{OBJETIVOS DEL PROYECTO}

\subsubsection{OBJETIVO GENERAL.}

El objetivo del presente proyecto es realizar una propuesta de arquitectura empresarial que permita obtener las brechas que se identifican entre la línea base y la línea destino, las cuales impiden cumplir con los objetivos estratégicos del proceso de Consultoría de la organización. La solución para reducir estas brechas, es mediante la automatización de la gestión del trabajo de la Auditoría Interna de Riesgos, mediante una solución tecnológica. Esta solución será desarrollada mediante un equipo de trabajo auto organizado con habilidades adecuadas que utilizará un marco de trabajo ágil con Scrum , 


\section{(1)}

\subsubsection{OBJETIVOS ESPECÍFICOS.}

- Realizar el análisis de la situación actual del sub proceso de la Auditoría Interna de Riesgos de la organización EY, desde el punto de vista de la arquitectura empresarial.

- Proponer una arquitectura empresarial para la empresa EY, que permita identificar las oportunidades de mejora mediante el análisis de brechas de la Arquitectura de la Línea Base y Destino.

- Realizar una propuesta para el desarrollo de una solución tecnológica que permita reducir las brechas encontradas, las cuales impiden el cumplimiento de los objetivos estratégicos asociados al proceso de negocio.

- Realizar una propuesta para trabajar mediante un marco de trabajo para el desarrollo de la solución tecnológica mediante el uso de SCRUM.

- Proponer dinámicas y/o talleres de trabajo en equipo para potenciar las fortalezas y eliminar las debilidades del equipo de proyectos.

- Construir un equipo de trabajo con las habilidades adecuados para llevar a cabo las actividades para el desarrollo de la solución tecnológica mediante las herramientas que ofrece Scrum como marco de trabajo ágil.

\subsection{BENEFICIOS DEL PROYECTO.}

\subsubsection{BENEFICIOS TANGIBLES}

- Minimizar el tiempo de trabajo de la Auditoría Interna de Riesgos de un proyecto entre $25 \%$ hasta $30 \%$.

- Aumentar en $1.5 \%$ los ingresos en el primer año, para la línea de servicio de consultoría, vendiendo la base de conocimiento por industria a los clientes. 


\section{(1)}

- Brindar una base de conocimiento informativa $24 \times 7$ (información cargada) de los procesos, riesgos y controles que se utilizarán como ayuda para el desarrollo de proyectos, ya que no se necesitaría utilizar las horas hombre de un experto (Gerente y/o Senior) para la retroalimentación de la identificación de riesgos y controles. Además de esto, contar con proyectos desarrollados anteriormente, como guía para trabajar otros proyectos (realizar réplicas de información para desarrollar proyectos recurrentes u otros proyectos) por parte del equipo de Auditoría Interna de Riesgos; alineándose al objetivo estratégico de optimizar costos y mejor márgenes, ya que reduciría las horas hombre.

- Automatizar el desarrollo del trabajo de la Auditoría Interna de Riesgos mejorando la organización y productividad en el procesamiento de la información.

\subsubsection{BENEFICIOS INTANGIBLES.}

- Empoderar a los clientes.

- Dar mayor valor a la marca en el concepto de líder de consultaría.

- Ser el primero a quien el cliente tenga que consultar en la toma de decisión. 


\section{(1) \\ CAPÍTULO 2: ARQUITECTURA EMPRESARIAL}

\subsection{INTRODUCCIÓN}

Este capítulo tiene como objetivo, realizar una propuesta de arquitectura empresarial para la empresa EY. Donde se hará en primer lugar, un análisis preliminar sobre la arquitectura que desea la organización; para luego, desarrollar una visión que se desea obtener del resultado de la arquitectura empresarial.

Asimismo, se expondrá como está la arquitectura en la actualidad $A S-I S$ y como se desea que este $T O-B E$, para llevar a cabo la solución propuesta en base a los objetivos que se han determinado, esta solución se descompone en tres elementos: arquitectura de negocio, arquitectura de sistemas de información y arquitectura tecnológica. Estas dan como conclusión, oportunidades y una solución en dar una base de conocimiento mediante una solución para el trabajo que se realiza en la Auditoría Interna de Riesgos.

\subsection{ALCANCE}

La propuesta es desarrollar una arquitectura empresarial en base a los objetivos de la empresa. Esta propuesta se basa su desarrollo sobre la sub línea de servicio que es Auditoría Interna de Riesgos que está dentro de la línea de servicio del proceso de Consultoría, se propone desarrollar un sistema donde se brinde una base de conocimiento que ayude a realizar el trabajo de la Auditoría Interna de Riesgos, facilitando el flujo de trabajo en base a las mejores prácticas que la firma ha realizado en cada industria. Por esta razón, se establece en un comienzo trabajar de manera conjunta con los interesados claves (gerentes y socios), que pueden dar el conocimiento previo para el desarrollo de la propuesta y en base a esta, realizar un análisis sobre la información para identificar los puntos para mejorar el trabajo que se realiza en el subproceso de la Auditoría Interna de Riesgos. Esta propuesta se proyecta realizarlo en un periodo de 15 meses donde se desarrollarán los 4 dominios de la arquitectura negocio, datos, 


\section{(1)}

aplicaciones y tecnológico. Además, se realizará el desarrollo e implementación de un proyecto tecnológico llamado ARMEY (Assessment Risk Management EY) para cumplir con los objetivos estratégicos de la organización.

\subsection{PRELIMINAR}

\subsubsection{PRINCIPIOS DE ARQUITECTURA}

Se definen las siguientes reglas de negocio dadas a continuación:

\section{NEGOCIO}

\begin{tabular}{|l|l|}
\hline Nombre & PN01 - Área de conocimiento \\
\hline Enunciado & $\begin{array}{l}\text { El trabajador recibe nuevo conocimiento en base a un experto } \\
\text { cuenta con la experiencia sobre un tema específico (proyectos por } \\
\text { industria), lo que hace que pueda estar perdido en como comenzar } \\
\text { a desarrollarlo, pero en este caso, siempre hay una persona a su } \\
\text { lado supervisándolo y apoyándolo en el conocimiento que este } \\
\text { necesite para cumplir con su proyecto. }\end{array}$ \\
\hline Repercusiones & $\begin{array}{l}\text { El personal obtiene nuevo conocimiento sobre el tema que fue } \\
\text { desconocido hasta ese momento por él, obteniendo nueva } \\
\text { información a fin de utilizarlo en algún momento que se requiera. } \\
\text { Esto ayudará al miembro a desempeñarse de mejor manera en los } \\
\text { proyectos sucesivos, haciendo que luego este de la mano a otro } \\
\text { miembro nuevo de la misma manera, haciendo que la } \\
\text { organización sea vista como una escuela de conocimiento. }\end{array}$ \\
\hline
\end{tabular}

\begin{tabular}{|l|l|}
\hline Nombre & PNO2 - Sinergia \\
\hline Enunciado & Trabajar conjuntamente para realizar un proyecto \\
\hline
\end{tabular}




\section{(1)}

\begin{tabular}{|l|l|} 
Fundamento & $\begin{array}{l}\text { Cada proyecto está conformado por un equipo donde se } \\
\text { encuentran asignados roles (gerente, senior y asistente). Estas } \\
\text { personas se ayudan mutuamente a fin de cumplir con cada } \\
\text { actividad que se les ha asignado y pueden estar alineados los } \\
\text { objetivos que se han establecido con el cliente. }\end{array}$ \\
\hline Repercusiones & $\begin{array}{l}\text { Los trabajadores se sienten que trabajan en un equipo de alto } \\
\text { desempeño donde cumplen sus metas en cada proyecto que se les } \\
\text { involucre. Por esta razón, la organización es vista como un lugar } \\
\text { donde todo el mundo quiere trabajar. }\end{array}$ \\
\hline
\end{tabular}

\begin{tabular}{|l|l|}
\hline Nombre & PN03 - Continuidad del negocio \\
\hline Enunciado & $\begin{array}{l}\text { El trabajo nunca puede ser interrumpido, a pesar de las fallas del } \\
\text { sistema. }\end{array}$ \\
\hline Fundamento & $\begin{array}{l}\text { Las empresas dependen cada día más, para manejar su } \\
\text { información, de la automatización de sus procesos usando } \\
\text { herramienta de TI. Por esta razón, estas tienen que tener planes } \\
\text { de contingencia para el resguardo su información (backups, } \\
\text { cloud, etc), a causa de diferentes eventos que podrían ocurrir } \\
\text { como fallas del sistema, servidores u desastres naturales. }\end{array}$ \\
\hline Repercusiones & $\begin{array}{l}\text { La causa los males acerca de la pérdida de información, podría } \\
\text { dar a las empresas verdaderos dolores de cabeza, lo que daría pie } \\
\text { a pérdidas de tiempo y dinero. }\end{array}$ \\
\hline
\end{tabular}

\section{DATOS}

\begin{tabular}{|l|l|}
\hline Nombre & PD01 - Seguridad de la información \\
\hline Enunciado & $\begin{array}{l}\text { La información tiene que contar con medidas de seguridad para } \\
\text { que usado de forma malintencionada }\end{array}$ \\
\hline Fundamento & $\begin{array}{l}\text { La información tiene que estar asegurada de acuerdo. En primer } \\
\text { lugar, si la persona forma parte de la organización. Segundo, si }\end{array}$ \\
\hline
\end{tabular}




\section{(4)}

forma parte de la línea de servicio. Por último, si forma parte del equipo del proyecto.

Repercusiones

Al no tener una política de uso de la información hará que personal no autorizado haga un mal uso de la información, perjudicando a la organización

\begin{tabular}{|c|c|}
\hline Nombre & PD02 - Información Integrada \\
\hline Enunciado & $\begin{array}{l}\text { El gerente que tiene a cargo un proyecto y este debe integrar la } \\
\text { información de su equipo }\end{array}$ \\
\hline Fundamento & $\begin{array}{l}\text { Cada miembro del equipo de forma independiente realiza un } \\
\text { parte del trabajo para el proyecto. El gerente analiza y brinda } \\
\text { retroalimentación, si es necesario, hacia su equipo. Finalmente, } \\
\text { este integrará la información que será el resultado final entregado } \\
\text { hacia el cliente. }\end{array}$ \\
\hline Repercusiones & $\begin{array}{l}\text { Controlar y dar seguimiento de lo que se está desarrollando en el } \\
\text { proyecto por cada actividad que los miembros estén realizando a } \\
\text { fin de que los proyectos tengan consistencia en la información } \\
\text { brindada hacia los clientes de la organización. }\end{array}$ \\
\hline
\end{tabular}

\begin{tabular}{|l|l|}
\hline Nombre & PD02-Activo de los procesos de la organización \\
\hline Enunciado & $\begin{array}{l}\text { La información debe considerarse como un activo de la } \\
\text { organización y no puede ser publicado ni difundido. }\end{array}$ \\
\hline Fundamento & $\begin{array}{l}\text { La información es de suma importancia para toda la } \\
\text { organización, por lo que debe ser administrada siguiente unas } \\
\text { reglas para asegurar su contenido y no sea utilizada como fuente } \\
\text { fuera de la empresa. }\end{array}$ \\
\hline Repercusiones & $\begin{array}{l}\text { El publicar la información fuera de los límites de la organización, } \\
\text { se expondrá a la organización a que otras entidades tomen ventaja } \\
\text { frente a la empresa. }\end{array}$ \\
\hline
\end{tabular}

\section{APLICACIONES}




\section{(1)}

\begin{tabular}{|l|l|}
\hline Enunciado & Todas las aplicaciones deben estar con licencia \\
\hline Fundamento & $\begin{array}{l}\text { La organización tiene como política que todo equipo } \\
\text { (computadoras personales y laptops) que tenga instalado alguna } \\
\text { aplicación, esta cuente con su respectiva licencia. }\end{array}$ \\
\hline Repercusiones & $\begin{array}{l}\text { El usar una máquina que no cuente con alguna licencia, } \\
\text { ocasionará una sanción económica a la organización por el estado }\end{array}$ \\
\hline
\end{tabular}

\begin{tabular}{|l|l|}
\hline Nombre & PA02 - Acceso por aplicación \\
\hline Enunciado & El personal tendrá asignado aplicaciones según su cargo \\
\hline Fundamento & $\begin{array}{l}\text { El personal cuenta con aplicaciones según el rol que desempeñe } \\
\text { en la organización. Estas aplicaciones serán instaladas por el área } \\
\text { de mesa de ayuda dentro de TI }\end{array}$ \\
\hline Repercusiones & $\begin{array}{l}\text { El tener instalados aplicaciones que no forman parte del trabajo } \\
\text { del personal, esto conlleva a posibles gastos de licencia por parte } \\
\text { de la organización y un riesgo en la seguridad de la información } \\
\text { de la organización. }\end{array}$ \\
\hline
\end{tabular}

\begin{tabular}{|l|l|}
\hline Nombre & PA03 - Fácil manejo en aplicaciones \\
\hline Enunciado & Los sistemas deben ser de fácil usabilidad \\
\hline Fundamento & $\begin{array}{l}\text { Los nuevos sistemas deben ser de fácil uso. Esto quiere decir que } \\
\text { se adapten al entorno de la organización trabaja y haciendo que } \\
\text { el personal se identifique en la ayuda que estos les puedan ofrecer } \\
\text { en su trabajo diario. }\end{array}$ \\
\hline Repercusiones & $\begin{array}{l}\text { El no hacer fácil el uso para cada miembro de la organización, } \\
\text { haría que estos se confundan y se retrasen en vez de mejorar }\end{array}$ \\
\hline
\end{tabular}




\section{(1)}

eficazmente en el proceso de trabajo que estos tengan en cara al cliente.

\section{TECNOLÓGIA}

\begin{tabular}{|l|l|}
\hline Nombre & PT01 - Copias de seguridad \\
\hline Enunciado & $\begin{array}{l}\text { Copias de seguridad de información importante de la } \\
\text { organización }\end{array}$ \\
\hline Fundamento & $\begin{array}{l}\text { Se realiza en forma recurrente el respaldo de la información } \\
\text { que la organización constantemente actualiza ya sea desde } \\
\text { documentos u archivos hasta sistema de información u base } \\
\text { de datos. Esto ayuda que a pesar que ocurra un imprevisto } \\
\text { en la información por situaciones como la eliminación de } \\
\text { información o por algún desastre natural. }\end{array}$ \\
\hline Repercusiones & $\begin{array}{l}\text { Tener en todo momento la información que la organización } \\
\text { necesite }\end{array}$ \\
\hline
\end{tabular}

\begin{tabular}{|c|c|}
\hline Nombre & PT02 - Soporte usuarios \\
\hline Enunciado & $\begin{array}{l}\text { Brindar soporte tecnológico a los miembros de la } \\
\text { organización. }\end{array}$ \\
\hline Fundamento & $\begin{array}{l}\text { La organización cuenta con un área especializada en dar } \\
\text { soporte a los distintos miembros de la organización, en } \\
\text { temas directamente tecnológicos. }\end{array}$ \\
\hline Repercusiones & $\begin{array}{l}\text { Al no dar soporte a los miembros de la organización, estos } \\
\text { pierden tiempo en realizar su trabajo diario, lo que causa } \\
\text { contratiempos en los entregables. Esto conlleva a que la } \\
\text { organización sea vista como una entidad que no es } \\
\text { confiable en realizar un trabajo en el tiempo estimado. }\end{array}$ \\
\hline
\end{tabular}




\section{(1)}

\begin{tabular}{|l|l|}
\hline Nombre & PT03-Cambios en base a los procesos internos \\
\hline Enunciado & $\begin{array}{l}\text { Los cambios tecnológicos van relacionados a la } \\
\text { automatización de los procesos de la organización }\end{array}$ \\
\hline Rundamento & $\begin{array}{l}\text { El entorno de la organización van observando la nueva } \\
\text { tendencia dentro de los ámbitos de TI, con las cuales se dan } \\
\text { cambios tecnológicos con el fin de mejorar los procesos de } \\
\text { trabajo dentro las líneas de servicio. }\end{array}$ \\
\hline Los cambios tecnológicos ofrecen un eficaz trabajo de los \\
miembros de la organización
\end{tabular}




\section{(1)}

\subsubsection{PETICIÓN DE TRABAJO DE ARQUITECURA}

\section{PATROCINADORES DE LA ORGANIZACIÓN}

Los patrocinadores de esta propuesta para EY son:

- Socio Líder de Consultoría - Jorge Acosta

- Socio Consultoría - Renato Urdaneta

\section{MISIÓN DE LA ORGANIZACIÓN}

Brindar servicios de consultoría que favorecen el aprovechamiento de oportunidades, mejoras en el desempeño del negocio y del alcance potencial para el cliente.

\section{OBJETIVOS DEL NEGOCIO}

Se definen los siguientes objetivos a continuación:

- Crear modelos de negocios alternativos

- Gestionar servicios de mayor escala

- Considerar la agenda digital a los clientes

- Usar tecnología en las líneas de servicio

- Desarrollar un ecosistema de alianzas y recursos

- Adoptar una visión a futuro acerca del trabajo

- Seguir una ruta de diversidad e inclusión

- Optimizar costos y mejor margen

\section{PLANES ESTRATEGICOS DEL NEGOCIO}

Se definen las siguientes estrategias:

- Tener reuniones o Kick Off con los clientes a fin de evaluar sus dolencias dentro de su organización dándoles distintas soluciones en un ambiente confortable.

- Empoderar a los clientes haciendo EY sea la primera puerta a la cual se le quiera consultar sobre un tema de su organización.

- Que cada miembro de la EY tenga las suficientes habilidades para que no haya una restricción de necesidad de algún superior frente al cliente. 


\section{(1)}

- Estudio continuo dentro de la organización para mejorar las habilidades de cada miembro de EY.

- Hay retroalimentación constante de los líderes para que los miembros de la organización vean la visión de la empresa y se sientan parte esa visión.

- Realizar constantes publicaciones sobre los distintos ámbitos de cambio del país dentro del marco tecnológico, económico y financiero.

\section{LÍMITES DE TIEMPO}

- El tiempo de realizar la documentación de la propuesta de la arquitectura empresarial y del uso de un marco ágil será de 3 meses.

- El tiempo del desarrollo e implementación del sistema será de 12 meses.

- La revisión y aceptación formal de la propuesta será 2 semanas antes de comenzar con el desarrollo del sistema.

- Se deberá realizar reuniones de avance cada 2 semanas con los interesados clave para ver el avance del sistema.

- Se deberá disponer de los interesados clave en cada reunión como máximo 2 horas.

\section{LIMITACIONES ORGANIZACIONALES}

- No definir de forma clara el alcance y objeticos del proyecto.

- No definir de forma clara los requerimientos por parte de los interesados clave.

- No contar con la disponibilidad de los interesados clave en cada reunión agendada.

- No contar con recursos para el desarrollo del proyecto.

- No poder desplegar en los servidores de EY Global, sin antes tener un período de auditoría (testing) de 6 meses con un costo de US\$ 60,000.00 aproximadamente, que lo desembolsará EY Perú.

\section{LIMITACIONES FINANCIERAS}

- El presupuesto para el desarrollo será de US\$ $140,000.00$ y la reserva para la contingencia será de US\$14,000.00 (10\% sobre el presupuesto del desarrollo).

- El presupuesto para el alquiler de un servidor en la nube anualmente es de US\$ 8,000.00. 


\section{(1)}

- El presupuesto para contratar a un proveedor de servicio para la configuración Windows Azure para alojar la solución tecnológica es de US\$ 5,500.00.

- El presupuesto de talleres y/o capacitaciones de Impro, Coaching y Scrum es de US\$ $3,500.00$

\section{LIMITACIONES EXTERNAS}

- El proyecto debe cumplir con los estándares de trabajo para realizar la Auditoría Interna de Riesgos según la metodología SOX.

- El proyecto debe cumplir con estándares de seguridad ISO/IEC 27000 


\section{(1)}

\section{DESCRIPCIÓN DE LA SITUACIÓN ACTUAL DEL NEGOCIO (PRINCIPALES PROBLEMAS Y REQUERIMIENTOS)}

Actualmente, el proceso misional llamada Consultoría contiene un subproceso de trabajo llamada Auditoría de Interna de Riesgos, que realiza su trabajo de forma manual mediante el programa Excel de Microsoft. En la cual, el trabajo comienza, cuando un cliente solicita la auditoría para algún (nos) de su(s) procesos. Luego, un equipo conformado por un Gerente (Líder) y su equipo (Senior y/o Asistentes) van al cliente y realizan un taller para el levantamiento de requerimientos de información, entre lo que se obtienen los procesos y sus objetivos que se van a auditar. Luego, todos los que conforman el equipo de auditoria, identifican los riesgos a alto nivel (riesgos generales) que están asociados a estos procesos. Posteriormente, en una reunión se ponen a analizar los riesgos de alto nivel y se evalúan con criterios de probabilidad e impacto para saber el nivel (estos pueden ser de 3 niveles: bajo, medio y alto; 4 niveles: bajo, moderado, alto y extremo, y 5 niveles: Muy bajo, bajo, moderado, alto y extremo) con lo que el equipo tiene que trabajar según esta priorización a fin de realizar un cronograma de trabajo (plan de auditoría) para visitar al cliente y mitigar los procesos correspondiente a esta evaluación. Además de esto, se crean riesgos de bajo nivel (riesgos más al detalle) que están asociados a los riesgos de alto nivel. Estos riegos, al igual que los riesgos de alto nivel, serán evaluados en base a los criterios definidos en los riesgos evaluados inicialmente. Adicionalmente, estos riesgos contienen controles que servirán para evaluar la operatividad, para saber si un control es Efectivo (Aprobado) o No Efectivo (Fallido) y verificar si el riesgo asociado al control a variado en base a la evaluación dada inicialmente (riesgo inherente) hasta el nivel final (riesgo residual). Por último, si el control fue No Efectivo, se realizará un plan de acción para rectificar el fallo del control por parte de un responsable del cliente.

Todo el trabajo realizado por parte del equipo va siendo observado por el Gerente y este da la conformidad del trabajo que está realizando el equipo. Una vez que el trabajo es observado y aceptado, va siendo integrado en cada momento, por lo que hay pérdida de tiempo en la integración por parte del equipo y; por último, el Gerente da la aceptación formal del proyecto y se le entrega al cliente el resultado de las pruebas y el plan de acción (La plantillas del trabajo 


\section{(1)}

de un proyecto de Auditoría Interna de Riesgos se ven en el Anexo 1, 2, 3, 4 y 5). Luego de esto, los archivos Excel se copian y pegan en una carpeta compartida (carpeta física) que será utilizado sólo por el área de Consultoría en un servidor local de la empresa. Esta información podría ser utilizado como base de conocimiento (base de datos con información de los proyectos terminados para ser reutilizados en otros proyectos o proyectos recurrentes). Al no contar con esa información de forma centralizada en un repositorio de datos (base de conocimiento), el proceso de trabajo de la Auditoría de Riesgos se realiza desde cero y de forma manual nuevamente. Esto conlleva a que haya mucha pérdida de tiempo y que no haya una automatización del trabajo para cada proyecto.

\section{DESCRIPCIÓN DE LA SITUACIÓN ACTUAL DE LA ARQUITECTURA DE TI}

Actualmente Ernst and Young en el Perú cuenta con una infraestructura mediante la cual, se conecta a la sede principal en Estados Unidos a través de un enlace WAN, la cual accede a las aplicaciones de la organización que se suministra a nivel global; además, utiliza diversos servidores para el correo corporativo (Exchange 2013), directorio activo (Active Directory), archivos (File Server) y de replicación de información. Por último, esta arquitectura cuenta con un firewall para asegurar el acceso de información de intrusos mediante un Router Cisco para la conexión a la red WAN.

El problema que abarca esta arquitectura son las trabas para usar el servidor de aplicaciones de Estados Unidos; por el motivo que en una primera instancia EY Perú tiene que hacer un desembolso de aproximadamente 60 mil dólares, para que EY Estados Unidos realice las pruebas de auditoría, para cumplir con los estándares de EY Global y el periodo de las pruebas se hacen dentro de un rango de seis meses. Por este motivo, la suma de estas brechas hace que sea complicado utilizar el servidor para desplegar la aplicación. 


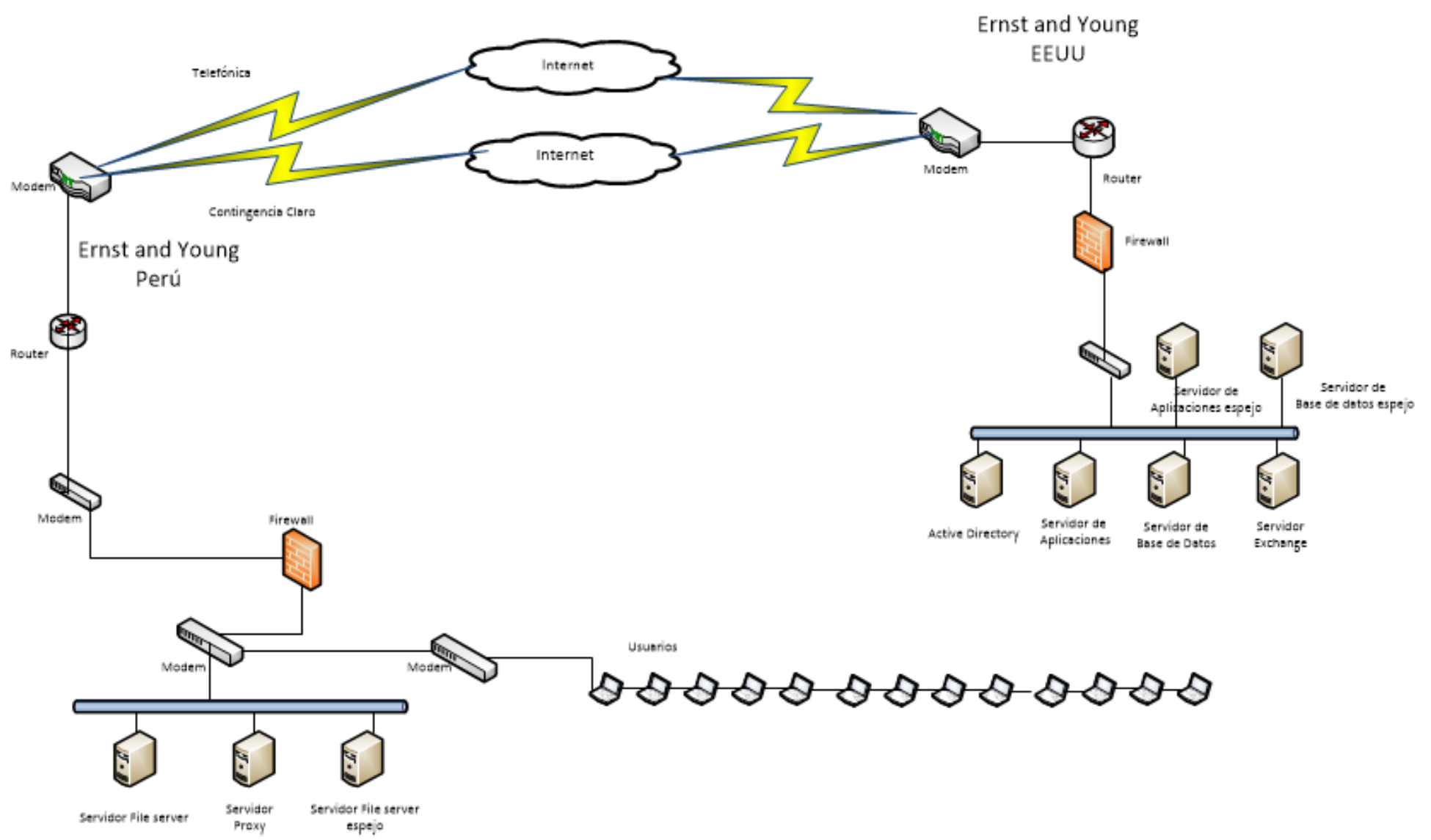

Figura $N^{\circ} 10$ Diagrama de Red Actual de EY

Fuente: Elaboración Propia 


\section{(1)}

\section{DECLARACIÓN DE TRABAJO DE ARQUITECURA}

\section{SOLICITUD DE PROYECTO DE ARQUITECTURA Y ANTECEDENTES}

El presente proyecto tiene por objetivo desarrollar una propuesta de arquitectura empresarial para el subproceso de Auditoría Interna de Riesgos para la empresa EY. Donde se muestra un análisis de la situación actual de la organización $A S$ - $I S$ y propone una solución de arquitectura empresarial $T O-B E$, que dividen en tres componentes que se dan a continuación: Arquitectura de Negocio, Arquitectura de Sistemas de Información y Arquitectura Tecnológica.

Dentro de la línea de servicio de consultoría hay un subproceso de servicio llamada Auditoría Interna de Riesgos, que se encarga de auditar los riesgos de los procesos de cada cliente de acuerdo a su industria (automotriz, productos de consumo y menudeo, servicios financieros, gobierno y sector público, entre otros). El equipo de un proyecto conformado por un gerente, seniors y asistente, evalúan los riesgos y controles que están asociados a determinados procesos (previamente definidos por el cliente). El resultado de esta información es integrado por el personal mediante la herramienta de office llamada Excel.

El problema aquí se da cuando hay algún o algunos miembros del equipo que no tienen la suficiencia experiencia, por lo que tiene que constantemente preguntar a algún experto de cómo hacer el trabajo y de donde sacar la información para poder comenzar a desarrollar el proyecto. Esto causa mucha pérdida de tiempo y el personal muchas veces se queda altas horas de la noche para terminar su trabajo, lo cual no es eficiente. De igual manera, la parte de integración de la información es otro dolor de cabeza, ya que todo el trabajo debe estar sincronizado con la información que cada miembro ha desarrollado y es responsabilidad del gerente verificar y validar el resultado final que esté integrado de forma correcta con los solicitado por el cliente.

\section{DESCRIPCIÓN DEL PROYECTO DE ARQUITECTURA Y ALCANCE}

El presente proyecto de arquitectura tiene por objetivo plantear una solución a los problemas que tiene el trabajo realizado en la Auditoría Interna de Riesgos hacia el cliente. Para esto, se plantea realizar un levantamiento de información del trabajo sobre el trabajo actual (AS-IS). 


\section{(1)}

Para luego, realizar un análisis y plasmar la idea, mediante una propuesta de solución que esté alineada a los objetivos estratégicos de la empresa (TO-BE).

\section{PROCEDIMIENTOS ESPECÍFICOS PARA CAMBIOS DE ALCANCE}

Cualquier cambio en el alcance del proyecto, deberá ser gestionado mediante una solicitud formal de control de cambios (Ver Plantilla de Solicitud de Control de Cambios en el Anexo 6) donde se ingresará datos como: la descripción del cambio, el objetivo y la severidad (nivel de importancia Baja, Media y Alta) que traerá realizar el cambio. Luego, la solicitud deberá ser evaluado por el comité de control de cambios (conformado por el Gerente de Proyecto de TI) para evaluar el impacto en tiempo y costo. Este control de cambios podrá ser ejecutado una vez aprobado la solicitud por parte del comité de control de cambios. Por último, la aceptación o rechazo de la solicitud deberá ser notificado al solicitante (interesado clave) en la cual se le informará el estado de la solicitud.

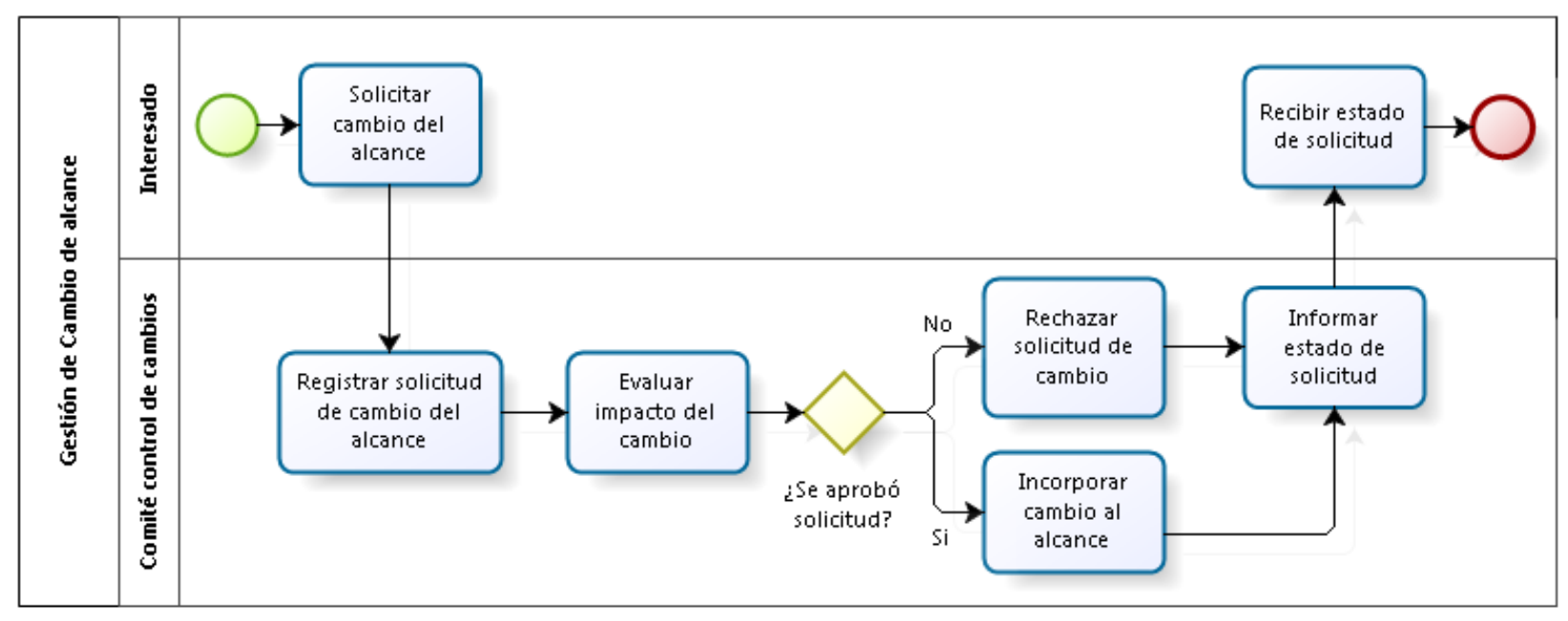

Figura $\mathrm{N}^{\circ} 11$ Diagrama de Gestión de Cambio

Fuente: Elaboración Propia

Tabla $N^{\circ} 5$ Descripción de Participantes de la Gestión de Cambio 


\section{(4)}

\begin{tabular}{|l|l|}
\hline \multicolumn{1}{|c|}{ Participante } & \multicolumn{1}{|c|}{ Descripción } \\
\hline Interesado & $\begin{array}{l}\text { Esta persona puede proponer un cambio en el alcance, ya que } \\
\text { puede deberse a que no estaba definido todo el alcance o alguna } \\
\text { mejora que haya visto en algún determinado momento por parte de } \\
\text { algún interesado clave }\end{array}$ \\
\hline $\begin{array}{l}\text { Comité control de } \\
\text { cambios }\end{array}$ & $\begin{array}{l}\text { Son los miembros que pueden aprobar o rechazar algún cambio en } \\
\text { el alcance de la propuesta }\end{array}$ \\
\hline
\end{tabular}

Fuente: Elaboración Propia

ROLES, RESPONSABILIDAD Y ENTREGABLES

Tabla $\mathrm{N}^{\circ} 6$ Matriz RACI

\begin{tabular}{|l|c|c|c|c|c|c|}
\hline \multirow{2}{*}{ Responsabilidades } & \multicolumn{5}{|c|}{ Roles } \\
\cline { 2 - 7 } & $\begin{array}{c}\text { Gerente } \\
\text { de } \\
\text { Proyecto }\end{array}$ & $\begin{array}{c}\text { Arquitecto } \\
\text { Empresarial }\end{array}$ & $\begin{array}{c}\text { Arquitecto } \\
\text { Negocio }\end{array}$ & $\begin{array}{c}\text { Arquitecto } \\
\text { Datos }\end{array}$ & $\begin{array}{c}\text { Arquitecto } \\
\text { Aplicaciones }\end{array}$ & $\begin{array}{c}\text { Arquitecto } \\
\text { Tecnológico }\end{array}$ \\
\hline $\begin{array}{l}\text { Desarrollar el documento de } \\
\text { principios de arquitectura }\end{array}$ & $\mathrm{A}$ & $\mathrm{R}$ & $\mathrm{C}$ & $\mathrm{I}$ & $\mathrm{I}$ & $\mathrm{I}$ \\
\hline $\begin{array}{l}\text { Desarrollar el documento de } \\
\text { petición de trabajo de } \\
\text { arquitectura }\end{array}$ & & $\mathrm{R}$ & $\mathrm{C}$ & $\mathrm{I}$ & $\mathrm{I}$ & $\mathrm{I}$ \\
\hline $\begin{array}{l}\text { Desarrollar la declaración del } \\
\text { trabajo de la arquitectura }\end{array}$ & & $\mathrm{R}$ & $\mathrm{C}$ & $\mathrm{I}$ & $\mathrm{I}$ & $\mathrm{I}$ \\
\hline $\begin{array}{l}\text { Desarrollar la misión y visión } \\
\text { de la arquitectura }\end{array}$ & & $\mathrm{R}$ & $\mathrm{C}$ & $\mathrm{I}$ & $\mathrm{I}$ & $\mathrm{I}$ \\
\hline $\begin{array}{l}\text { Desarrollar el documento de } \\
\text { la definición de la } \\
\text { arquitectura }\end{array}$ & & $\mathrm{I}$ & $\mathrm{R}$ & $\mathrm{R}$ & $\mathrm{R}$ & $\mathrm{R}$ \\
\hline $\begin{array}{l}\text { Desarrollar el plan de } \\
\text { implementación }\end{array}$ & & $\mathrm{I}$ & $\mathrm{R}$ & $\mathrm{R}$ & $\mathrm{R}$ & $\mathrm{R}$ \\
\hline $\begin{array}{l}\text { Desarrollar la EDT } \\
\text { Desarrollar el cronograma y } \\
\text { presupuesto }\end{array}$ & $\mathrm{R}$ & $\mathrm{C}$ & $\mathrm{C}$ & $\mathrm{C}$ & $\mathrm{C}$ & $\mathrm{C}$ \\
\hline $\begin{array}{l}\text { Elaborar el documento final } \\
\text { de la propuesta de } \\
\text { arquitectura }\end{array}$ & $\mathrm{I}$ & $\mathrm{R}$ & $\mathrm{C}$ & $\mathrm{C}$ & $\mathrm{C}$ & $\mathrm{C}$ \\
\hline
\end{tabular}




\begin{tabular}{|l}
\begin{tabular}{|l|c|c|c|c|c|c|}
\hline $\begin{array}{l}\text { Corregir las observaciones } \\
\text { del documento final de la } \\
\text { propuesta de la arquitectura }\end{array}$ & $\mathrm{I}$ & $\mathrm{R}$ & $\mathrm{R}$ & $\mathrm{R}$ & $\mathrm{R}$ & $\mathrm{R}$ \\
\hline
\end{tabular} \\
\hline \\
\hline
\end{tabular}

Fuente: Elaboración Propia

\section{CRITERIOS DE ACEPTACIÓN}

Se declaran los siguientes entregables como criterios de aceptación:

- Aprobar la documentación de princípios de arquitectura

- Aprobar la documentación de la petición de trabajo de Arquitectura

- Aprobar la declaración de trabajo de arquitectura

- Aprobar la documentación de la visión de la arquitectura

- Aprobar la documentación de definición de la arquitectura

- Aprobar la documentación del plan de implementación y migración

- Aprobar el EDT

- Aprobar el cronograma y presupuesto

- Aprobar la documentación final de la propuesta de arquitectura empresaria

- Aprobar la corrección de la documentación final de la propuesta de la arquitectura empresarial.

\section{CRONOGRAMA TENTATIVO}




\section{(U)}

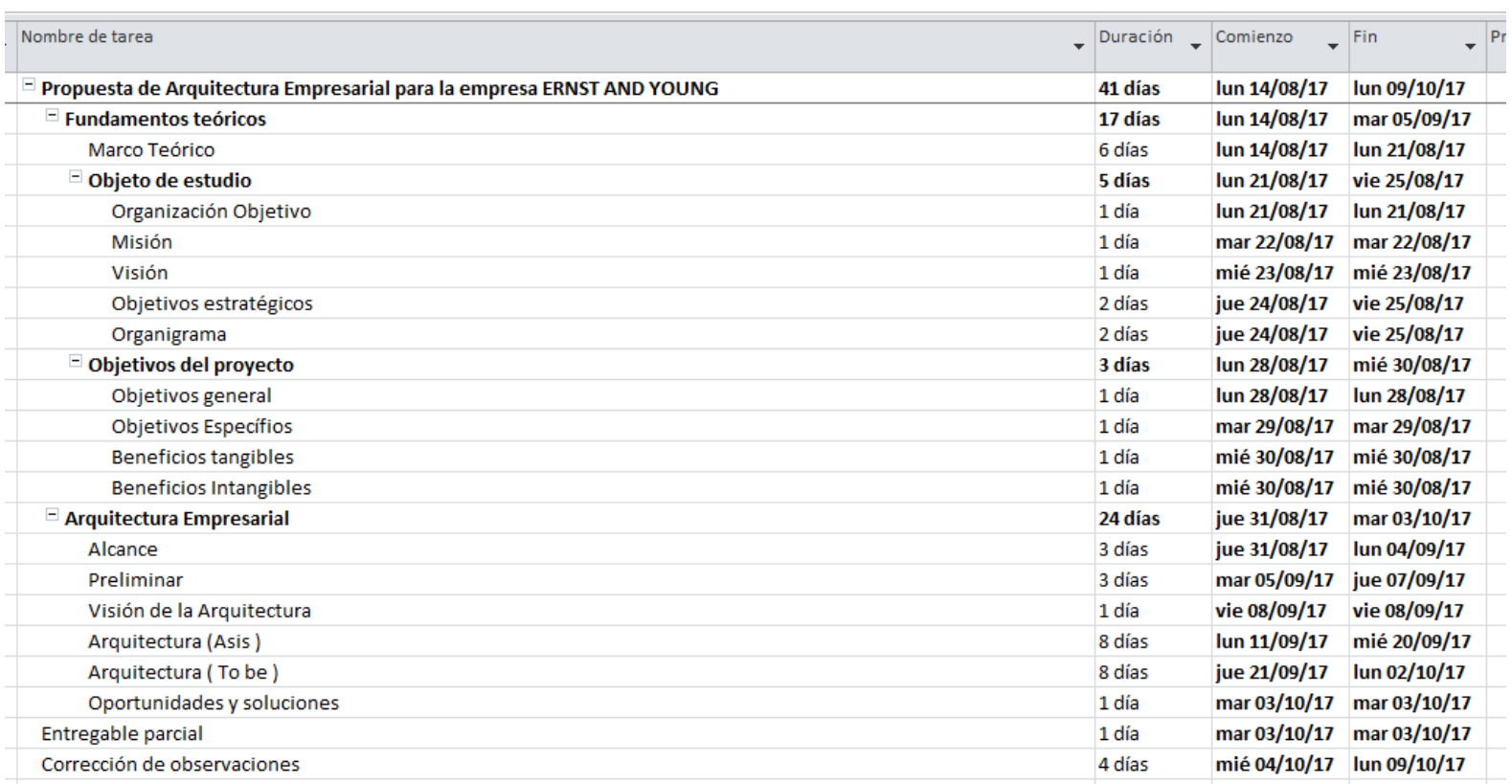

Figura $\mathrm{N}^{\circ} 12$ Cronograma Tentativo

Fuente: Elaboración Propia

\subsection{VISIÓN DE LA ARQUITECTURA}

\subsubsection{INTERESADOS Y SUS PREOCUPACIONES}

Tabla N ${ }^{\circ} 7$ Interesados y sus Preocupaciones

\begin{tabular}{|l|c|c|c|c|}
\hline \multirow{2}{*}{ Preocupaciones } & \multicolumn{4}{|c|}{ Interesados } \\
\cline { 2 - 5 } & $\begin{array}{c}\text { Gerente de } \\
\text { proyecto }\end{array}$ & $\begin{array}{c}\text { Socio de } \\
\text { consultoría }\end{array}$ & $\begin{array}{c}\text { Gerente de } \\
\text { consultoría }\end{array}$ & $\begin{array}{c}\text { Gerencia de } \\
\text { finanzas }\end{array}$ \\
\hline $\begin{array}{l}\text { Mala definición del } \\
\text { caso de negocio y } \\
\text { los objetivos }\end{array}$ & $\mathrm{X}$ & $\mathrm{X}$ & $\mathrm{X}$ \\
\hline $\begin{array}{l}\text { Mala definición del } \\
\text { alcance }\end{array}$ & $\mathrm{X}$ & $\mathrm{X}$ & $\mathrm{X}$ & $\mathrm{X}$ \\
\hline $\begin{array}{l}\text { Mala gestión del } \\
\text { tiempo de las } \\
\text { actividades }\end{array}$ & & & & \\
\hline
\end{tabular}




\section{(1)}

\begin{tabular}{|l|c|c|c|c|}
\hline $\begin{array}{l}\text { Mala gestión del } \\
\text { costo de las } \\
\text { actividades }\end{array}$ & $\mathrm{X}$ & $\mathrm{X}$ & $\mathrm{X}$ & $\mathrm{X}$ \\
\hline $\begin{array}{l}\text { Mala gestión de } \\
\text { recursos }\end{array}$ & $\mathrm{X}$ & $\mathrm{X}$ & & $\mathrm{X}$ \\
\hline $\begin{array}{l}\text { Mala gestión de } \\
\text { adquisiciones }\end{array}$ & $\mathrm{X}$ & & \\
\hline $\begin{array}{l}\text { Realizar cambios } \\
\text { innecesarios }\end{array}$ & $\mathrm{X}$ & & & \\
\hline
\end{tabular}

Fuente: Elaboración Propia

\subsubsection{LISTA DE ASUNTOS / ESCENARIOS QUE DEBEN ABORDARSE}

- Disponibilidad de interesados clave para la planificación del proyecto.

- Definir la tecnología que se va a utilizar para el proyecto

- Definir de si el costo y tiempo están alineados de acuerdo a las actividades que se van a desarrollar en el proyecto

- Definir acuerdos y/o entregables para la aceptación del proyecto 


\subsection{ARQUITECTURAS (AS IS)}

2.5.1 ARQUITECTURA DE NEGOCIO DE LA LÍNEA BASE

2.5.2 ESTRUCTURA DE LA ORGANIZACIÓN DE LA LÍNEA BASE 


\section{(}

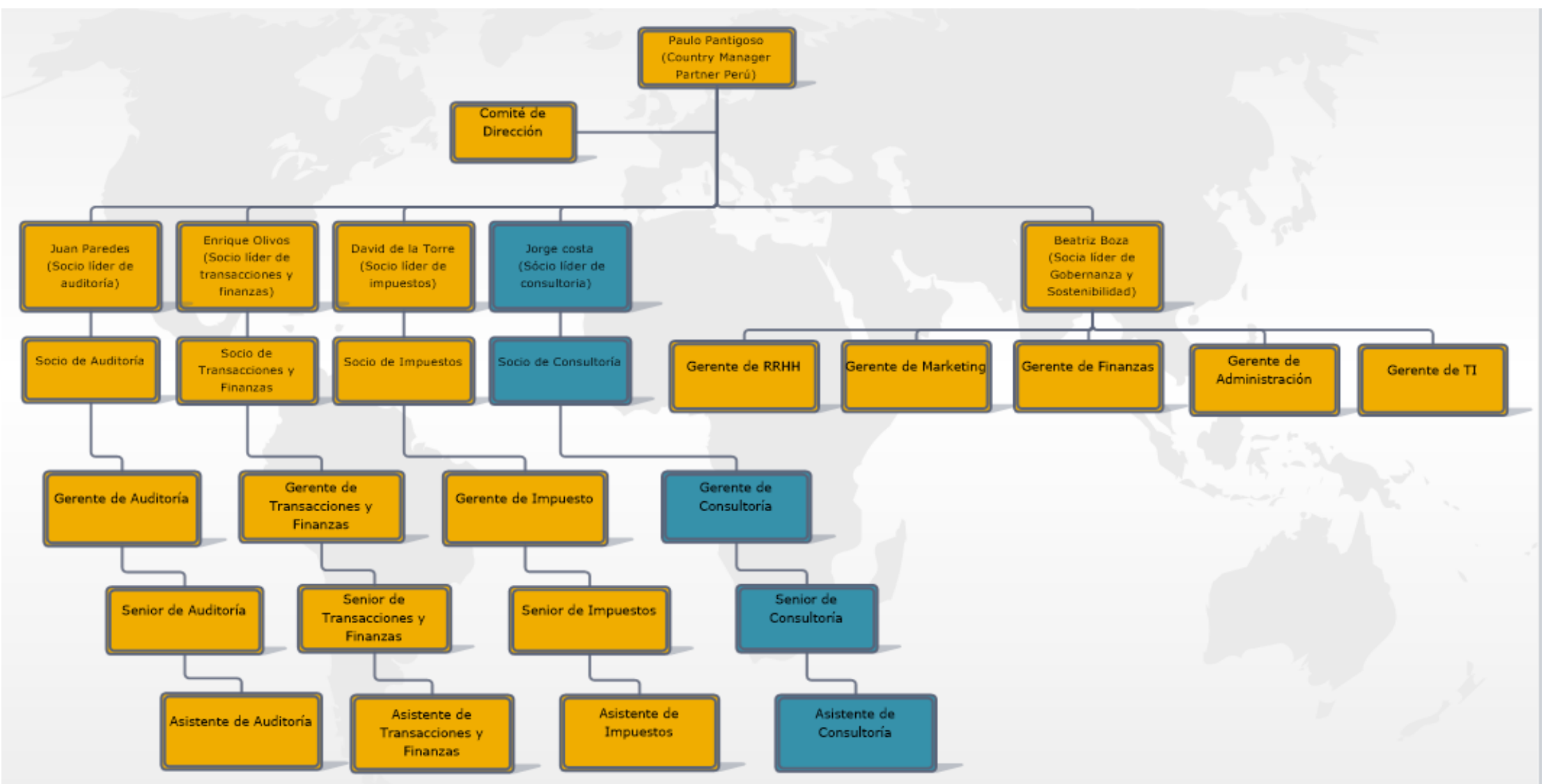

Figura $N^{\circ} 13$ Estructura de la Organización del Proceso Seleccionado de la Línea Base

Fuente: Elaboración Propia 


\section{(4)}

\subsubsection{MAPA DE PROCESO Y FUNCIONES DE NEGOCIO DE LA LÍNEA}

\section{BASE}
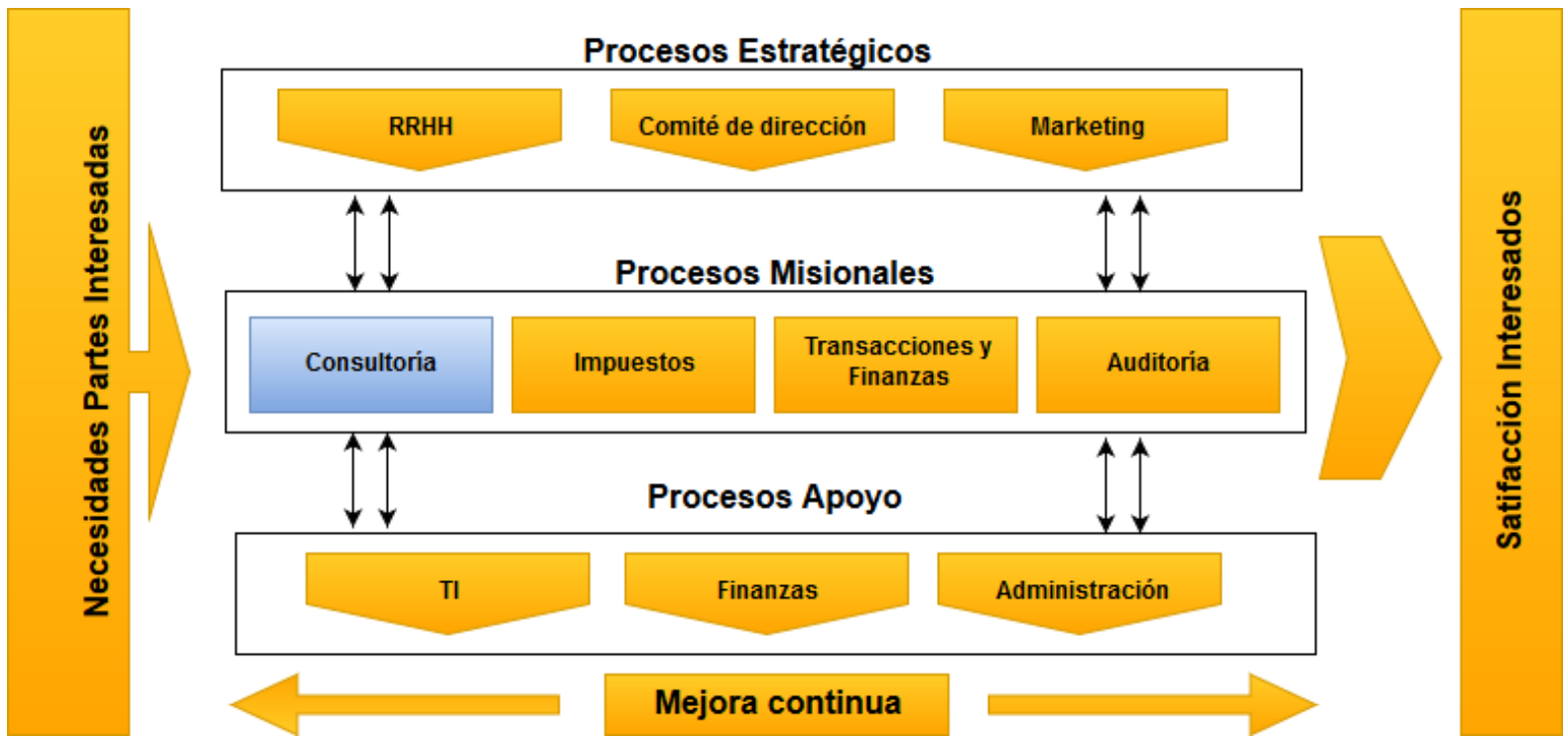

Figura $N^{\circ} 14$ Mapa de Proceso del Proceso Seleccionado de la Línea Base

Fuente: Elaboración propia

Tabla $N^{\circ} 8$ Descripción de Mapa de Proceso

\begin{tabular}{|l|l|}
\hline \multicolumn{1}{|c|}{ Proceso } & \multicolumn{1}{|c|}{ Descripción } \\
\hline RRHH & $\begin{array}{l}\text { Este proceso es el pilar de la organización, ya } \\
\text { que se encarga de gestionar y coordinar la } \\
\text { aplicación de las normas y los } \\
\text { procedimientos de los recursos humanos. Las } \\
\text { cuales desarrollan y aplican en los sistemas } \\
\text { de información en la gestión del talento } \\
\text { humano. }\end{array}$ \\
\hline Comité de dirección & $\begin{array}{l}\text { Es el proceso que se encarga de garantizar la } \\
\text { viabilidad del negocio, asegurar la } \\
\text { supervivencia, buscar crecimiento, fija el } \\
\text { marco estratégico y asegurar su compresión } \\
\text { en toda la organización }\end{array}$ \\
\hline Marketing & $\begin{array}{l}\text { Es el proceso que se encarga de desarrollar } \\
\text { estrategias de marketing a corto y largo plazo } \\
\text { de la organización. Estas estrategias pueden }\end{array}$ \\
\hline
\end{tabular}




\section{(1)}

\begin{tabular}{|l|l|}
\hline & $\begin{array}{l}\text { ser: desarrollo de la marca, inteligencia } \\
\text { competitiva y relaciones públicas }\end{array}$ \\
\hline Consultoría & $\begin{array}{l}\text { Es el proceso que se encarga de gestionar la } \\
\text { línea de servicio de Consultoría hacia los } \\
\text { clientes de la organización }\end{array}$ \\
\hline Impuestos & $\begin{array}{l}\text { Es el proceso que se encarga de gestionar la } \\
\text { línea de servicio de Impuestos hacia los } \\
\text { clientes de la organización }\end{array}$ \\
\hline Transacciones y Finanzas & $\begin{array}{l}\text { Es el proceso que se encarga de gestionar la } \\
\text { línea de servicio de Transacciones y } \\
\text { Finanzas hacia los clientes de la organización }\end{array}$ \\
\hline TI & $\begin{array}{l}\text { Es el proceso que se encarga de gestionar la } \\
\text { línea de servicio de Auditoría hacia los } \\
\text { clientes de la organización }\end{array}$ \\
\hline Finanzas & $\begin{array}{l}\text { Es el proceso que se encarga de planificar, } \\
\text { diseñar, ejecutar y monitorear la estrategia de } \\
\text { las tecnologías de la información. Además, } \\
\text { de supervisar y evaluar el alineamiento de los } \\
\text { sistemas de información a los procesos de la } \\
\text { organización }\end{array}$ \\
\hline $\begin{array}{l}\text { Es el proceso que se encarga de la eficiencia } \\
\text { administrativa del capital de trabajo dentro } \\
\text { de un criterio de riesgos y rentabilidad; } \\
\text { además, de orientar la estrategia financiera } \\
\text { para garantizar la disponibilidad de fuentes } \\
\text { de financiación. }\end{array}$ \\
\hline $\begin{array}{l}\text { Es el proceso que se encarga de la aplicación } \\
\text { de herramientas gerenciales que respondan a } \\
\text { las necesidades estratégicas, competitivas e } \\
\text { innovadoras para la organización en el } \\
\text { mercado }\end{array}$ \\
\hline
\end{tabular}

Fuente: Elaboración Propia 


\subsubsection{MATRIZ DE OBJETIVOS ESTRATÉGICOS VERSUS PROCESOS DE LA LÍNEA BASE}

Tabla N 9 Matriz de Objetivos Estratégicos Versus Procesos de la Línea Base

\begin{tabular}{|c|c|c|c|c|c|c|c|c|c|c|c|}
\hline \multirow[b]{2}{*}{ Proceso } & \multicolumn{11}{|c|}{ Objetivo } \\
\hline & Subproceso & $\begin{array}{l}\text { Innovar } \\
\text { en toda } \\
\text { la } \\
\text { organiz } \\
\text { ación }\end{array}$ & $\begin{array}{l}\text { Crear } \\
\text { modelos } \\
\text { de } \\
\text { negocios } \\
\text { alternativ } \\
\text { os }\end{array}$ & $\begin{array}{l}\text { Gestio } \\
\text { nar } \\
\text { servici } \\
\text { os de } \\
\text { mayor } \\
\text { escala }\end{array}$ & $\begin{array}{l}\text { Consider } \\
\text { ar la } \\
\text { agenda } \\
\text { digital a } \\
\text { los } \\
\text { clientes }\end{array}$ & $\begin{array}{l}\text { Usar la } \\
\text { tecnología } \\
\text { en las } \\
\text { líneas de } \\
\text { servicio }\end{array}$ & $\begin{array}{l}\text { Desarrollar } \\
\text { un } \\
\text { ecosistema } \\
\text { de alianzas } \\
\text { y recursos }\end{array}$ & $\begin{array}{l}\text { Adoptar } \\
\text { una visión } \\
\text { a futuro } \\
\text { acerca del } \\
\text { trabajo }\end{array}$ & $\begin{array}{l}\text { Seguir } \\
\text { una ruta } \\
\text { de } \\
\text { diversida } \\
\text { d e } \\
\text { inclusión }\end{array}$ & $\begin{array}{l}\text { Optimizar } \\
\text { costos y } \\
\text { mejor } \\
\text { márgenes }\end{array}$ & $\begin{array}{l}\text { Contro } \\
1 \mathrm{de} \\
\text { costos } \\
\text { indirec } \\
\text { tos }\end{array}$ \\
\hline Comité de Dirección & & $\mathrm{X}$ & $\mathrm{X}$ & $\mathrm{X}$ & & $\mathrm{X}$ & $\mathrm{X}$ & $\mathrm{X}$ & $\mathrm{X}$ & $\mathrm{X}$ & $\mathrm{X}$ \\
\hline RRHH & & $\mathrm{X}$ & & & & & $\mathrm{X}$ & $\mathrm{X}$ & $X$ & & \\
\hline Marketing & & $\mathrm{X}$ & & & & & & $\mathrm{X}$ & & & \\
\hline Auditoría & & & $\mathrm{X}$ & $\mathrm{X}$ & $\mathrm{X}$ & $\mathrm{X}$ & $\mathrm{X}$ & $\mathrm{X}$ & $\mathrm{X}$ & $\mathrm{X}$ & \\
\hline Transacciones y Finanzas & & & $\mathrm{X}$ & $\mathrm{X}$ & $\mathrm{X}$ & $\mathrm{X}$ & $\mathrm{X}$ & $\mathrm{X}$ & $\mathrm{X}$ & $\mathrm{X}$ & \\
\hline Impuestos & & & $\mathrm{X}$ & $\mathrm{X}$ & $\mathrm{X}$ & $\mathrm{X}$ & $\mathrm{X}$ & $\mathrm{X}$ & $\mathrm{X}$ & $\mathrm{X}$ & \\
\hline \multirow{3}{*}{ Consultoría } & $\begin{array}{l}\text { Auditoría Interna } \\
\text { Control interno } \\
\text { basado en COSO }\end{array}$ & & \multirow{3}{*}{$\mathrm{X}$} & \multirow{3}{*}{$\mathrm{X}$} & \multirow{3}{*}{$\mathrm{X}$} & \multirow{3}{*}{$\mathrm{X}$} & \multirow{3}{*}{$\mathrm{X}$} & \multirow{3}{*}{$\mathrm{X}$} & \multirow{3}{*}{$\mathrm{X}$} & \multirow{3}{*}{$\mathrm{X}$} & \\
\hline & $\begin{array}{l}\text { Asesoría en } \\
\text { Basilea III y } \\
\text { Solvencia II }\end{array}$ & & & & & & & & & & \\
\hline & $\begin{array}{l}\text { Asesoría en el } \\
\text { cumplimiento de }\end{array}$ & & & & & & & & & & \\
\hline
\end{tabular}


la ley de

prevención de

lavado de activos

Asesoría en el

cumplimiento de

la ley Sarbanes -

Oxley (SOX)

Asesoría en el

cumplimiento

regulatorio

Asesoría en la

adecuación a la

regulación

FATCA

Asesoría y

evaluación del

cumplimiento de

la regulación de

prácticas

anticorrupción

(FCPA y UK

Bribery Act)

Capacitación y

aplicación de

IFRS - NIIF

Gestión de

riesgos (ERM -

Enterprise Risk

Management)

Informática

forense

Análisis forense 


\section{$\boldsymbol{\theta}$}

\begin{tabular}{|l|l|l|l|l|l|l|l|l|l|} 
& $\begin{array}{l}\text { de datos } \\
\text { electrónicos }\end{array}$ & & & & & & & & \\
\hline TI & & $\mathrm{X}$ & & & & $\mathrm{X}$ & & \\
\hline Finanzas & & & & & & & \\
\hline Administración & & & & & & & $\mathrm{X}$ & \\
\hline
\end{tabular}

Fuente: Elaboración Propia 


\section{(1)}

\subsubsection{DESCRIPCIÓN DE PROCESO SELECCIONADO DE LA LÍNEA}

\section{BASE}

El subproceso seleccionado se llama Auditoría Interna de Riesgos que se encuentra en la línea de servicio de consultoría, a continuación, se explica las actividades correspondientes:

Tabla N ${ }^{\circ} 10$ Descripción de Actividades del Proceso Seleccionado de la Línea Base

\begin{tabular}{|c|c|c|}
\hline $\mathbf{N}^{\circ}$ & Actividad & Descripción \\
\hline 1 & $\begin{array}{l}\text { Realizar taller } \\
\text { de procesos }\end{array}$ & $\begin{array}{l}\text { El gerente de EY realiza un taller, conjuntamente con el cliente, para } \\
\text { identificar procesos }\end{array}$ \\
\hline 2 & $\begin{array}{l}\text { Brindar los } \\
\text { procesos para la } \\
\text { auditoría }\end{array}$ & $\begin{array}{l}\text { El cliente comienza a identificar los procesos para la auditoría y se } \\
\text { los va comunicando al gerente de EY de forma detallada. Además, } \\
\text { el gerente asocia criterios de proceso (materialidad, objetivos } \\
\text { estratégicos, complejidad de operaciones, volumen de transacciones } \\
\text { y automatización), para luego ser evaluados con el equipo de } \\
\text { auditoría. }\end{array}$ \\
\hline 3 & $\begin{array}{l}\text { Identificar el } \\
\text { tipo de matriz } \\
\text { del proyecto }\end{array}$ & $\begin{array}{l}\text { El gerente de EY, conjuntamente con el cliente, identifica que matriz } \\
(3 \times 3,4 \times 4 \text { o } 5 \times 5) \text {, se utilizará para evaluar los riesgos de alto nivel y } \\
\text { bajo nivel. }\end{array}$ \\
\hline 4 & $\begin{array}{l}\text { Identificar los } \\
\text { riesgos de alto } \\
\text { nivel de los } \\
\text { procesos }\end{array}$ & $\begin{array}{l}\text { Los seniors y asistente de EY, en base a los procesos descritos por } \\
\text { el gerente. Ellos comienzan a identificar los riesgos de alto nivel. } \\
\text { Estos riesgos están asociados a criterios de probabilidad e impacto } \\
\text { (tipo cuantitativo y/o cualitativo)) que estarán definidos de acuerdo } \\
\text { a una matriz de mapa de calor ( } 3 \times 3,4 \times 4 \text { o } 5 \times 5) \text {. Luego, cada riesgo } \\
\text { será evaluado de acuerdo a sus criterios que se les haya definido. }\end{array}$ \\
\hline 5 & $\begin{array}{l}\text { Evaluar los } \\
\text { riegos de alto } \\
\text { nivel por } \\
\text { probabilidad e } \\
\text { impacto }\end{array}$ & $\begin{array}{l}\text { Los riegos de alto nivel serán evaluados en base a los criterios } \\
\text { definidos para cada proceso (probabilidad e impacto) mediante una } \\
\text { ponderación de acuerdo a la matriz que haya seleccionado el cliente, } \\
\text { para la evaluación que puede ser de } 3 \times 3 \text { ( } 1=\text { bajo, } 2=\text { medio y } 3=\end{array}$ \\
\hline
\end{tabular}




\section{(1)}

\begin{tabular}{|c|c|c|}
\hline & & $\begin{array}{l}\text { alto), } 4 \times 4 \text { (bajo }=1, \text { medio }=2, \text { alto }=3, \text { extremo }=4) \text { y } 5 \times 5 \text { (más } \\
\text { bajo }=1, \text { bajo }=2, \text { medio }=3, \text { alto }=4 \text { y extremo }=5)\end{array}$ \\
\hline 6 & $\begin{array}{l}\text { Validar } \\
\text { resultado de } \\
\text { riesgos de alto } \\
\text { nivel }\end{array}$ & $\begin{array}{l}\text { El gerente válida el resultado de lo que se evaluó, por parte del } \\
\text { equipo, y da una retroalimentación si es necesario }\end{array}$ \\
\hline 7 & $\begin{array}{l}\text { Priorizar los } \\
\text { procesos }\end{array}$ & $\begin{array}{l}\text { El equipo en base a los riesgos de alto nivel evaluados y también } \\
\text { sobre la evaluación de criterios de proceso, pasará a realizar una } \\
\text { priorización de los procesos que son más urgentes de trabajar. }\end{array}$ \\
\hline 8 & $\begin{array}{l}\text { Crear el plan de } \\
\text { auditoría }\end{array}$ & $\begin{array}{l}\text { El equipo crea un plan de auditoría, definiendo periodos de visita en } \\
\text { el cliente (rango de fechas) para trabajar cada proceso priorizado }\end{array}$ \\
\hline 9 & $\begin{array}{l}\text { Identificar los } \\
\text { riesgos de bajo } \\
\text { nivel y } \\
\text { controles de los } \\
\text { procesos dados } \\
\text { en el plan de } \\
\text { auditoría }\end{array}$ & $\begin{array}{l}\text { Los seniors y asistente de EY, en base a los riesgos de alto nivel } \\
\text { dados en los procesos priorizados dentro del plan de auditoría; estos } \\
\text { comienzan a identificar los riesgos de bajo nivel y sus controles, } \\
\text { para realizar las pruebas en el cliente }\end{array}$ \\
\hline 10 & $\begin{array}{l}\text { Evaluar los } \\
\text { riesgos de bajo } \\
\text { nivel por } \\
\text { probabilidad e } \\
\text { impacto }\end{array}$ & $\begin{array}{l}\text { De igual manera que los riesgos de alto nivel, los riegos de bajo nivel } \\
\text { serán evaluados de acuerdo a la misma metodología }\end{array}$ \\
\hline 11 & $\begin{array}{l}\text { Validar } \\
\text { resultado de } \\
\text { riesgos de bajo } \\
\text { nivel }\end{array}$ & $\begin{array}{l}\text { De igual manera que los riesgos de alto nivel, los riesgos de bajo } \\
\text { nivel serán validados por el Gerente y en caso de alguna observación } \\
\text { se le dará la retroalimentación necesaria al equipo }\end{array}$ \\
\hline 12 & $\begin{array}{l}\text { Evaluar diseño } \\
\text { de controles }\end{array}$ & $\begin{array}{l}\text { Los seniors y/o asistente evalúan el diseño de los controles de cada } \\
\text { riesgo asociando atributos para cada control (atributos como: tipo } \\
\text { control, naturaleza, frecuencia, responsable, observación, }\end{array}$ \\
\hline
\end{tabular}




\section{(1)}

\begin{tabular}{|c|c|c|}
\hline & & $\begin{array}{l}\text { recomendación y resultado). En este parte, podría suceder que los } \\
\text { controles no hayan pasado el diseño, por lo cual tienen como } \\
\text { resultado en controles No Efectivo y directamente pasan a realizar } \\
\text { un plan de acción para dar observación y recomendación } \\
\text { correspondiente. }\end{array}$ \\
\hline 13 & $\begin{array}{l}\text { Evaluar la } \\
\text { operatividad de } \\
\text { controles }\end{array}$ & $\begin{array}{l}\text { El senior y/o asistente una vez que los controles hayan pasado como } \\
\text { resultado Efectivo serán evaluados en forma operativa. Esto quiere } \\
\text { decir, que pasarán a evaluarse estos controles en el cliente para ver } \\
\text { si dan como resultado Efectivo o No Efectivo y ver si el riesgo de } \\
\text { bajo nivel que se evaluó inicialmente (riesgo inherente) ha cambiado } \\
\text { en comparación; luego de la evaluación operativa del control (riesgo } \\
\text { residual) y verificar si necesita de alguna observación o } \\
\text { recomendación ese control en el plan de acción. }\end{array}$ \\
\hline 14 & $\begin{array}{l}\text { Validar } \\
\text { resultado de } \\
\text { operatividad de } \\
\text { controles }\end{array}$ & $\begin{array}{l}\text { El gerente en base a la evaluación operativa, valida la información } \\
\text { correspondiente y en caso necesite alguna observación el resultado } \\
\text { de la evaluación se lo hará saber al equipo. }\end{array}$ \\
\hline 15 & $\begin{array}{l}\text { Crear el plan de } \\
\text { acción de los } \\
\text { controles } \\
\text { fallidos }\end{array}$ & $\begin{array}{l}\text { El senior y/o asistente crean las observaciones o recomendación si } \\
\text { es que los controles evaluados en el diseño y operatividad pasaron } \\
\text { con resultado como No Efectivo, lo que el equipo ingresa las } \\
\text { observaciones y/o recomendaciones para que un responsable del } \\
\text { cliente puedan realizar lo recomendado por el equipo de auditoría }\end{array}$ \\
\hline 16 & $\begin{array}{l}\text { Generar } \\
\text { resultado de } \\
\text { operatividad y } \\
\text { plan de acción } \\
\text { de controles }\end{array}$ & $\begin{array}{l}\text { El equipo de auditoría genera los entregables correspondientes } \\
\text { integrando la información de los distintos miembros del equipo y } \\
\text { dan como resultado los planes de acción y el resultado final del } \\
\text { trabajo de auditoría. }\end{array}$ \\
\hline 17 & $\begin{array}{l}\text { Dar resultado } \\
\text { de operatividad } \\
\text { y plan de }\end{array}$ & $\begin{array}{l}\text { El gerente da el visto bueno de los entregables y se los entrega al } \\
\text { cliente. }\end{array}$ \\
\hline
\end{tabular}




\section{(}

\begin{tabular}{|l|l|l|}
\hline $\begin{array}{l}\text { acción de } \\
\text { controles }\end{array}$ & \\
\hline
\end{tabular}

Fuente: Elaboración Propia

\subsubsection{ROLES DE NEGOCIO DE LA LÍNEA BASE}

Tabla $N^{\circ} 11$ Roles del Negocio de la Línea Base

\begin{tabular}{|l|c|c|c|c|}
\hline \multirow{2}{*}{ Responsabilidades } & \multicolumn{4}{|c|}{ Roles } \\
\cline { 2 - 5 } & Gerente & Senior & Asistente & Cliente \\
\hline $\begin{array}{l}\text { Realizar taller de } \\
\text { procesos }\end{array}$ & $\mathrm{R}$ & & & $\mathrm{I}$ \\
\hline $\begin{array}{l}\text { Brindar los proceso } \\
\text { para la auditoría }\end{array}$ & $\mathrm{I}, \mathrm{C}$ & & & $\mathrm{R}, \mathrm{A}$ \\
\hline $\begin{array}{l}\text { Identificar el tipo de } \\
\text { matriz del proyecto }\end{array}$ & $\mathrm{C}, \mathrm{I}$ & & & $\mathrm{R}, \mathrm{A}$ \\
\hline $\begin{array}{l}\text { Identificar los riesgos } \\
\text { de alto nivel de los } \\
\text { procesos }\end{array}$ & $\mathrm{C}, \mathrm{A}$ & $\mathrm{R}$ & $\mathrm{R}$ & \\
\hline $\begin{array}{l}\text { Evaluar los riegos de } \\
\text { alto nivel por } \\
\text { probabilidad e } \\
\text { impacto }\end{array}$ & $\mathrm{C}, \mathrm{A}$ & $\mathrm{R}$ & $\mathrm{R}$ & \\
\hline $\begin{array}{l}\text { Validar resultado de } \\
\text { riesgos de alto nivel }\end{array}$ & $\mathrm{R}, \mathrm{A}$ & $\mathrm{C}, \mathrm{I}$ & $\mathrm{C}, \mathrm{I}$ & $\mathrm{I}$ \\
\hline Priorizar los procesos & $\mathrm{I}, \mathrm{C}$ & $\mathrm{R}$ & $\mathrm{R}$ & \\
\hline $\begin{array}{l}\text { Crear el plan de } \\
\text { auditoría }\end{array}$ & $\mathrm{I}, \mathrm{C}$ & $\mathrm{R}$ & $\mathrm{R}$ & $\mathrm{I}$ \\
\hline $\begin{array}{l}\text { Identificar los riesgos } \\
\text { de bajo nivel y } \\
\text { controles de los } \\
\text { procesos dados en el } \\
\text { plan de auditoría }\end{array}$ & $\mathrm{C}, \mathrm{A}$ & $\mathrm{R}$ & $\mathrm{R}$ & \\
\hline $\begin{array}{l}\text { Evaluar los riesgos de } \\
\text { bajo nivel por } \\
\text { probabilidad e } \\
\text { impacto }\end{array}$ & $\mathrm{C}, \mathrm{A}$ & $\mathrm{R}$ & $\mathrm{R}$ & \\
\hline $\begin{array}{l}\text { Validar resultado de } \\
\text { resgos de bajo nivel }\end{array}$ & $\mathrm{R}, \mathrm{A}$ & $\mathrm{C}, \mathrm{I}$ & $\mathrm{C}, \mathrm{I}$ & \\
\hline $\begin{array}{l}\text { Evaluar diseño de } \\
\text { controles }\end{array}$ & $\mathrm{C}, \mathrm{I}$ & $\mathrm{R}$ & & \\
\hline
\end{tabular}




\section{(9)}

\begin{tabular}{|l|c|c|c|c|}
\hline $\begin{array}{l}\text { Evaluar la } \\
\text { operatividad de } \\
\text { controles }\end{array}$ & C,I & R & R & \\
\hline $\begin{array}{l}\text { Validar resultado de } \\
\text { operatividad de } \\
\text { controles }\end{array}$ & R,A & C,I & C,I & R \\
\hline $\begin{array}{l}\text { Crear el plan de } \\
\text { acción de los controles } \\
\text { fallidos }\end{array}$ & C,I & R & R & \\
\hline $\begin{array}{l}\text { Generar resultado de } \\
\text { operatividad y plan de } \\
\text { acción de controles }\end{array}$ & C,I & R & I \\
\hline $\begin{array}{l}\text { Dar resultado de } \\
\text { operatividad y plan de } \\
\text { acción de controles }\end{array}$ & R,A & \multicolumn{1}{|l|}{} \\
\hline \multicolumn{2}{|c|}{ R - Responsable A - Aprobador C-Consultar I - Informar } \\
\hline
\end{tabular}

Fuente: Elaboración Propia

\subsubsection{MODELO DE DATOS DEL NEGOCIO DE LA LÍNEA BASE}

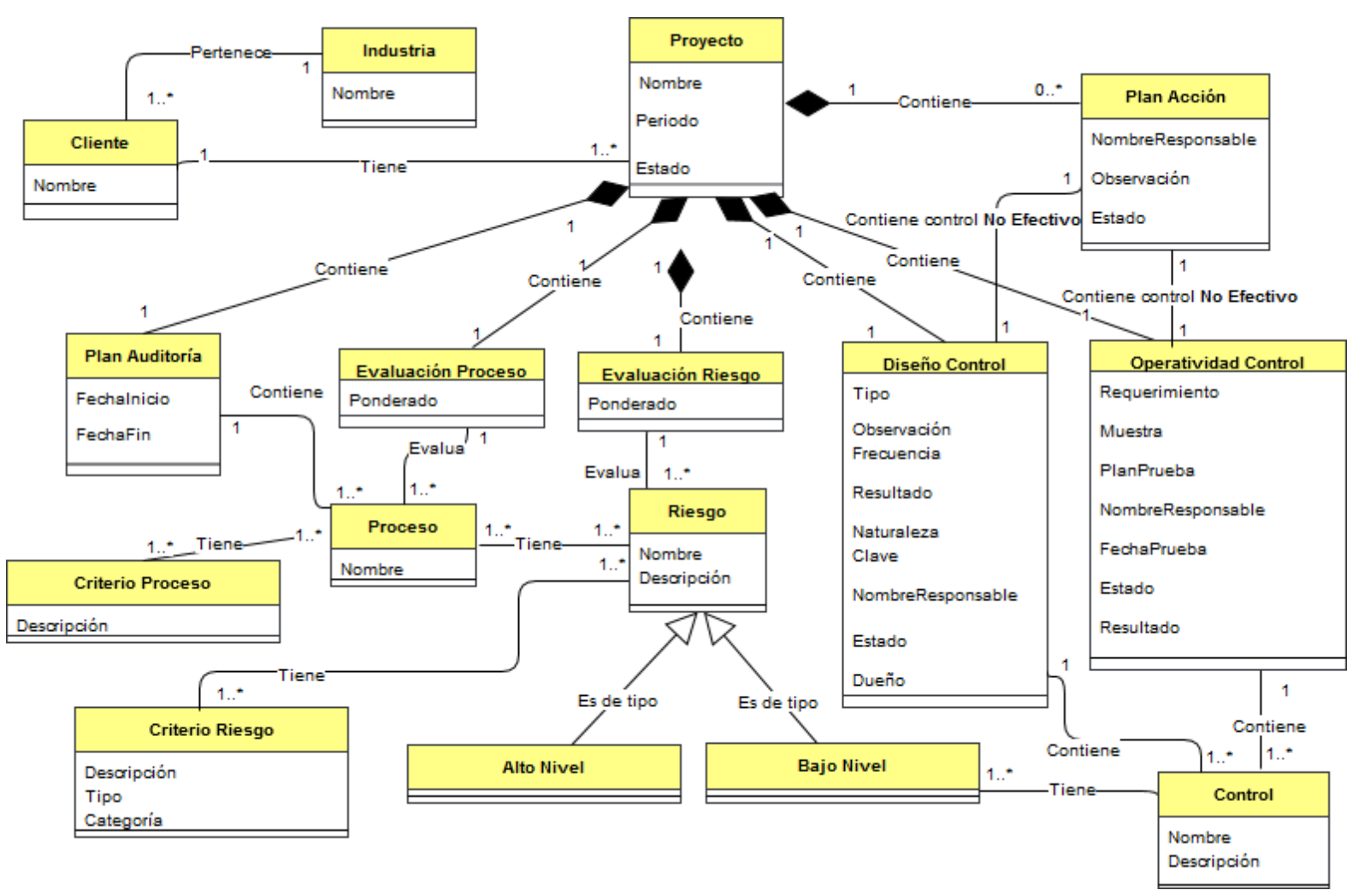

Figura $\mathrm{N}^{\circ} 15$ Modelo de Datos de Negocio de la Línea Base 


\section{(1)}

Fuente: Elaboración Propia

Tabla N 12 Descripción de los Datos del Negocio de la Línea Base

\begin{tabular}{|c|c|}
\hline Nombre & Descripción \\
\hline Industria & $\begin{array}{l}\text { Contiene las industrias que son trabajadas en cada } \\
\text { proyecto de la Auditoría Interna de Riesgos }\end{array}$ \\
\hline Cliente & Contiene los clientes de la organización \\
\hline Proyecto & $\begin{array}{l}\text { Contiene los proyectos realizados o que se están } \\
\text { desarrollando en el cliente }\end{array}$ \\
\hline Proceso & $\begin{array}{l}\text { Contiene los procesos que se van a auditar del cliente } \\
\text { por proyecto }\end{array}$ \\
\hline Evaluación Riesgo & $\begin{array}{l}\text { Contiene la evaluación de los riesgos de alto nivel y bajo } \\
\text { nivel que se han realizado de acuerdo a los criterios de } \\
\text { categoría de probabilidad e impacto por tipo (cualitativo } \\
\text { y/o cuantitativo) }\end{array}$ \\
\hline Evaluación Proceso & $\begin{array}{l}\text { Contiene la evaluación de control. En primer lugar, se } \\
\text { basa en dos valores, por un lado sobre la evaluación de } \\
\text { riesgos de alto nivel y por otro lado la evaluación misma } \\
\text { de del proceso de acuerdo a los criterios de proceso } \\
\text { asignado. Estos resultados dan una ponderación, la cual } \\
\text { servirá para priorizar el proceso con mayor resultado que } \\
\text { será utilizado en el plan de auditoría }\end{array}$ \\
\hline Plan Auditoría & $\begin{array}{l}\text { Contiene el plan de auditoría, aquí se registrará las } \\
\text { fechas de visita de acuerdo a la priorización previa de } \\
\text { los procesos en la que el consultor podrá crear un } \\
\text { cronograma de visitas para la evaluación de los controles } \\
\text { asignados al riesgo del proceso }\end{array}$ \\
\hline Diseño Control & $\begin{array}{l}\text { Contiene el diseño de los controles para los riesgos de } \\
\text { bajo nivel. El diseño del control se basa en atributos para } \\
\text { luego ser evaluados en la evaluación de la operatividad } \\
\text { del control si en caso el resultado del mismo es } \\
\text { Efectivo, caso contrario pasará a generarle un plan de } \\
\text { acción }\end{array}$ \\
\hline Operatividad Control & $\begin{array}{l}\text { Contiene la evaluación de la operatividad del control } \\
\text { para verificar si el resultado del control paso o no paso } \\
\text { las pruebas (Efectivo o No Efectivo) }\end{array}$ \\
\hline Plan Acción & $\begin{array}{l}\text { Contiene los planes de acción que se desarrollan en base } \\
\text { a si el control paso con un resultado de No Efectivo, ya } \\
\text { sea en la evaluación del diseño del control y/o en la } \\
\text { evaluación de la operatividad del control }\end{array}$ \\
\hline Riesgo & Contiene los riesgos de alto y bajo nivel \\
\hline
\end{tabular}




\begin{tabular}{|l|l|}
\hline Alto Nivel & $\begin{array}{l}\text { Contiene los riesgos de alto nivel o llamados riesgos de } \\
\text { entidad que serán identificados de acuerdo a los } \\
\text { procesos del proyecto }\end{array}$ \\
\hline Bajo Nivel & $\begin{array}{l}\text { Contiene los riesgos de bajo nivel o llamados riesgos } \\
\text { detallados o de proceso. Son los riesgos identificados de } \\
\text { acuerdo a su riesgo de alto nivel. }\end{array}$ \\
\hline Control & $\begin{array}{l}\text { Contiene los controles de evaluación de los procesos que } \\
\text { están asociados al riesgo de bajo nivel }\end{array}$ \\
\hline Criterio Proceso & $\begin{array}{l}\text { Contiene los criterios de los procesos, estos son } \\
\text { utilizados para evaluar los procesos }\end{array}$ \\
\hline Criterio Riesgo & $\begin{array}{l}\text { Contiene los criterios de los riesgos que están } \\
\text { clasificados por probabilidad e impacto de acuerdo a su } \\
\text { tipo de criterio que pueden ser cualitativos o } \\
\text { cuantitativos }\end{array}$ \\
\hline
\end{tabular}

Fuente: Elaboración Propia 


\section{(4)}

2.5.8 DIAGRAMA DE ACTIVIDADES DEL PROCESO DE LA LÍNEA BASE

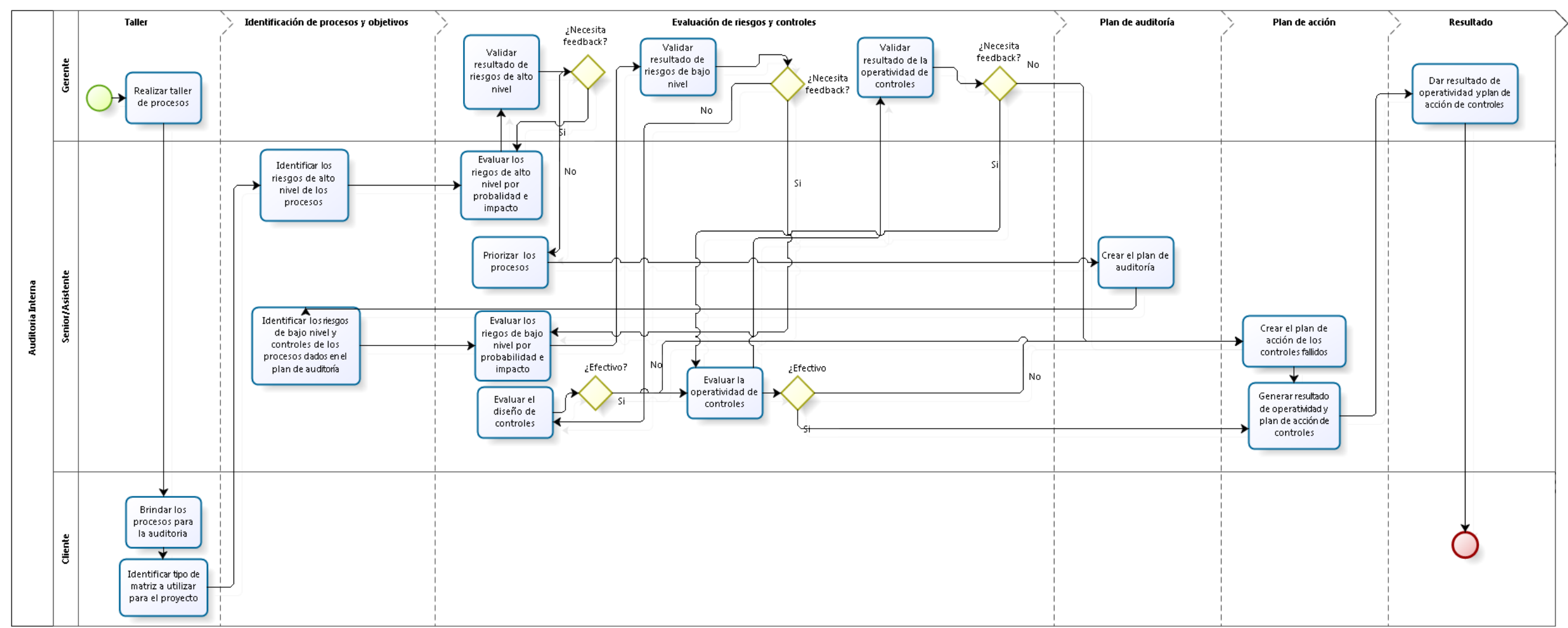

Figura $N^{\circ} 16$ Diagrama de Actividades de la Línea Base

Fuente: Elaboración Propia 


\section{(4)}

\subsubsection{ARQUITECTURA DE SISTEMAS DE INFORMACIÓN DE LA LÍNEA BASE}

\subsubsection{ARQUITECTURA DE DATOS DE LA LÍNEA BASE}

\subsubsection{MODELO DE DATOS LÓGICO DE LA LÍNEA BASE}

No cuenta con un modelo de datos en la línea base, ya que es una implementación que se verá reflejado en el modelo de datos de la línea destino.

\subsubsection{MATRIZ DE DATOS DE PROCESO SELECCIONADO VERSUS PROCESOS DE NEGOCIO DE LA LÍNEA BASE}

No cuenta con un matriz de datos de proceso versus procesos de negocio, porque la línea base no cuenta con un modelo de datos.

\subsubsection{ARQUITECTURA DE APLICACIONES DE LA LÍNEA BASE}

Tabla $N^{\circ} 13$ Arquitectura de aplicaciones de la Línea Base

\begin{tabular}{|l|l|}
\hline \multicolumn{1}{|c|}{ Aplicación } & \multicolumn{1}{c|}{ Descripción } \\
\hline LEAD & $\begin{array}{l}\text { Es una herramienta con un nuevo modelo de evaluación hacia el } \\
\text { trabajador de la organización. Esta ofrece retroalimentación } \\
\text { continua de los supervisores y también una evaluación respecto al } \\
\text { desempeño }\end{array}$ \\
\hline $\begin{array}{l}\text { BREAT (Bussiness } \\
\text { Relationship Evaluation } \\
\text { tracking) }\end{array}$ & $\begin{array}{l}\text { Es una herramienta que ayuda al usuario a evaluar un riesgo antes } \\
\text { de entablar una relación comercial con el cliente }\end{array}$ \\
\hline $\begin{array}{l}\text { PACE (Process for } \\
\text { Acceptance of Clients } \\
\text { and Engagements) }\end{array}$ & $\begin{array}{l}\text { Es una herramienta que ayuda al usuario a cumplir con las leyes y } \\
\text { normas profesionales aplicables que protege a la organización de } \\
\text { posibles riesgos reglamentarios, estratégicos y reputacionales al } \\
\text { aceptar a un posible cliente o proyecto }\end{array}$ \\
\hline $\begin{array}{l}\text { GT\&E (Global Time \& } \\
\text { Expense) }\end{array}$ & $\begin{array}{l}\text { Es una herramienta donde el trabajador tiene que reportar todas las } \\
\text { horas por semana que ha realizado de acuerdo a los diferentes } \\
\text { proyectos donde este asignado }\end{array}$ \\
\hline
\end{tabular}




\section{()}

\begin{tabular}{|l|l|} 
Discover & $\begin{array}{l}\text { Es una herramienta para encontrar información sobre las líneas de } \\
\text { servicios de EY, compartiendo información entre comunidades y } \\
\text { personas en todo el mundo }\end{array}$ \\
\hline $\begin{array}{l}\text { GFIS (Global financial } \\
\text { information system) }\end{array}$ & $\begin{array}{l}\text { Es una herramienta que ofrece: conferencias, talleres de TIC y e- } \\
\text { learning, trabajo en grupo, aprendizaje basado en problemas } \\
\text { centrados en la industria, presentaciones, una serie de seminarios } \\
\text { con expertos de la industria y visitas educativas a las oficinas } \\
\text { centrales de organizaciones de Servicios Financieros. }\end{array}$ \\
\hline
\end{tabular}

Fuente: Elaboración Propia

\subsubsection{MATRIZ DE APLICACIONES VERSUS PROCESOS DE NEGOCIO DE LA LÍNEA BASE}

Tabla N 14 Matriz de Aplicación Versus Procesos del Negocio de la Línea Base

\begin{tabular}{|c|c|c|c|c|c|c|c|c|c|c|}
\hline \multirow[b]{2}{*}{ Aplicación } & \multicolumn{10}{|c|}{ Proceso } \\
\hline & $\underset{\underline{a}}{\underline{\underline{\alpha}}}$ & 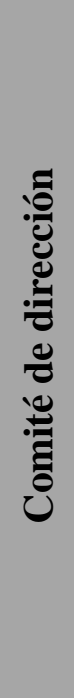 & 胥 & 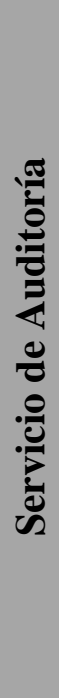 & 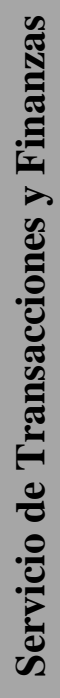 & 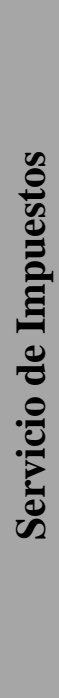 & 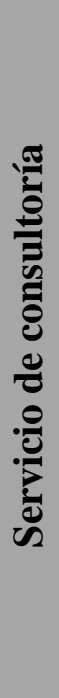 & 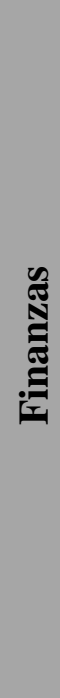 & 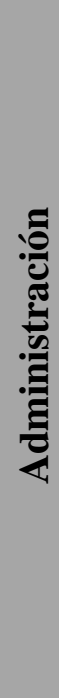 & $E$ \\
\hline LEAD & & & & $X$ & $X$ & $X$ & $X$ & & & \\
\hline $\begin{array}{l}\text { BREAT (Bussiness } \\
\text { Relationship } \\
\text { Evaluation tracking) }\end{array}$ & & & & $X$ & $X$ & $X$ & $X$ & & & \\
\hline $\begin{array}{l}\text { PACE (Process for } \\
\text { Acceptance of Clients } \\
\text { and Engagements) }\end{array}$ & & & & $X$ & $X$ & $X$ & $X$ & & & \\
\hline $\begin{array}{l}\text { GT\&E (Global Time } \\
\text { \& Expense) }\end{array}$ & & & & $\mathrm{X}$ & $X$ & $\mathrm{X}$ & $X$ & & & \\
\hline
\end{tabular}




\begin{tabular}{|l|l|l|l|l|l|l|l|l|l|l|}
\hline Discover & & & & $X$ & $X$ & $X$ & $X$ & & & \\
\hline $\begin{array}{l}\text { GFIS (Global financial } \\
\text { information system) }\end{array}$ & & & & $X$ & $X$ & $X$ & $X$ & & & \\
\hline
\end{tabular}

Fuente: Elaboración Propia 


\section{(1)}

\subsubsection{ARQUITECTURA TECNOLÓGICA DE LA LÍNEA BASE}

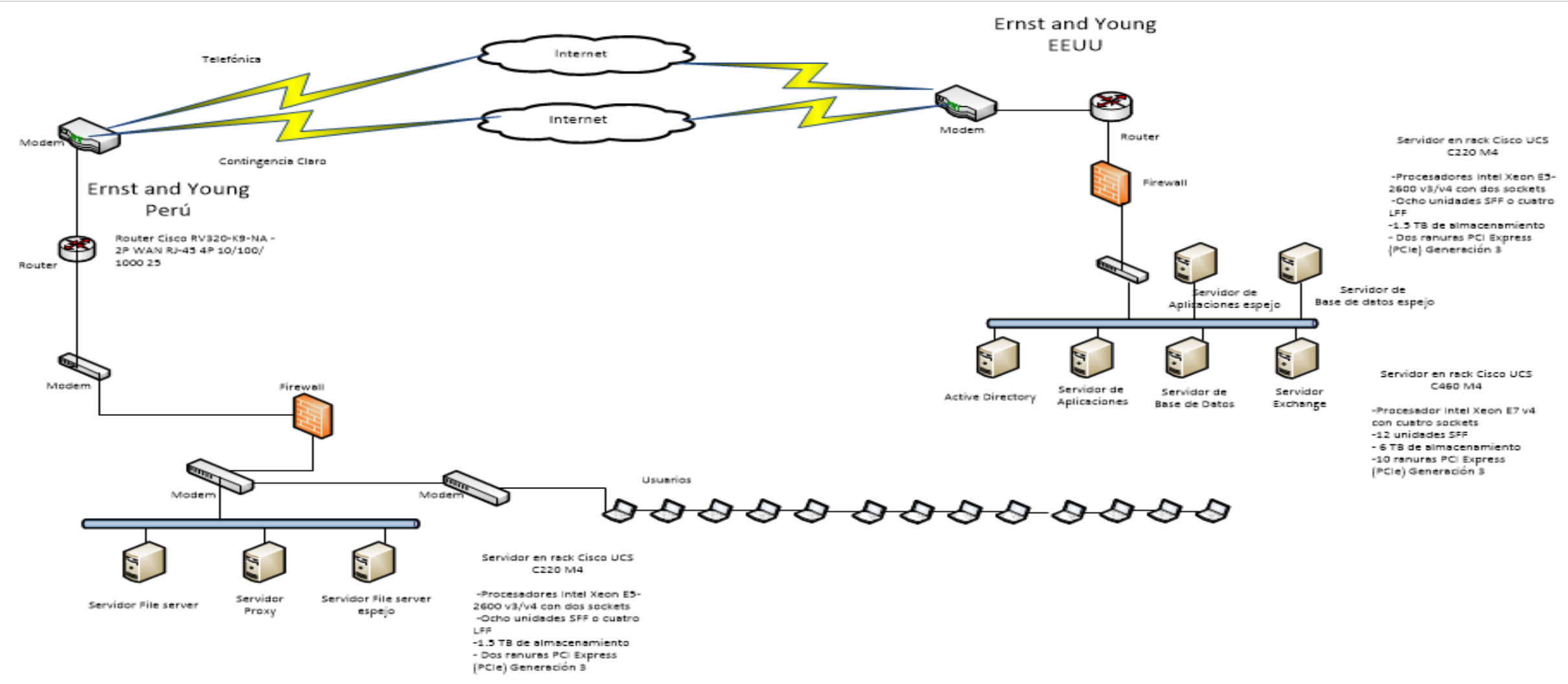

Figura $\mathrm{N}^{\circ} 17$ Arquitectura Tecnológica de la Línea Base

Fuente: Elaboración Propia 


\section{(1)}

Tabla N 15 Descripción de los Dispositivos de la Arquitectura Tecnológica de la Línea Base

\begin{tabular}{|c|c|c|}
\hline $\mathbf{N}^{\circ}$ & Nombre del Dispositivo & Descripción \\
\hline 1 & Internet & $\begin{array}{l}\text { Servicio utilizado para la intercomunicación de redes } \\
\text { mediante el uso de protocolos TCP/IP, para el uso } \\
\text { dentro y fuera de la organización. }\end{array}$ \\
\hline 2 & Firewall & $\begin{array}{l}\text { Dispositivo encargado de brindar seguridad ante } \\
\text { intrusiones a la red (IPS). }\end{array}$ \\
\hline 3 & Modem & $\begin{array}{l}\text { Dispositivo que convierte las señales digitales } \\
\text { en analógicas y viceversa, permite así la } \\
\text { comunicación entre computadoras. }\end{array}$ \\
\hline 4 & Router & $\begin{array}{l}\text { Dispositivo que proporciona conectividad a nivel de } \\
\text { red o nivel tres en el modelo OSI. Su función } \\
\text { principal consiste en enviar o encaminar paquetes de } \\
\text { datos de una red a otra. }\end{array}$ \\
\hline 5 & Servidor Proxy & $\begin{array}{l}\text { Es una interfaz de comunicación que actúa como } \\
\text { intermediaria entre dos sistemas informáticos, como } \\
\text { el navegador de un ordenador o móvil y la propia red } \\
\text { de Internet. }\end{array}$ \\
\hline 6 & Servidor Exchange & $\begin{array}{l}\text { Servido Exchange } 2013 \text { que se utiliza para gestionar } \\
\text { los correos de la organización y es posible el acceso } \\
\text { desde las laptops, por el SmartPhone y por el OWA. }\end{array}$ \\
\hline 7 & Servidor Active Directory & $\begin{array}{l}\text { Servidor que permite almacenar información relativa } \\
\text { de los recursos de una red con el fin de facilitar su } \\
\text { localización y administración. }\end{array}$ \\
\hline 8 & Servidor de Aplicaciones & $\begin{array}{l}\text { Servidor donde se encuentran las aplicaciones de la } \\
\text { organización. }\end{array}$ \\
\hline 9 & Servidor de Base de datos & $\begin{array}{l}\text { Servidor que contiene las bases de datos de la } \\
\text { organización. }\end{array}$ \\
\hline 10 & $\begin{array}{l}\text { Servidor de Aplicación } \\
\text { espejo }\end{array}$ & $\begin{array}{l}\text { Servidor de respaldo de las aplicaciones de la } \\
\text { organización. }\end{array}$ \\
\hline 11 & $\begin{array}{l}\text { Servidor de Base de datos } \\
\text { espejo }\end{array}$ & Servidor de respaldo de base de datos. \\
\hline 12 & Servidor File server & Servidor de almacenamiento de archivos físicos. \\
\hline 13 & Servidor File server espejo & Respaldo de los archivos guardados en el File Server \\
\hline 14 & Laptop & $\begin{array}{l}\text { Computadora portátil, quiere decir que puede ser } \\
\text { llevada a cualquier lado debido a su funcionamiento } \\
\text { a través de una batería o de electricidad }\end{array}$ \\
\hline 15 & Office 2013 & $\begin{array}{l}\text { Es una suite ofimática que abarca el mercado } \\
\text { completo en Internet e interrelaciona aplicaciones de } \\
\text { escritorio, servidores y servicios para los sistemas } \\
\text { operativos entre los que se usan herramientas para la } \\
\text { organización como Excel, Word y Power Point. }\end{array}$ \\
\hline
\end{tabular}

Fuente: Elaboración Propia 


\subsubsection{MATRIZ TECNOLÓGICA VERSUS PROCESOS DE NEGOCIO DE LA LÍNEA BASE}

Tabla N 16 Matriz de Aplicación Versus Procesos del Negocio de la Línea Base

\begin{tabular}{|c|c|c|c|c|c|c|c|c|c|c|}
\hline \multirow[b]{2}{*}{ Tecnológico } & \multicolumn{10}{|c|}{ Proceso } \\
\hline & 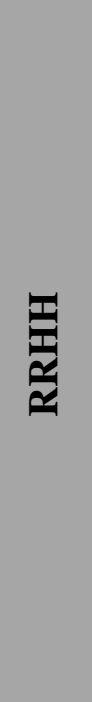 & $\begin{array}{l}\text { } \\
\\
\end{array}$ & 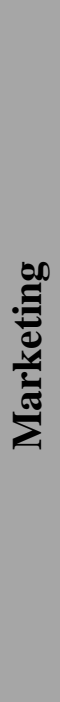 & 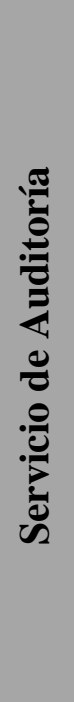 & 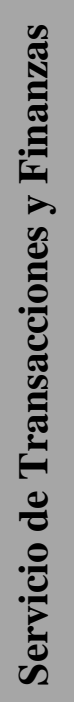 & 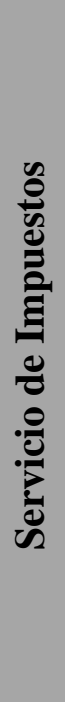 & 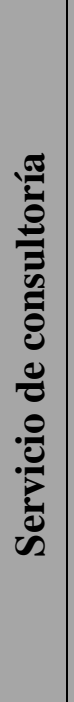 & 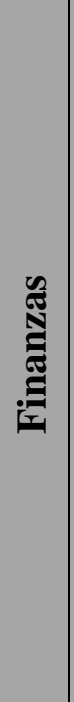 & 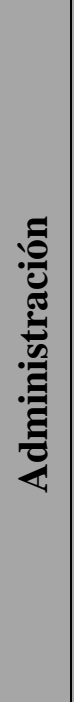 & $F$ \\
\hline Internet & $\mathrm{X}$ & $\mathrm{X}$ & $\mathrm{X}$ & $\mathrm{X}$ & $\mathrm{X}$ & $\mathrm{X}$ & $\mathrm{X}$ & $\mathrm{X}$ & $\mathrm{X}$ & $\mathrm{X}$ \\
\hline Firewall & $\mathrm{X}$ & $\mathrm{X}$ & $\mathrm{X}$ & $\mathrm{X}$ & $\mathrm{X}$ & $\mathrm{X}$ & $\mathrm{X}$ & $\mathrm{X}$ & $\mathrm{X}$ & $\mathrm{X}$ \\
\hline Modem & $\mathrm{X}$ & $\mathrm{X}$ & $\mathrm{X}$ & $\mathrm{X}$ & $\mathrm{X}$ & $\mathrm{X}$ & $\mathrm{X}$ & $\mathrm{X}$ & $\mathrm{X}$ & $\mathrm{X}$ \\
\hline Router & $\mathrm{X}$ & $\mathrm{X}$ & $\mathrm{X}$ & $\mathrm{X}$ & $\mathrm{X}$ & $\mathrm{X}$ & $\mathrm{X}$ & $\mathrm{X}$ & $\mathrm{X}$ & $\mathrm{X}$ \\
\hline \begin{tabular}{|l|} 
Servidor Proxy \\
\end{tabular} & $\mathrm{X}$ & $\mathrm{X}$ & $\mathrm{X}$ & $\mathrm{X}$ & $\mathrm{X}$ & $\mathrm{X}$ & $\mathrm{X}$ & $\mathrm{X}$ & $\mathrm{X}$ & $\mathrm{X}$ \\
\hline \begin{tabular}{|l} 
Servidor Exchange \\
\end{tabular} & $\mathrm{X}$ & $\mathrm{X}$ & $\mathrm{X}$ & $\mathrm{X}$ & $\mathrm{X}$ & $\mathrm{X}$ & $\mathrm{X}$ & $\mathrm{X}$ & $\mathrm{X}$ & $\mathrm{X}$ \\
\hline Active Directory & $\mathrm{X}$ & $\mathrm{X}$ & $\mathrm{X}$ & $\mathrm{X}$ & $\mathrm{X}$ & $\mathrm{X}$ & $\mathrm{X}$ & $\mathrm{X}$ & $\mathrm{X}$ & $\mathrm{X}$ \\
\hline \begin{tabular}{|l} 
Servidor de \\
Aplicaciones
\end{tabular} & $\mathrm{x}$ & $\mathrm{X}$ & $\mathrm{X}$ & $\mathrm{x}$ & $\mathrm{x}$ & $\mathrm{x}$ & $\mathrm{X}$ & $\mathrm{x}$ & $\mathrm{x}$ & $\mathrm{X}$ \\
\hline \begin{tabular}{|l|}
$\begin{array}{l}\text { Servidor de Base de } \\
\text { datos }\end{array}$ \\
\end{tabular} & $\mathrm{X}$ & $\mathrm{X}$ & $\mathrm{X}$ & $X$ & $X$ & $\mathrm{X}$ & $\mathrm{X}$ & $\mathrm{X}$ & $\mathrm{X}$ & $\mathrm{X}$ \\
\hline $\begin{array}{l}\text { Servidor de Aplicación } \\
\text { espejo }\end{array}$ & & & & & & & & & & $\mathrm{X}$ \\
\hline $\begin{array}{l}\begin{array}{l}\text { Servidor de Base de } \\
\text { datos espejo }\end{array} \\
\end{array}$ & & & & & & & & & & $\mathrm{X}$ \\
\hline \begin{tabular}{|l|} 
Servidor File server \\
\end{tabular} & $\mathrm{X}$ & $\mathrm{X}$ & $X$ & $\mathrm{X}$ & $\mathrm{X}$ & $X$ & $\mathrm{X}$ & $\mathrm{X}$ & $\mathrm{X}$ & $\mathrm{X}$ \\
\hline \begin{tabular}{|l|}
$\begin{array}{l}\text { Servidor File server } \\
\text { espejo }\end{array}$ \\
\end{tabular} & & & & & & & & & & $X$ \\
\hline Laptop & $\mathrm{X}$ & $\mathrm{X}$ & $\mathrm{X}$ & $\mathrm{X}$ & $\mathrm{X}$ & $\mathrm{X}$ & $\mathrm{X}$ & $\mathrm{X}$ & $\mathrm{X}$ & $\mathrm{X}$ \\
\hline Office 2013 & $\mathrm{X}$ & $\mathrm{X}$ & $\mathrm{X}$ & $\mathrm{X}$ & $\mathrm{X}$ & $\mathrm{X}$ & $\mathrm{X}$ & $\mathrm{X}$ & $\mathrm{X}$ & $\mathrm{X}$ \\
\hline
\end{tabular}




\section{(}

Fuente: Elaboración Propia

\subsubsection{FUNDAMENTOS Y JUSTIFICACIÓN DEL ENFOQUE ARQUITECTÓNICO}

De acuerdo al análisis de Arquitectura Empresarial usando TOGAF para la empresa EY; se concluyó que esta tiene los siguientes problemas que se describirán a continuación:

\section{$\underline{\text { Problemas }}$}

- No tener una base de conocimiento como ayuda en la gestión del trabajo del proyecto.

- Desarrollar e integrar el trabajo de forma manual por cada miembro del equipo perdiendo horas hombre de trabajo.

- El gerente no visualiza en tiempo real el avance del equipo y no puede dar la retroalimentación necesario (todo se hace de forma presencial con el equipo).

- La descentralización de la información mediante archivos esparcidos en una carpeta física compartida en el servidor como base de conocimiento para futuros proyectos.

\section{$\underline{\text { Requerimientos }}$}

- Implementar un sistema de Auditoría Interna de Riesgos que cubra las brechas identificadas.

- Establecer un repositorio de información para mantener de forma centralizada toda la información referente al trabajo del proyecto por parte del equipo de Auditoría Interna de Riesgos.

- Facilidad de uso de la gestión de riesgos para los proyectos de Auditoría Interna de Riesgos 


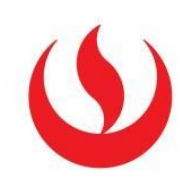

2.6 ARQUITECTURA (TO-BE)

2.6.1 ARQUITECTURA DE NEGOCIO DE LA LÍNEA DESTINO 


\section{(1)}

\subsubsection{ESTRUCTURA DE LA ORGANIZACIÓN DE LA LÍNEA DESTINO}

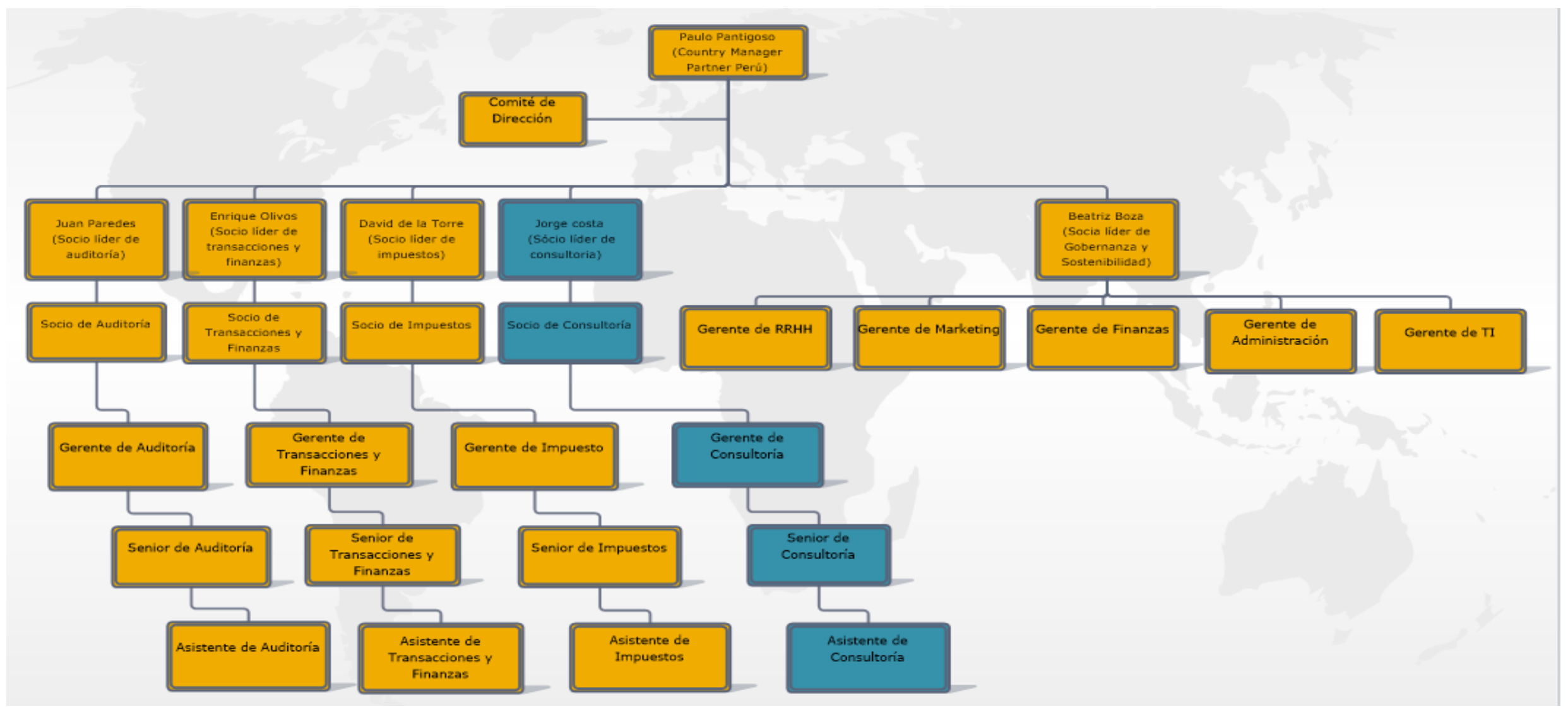

Figura $\mathrm{N}^{\circ} 18$ Estructura de la Organización del Proceso Seleccionado de la Línea Destino

Fuente: Elaboración Propia 


\section{(4)}

\subsubsection{MAPA DE PROCESO Y FUNCIONES DE NEGOCIO DE LA LÍNEA DE DESTINO}

Se mantiene igual que la línea base
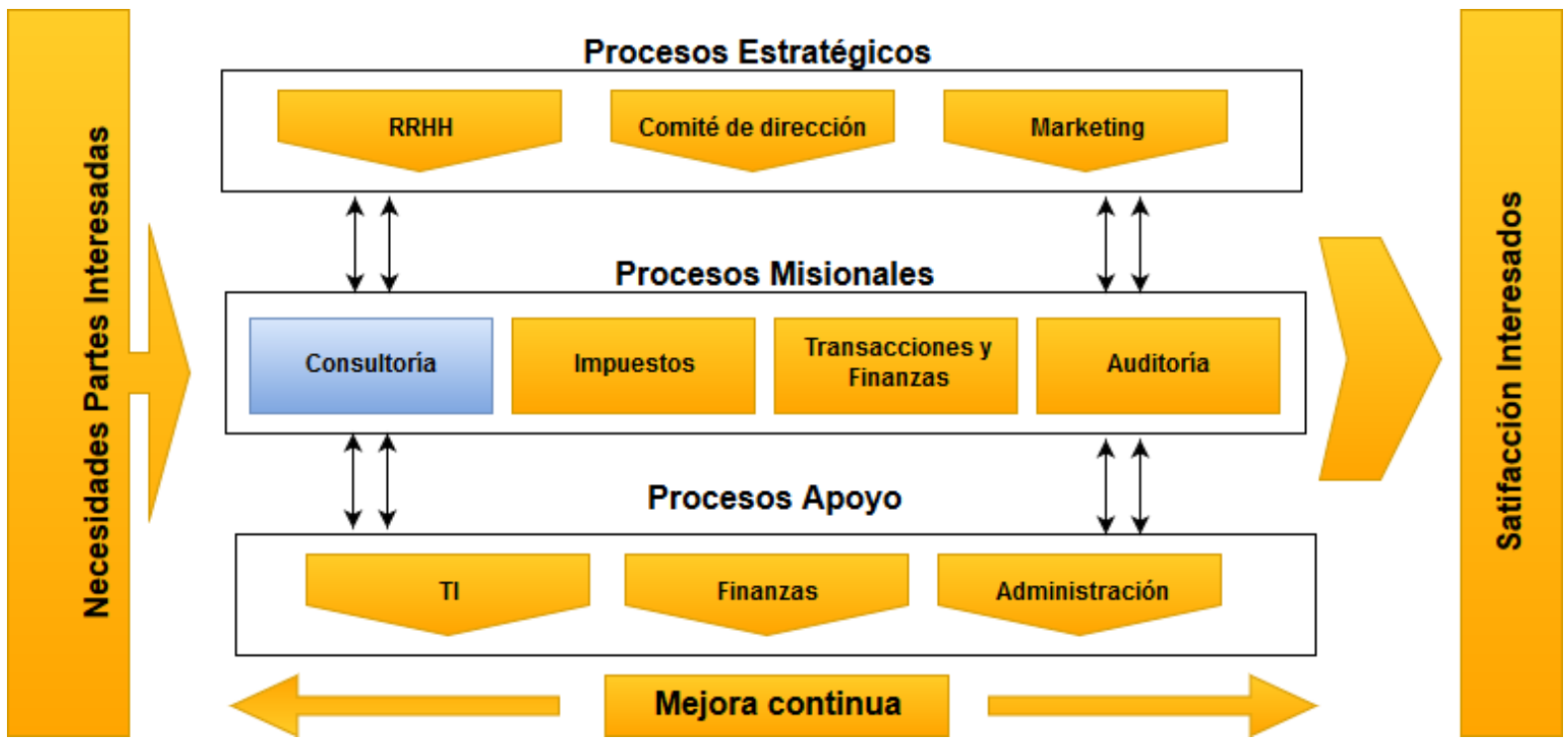

Figura $N^{\circ} 19$ Mapa de Proceso del Proceso Seleccionado de la Línea Destino

Fuente: Elaboración Propia

Tabla $N^{\circ} 17$ Descripción de Mapa de Proceso

\begin{tabular}{|l|l|}
\hline \multicolumn{1}{|c|}{ Proceso } & \multicolumn{1}{|c|}{ Descripción } \\
\hline RRHH & $\begin{array}{l}\text { Este proceso es el pilar de la organización, ya } \\
\text { que se encarga de gestionar y coordinar la } \\
\text { aplicación de las normas y los } \\
\text { procedimientos de los recursos humanos. Las } \\
\text { cuales desarrollan y aplican en los sistemas } \\
\text { de información en la gestión del talento } \\
\text { humano. }\end{array}$ \\
\hline Comité de dirección & $\begin{array}{l}\text { Es el proceso que se encarga de garantizar la } \\
\text { viabilidad del negocio, asegurar la } \\
\text { supervivencia, buscar crecimiento, fija el } \\
\text { marco estratégico y asegurar su compresión } \\
\text { en toda la organización }\end{array}$ \\
\hline Marketing & $\begin{array}{l}\text { Es el proceso que se encarga de desarrollar } \\
\text { estrategias de marketing a corto y largo plazo }\end{array}$ \\
\hline
\end{tabular}




\section{(1)}

\begin{tabular}{|c|c|}
\hline & $\begin{array}{l}\text { de la organización. Estas estrategias pueden } \\
\text { ser: desarrollo de la marca, inteligencia } \\
\text { competitiva y relaciones públicas }\end{array}$ \\
\hline Consultoría & $\begin{array}{l}\text { Es el proceso que se encarga de gestionar la } \\
\text { línea de servicio de Consultoría hacia los } \\
\text { clientes de la organización }\end{array}$ \\
\hline Impuestos & $\begin{array}{l}\text { Es el proceso que se encarga de gestionar la } \\
\text { línea de servicio de Impuestos hacia los } \\
\text { clientes de la organización }\end{array}$ \\
\hline Transacciones y Finanzas & $\begin{array}{l}\text { Es el proceso que se encarga de gestionar la } \\
\text { línea de servicio de Transacciones y } \\
\text { Finanzas hacia los clientes de la organización }\end{array}$ \\
\hline Auditoría & $\begin{array}{l}\text { Es el proceso que se encarga de gestionar la } \\
\text { línea de servicio de Auditoría hacia los } \\
\text { clientes de la organización }\end{array}$ \\
\hline TI & $\begin{array}{l}\text { Es el proceso que se encarga de planificar, } \\
\text { diseñar, ejecutar y monitorear la estrategia de } \\
\text { las tecnologías de la información. Además, } \\
\text { de supervisar y evaluar el alineamiento de los } \\
\text { sistemas de información a los procesos de la } \\
\text { organización }\end{array}$ \\
\hline Finanzas & $\begin{array}{l}\text { Es el proceso que se encarga de la eficiencia } \\
\text { administrativa del capital de trabajo dentro } \\
\text { de un criterio de riesgos y rentabilidad; } \\
\text { además, de orientar la estrategia financiera } \\
\text { para garantizar la disponibilidad de fuentes } \\
\text { de financiación. }\end{array}$ \\
\hline Administración & $\begin{array}{l}\text { Es el proceso que se encarga de la aplicación } \\
\text { de herramientas gerenciales que respondan a } \\
\text { las necesidades estratégicas, competitivas e } \\
\text { innovadoras para la organización en el } \\
\text { mercado }\end{array}$ \\
\hline
\end{tabular}

Fuente: Elaboración Propia 


\subsubsection{MATRIZ DE OBJETIVOS ESTRATÉGICOS VERSUS PROCESOS DE LA LÍNEA DESTINO}

Se mantiene igual que la línea base

Tabla N ${ }^{\circ} 18$ Matriz de Objetivos Estratégicos Versus Procesos de la Línea Destino

\begin{tabular}{|c|c|c|c|c|c|c|c|c|c|c|c|}
\hline & \multicolumn{11}{|c|}{ Objetivo } \\
\hline Proceso & Subproceso & \begin{tabular}{|l|} 
Innovar \\
en toda \\
la \\
organiz \\
ación
\end{tabular} & $\begin{array}{l}\text { Crear } \\
\text { modelos } \\
\text { de } \\
\text { negocios } \\
\text { alternativ } \\
\text { os }\end{array}$ & $\begin{array}{l}\text { Gestio } \\
\text { nar } \\
\text { servici } \\
\text { os de } \\
\text { mayor } \\
\text { escala }\end{array}$ & $\begin{array}{l}\text { Consider } \\
\text { ar la } \\
\text { agenda } \\
\text { digital a } \\
\text { los } \\
\text { clientes }\end{array}$ & $\begin{array}{l}\text { Usar la } \\
\text { tecnología } \\
\text { en las } \\
\text { líneas de } \\
\text { servicio }\end{array}$ & $\begin{array}{l}\text { Desarrollar } \\
\text { un } \\
\text { ecosistema } \\
\text { de alianzas } \\
\text { y recursos }\end{array}$ & $\begin{array}{l}\text { Adoptar } \\
\text { una visión } \\
\text { a futuro } \\
\text { acerca del } \\
\text { trabajo }\end{array}$ & $\begin{array}{l}\text { Seguir } \\
\text { una ruta } \\
\text { de } \\
\text { diversida } \\
\text { d e } \\
\text { inclusión }\end{array}$ & $\begin{array}{l}\text { Optimizar } \\
\text { costos y } \\
\text { mejor } \\
\text { márgenes }\end{array}$ & $\begin{array}{l}\text { Contro } \\
1 \text { de } \\
\text { costos } \\
\text { indirec } \\
\text { tos }\end{array}$ \\
\hline Comité de Dirección & & $\mathrm{X}$ & $\mathrm{X}$ & $X$ & & $\mathrm{X}$ & $X$ & $\mathrm{X}$ & $\mathrm{X}$ & $\mathrm{X}$ & $\mathrm{X}$ \\
\hline RRHH & & $\mathrm{X}$ & & & & & $\mathrm{X}$ & $\mathrm{X}$ & $\mathrm{X}$ & & \\
\hline Marketing & & $\mathrm{X}$ & & & & & & $\mathrm{X}$ & & & \\
\hline Auditoría & & & $\mathrm{X}$ & $\mathrm{X}$ & $\mathrm{X}$ & $\mathrm{X}$ & $\mathrm{X}$ & $\mathrm{X}$ & $\mathrm{X}$ & $\mathrm{X}$ & \\
\hline Transacciones y Finanzas & & & $\mathrm{X}$ & $\mathrm{X}$ & $X$ & $\mathrm{X}$ & $X$ & $\mathrm{X}$ & $\mathrm{X}$ & $\mathrm{X}$ & \\
\hline Impuestos & & & $X$ & $X$ & $\mathrm{X}$ & $X$ & $\mathrm{X}$ & $\mathrm{X}$ & $X$ & $\mathrm{X}$ & \\
\hline Consultoría & $\begin{array}{l}\text { Auditoría Interna } \\
\text { Control interno } \\
\text { basado en COSO }\end{array}$ & & $X$ & $X$ & $X$ & $\mathrm{X}$ & $\mathrm{X}$ & $\mathrm{X}$ & $X$ & $\mathrm{X}$ & \\
\hline
\end{tabular}


Asesoría en Basilea III y

Solvencia II

Asesoría en el

cumplimiento de

la ley de

prevención de

lavado de activos

Asesoría en el

cumplimiento de

la ley Sarbanes -

Oxley (SOX)

Asesoría en el

cumplimiento

regulatorio

Asesoría en la

adecuación a la

regulación

FATCA

Asesoría y

evaluación del

cumplimiento de

la regulación de

prácticas

anticorrupción

(FCPA y UK

Bribery Act)

Capacitación y

aplicación de

IFRS - NIIF

Gestión de

riesgos (ERM - 


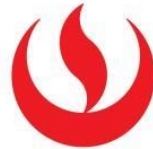

\begin{tabular}{|c|c|c|c|c|c|c|c|c|c|c|c|}
\hline & $\begin{array}{l}\text { Enterprise Risk } \\
\text { Management) } \\
\text { Informática } \\
\text { forense - } \\
\text { Análisis forense } \\
\text { de datos } \\
\text { electrónicos }\end{array}$ & & & & & & & & & & \\
\hline TI & & $X$ & & & & $X$ & & & & $\mathrm{X}$ & \\
\hline Finanzas & & & & & & & & & & $X$ & $\mathrm{X}$ \\
\hline \multirow[t]{2}{*}{ Administración } & & & & & & & & & & $\mathrm{X}$ & $\mathrm{X}$ \\
\hline & 4 & & 5 & 5 & 4 & 6 & 6 & 7 & 6 & 8 & 3 \\
\hline
\end{tabular}

Fuente: Elaboración Propia 


\section{(1)}

\subsubsection{DESCRIPCIÓN DE PROCESO SELECCIONADO DE LA LÍNEA DESTINO}

El subproceso seleccionado se llama Auditoría Interna de Riesgos que se encuentra en la línea de servicio de consultoría, a continuación, se enmarca las actividades que se van a desarrollar dentro del marco de la arquitectura empresarial.

Tabla $N^{\circ} 19$ Descripción de las Actividades del Proceso Seleccionado de la Línea Destino

\begin{tabular}{|c|c|c|}
\hline $\mathbf{N}^{\circ}$ & Actividad & Descripción \\
\hline 1 & $\begin{array}{l}\text { Realizar taller } \\
\text { de procesos }\end{array}$ & $\begin{array}{l}\text { El gerente de EY realiza un taller, conjuntamente con el cliente, para } \\
\text { identificar procesos }\end{array}$ \\
\hline 2 & $\begin{array}{l}\text { Brindar los } \\
\text { procesos para la } \\
\text { auditoría }\end{array}$ & $\begin{array}{l}\text { El cliente comienza a identificar los procesos para la auditoría y se } \\
\text { los va comunicando al gerente de EY de forma detallada. Además, } \\
\text { el gerente asocia criterios de proceso (materialidad, objetivos } \\
\text { estratégicos, complejidad de operaciones, volumen de transacciones } \\
\text { y automatización), para luego ser evaluados con el equipo de } \\
\text { auditoría. }\end{array}$ \\
\hline 3 & $\begin{array}{l}\text { Identificar el } \\
\text { tipo de matriz } \\
\text { del proyecto }\end{array}$ & $\begin{array}{l}\text { El gerente de EY, conjuntamente con el cliente, identifica que matriz } \\
(3 \times 3,4 \times 4 \text { o } 5 \times 5) \text {, se utilizará para evaluar los riesgos de alto nivel y } \\
\text { bajo nivel. }\end{array}$ \\
\hline 4 & $\begin{array}{l}\text { Identificar los } \\
\text { riesgos de alto } \\
\text { nivel de los } \\
\text { procesos }\end{array}$ & $\begin{array}{l}\text { Los seniors y asistente de EY, en base a los procesos descritos por } \\
\text { el gerente. Ellos comienzan a identificar los riesgos de alto nivel. } \\
\text { Estos riesgos están asociados a criterios de probabilidad e impacto } \\
\text { (tipo cuantitativo y/o cualitativo)) que estarán definidos de acuerdo } \\
\text { a una matriz de mapa de calor }(3 \times 3,4 \times 4 \text { o } 5 \times 5) \text {. Luego, cada riesgo } \\
\text { será evaluado de acuerdo a sus criterios que se les haya definido. }\end{array}$ \\
\hline 5 & $\begin{array}{l}\text { Evaluar los } \\
\text { riegos de alto } \\
\text { nivel por }\end{array}$ & $\begin{array}{l}\text { Los riegos de alto nivel serán evaluados en base a los criterios } \\
\text { definidos para cada proceso (probabilidad e impacto) mediante una } \\
\text { ponderación de acuerdo a la matriz que haya seleccionado el cliente, } \\
\text { para la evaluación que puede ser de } 3 \times 3 \text { ( } 1=\text { bajo, } 2=\text { medio y } 3=\end{array}$ \\
\hline
\end{tabular}




\section{(1)}

\begin{tabular}{|c|c|c|}
\hline & $\begin{array}{l}\text { probabilidad e } \\
\text { impacto }\end{array}$ & $\begin{array}{l}\text { alto), } 4 \times 4 \text { (bajo }=1, \text { medio }=2, \text { alto }=3, \text { extremo }=4) \text { y } 5 \times 5 \text { (más } \\
\text { bajo }=1 \text {, bajo }=2, \text { medio }=3, \text { alto }=4 \text { y extremo }=5)\end{array}$ \\
\hline 6 & $\begin{array}{l}\text { Validar } \\
\text { resultado de } \\
\text { riesgos de alto } \\
\text { nivel }\end{array}$ & $\begin{array}{l}\text { El gerente válida el resultado de lo que se evaluó, por parte del } \\
\text { equipo, y da una retroalimentación si es necesario }\end{array}$ \\
\hline 7 & $\begin{array}{l}\text { Priorizar los } \\
\text { procesos }\end{array}$ & $\begin{array}{l}\text { El equipo en base a los riesgos de alto nivel evaluados y también } \\
\text { sobre la evaluación de criterios de proceso, pasará a realizar una } \\
\text { priorización de los procesos que son más urgentes de trabajar. }\end{array}$ \\
\hline 8 & $\begin{array}{l}\text { Crear el plan de } \\
\text { auditoría }\end{array}$ & $\begin{array}{l}\text { El equipo crea un plan de auditoría, definiendo periodos de visita en } \\
\text { el cliente (rango de fechas) para trabajar cada proceso priorizado }\end{array}$ \\
\hline 9 & $\begin{array}{l}\text { Identificar los } \\
\text { riesgos de bajo } \\
\text { nivel y } \\
\text { controles de los } \\
\text { procesos dados } \\
\text { en el plan de } \\
\text { auditoría }\end{array}$ & $\begin{array}{l}\text { Los seniors y asistente de EY, en base a los riesgos de alto nivel } \\
\text { dados en los procesos priorizados dentro del plan de auditoría; estos } \\
\text { comienzan a identificar los riesgos de bajo nivel y sus controles, } \\
\text { para realizar las pruebas en el cliente }\end{array}$ \\
\hline 10 & $\begin{array}{l}\text { Evaluar los } \\
\text { riesgos de bajo } \\
\text { nivel por } \\
\text { probabilidad e } \\
\text { impacto }\end{array}$ & $\begin{array}{l}\text { De igual manera que los riesgos de alto nivel, los riegos de bajo nivel } \\
\text { serán evaluados de acuerdo a la misma metodología }\end{array}$ \\
\hline 11 & $\begin{array}{l}\text { Validar } \\
\text { resultado de } \\
\text { riesgos de bajo } \\
\text { nivel }\end{array}$ & $\begin{array}{l}\text { De igual manera que los riesgos de alto nivel, los riesgos de bajo } \\
\text { nivel serán validados por el Gerente y en caso de alguna observación } \\
\text { se le dará la retroalimentación necesaria al equipo }\end{array}$ \\
\hline 12 & $\begin{array}{l}\text { Evaluar diseño } \\
\text { de controles }\end{array}$ & $\begin{array}{l}\text { Los seniors y/o asistente evalúan el diseño de los controles de cada } \\
\text { riesgo asociando atributos para cada control (atributos como: tipo } \\
\text { control, naturaleza, frecuencia, responsable, observación, }\end{array}$ \\
\hline
\end{tabular}




\section{(1)}

\begin{tabular}{|c|c|c|}
\hline & & $\begin{array}{l}\text { recomendación y resultado). En este parte, podría suceder que los } \\
\text { controles no hayan pasado el diseño, por lo cual tienen como } \\
\text { resultado en controles No Efectivo y directamente pasan a realizar } \\
\text { un plan de acción para dar observación y recomendación } \\
\text { correspondiente. }\end{array}$ \\
\hline 13 & $\begin{array}{l}\text { Evaluar la } \\
\text { operatividad de } \\
\text { controles }\end{array}$ & $\begin{array}{l}\text { El senior y/o asistente una vez que los controles hayan pasado como } \\
\text { resultado Efectivo serán evaluados en forma operativa. Esto quiere } \\
\text { decir, que pasarán a evaluarse estos controles en el cliente para ver } \\
\text { si dan como resultado Efectivo o No Efectivo y ver si el riesgo de } \\
\text { bajo nivel que se evaluó inicialmente (riesgo inherente) ha cambiado } \\
\text { en comparación; luego de la evaluación operativa del control (riesgo } \\
\text { residual) y verificar si necesita de alguna observación o } \\
\text { recomendación ese control en el plan de acción. }\end{array}$ \\
\hline 14 & $\begin{array}{l}\text { Validar } \\
\text { resultado de } \\
\text { operatividad de } \\
\text { controles }\end{array}$ & $\begin{array}{l}\text { El gerente en base a la evaluación operativa, valida la información } \\
\text { correspondiente y en caso necesite alguna observación el resultado } \\
\text { de la evaluación se lo hará saber al equipo. }\end{array}$ \\
\hline 15 & $\begin{array}{l}\text { Crear el plan de } \\
\text { acción de los } \\
\text { controles } \\
\text { fallidos }\end{array}$ & $\begin{array}{l}\text { El senior y/o asistente crean las observaciones o recomendación si } \\
\text { es que los controles evaluados en el diseño y operatividad pasaron } \\
\text { con resultado como No Efectivo, lo que el equipo ingresa las } \\
\text { observaciones y/o recomendaciones para que un responsable del } \\
\text { cliente puedan realizar lo recomendado por el equipo de auditoría }\end{array}$ \\
\hline 16 & $\begin{array}{l}\text { Generar } \\
\text { resultado de } \\
\text { operatividad y } \\
\text { plan de acción } \\
\text { de controles }\end{array}$ & $\begin{array}{l}\text { El equipo de auditoría genera los entregables correspondientes } \\
\text { integrando la información de los distintos miembros del equipo y } \\
\text { dan como resultado los planes de acción y el resultado final del } \\
\text { trabajo de auditoría. }\end{array}$ \\
\hline
\end{tabular}




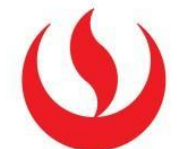

\begin{tabular}{|l|l|l|}
\hline 17 & $\begin{array}{l}\text { Dar resultado } \\
\text { de operatividad } \\
\text { y plan de } \\
\text { acción de } \\
\text { controles }\end{array}$ & $\begin{array}{l}\text { El gerente da el visto bueno de los entregables y se los entrega al } \\
\text { cliente. }\end{array}$ \\
\hline
\end{tabular}

Fuente: Elaboración Propia

\subsubsection{ROLES DE NEGOCIO DE LA LÍNEA DESTINO}

Se mantiene la matriz RACI como la línea base.

Tabla Nº 20 Roles del Negocio de la Línea Destino

\begin{tabular}{|l|c|c|c|c|}
\hline \multirow{2}{*}{ Responsabilidades } & \multicolumn{4}{|c|}{ Roles } \\
\cline { 2 - 5 } $\begin{array}{l}\text { Realizar taller de } \\
\text { procesos }\end{array}$ & Rerente & Senior & Asistente & Cliente \\
\hline $\begin{array}{l}\text { Brindar los proceso } \\
\text { para la auditoría }\end{array}$ & I,C & & & I \\
\hline $\begin{array}{l}\text { Identificar el tipo de } \\
\text { matriz del proyecto }\end{array}$ & C,I & & R,A \\
\hline $\begin{array}{l}\text { Identificar los riesgos } \\
\text { de alto nivel de los } \\
\text { procesos }\end{array}$ & C,A & R & R & \\
\hline $\begin{array}{l}\text { Evaluar los riegos de } \\
\text { alto nivel por } \\
\text { probabilidad e } \\
\text { impacto }\end{array}$ & C,A & R & R & \\
\hline $\begin{array}{l}\text { Validar resultado de } \\
\text { riesgos de alto nivel }\end{array}$ & R,A & C,I & C,I & I \\
\hline Priorizar los procesos & I,C & R & R & \\
\hline $\begin{array}{l}\text { Crear el plan de } \\
\text { auditoría }\end{array}$ & I,C & R & R & I \\
\hline $\begin{array}{l}\text { Identificar los riesgos } \\
\text { de bajo nivel y } \\
\text { controles de los } \\
\text { procesos dados en el } \\
\text { plan de auditoría }\end{array}$ & C,A & R & R & \\
\hline
\end{tabular}




\section{(1)}

\begin{tabular}{|l|c|c|c|c|}
\hline $\begin{array}{l}\text { Evaluar los riesgos de } \\
\text { bajo nivel por } \\
\text { probabilidad e } \\
\text { impacto }\end{array}$ & C,A & $\mathrm{R}$ & $\mathrm{R}$ & \\
\hline $\begin{array}{l}\text { Validar resultado de } \\
\text { riesgos de bajo nivel }\end{array}$ & $\mathrm{R}, \mathrm{A}$ & $\mathrm{C}, \mathrm{I}$ & $\mathrm{C}, \mathrm{I}$ & \\
\hline $\begin{array}{l}\text { Evaluar diseño de } \\
\text { controles }\end{array}$ & $\mathrm{C}, \mathrm{I}$ & $\mathrm{R}$ & & \\
\hline $\begin{array}{l}\text { Evaluar la } \\
\text { operatividad de } \\
\text { controles }\end{array}$ & $\mathrm{C}, \mathrm{I}$ & $\mathrm{R}$ & $\mathrm{R}$ & \\
\hline $\begin{array}{l}\text { Validar resultado de } \\
\text { operatividad de } \\
\text { controles }\end{array}$ & $\mathrm{R}, \mathrm{A}$ & $\mathrm{C}, \mathrm{I}$ & $\mathrm{C}, \mathrm{I}$ & \\
\hline $\begin{array}{l}\text { Crear el plan de } \\
\text { acción de los controles } \\
\text { fallidos }\end{array}$ & $\mathrm{C}, \mathrm{I}$ & $\mathrm{R}$ & $\mathrm{R}$ & \\
\hline $\begin{array}{l}\text { Generar resultado de } \\
\text { operatividad y plan de } \\
\text { acción de controles }\end{array}$ & $\mathrm{C}, \mathrm{I}$ & $\mathrm{R}$ & $\mathrm{R}$ & \\
\hline $\begin{array}{l}\text { Dar resultado de } \\
\text { operatividad y plan de } \\
\text { acción de controles }\end{array}$ & $\mathrm{R}, \mathrm{A}$ & \multicolumn{2}{|l|}{} \\
\hline \multicolumn{2}{|c|}{$\mathbf{R}-$ Responsable A-Aprobador C-Consultar I - Informar } \\
\hline
\end{tabular}

Fuente: Elaboración Propia

\subsubsection{MODELO DE DATOS DEL NEGOCIO DE LA LÍNEA DESTINO}

El modelo de datos de la línea destino queda igual que la línea base, ya que todos los datos por parte del negocio están de forma manual (mediante Excel) y se espera crear una aplicación para gestionar esta información. 


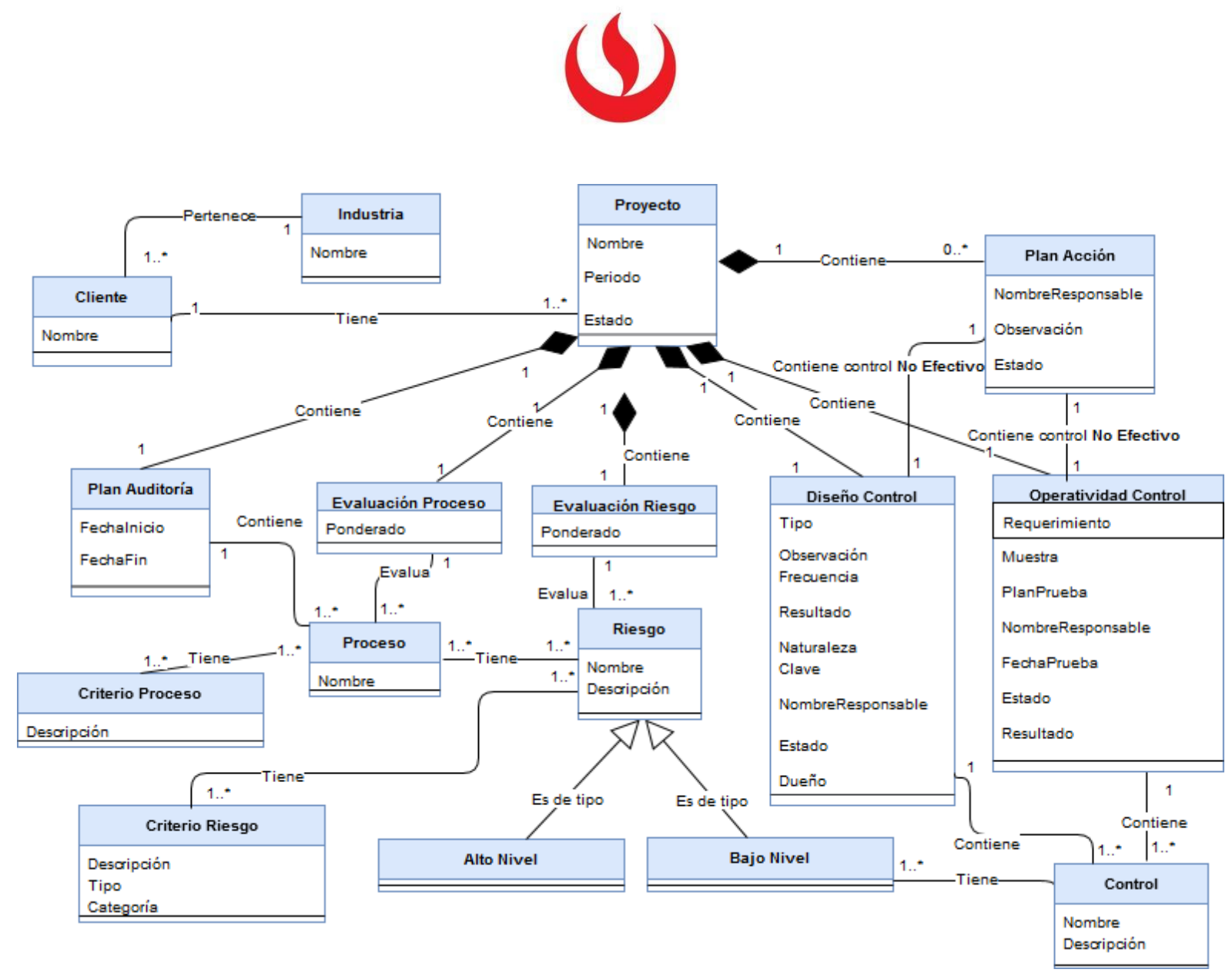

Figura $N^{\circ} 20$ Modelo de Datos del Negocio de la Línea Destino

Fuente: Elaboración Propia

Tabla N 21 Descripción de los Datos del Negocio de la Línea Destino

\begin{tabular}{|l|l|}
\hline \multicolumn{1}{|c|}{ Nombre } & \multicolumn{1}{c|}{ Descripción } \\
\hline Industria & $\begin{array}{l}\text { Contiene las industrias que son trabajas en cada } \\
\text { proyecto de la Auditoría Interna de Riesgos }\end{array}$ \\
\hline Cliente & Contiene los clientes de la organización \\
\hline Proyecto & $\begin{array}{l}\text { Contiene los proyectos realizados o que se están } \\
\text { desarrollando en el cliente }\end{array}$ \\
\hline Proceso & $\begin{array}{l}\text { Contiene los procesos que se van a auditar del cliente } \\
\text { por proyecto }\end{array}$ \\
\hline Evaluación Riesgo & $\begin{array}{l}\text { Contiene la evaluación de los riesgos de alto nivel y bajo } \\
\text { nivel que se han realizado de acuerdo a los criterios de } \\
\text { categoría de probabilidad e impacto por tipo (cualitativo } \\
\text { y/o cuantitativo) }\end{array}$ \\
\hline Evaluación Proceso & $\begin{array}{l}\text { Contiene la evaluación de control. En primer lugar, se } \\
\text { basa en dos valores, por un lado, sobre la evaluación de } \\
\text { riesgos de alto nivel y por otro lado la evaluación misma } \\
\text { de del proceso de acuerdo a los criterios de proceso }\end{array}$ \\
\hline
\end{tabular}




\section{()}

\begin{tabular}{|c|c|}
\hline & $\begin{array}{l}\text { asignado. Estos resultados dan una ponderación, la cual } \\
\text { servirá para priorizar el proceso con mayor resultado que } \\
\text { será utilizado en el plan de auditoría }\end{array}$ \\
\hline Plan Auditoría & $\begin{array}{l}\text { Contiene el plan de auditoría, aquí se registrará las } \\
\text { fechas de visita de acuerdo a la priorización previa de } \\
\text { los procesos en la que el consultor podrá crear un } \\
\text { cronograma de visitas para la evaluación de los controles } \\
\text { asignados al riesgo del proceso }\end{array}$ \\
\hline Diseño Control & $\begin{array}{l}\text { Contiene el diseño de los controles para los riesgos de } \\
\text { bajo nivel. El diseño del control se basa en atributos para } \\
\text { luego ser evaluados en la evaluación de la operatividad } \\
\text { del control si en caso el resultado del mismo es } \\
\text { Efectivo, caso contrario pasará a generarle un plan de } \\
\text { acción }\end{array}$ \\
\hline Operatividad Control & $\begin{array}{l}\text { Contiene la evaluación de la operatividad del control } \\
\text { para verificar si el resultado del control paso o no paso } \\
\text { las pruebas (Efectivo o No Efectivo) }\end{array}$ \\
\hline Plan Acción & $\begin{array}{l}\text { Contiene los planes de acción que se desarrollan en base } \\
\text { a si el control paso con un resultado de No Efectivo, ya } \\
\text { sea en la evaluación del diseño del control y/o en la } \\
\text { evaluación de la operatividad del control }\end{array}$ \\
\hline Riesgo & Contiene los riesgos de alto y bajo nivel \\
\hline Alto Nivel & $\begin{array}{l}\text { Contiene los riesgos de alto nivel o llamados riesgos de } \\
\text { entidad que serán identificados de acuerdo a los } \\
\text { procesos del proyecto }\end{array}$ \\
\hline Bajo Nivel & $\begin{array}{l}\text { Contiene los riesgos de bajo nivel o llamados riesgos } \\
\text { detallados o de proceso. Son los riesgos identificados de } \\
\text { acuerdo a su riesgo de alto nivel. }\end{array}$ \\
\hline Control & $\begin{array}{l}\text { Contiene los controles de evaluación de los procesos que } \\
\text { están asociados al riesgo de bajo nivel }\end{array}$ \\
\hline Criterio Proceso & $\begin{array}{l}\text { Contiene los criterios de los procesos, estos son } \\
\text { utilizados para evaluar los procesos }\end{array}$ \\
\hline Criterio Riesgo & $\begin{array}{l}\text { Contiene los criterios de los riesgos que están } \\
\text { clasificados por probabilidad e impacto de acuerdo a su } \\
\text { tipo de criterio que pueden ser cualitativos o } \\
\text { cuantitativos }\end{array}$ \\
\hline
\end{tabular}

Fuente: Elaboración Propia 


\section{(4)}

\subsubsection{DIAGRAMA DE ACTIVIDADES DEL PROCESO DE LA LÍNEA DESTINO}

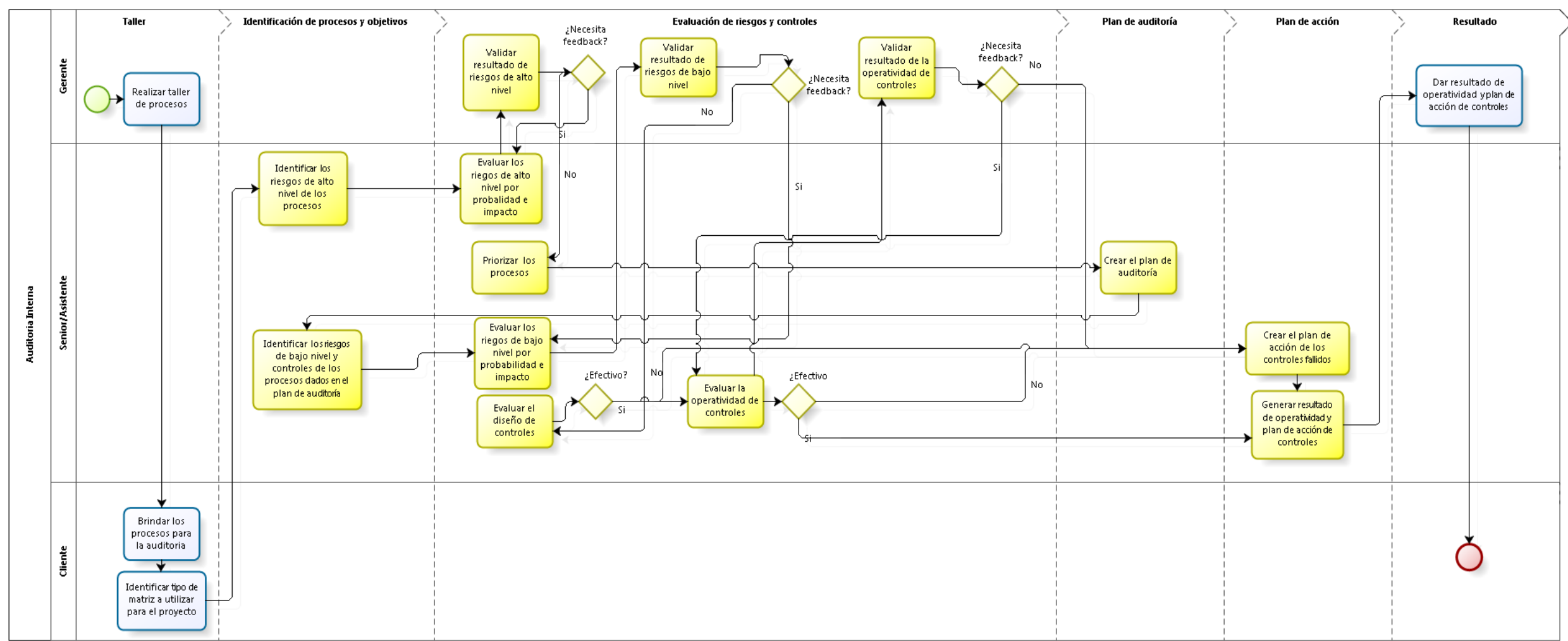

Figura $\mathrm{N}^{\circ} 21$ Diagrama de Actividades de la Línea Destino

Fuente: Elaboración Propia 
2.6.9 ARQUITECTURA DE SISTEMAS DE INFORMACIÓN DE LA LÍNEA DESTINO

2.6.10 ARQUITECTURA DE DATOS DE LA LÍNEA DESTINO

2.6.11 MODELO DE DATOS LÓGICO DE LA LÍNEA DESTINO 


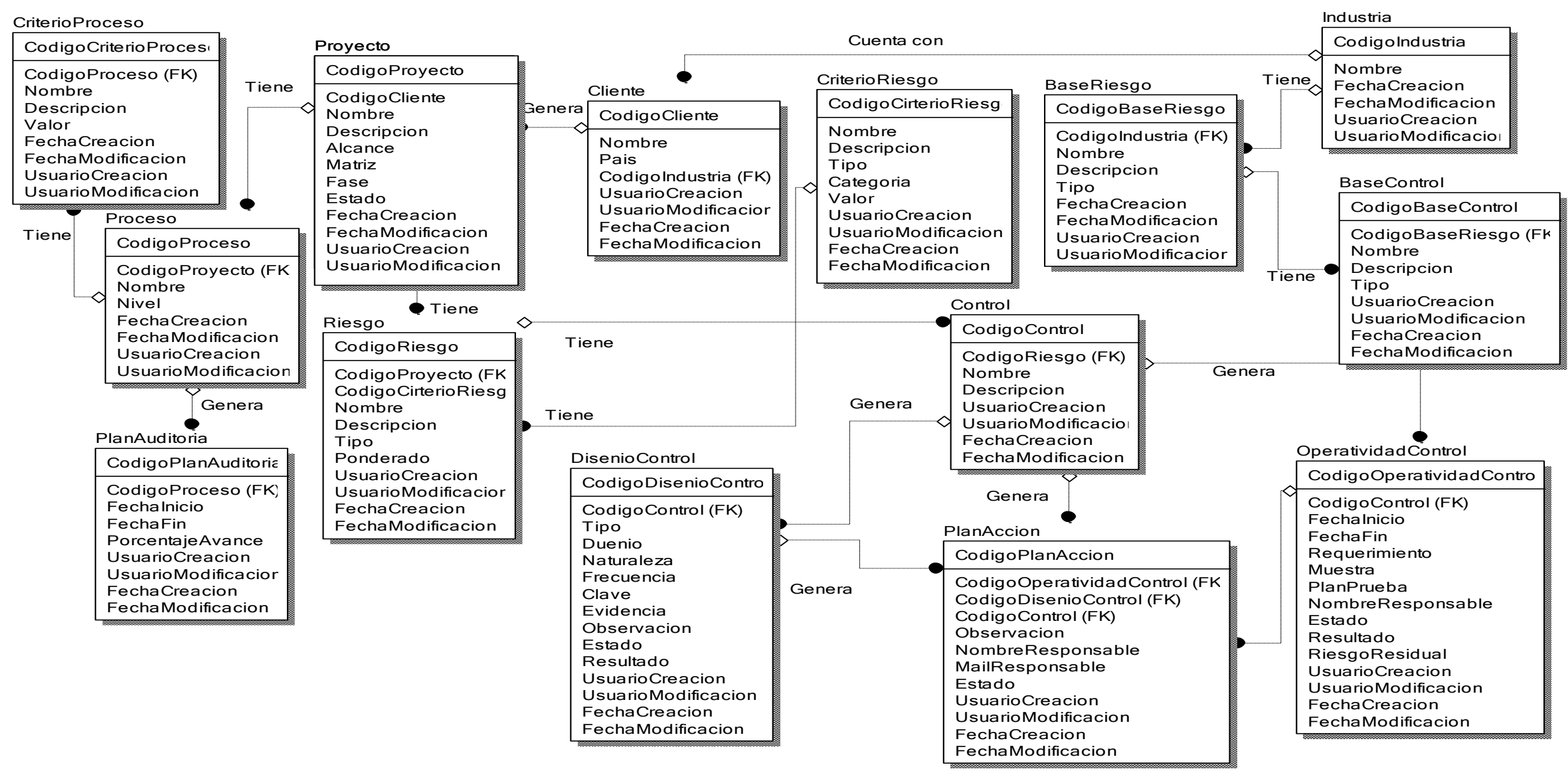

Figura $\mathrm{N}^{\circ} 22$ Modelo de Datos Lógico de la Línea Destino

Fuente: Elaboración Propia 


\section{(4)}

\subsubsection{DICCIONARIO DE DATOS}

Tabla $N^{\circ} 22$ Diccionario de Datos de la Línea Destino

\begin{tabular}{|l|l|}
\hline \multicolumn{2}{|c|}{ Industria } \\
\hline Tabla de registro de la industria del cliente \\
\hline Campo & Descripción \\
\hline CodigoIndustria - PK & Código de industria \\
\hline Nombre & Nombre de industria \\
\hline UsuarioCreacion & Usuario de creación del registro \\
\hline UsuarioModificacion & Usuario de la modificación del registro \\
\hline FechaCreacion & Fecha de creación del registro \\
\hline FechaModificacion & Fecha de modificación del registro \\
\hline
\end{tabular}

\section{BaseRiesgo}

Tabla con información cargada de riesgos, como base de conocimiento por industria

\section{Campo}

CodigoBaseRiesgo - PK

CodigoIndustria - FK

Nombre

Descripcion

Tipo

UsuarioCreacion

UsuarioModificacion

FechaCreacion

FechaModificacion

\section{Descripción}

Código base del riesgo

Código de industria

Nombre del riesgo

Descripción del riesgo

Si es de tipo A = Alto nível ó B = Bajo Nivel

Usuario de creación del registro

Usuario de la modificación del registro

Fecha de creación del registro

Fecha de modificación del registro

\section{BaseControl}

Tabla con información cargada de controles, como base de conocimiento por riesgo de bajo nivel

\begin{tabular}{|l|l|}
\hline Campo & Descripción \\
\hline CodigoBaseControl - PK & Código base del control \\
\hline Nombre & Nombre del control \\
\hline Descripcion & Descripción del control \\
\hline UsuarioCreacion & Usuario de creación del registro \\
\hline UsuarioModificacion & Usuario de la modificación del registro \\
\hline FechaCreacion & Fecha de creación del registro \\
\hline FechaModificacion & Fecha de modificación del registro \\
\hline
\end{tabular}

\section{Cliente}

Tabla de registro del cliente 


\section{(4)}

\begin{tabular}{|l|l|}
\hline CodigoCliente - PK & Código del cliente \\
\hline Nombre & Nombre del cliente \\
\hline Pais & Pais del cliente \\
\hline CodigoIndustria & Código de la industria \\
\hline UsuarioCreacion & Usuario de creación del registro \\
\hline UsuarioModificacion & Usuario de la modificación del registro \\
\hline FechaCreacion & Fecha de creación del registro \\
\hline FechaModificacion & Fecha de modificación del registro \\
\hline
\end{tabular}

\section{Proyecto}

Tabla de registro del proyecto que se le genera al cliente

\begin{tabular}{|l|l|}
\hline Campo & Descripción \\
\hline CodigoProyecto - PK & Código del proyecto \\
\hline CodigoCliente - FK & Código del cliente \\
\hline Nombre & Nombre del proyecto \\
\hline Descripcion & Descripción del proyecto \\
\hline Alcance & $\begin{array}{l}\text { Descripción del alcance que va a tener el } \\
\text { proyecto }\end{array}$ \\
\hline Matriz & $\begin{array}{l}\text { El tipo de matriz o mapa de calor de 3 X 3, } \\
\text { X 4 o 5 X 5 de la probabilidad e impacto }\end{array}$ \\
\hline Fase & $\begin{array}{l}\text { Fase actual donde se encuentra el proyecto } \\
\text { (I= Inicial, C=Configuración, E=Ejecución o } \\
\text { M=Monitoreo) }\end{array}$ \\
\hline Estado & $\begin{array}{l}\text { Estado del proyecto (A=Activo, C=Cerrado } \\
\text { o N=Anulado) }\end{array}$ \\
\hline UsuarioCreacion & Usuario de creación del registro \\
\hline UsuarioModificacion & Usuario de la modificación del registro \\
\hline FechaCreacion & Fecha de creación del registro \\
\hline FechaModificacion & Fecha de modificación del registro \\
\hline
\end{tabular}

\section{Proceso}

Tabla de registro de los procesos que serán auditados del proyecto

\begin{tabular}{|l|l|}
\hline Campo & Descripción \\
\hline CodigoProceso - PK & Código del proceso \\
\hline CodigoProyecto - FK & Código del proyecto \\
\hline Nombre & Nombre del proceso \\
\hline Nivel & $\begin{array}{l}\text { Nivel del processo (Macro, processo, } \\
\text { subproceso, actividad o tarea) }\end{array}$ \\
\hline UsuarioCreacion & Usuario de creación del registro \\
\hline UsuarioModificacion & Usuario de la modificación del registro \\
\hline FechaCreacion & Fecha de creación del registro \\
\hline FechaModificacion & Fecha de modificación del registro \\
\hline
\end{tabular}


Riesgo

Tabla de registro de los riesgos de alto nivel y bajo nivel del proyecto

\begin{tabular}{|c|c|}
\hline Campo & Descripción \\
\hline CodigoRiesgo - PK & Código del riesgo \\
\hline CodigoProceso $-\mathrm{FK}$ & Código del proceso \\
\hline Nombre & Nombre del riesgo \\
\hline Descripcion & Descripción del riesgo \\
\hline Tipo & Si es de alto nível o bajo nível \\
\hline Ponderado & $\begin{array}{l}\text { Ponderado de acuerdo a la evaluación de los } \\
\text { criterios de riesgos de probabilidad e impacto } \\
\text { ( } 3 \times 3=1 \text { - Bajo, } 2 \text { - Medio y } 3 \text { - alto; } 4 \times 4= \\
1 \text { - bajo, } 2 \text { - medio, } 3 \text { - alto, } 4 \text { - extremo, y } \\
5 \times 5=1 \text { - más bajo, } 2 \text { - bajo, } 3 \text { - medio, } 4 \text { - } \\
\text { alto y } 5 \text { - extremo) }\end{array}$ \\
\hline UsuarioCreacion & Usuario de creación del registro \\
\hline UsuarioModificacion & Usuario de la modificación del registro \\
\hline FechaCreacion & Fecha de creación del registro \\
\hline FechaModificacion & Fecha de modificación del registro \\
\hline
\end{tabular}

\section{CriterioRiesgo}

Tabla de registro de los criterios de los riesgos del proyecto

\begin{tabular}{|l|l|}
\hline Campo & Descripción \\
\hline CodigoCriterioRiesgo - PK & Código del critério del riesgo \\
\hline CodigoRiesgo - FK & Código del riesgo \\
\hline Nombre & Nombre del criterio del riesgo \\
\hline Descripcion & Descripción del critério del riesgo \\
\hline Tipo & Si es cualitativo o cuantitativo \\
\hline Categoria & Si es probabilidad o impacto \\
\hline Valor & Valor de acuerdo a la matriz del proyecto ( \\
& $3 x 3=1-$ Bajo, $2-$ Medio y $3-$ alto; $4 \times 4=$ \\
& $1-$ bajo, $2-$ medio, $3-$ alto, $4-$ extremo , y \\
& $5 x 5=1-$ más bajo, $2-$ bajo, $3-$ medio, $4-$ \\
& alto y $5-$ extremo) \\
\hline UsuarioCreacion & Usuario de creación del registro \\
\hline UsuarioModificacion & Usuario de la modificación del registro \\
\hline FechaCreacion & Fecha de creación del registro \\
\hline FechaModificacion & Fecha de modificación del registro \\
\hline &
\end{tabular}

\section{CriterioProceso}

Tabla de registro de los criterios de los procesos del proyecto

\begin{tabular}{|l|l|}
\hline Campo & Descripción \\
\hline CodigoCriterioProceso- PK & Código del critério del proceso \\
\hline CodigoProceso - FK & Código del proceso \\
\hline
\end{tabular}




\section{()}

\begin{tabular}{|l|l|}
\hline Nombre & Nombre del critério del proceso \\
\hline Descripcion & Descripción del critério del proceso \\
\hline Valor & Valor de acuerdo a la matriz del proyecto ( \\
& $3 \times 3=1-$ Bajo, $2-$ Medio y $3-$ alto; $4 \times 4=$ \\
& $1-$ bajo, $2-$ medio, $3-$ alto, $4-$ extremo, y \\
& $5 \times 5=1-$ más bajo, $2-$ bajo, $3-$ medio, $4-$ \\
& alto y 5 - extremo) \\
\hline UsuarioCreacion & Usuario de creación del registro \\
\hline UsuarioModificacion & Usuario de la modificación del registro \\
\hline FechaCreacion & Fecha de creación del registro \\
\hline FechaModificacion & Fecha de modificación del registro \\
\hline
\end{tabular}

\section{PlanAuditoria}

Tabla de registro de las visitas al cliente sobre los procesos a auditar del proyecto

\begin{tabular}{|l|l|}
\hline Campo & Descripción \\
\hline CodigoPlanAuditoria - PK & Código del plan de auditoría \\
\hline CodigoProceso - FK & Código del proceso \\
\hline FechaInicio & Fecha de inicio de la visita al cliente \\
\hline FechaFin & Fecha de fin de la visita al cliente \\
\hline PorcentajeAvance & Porcentaje de avance de la visita \\
\hline UsuarioCreacion & Usuario de creación del registro \\
\hline UsuarioModificacion & Usuario de la modificación del registro \\
\hline FechaCreacion & Fecha de creación del registro \\
\hline FechaModificacion & Fecha de modificación del registro \\
\hline
\end{tabular}

\section{Control}

Tabla de registro de los controles que tienen los riesgos de bajo nivel

\begin{tabular}{|l|l|}
\hline Campo & Descripción \\
\hline CodigoControl - PK & Código del control \\
\hline CodigoRiesgo - FK & Código del riesgo de bajo nivel \\
\hline Nombre & Nombre del control \\
\hline Descripcion & Descripción del control \\
\hline UsuarioCreacion & Usuario de creación del registro \\
\hline UsuarioModificacion & Usuario de la modificación del registro \\
\hline FechaCreacion & Fecha de creación del registro \\
\hline FechaModificacion & Fecha de modificación del registro \\
\hline
\end{tabular}

\section{DisenioControl}

Tabla de registro del diseño de los atributos que contiene cada control

\begin{tabular}{|l|l|}
\hline Campo & Descripción \\
\hline CodigoDisenioControl - PK & Código del diseño del control \\
\hline CodigoControl - FK & Código del control \\
\hline
\end{tabular}




\section{(4)}

\begin{tabular}{|l|l|}
\hline Tipo & Si es preventivo o detectivo \\
\hline Duenio & Nombre del dueño del control \\
\hline Naturaleza & Si es manual, automático o semiautomático \\
\hline Frecuencia & $\begin{array}{l}\text { Si es diario, semanal, mensual, bianual o } \\
\text { anual }\end{array}$ \\
\hline Clave & Si es clave o no el control \\
\hline Evidencia & $\begin{array}{l}\text { Detalle descriptivo de la evidencia vista en el } \\
\text { control }\end{array}$ \\
\hline Observacion & $\begin{array}{l}\text { Descripción de alguna observación del } \\
\text { diseño del control }\end{array}$ \\
\hline Estado & $\begin{array}{l}\text { Los estados son: con limitaciones, no } \\
\text { iniciado, en proceso o concluido }\end{array}$ \\
\hline Resultado & Si es efectivo o no efectivo el diseño \\
\hline UsuarioCreacion & Usuario de creación del registro \\
\hline UsuarioModificacion & Usuario de la modificación del registro \\
\hline FechaCreacion & Fecha de creación del registro \\
\hline FechaModificacion & Fecha de modificación del registro \\
\hline
\end{tabular}

\section{OperatividadControl}

Tabla de registro de las pruebas que se harán a cada control que haya pasado la evaluación de diseño de controles

\begin{tabular}{|l|l|}
\hline Campo & Descripción \\
\hline CodigoOperatividadControl - PK & Código de la operatividad del control \\
\hline CodigoControl - FK & Código del control \\
\hline FechaInicio & Fecha inicial de la prueba \\
\hline FechaFin & Fecha fin de la prueba \\
\hline Requerimiento & $\begin{array}{l}\text { Descripción del requerimiento para evaluar } \\
\text { la prueba }\end{array}$ \\
\hline Muestra & $\begin{array}{l}\text { Descripción de la muestra obtenida para la } \\
\text { prueba }\end{array}$ \\
\hline PlanPrueba & Descripción del plan de pruebas \\
\hline NombreResponsable & Nombre del responsable de la prueba \\
\hline Estado & $\begin{array}{l}\text { Los estados son: con limitaciones, no } \\
\text { iniciado, en proceso o concluido }\end{array}$ \\
\hline Resultado & Si es efectivo o no efectivo la prueba \\
\hline RiesgoResidual & $\begin{array}{l}\text { Si ha cambiado el riesgo su ponderado inicial } \\
\text { (riesgo inherente) con respecto a las pruebas } \\
\text { hechas en el control (riesgo residual) }\end{array}$ \\
\hline UsuarioCreacion & Usuario de creación del registro \\
\hline UsuarioModificacion & \begin{tabular}{l} 
Usuario de la modificación del registro \\
\hline FechaCreacion
\end{tabular} \\
\hline FechaModificacion & Fecha de creación del registro \\
\hline
\end{tabular}




\section{PlanAccion}

Tabla de registro del plan de acción sale en base a los controles con resultado No efectivo que salen de las tablas de DisenioControl y OperatividadControl

\begin{tabular}{|l|l|}
\hline Campo & Descripción \\
\hline CodigoPlanAccion - PK & Código del plan de acción \\
\hline CodigoDisenioControl - FK & Código del diseño del control \\
\hline CodigoOperatividadControl - FK & Código de la operatividad del control \\
\hline CodigoControl - FK & Código del control \\
\hline Observacion & Observación del plan de acción \\
\hline NombreResponsable & Nombre del responsable del plan de acción \\
\hline MailResponsable & Correo electrónico del responsable \\
\hline Estado & $\begin{array}{l}\text { Los estados son: No iniciado, En proceso, } \\
\text { Implementado y Vencido }\end{array}$ \\
\hline UsuarioCreacion & Usuario de creación del registro \\
\hline UsuarioModificacion & Usuario de la modificación del registro \\
\hline FechaCreacion & Fecha de creación del registro \\
\hline FechaModificacion & Fecha de modificación del registro \\
\hline
\end{tabular}

Fuente: Elaboración Propia 


\subsubsection{MATRIZ DE DATOS DE PROCESO SELECCIONADO VERSUS PROCESOS DE NEGOCIO DE LA LÍNEA DESTINO}

Tabla N ${ }^{\circ} 23$ Entidades del Proceso Versus Procesos del Negocio de la Línea Destino

\begin{tabular}{|c|c|c|c|c|c|c|c|c|c|c|}
\hline \multirow[b]{2}{*}{ Entidad } & \multicolumn{10}{|c|}{ Proceso } \\
\hline & $\underline{\underline{a}}$ & 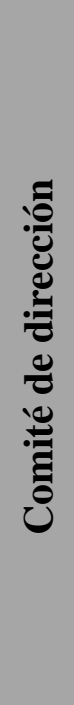 & 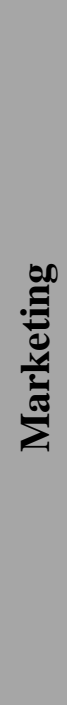 & 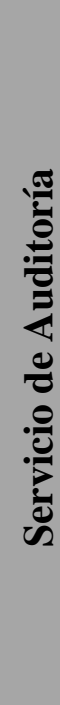 & 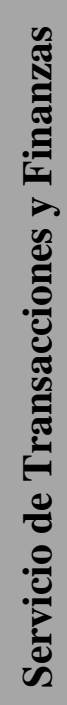 & 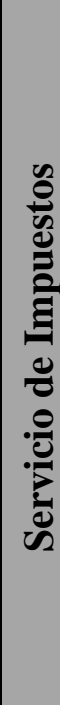 & 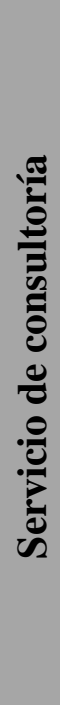 & 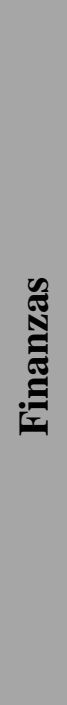 & 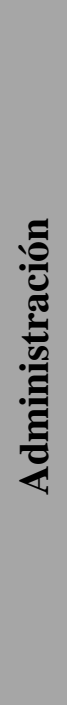 & $E$ \\
\hline Industria & & & & & & & $\mathrm{X}$ & & & \\
\hline BaseRiesgo & & & & & & & $\mathrm{X}$ & & & \\
\hline BaseControl & & & & & & & $\mathrm{X}$ & & & \\
\hline Cliente & & & & & & & $\mathrm{X}$ & & & \\
\hline Proyecto & & & & & & & $\mathrm{X}$ & & & \\
\hline Proceso & & & & & & & $\mathrm{X}$ & & & \\
\hline Riesgo & & & & & & & $\mathrm{X}$ & & & \\
\hline CriterioRiesgo & & & & & & & $\mathrm{X}$ & & & \\
\hline CriterioProceso & & & & & & & $\mathrm{X}$ & & & \\
\hline PlanAuditoria & & & & & & & $\mathrm{X}$ & & & \\
\hline Control & & & & & & & $\mathrm{X}$ & & & \\
\hline DisenioControl & & & & & & & $\mathrm{X}$ & & & \\
\hline OperatividadControl & & & & & & & $\mathrm{X}$ & & & \\
\hline PlanAccion & & & & & & & $\mathrm{X}$ & & & \\
\hline
\end{tabular}

Fuente: Elaboración Propia 


\section{(4)}

\subsubsection{ARQUITECTURA DE APLICACIONES DE LA LÍNEA DESTINO}

Tabla N ${ }^{\circ} 24$ Arquitectura de Aplicaciones de la Línea Destino

\begin{tabular}{|c|c|}
\hline Aplicación & Descripción \\
\hline LEAD & $\begin{array}{l}\text { Es una herramienta con un nuevo modelo de evaluación hacia el } \\
\text { trabajador de la organización. Esta ofrece retroalimentación } \\
\text { continua de los supervisores y también una evaluación respecto al } \\
\text { desempeño }\end{array}$ \\
\hline $\begin{array}{ll}\text { BREAT } & \text { (Bussiness } \\
\text { Relationship } & \text { Evaluation } \\
\text { tracking) } & \end{array}$ & $\begin{array}{l}\text { Es una herramienta que ayuda al usuario a evaluar un riesgo antes } \\
\text { de entablar una relación comercial con el cliente }\end{array}$ \\
\hline $\begin{array}{l}\text { PACE (Process for } \\
\text { Acceptance of Clients } \\
\text { and Engagements) }\end{array}$ & $\begin{array}{l}\text { Es una herramienta que ayuda al usuario a cumplir con las leyes y } \\
\text { normas profesionales aplicables que protege a la organización de } \\
\text { posibles riesgos reglamentarios, estratégicos y reputacionales al } \\
\text { aceptar a un posible cliente o proyecto }\end{array}$ \\
\hline $\begin{array}{l}\text { GT\&E (Global Time \& } \\
\text { Expense) }\end{array}$ & $\begin{array}{l}\text { Es una herramienta donde el trabajador tiene que reportar todas las } \\
\text { horas por semana que ha realizado de acuerdo a los diferentes } \\
\text { proyectos donde este asignado }\end{array}$ \\
\hline Discover & $\begin{array}{l}\text { Es una herramienta para encontrar información sobre las líneas de } \\
\text { servicios de EY, compartiendo información entre comunidades y } \\
\text { personas en todo el mundo }\end{array}$ \\
\hline $\begin{array}{l}\text { GFIS (Global financial } \\
\text { information system) }\end{array}$ & $\begin{array}{l}\text { Es una herramienta que ofrece: conferencias, talleres de TIC y e- } \\
\text { learning, trabajo en grupo, aprendizaje basado en problemas } \\
\text { centrados en la industria, presentaciones, una serie de seminarios } \\
\text { con expertos de la industria y visitas educativas a las oficinas } \\
\text { centrales de organizaciones de Servicios Financieros. }\end{array}$ \\
\hline $\begin{array}{l}\text { ARMEY (Assessment } \\
\text { Risk Management Ernst } \\
\text { and Young) }\end{array}$ & $\begin{array}{l}\text { Es la herramienta que se encargará del trabajo de la Auditoría } \\
\text { Interna de Riesgos }\end{array}$ \\
\hline
\end{tabular}

Fuente: Elaboración Propia 


\section{()}

\subsubsection{MATRIZ DE APLICACIONES VERSUS PROCESOS DE NEGOCIO DE LA LÍNEA DESTINO}

Tabla N ${ }^{\circ} 25$ Matriz de Aplicación Versus Procesos del Negocio de la Línea Destino

\begin{tabular}{|c|c|c|c|c|c|c|c|c|c|c|}
\hline \multirow{2}{*}{ Aplicación } & \multicolumn{10}{|c|}{ Proceso } \\
\hline & $\underline{\underline{z}}$ & 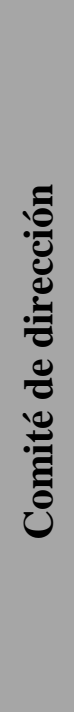 & 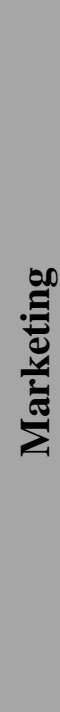 & 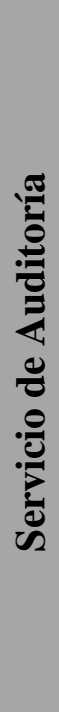 & 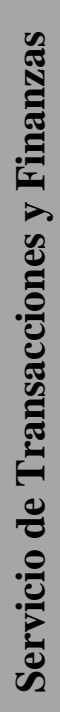 & 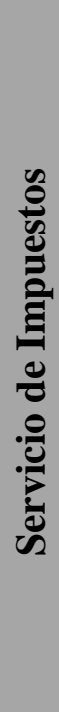 & 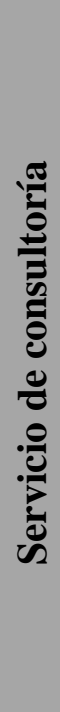 & : & 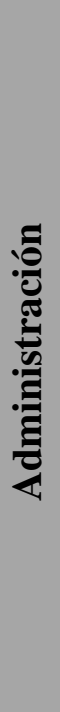 & F \\
\hline LEAD & & & & $X$ & $X$ & $X$ & $X$ & & & \\
\hline $\begin{array}{l}\text { BREAT (Bussiness } \\
\text { Relationship } \\
\text { Evaluation tracking) }\end{array}$ & & & & $X$ & $X$ & $X$ & $X$ & & & \\
\hline $\begin{array}{l}\text { PACE (Process for } \\
\text { Acceptance of Clients } \\
\text { and Engagements) }\end{array}$ & & & & $X$ & $X$ & $X$ & $X$ & & & \\
\hline $\begin{array}{l}\text { GT\&E (Global Time } \\
\text { \& Expense) }\end{array}$ & & & & $X$ & $X$ & $X$ & $X$ & & & \\
\hline Discover & & & & $X$ & $X$ & $X$ & $X$ & & & \\
\hline $\begin{array}{l}\text { GFIS (Global financial } \\
\text { information system) }\end{array}$ & & & & $X$ & $X$ & X & $X$ & & & \\
\hline $\begin{array}{l}\text { ARMEY (Assessment } \\
\text { Risk Management } \\
\text { Ernst and Young) }\end{array}$ & & & & & & & $X$ & & & \\
\hline
\end{tabular}

Fuente: Elaboración Propia 


\subsubsection{ARQUITECTURA TECNOLÓGICA DE LA LINEA DESTINO}

Para la implantación y despliegue de la aplicación en el servidor de EY Global (Sede Estados Unidos), se ha visto la necesidad de optar por el uso de un servicio situado en la nube (Windows Azure). Por el motivo que EY Global tiene unas restricciones para que el servidor contenga la aplicación propuesta (ver limitaciones de la organización). 


\section{(1)}

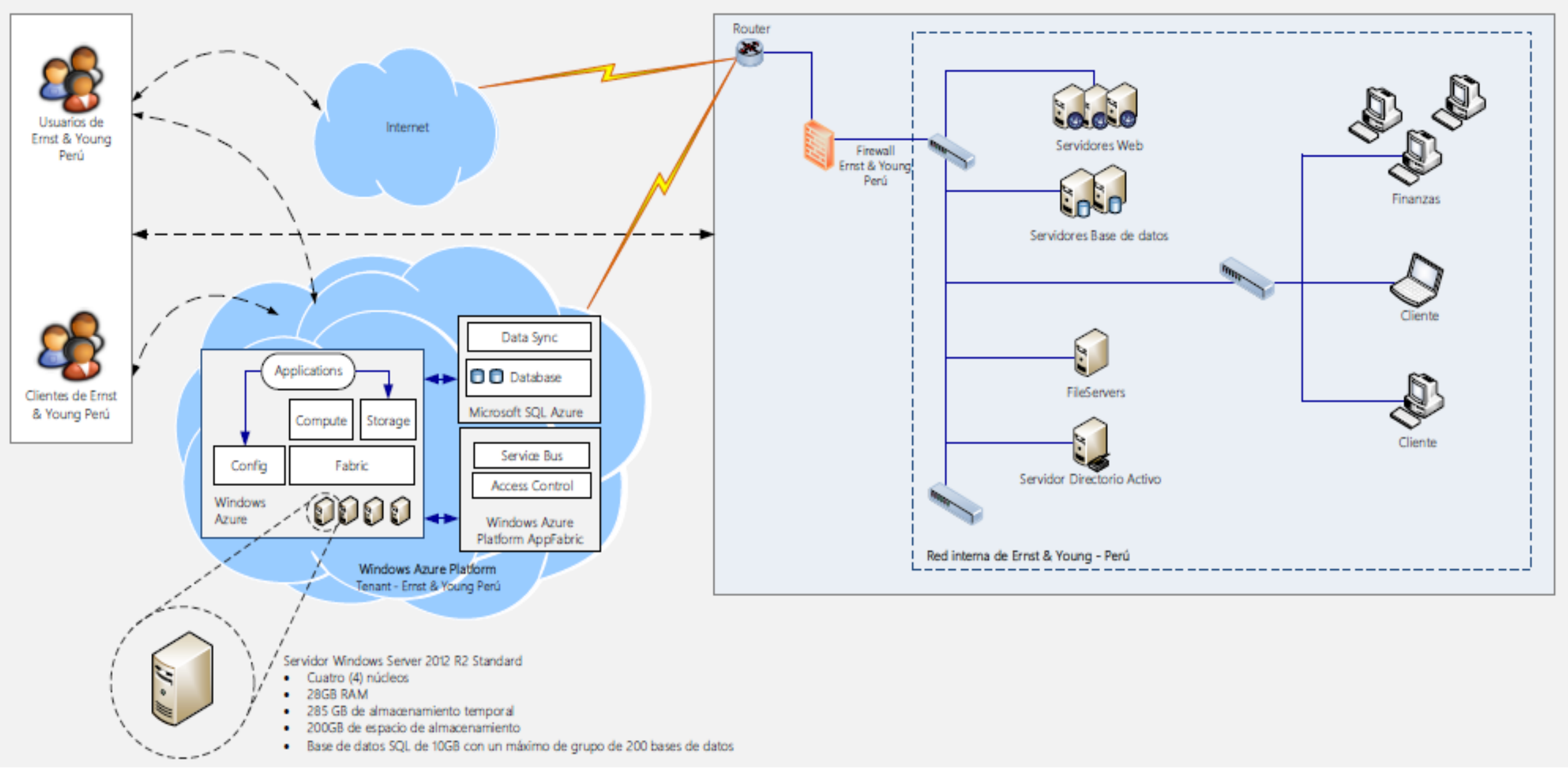

Figura $\mathrm{N}^{\circ} 23$ Arquitectura Tecnológica de la Línea Destino

Fuente: Elaboración del Proveedor 


\section{(1)}

Tabla $N^{\circ} 26$ Descripción de los Dispositivos de la Arquitectura Tecnológica de la Línea Destino

\begin{tabular}{|c|c|c|}
\hline $\mathbf{N}^{\circ}$ & Nombre del Dispositivo & Descripción \\
\hline 1 & Internet & $\begin{array}{l}\text { Servicio utilizado para la intercomunicación de redes } \\
\text { mediante el uso de protocolos TCP/IP, para el uso } \\
\text { dentro y fuera de la organización. }\end{array}$ \\
\hline 2 & Firewall & $\begin{array}{l}\text { Dispositivo encargado de brindar seguridad ante } \\
\text { intrusiones a la red (IPS). }\end{array}$ \\
\hline 3 & Modem & $\begin{array}{l}\text { Dispositivo que convierte las señales digitales } \\
\text { en analógicas y viceversa, permite así la } \\
\text { comunicación entre computadoras. }\end{array}$ \\
\hline 4 & Router & $\begin{array}{l}\text { Dispositivo que proporciona conectividad a nivel de } \\
\text { red o nivel tres en el modelo OSI. Su función } \\
\text { principal consiste en enviar o encaminar paquetes de } \\
\text { datos de una red a otra. }\end{array}$ \\
\hline 5 & Servidor Proxy & $\begin{array}{l}\text { Es una interfaz de comunicación que actúa como } \\
\text { intermediaria entre dos sistemas informáticos, como } \\
\text { el navegador de un ordenador o móvil y la propia red } \\
\text { de Internet. }\end{array}$ \\
\hline 6 & Servidor Exchange & $\begin{array}{l}\text { Servido Exchange } 2013 \text { que se utiliza para gestionar } \\
\text { los correos de la organización y es posible el acceso } \\
\text { desde las laptops, por el SmartPhone y por el OWA. }\end{array}$ \\
\hline 7 & Servidor Active Directory & $\begin{array}{l}\text { Servidor que permite almacenar información relativa } \\
\text { de los recursos de una red con el fin de facilitar su } \\
\text { localización y administración. }\end{array}$ \\
\hline 8 & Servidor de Aplicaciones & $\begin{array}{l}\text { Servidor donde se encuentran las aplicaciones de la } \\
\text { organización. }\end{array}$ \\
\hline 9 & Servidor de Base de datos & $\begin{array}{l}\text { Servidor que contiene las bases de datos de la } \\
\text { organización. }\end{array}$ \\
\hline 10 & $\begin{array}{l}\text { Servidor de Aplicación } \\
\text { espejo }\end{array}$ & $\begin{array}{l}\text { Servidor de respaldo de las aplicaciones de la } \\
\text { organización. }\end{array}$ \\
\hline 11 & $\begin{array}{l}\text { Servidor de Base de datos } \\
\text { espejo }\end{array}$ & Servidor de respaldo de base de datos. \\
\hline 12 & Servidor File server & Servidor de almacenamiento de archivos físicos. \\
\hline 13 & Servidor File server espejo & Respaldo de los archivos guardados en el File Server \\
\hline 14 & Laptop & $\begin{array}{l}\text { Computadora portátil, puede ser llevada a cualquier } \\
\text { lado debido a su funcionamiento a través de una } \\
\text { batería o de electricidad. }\end{array}$ \\
\hline 15 & Office 2013 & $\begin{array}{l}\text { Es una suite ofimática que abarca el mercado } \\
\text { completo en Internet e interrelaciona aplicaciones de } \\
\text { escritorio, servidores y servicios para los sistemas } \\
\text { operativos entre los que se usan herramientas para la } \\
\text { organización como Excel, Word y Power Point. }\end{array}$ \\
\hline
\end{tabular}




\section{()}

\begin{tabular}{|c|l|l|}
\hline 16 & Windows Azure & $\begin{array}{l}\text { Servicio ubicado en la nube ofrecida como servicio y } \\
\text { alojado en los Data Centers de Microsoft }\end{array}$ \\
\hline 17 & Microsoft SQL Azure & $\begin{array}{l}\text { Servicio provisto desde Microsoft, referente a proveer } \\
\text { almacenamiento y seguridad en cuanto a base de datos } \\
\text { pero basado en un 100\% en la nube. }\end{array}$ \\
\hline 18 & $\begin{array}{l}\text { Windows Azure Platform } \\
\text { AppFabric }\end{array}$ & $\begin{array}{l}\text { Servicio proveído por Microsoft para que los } \\
\text { usuarios implementen y administren flujos de trabajo } \\
\text { Windows Workflow Foundation (WF) alojados en } \\
\text { los servicios de Windows Communication } \\
\text { Foundation (WCF). Incluye, Internet Information } \\
\text { Services (IIS) que permite administrar el } \\
\text { rendimiento de los servicios y flujos de trabajo. }\end{array}$ \\
\hline
\end{tabular}

Fuente: Elaboración Propia

\subsubsection{MATRIZ TECNOLÓGICA VERSUS PROCESOS DE NEGOCIO DE LA LÍNEA DESTINO}

Tabla N²7 Matriz de Aplicación Versus Procesos del Negocio de la Línea Destino

\begin{tabular}{|c|c|c|c|c|c|c|c|c|c|c|}
\hline \multirow[b]{2}{*}{ Tecnológico } & \multicolumn{10}{|c|}{ Proceso } \\
\hline & $\begin{array}{l}\underline{\underline{Z}} \\
\underline{\alpha}\end{array}$ & 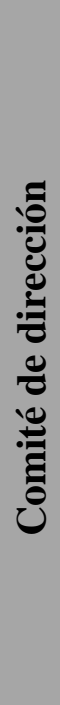 & 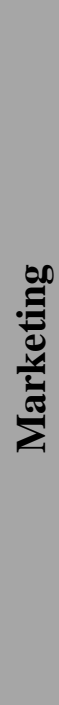 & 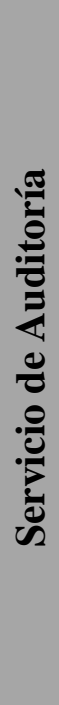 & 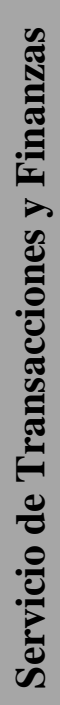 & 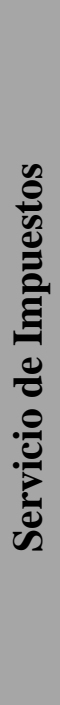 & 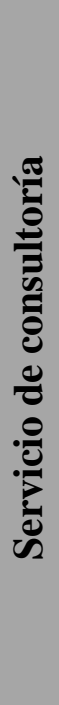 & 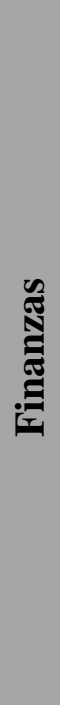 & 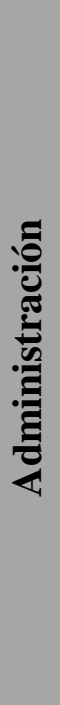 & F \\
\hline Internet & $\mathrm{X}$ & $\mathrm{X}$ & $X$ & $\mathrm{X}$ & $X$ & $X$ & $X$ & $X$ & $X$ & $X$ \\
\hline Firewall & $\mathrm{X}$ & $X$ & $\mathrm{X}$ & $\mathrm{X}$ & $X$ & $\mathrm{X}$ & $\mathrm{X}$ & $X$ & $\mathrm{X}$ & $X$ \\
\hline Modem & $\mathrm{X}$ & $\mathrm{X}$ & $\mathrm{X}$ & $\mathrm{X}$ & $X$ & $\mathrm{X}$ & $X$ & $X$ & $\mathrm{X}$ & $\mathrm{X}$ \\
\hline
\end{tabular}




\section{(4)}

\begin{tabular}{|l|c|c|c|c|c|c|c|c|c|c|}
\hline Router & X & X & X & X & X & X & X & X & X & X \\
\hline Servidor Proxy & X & X & X & X & X & X & X & X & X & X \\
\hline Servidor Exchange & X & X & X & X & X & X & X & X & X & X \\
\hline Active Directory & X & X & X & X & X & X & X & X & X & X \\
\hline $\begin{array}{l}\text { Servidor de } \\
\text { Aplicaciones }\end{array}$ & X & X & X & X & X & X & X & X & X & X \\
\hline $\begin{array}{l}\text { Servidor de Base de } \\
\text { datos }\end{array}$ & $\mathrm{X}$ & $\mathrm{X}$ & $\mathrm{X}$ & $\mathrm{X}$ & $\mathrm{X}$ & $\mathrm{X}$ & $\mathrm{X}$ & $\mathrm{X}$ & $\mathrm{X}$ & $\mathrm{X}$ \\
\hline $\begin{array}{l}\text { Servidor de Aplicación } \\
\text { espejo }\end{array}$ & & & & & & & & & & $\mathrm{X}$ \\
\hline $\begin{array}{l}\text { Servidor de Base de } \\
\text { datos espejo }\end{array}$ & & & & & & & & & & $\mathrm{X}$ \\
\hline Servidor File server & $\mathrm{X}$ & $\mathrm{X}$ & $\mathrm{X}$ & $\mathrm{X}$ & $\mathrm{X}$ & $\mathrm{X}$ & $\mathrm{X}$ & $\mathrm{X}$ & $\mathrm{X}$ & $\mathrm{X}$ \\
\hline $\begin{array}{l}\text { Servidor File server } \\
\text { espejo }\end{array}$ & & & & & & & & & & $\mathrm{X}$ \\
\hline Laptop & $\mathrm{X}$ & $\mathrm{X}$ & $\mathrm{X}$ & $\mathrm{X}$ & $\mathrm{X}$ & $\mathrm{X}$ & $\mathrm{X}$ & $\mathrm{X}$ & $\mathrm{X}$ & $\mathrm{X}$ \\
\hline Office 2013 & $\mathrm{X}$ & $\mathrm{X}$ & $\mathrm{X}$ & $\mathrm{X}$ & $\mathrm{X}$ & $\mathrm{X}$ & $\mathrm{X}$ & $\mathrm{X}$ & $\mathrm{X}$ & $\mathrm{X}$ \\
\hline Windows Azure & & & & & & & $\mathrm{X}$ & & & \\
\hline Microsoft SQL Azure & & & & & & & X & & & \\
\hline $\begin{array}{l}\text { Windows Azure } \\
\text { Platform AppFabric }\end{array}$ & & & & & & & $\mathrm{X}$ & & & \\
\hline
\end{tabular}

Fuente: Elaboración Propia

\subsection{ANÁLISIS DE BRECHAS}

\subsubsection{ANÁLISIS DE BRECHAS DEL NEGOCIO}


Tabla N²8 Análisis de Brechas - Arquitectura de Negocio

\begin{tabular}{|c|c|c|c|c|c|c|c|c|c|c|c|c|c|c|c|c|c|c|c|}
\hline \multirow[b]{2}{*}{\begin{tabular}{|c} 
\\
Arquitectura \\
Línea Base
\end{tabular}} & \multicolumn{19}{|c|}{ Arquitectura Destino } \\
\hline & $\begin{array}{l}\text { Realiz } \\
\text { ar } \\
\text { taller } \\
\text { de } \\
\text { proces } \\
\text { os }\end{array}$ & $\begin{array}{l}\text { Brin } \\
\text { dar } \\
\text { los } \\
\text { proc } \\
\text { eso } \\
\text { para } \\
\text { la } \\
\text { audit } \\
\text { oría }\end{array}$ & \begin{tabular}{|l|} 
Identif \\
icar el \\
tipo de \\
matriz \\
del \\
proyec \\
to
\end{tabular} & $\begin{array}{l}\text { Identif } \\
\text { icar } \\
\text { los } \\
\text { riesgos } \\
\text { de alto } \\
\text { nivel } \\
\text { de los } \\
\text { proces } \\
\text { os }\end{array}$ & $\begin{array}{l}\text { Evaluar } \\
\text { los } \\
\text { riegos } \\
\text { de alto } \\
\text { nivel } \\
\text { por } \\
\text { probabil } \\
\text { idad e } \\
\text { impacto }\end{array}$ & $\begin{array}{l}\text { Vali } \\
\text { dar } \\
\text { resul } \\
\text { tado } \\
\text { de } \\
\text { riesg } \\
\text { os de } \\
\text { alto } \\
\text { nivel }\end{array}$ & $\begin{array}{l}\text { Prior } \\
\text { izar } \\
\text { los } \\
\text { proc } \\
\text { esos }\end{array}$ & $\begin{array}{l}\text { Crea } \\
\text { r el } \\
\text { plan } \\
\text { de } \\
\text { audit } \\
\text { oría }\end{array}$ & \begin{tabular}{|l|} 
Identificar \\
los riesgos \\
de bajo \\
nivel y \\
controles \\
de los \\
procesos \\
dados en \\
el plan de \\
auditoría
\end{tabular} & \begin{tabular}{|l|} 
Evalua \\
r los \\
riesgos \\
de \\
bajo \\
nivel \\
por \\
probab \\
ilidad \\
e \\
impact \\
o
\end{tabular} & $\begin{array}{l}\text { Vali } \\
\text { dar } \\
\text { resul } \\
\text { tado } \\
\text { de } \\
\text { riesg } \\
\text { os de } \\
\text { bajo } \\
\text { nivel }\end{array}$ & \begin{tabular}{|l} 
Evalua \\
$\mathrm{r}$ \\
diseño \\
de \\
control \\
es
\end{tabular} & \begin{tabular}{|l} 
Evalua \\
r la \\
operati \\
vidad \\
de \\
control \\
es
\end{tabular} & $\begin{array}{l}\text { Vali } \\
\text { dar } \\
\text { resul } \\
\text { tado } \\
\text { de } \\
\text { oper } \\
\text { ativi } \\
\text { dad } \\
\text { de } \\
\text { contr } \\
\text { oles }\end{array}$ & $\begin{array}{l}\text { Crear } \\
\text { el plan } \\
\text { de } \\
\text { acción } \\
\text { de los } \\
\text { control } \\
\text { es } \\
\text { fallido } \\
\text { s }\end{array}$ & $\begin{array}{l}\text { Crea } \\
\text { r el } \\
\text { plan } \\
\text { de } \\
\text { acció } \\
\text { n de } \\
\text { los } \\
\text { contr } \\
\text { oles } \\
\text { fallid } \\
\text { os }\end{array}$ & $\begin{array}{l}\text { Dar } \\
\text { resulta } \\
\text { do de } \\
\text { operati } \\
\text { vidad } \\
\text { y plan } \\
\text { de } \\
\text { acción } \\
\text { de } \\
\text { control } \\
\text { es }\end{array}$ & $\begin{array}{l}\text { Dar una } \\
\text { base de } \\
\text { conocimie } \\
\text { nto sobre } \\
\text { riesgos de } \\
\text { bajo nivel } \\
\text { y alto } \\
\text { nivel con } \\
\text { controles } \\
\text { por } \\
\text { industria }\end{array}$ & $\begin{array}{l}\text { ELIM } \\
\text { INAR }\end{array}$ \\
\hline $\begin{array}{l}\text { Realizar taller de } \\
\text { procesos }\end{array}$ & M & & & & & & & & & & & & & & & & & & \\
\hline $\begin{array}{l}\text { Brindar los proceso } \\
\text { para la auditoría }\end{array}$ & & M & & & & & & & & & & & & & & & & & \\
\hline $\begin{array}{l}\text { Identificar el tipo de } \\
\text { matriz del proyecto }\end{array}$ & & & M & & & & & & & & & & & & & & & & \\
\hline $\begin{array}{l}\text { Identificar los riesgos } \\
\text { de alto nivel de los } \\
\text { procesos }\end{array}$ & & & & A & & & & & & & & & & & & & & & \\
\hline $\begin{array}{l}\text { Evaluar los riegos de } \\
\text { alto nivel por } \\
\text { probabilidad e } \\
\text { impacto }\end{array}$ & & & & & A & & & & & & & & & & & & & & \\
\hline $\begin{array}{l}\text { Validar resultado de } \\
\text { riesgos de alto nivel }\end{array}$ & & & & & & & & & & & & & & & & & & & \\
\hline Priorizar los procesos & & & & & & & $\mathrm{A}$ & & & & & & & & & & & & \\
\hline
\end{tabular}




\section{(}

Crear el plan de

auditoría

Identificar los riesgos

de bajo nivel y

controles de los

procesos dados en el

plan de auditoría

Evaluar los riesgos de

bajo nivel por

probabilidad e

impacto

Validar resultado de

riesgos de bajo nivel

Evaluar diseño de

controles

Evaluar la

operatividad de

controles

Validar resultado de

operatividad de

controles

Crear el plan de

acción de los

controles fallidos

Generar resultado de

operatividad y plan

de acción de

controles

Dar resultado de

operatividad y plan

de acción de

controles

NUEVO

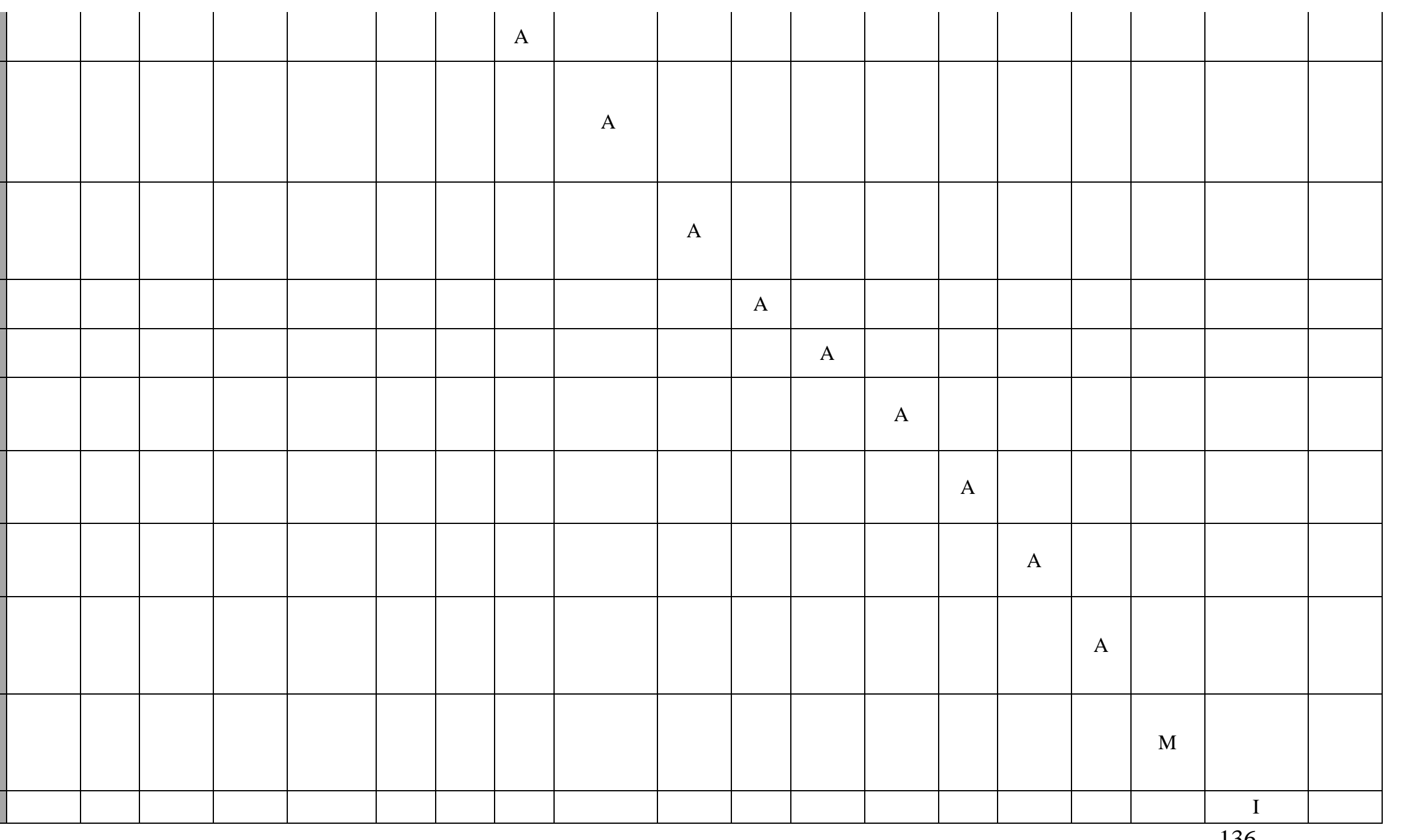




\section{(4)}

M - Mantener A - Actualizar I - Implementar E - Eliminar

Fuente: Elaboración Propia 


\section{(1)}

GAPS Arquitectura de Negocio:

- GAP 01: Se propone actualizar la forma de trabajo de identificar los riesgos de alto nivel de los procesos mediante el uso de un formulario que agilice la realización del trabajo del equipo y donde cada miembro pueda tener centralizada su información para trabajarla en cualquier lugar. Además, de contar con información de proyectos pasados como referencia para los nuevos proyectos, que ayudará en mejorar los tiempos por ejemplo en caso de proyectos parecidos y/o recurrentes.

- GAP 02: Se propone actualizar la forma de trabajo de la evaluación de los riesgos de alto nivel mediante el uso de un formulario que permita mostrar los riesgos de alto nivel con sus criterios de riesgos (los criterios saldrán en base a la matriz seleccionada 3x3, 4x4 o $5 \times 5$ y de acuerdo a la industria del cliente, con opción a personalizar la información de los criterios), cuyo criterio pueden ser de categoría de probabilidad e impacto y que son de tipo cualitativo y/o cuantitativo.

- GAP 03: Se propone actualizar la forma de trabajo de la validación de los riesgos de alto nivel mediante el uso de un formulario que el Gerente puede gestionar lo realizado por su equipo y dar retroalimentación en caso se necesario.

- GAP 04: Se propone actualizar la forma de trabajo de la priorización de los procesos mediante el uso de un formulario, donde el equipo realiza la priorización de acuerdo a dos ponderaciones. En primer lugar, sobre los valores obtenidos de la ponderación de los riesgos entidad y, además de la ponderación de los procesos, basados en los criterios de proceso. La suma de esas dos ponderaciones da una puntuación donde se ordenará cada 


\section{(1)}

proceso, dando así el resultado sobre que procesos se dará prioridad en las visitas por parte del equipo al cliente.

- GAP 05: Se propone actualizar la forma de trabajo de crear el plan de auditoría mediante el uso de un formulario donde el equipo pueda gestionar las visitas de cada miembro del equipo para auditar los procesos que se han priorizado.

- GAP 06: Se propone actualizar la forma de trabajo de identificar los riesgos de bajo nivel y sus controles mediante el uso de un formulario donde al equipo se les brinda información predefinida de riesgos y controles por industria y se le facilite la identificación de los mismos. Adicionalmente, el equipo puede personalizar esa información cambiando la información o agregando si estos lo consideran necesario. Además, de poder utilizar información de proyectos pasados para el desarrollo del trabajo.

- GAP 07: Se propone actualizar la forma de trabajo de la evaluación de los riesgos de bajo nivel mediante el uso de una formulario que permita mostrar los riesgos con sus criterios de riesgos (los criterios saldrán en base a la matriz seleccionada $3 \times 3,4 \times 4$ o $5 \times 5$ y de acuerdo a la industria del cliente, con opción a personalizar la información de los criterios), cuyo criterio pueden ser de categoría de probabilidad e impacto y que son de tipo cualitativo y/o cuantitativo (los criterios se obtienen de los riesgos de alto nivel, que aplicará la misma metodología de evaluación para el caso de riesgos de bajo nivel).

- GAP 08: Se propone actualizar la forma de trabajo de la validación de los riesgos de bajo nivel mediante el uso de un formulario que el Gerente puede gestionar lo realizado por su equipo y dar retroalimentación en caso se necesario.

- GAP 09: Se propone actualizar la forma de trabajo de evaluar el diseño del control mediante el uso de un formulario donde el equipo pueda registrar los atributos de cada 


\section{(1)}

control identificado en los procesos del plan de auditoría. Luego, el equipo evalúa si el control es efectivo o no efectivo para luego evaluar la operatividad del mismo.

- GAP 10: Se propone actualizar la forma de trabajo de evaluar la operatividad del control mediante el uso de un formulario donde el equipo pueda realizar la evaluación correspondiente en base a los atributos asignados en el diseño del control.

- GAP 11: Se propone actualizar la forma de trabajo de validar el resultado de la operatividad del control mediante el uso de un formulario que el Gerente puede gestionar lo realizado por su equipo y dar retroalimentación en caso se necesario.

- GAP 12: Se propone actualizar la forma de trabajo de crear el plan de acción de los controles fallidos (en caso que el control haya dado como resultado no efectivo tanto en la evaluación de diseño u operatividad) mediante el uso de un formulario el equipo gestiona un panel de control dando observaciones para mejorarlo o eliminar el fallo.

- GAP 13: Se propone implementar una base de conocimiento sobre riegos de alto y bajo nivel y los controles asociados a sus distintas industrias. Esto ayuda como una guía de desarrollo del trabajo de auditoría de riegos para el miembro del equipo.

\subsubsection{ANÁLISIS DE BRECHAS DE DATOS}

Tabla Nº 29 Análisis de Brechas - Arquitectura de Datos

\section{Arquitectura Destino}

\begin{tabular}{|c|c|c|c|c|c|c|c|c|c|c|c|c|c|c|c|}
\hline $\begin{array}{c}\text { Arquitect } \\
\text { ura Línea } \\
\text { Base }\end{array}$ & $\begin{array}{l}\text { Ind } \\
\text { ust } \\
\text { ria }\end{array}$ & $\begin{array}{l}\text { Base } \\
\text { Riesg } \\
\text { o }\end{array}$ & $\begin{array}{l}\text { BaseC } \\
\text { ontrol }\end{array}$ & $\begin{array}{l}\text { Clie } \\
\text { nte }\end{array}$ & $\begin{array}{l}\text { Pro } \\
\text { yec } \\
\text { to }\end{array}$ & $\begin{array}{l}\text { Proc } \\
\text { eso }\end{array}$ & Riesgo & $\begin{array}{l}\text { Criterio } \\
\text { Riesgo }\end{array}$ & $\begin{array}{l}\text { Crite } \\
\text { rioPr } \\
\text { oces } \\
\text { oce }\end{array}$ & $\begin{array}{l}\text { Pudi } \\
\text { toria }\end{array}$ & $\begin{array}{l}\text { Cont } \\
\text { rol }\end{array}$ & $\begin{array}{l}\text { Disenio } \\
\text { Control }\end{array}$ & $\begin{array}{l}\text { Operat } \\
\text { ividad } \\
\text { Contro } \\
\text { l }\end{array}$ & $\begin{array}{l}\text { PlanA } \\
\text { ccion }\end{array}$ & $\begin{array}{l}\text { ELI } \\
\text { MIN } \\
\text { AR }\end{array}$ \\
\hline NUEVO & I & I & I & I & I & I & I & I & I & I & I & I & I & I & \\
\hline
\end{tabular}




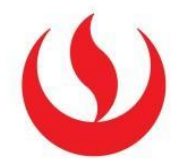

Fuente: Elaboración Propia

GAPS Arquitectura de Datos:

- GAP 14: Implementar la entidad "Industria" para registrar la información correspondiente de las industrias del cliente.

- GAP 15: Implementar la entidad "BaseRiesgo" para tener información cargada de los riesgos de alto y bajo nivel por industria.

- GAP 16: Implementar la entidad "BaseControl" para tener información cargada de los controles de cada riesgo de alto nivel.

- GAP 17: Implementar la entidad "Cliente" para registrar la información correspondiente del cliente como también a que industria este pertenece.

- GAP 18: Implementar la entidad "Proyecto" para registrar la información correspondiente a los proyectos del cliente.

- GAP 19: Implementar la entidad "Proceso" para registrar los procesos que se van va a auditar de acuerdo al proyecto.

- GAP 20: Implementar la entidad "Riesgo" para registrar los riesgos de alto nivel y bajo nivel que correspondan a los procesos del proyecto.

- GAP 21: Implementar la entidad "CriterioRiesgo" para registrar los criterios de riesgo del riesgo (alto nivel y bajo nivel) que pueden ser de categoría de probabilidad e impacto y de tipo cualitativo y/o cuantitativo. 
- GAP 22: Implementar la entidad "CriterioProceso" para registrar los criterios de proceso del proceso.

- GAP 23: Implementar la entidad "PlanAuditoria" para registrar los periodos de visita de los procesos que se van a auditar.

- GAP 24: Implementar la entidad "Control" para registrar los controles de los riesgos de bajo nivel que serán evaluados.

- GAP 25: Implementar la entidad "DisenioControl" para registrar la evaluación del diseño de los atributos que tendrá cada control, para que luego sea evaluado por el equipo.

- GAP 26: Implementar la entidad "OperatividadControl" para registrar la evaluación de la operatividad del control y dar como resultado el estado del mismo.

- GAP 27: Implementar la entidad "PlanAccion" para registrar los planes de acción a considerar cuando un control tiene fallas y en base a esto, se dan consideraciones a tomar en cuenta para el cliente. 


\section{(1)}

\subsubsection{ANÁLISIS DE BRECHAS DE APLICACIONES}

Tabla N 30 Análisis de Brechas - Arquitectura de Aplicaciones

\begin{tabular}{|c|c|c|c|c|c|c|c|c|}
\hline \multirow[b]{2}{*}{$\begin{array}{l}\text { Arquitectura } \\
\text { Línea Base }\end{array}$} & \multicolumn{8}{|c|}{ Arquitectura Destino } \\
\hline & $\begin{array}{l}\text { LEA } \\
\text { D }\end{array}$ & \begin{tabular}{|l} 
BREAT \\
(Bussines \\
$\mathrm{s}$ \\
Relations \\
hip \\
Evaluatio \\
$\mathrm{n}$ \\
tracking)
\end{tabular} & $\begin{array}{l}\text { PACE } \\
\text { (Process } \\
\text { for } \\
\text { Accepta } \\
\text { nce of } \\
\text { Clients } \\
\text { and } \\
\text { Engage } \\
\text { ments) }\end{array}$ & $\begin{array}{l}\text { GT\&E } \\
\text { (Global } \\
\text { Time \& } \\
\text { Expense } \\
\text { ) }\end{array}$ & \begin{tabular}{|l|} 
Disco \\
ver
\end{tabular} & $\begin{array}{l}\text { GFIS } \\
\text { (Global } \\
\text { financial } \\
\text { informati } \\
\text { on } \\
\text { system) }\end{array}$ & \begin{tabular}{|l} 
ARMEY \\
(Assessme \\
nt Risk \\
Manageme \\
nt Ernst \\
and \\
Young)
\end{tabular} & ELIMINAR \\
\hline LEAD & $M$ & & & & & & & \\
\hline $\begin{array}{l}\text { BREAT } \\
\text { (Bussiness } \\
\text { Relationship } \\
\text { Evaluation } \\
\text { tracking) }\end{array}$ & & M & & & & & & \\
\hline $\begin{array}{l}\text { PACE (Process } \\
\text { for Acceptance of } \\
\text { Clients and } \\
\text { Engagements) }\end{array}$ & & & M & & & & & \\
\hline $\begin{array}{l}\text { GT\&E (Global } \\
\text { Time \& Expense) }\end{array}$ & & & & M & & & & \\
\hline Discover & & & & & M & & & \\
\hline $\begin{array}{l}\text { GFIS (Global } \\
\text { financial } \\
\text { information } \\
\text { system) }\end{array}$ & & & & & & M & & \\
\hline NUEVO & & & & & & & I & \\
\hline
\end{tabular}

Fuente: Elaboración Propia

GAPS Arquitectura de Aplicaciones 


\section{(1)}

- GAP 28: Implementar un sistema de Auditoría Interna de Riesgos que trabaje los proyectos del cliente de forma automatizada mediante la información obtenida de la base al conocimiento de la organización. 


\subsubsection{ANÁLISIS DE BRECHAS DE ARQUITECTURA TECNOLÓGICA}

Tabla $N^{\circ} 31$ Análisis de Brechas - Arquitectura Tecnológica

\begin{tabular}{|c|c|c|c|c|c|c|c|c|c|c|c|c|c|c|c|c|c|c|c|}
\hline & \multicolumn{19}{|c|}{ Arquitectura Destino } \\
\hline $\begin{array}{l}\text { Arquitectura } \\
\text { Línea Base }\end{array}$ & $\stackrel{\vec{U}}{\stackrel{\Xi}{\Xi}}$ & 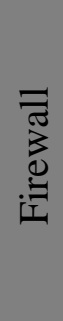 & 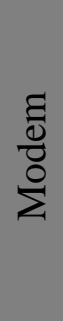 & 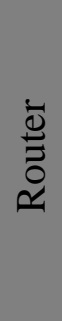 & 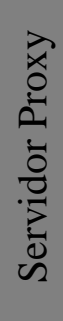 & 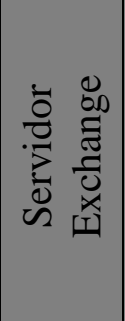 & 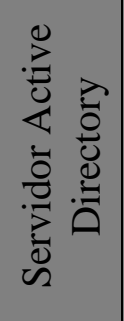 & 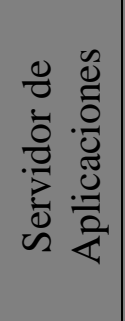 & 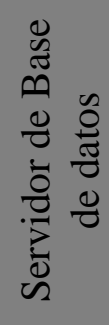 & 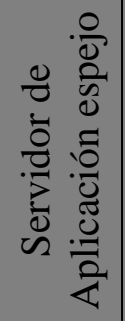 & 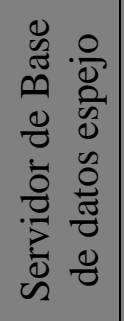 & 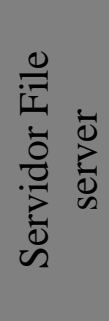 & 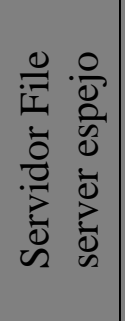 & 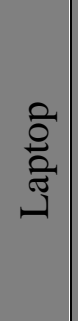 & 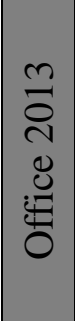 & 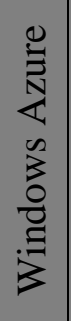 & 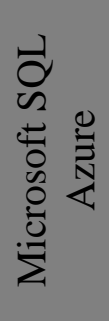 & 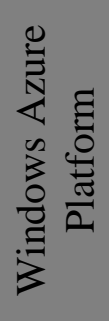 & 竞 \\
\hline Internet & $\mathrm{M}$ & & & & & & & & & & & & & & & & & & \\
\hline Firewall & & $\mathrm{M}$ & & & & & & & & & & & & & & & & & \\
\hline Modem & & & $\mathrm{M}$ & & & & & & & & & & & & & & & & \\
\hline Router & & & & $\mathrm{M}$ & & & & & & & & & & & & & & & \\
\hline Servidor Proxy & & & & & M & & & & & & & & & & & & & & \\
\hline \begin{tabular}{|l} 
Servidor \\
Exchange
\end{tabular} & & & & & & M & & & & & & & & & & & & & \\
\hline \begin{tabular}{|l|} 
Servidor Active \\
Directory \\
\end{tabular} & & & & & & & $\mathrm{M}$ & & & & & & & & & & & & \\
\hline \begin{tabular}{|l} 
Servidor de \\
Aplicaciones
\end{tabular} & & & & & & & & M & & & & & & & & & & & \\
\hline
\end{tabular}




\section{$(1$}

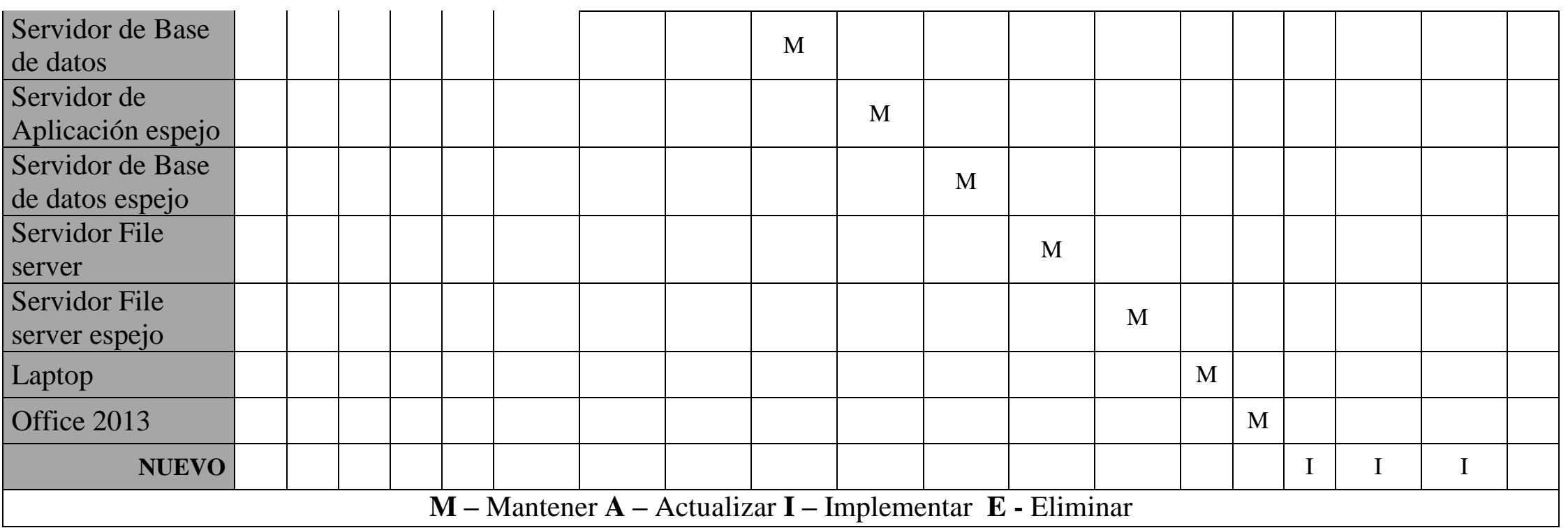

Fuente: Elaboración Propia 


\section{(1)}

GAPS Arquitectura Tecnológica

- GAP 29: Implementar un servicio tecnológico en la nube llamado Windows Azure, para usarlo para desplegar el desarrollo de la aplicación de la propuesta hecha en la arquitectura empresarial.

- GAP 30: Implementar en base al servicio de Windows Azure (GAP 29), un servicio de base de datos llamado Microsoft SQL Azure como repositorio de información de la base de conocimiento de los proyectos ejecutados en la Auditoría Interna de Riesgos.

- GAP 31: Implementar en base al servicio de Windows Azure (GAP 29), un gestor de servicios llamado Windows Azure Platform para desplegar el proyecto que se va a desarrollar como parte de la propuesta y solución dadas en la arquitectura empresarial. 


\subsection{EVALUACIÓN DEL IMPACTO}

Tabla N 32 Mapa de Riesgos de Probabilidad e Impacto

\begin{tabular}{|c|c|c|c|c|c|}
\hline \multirow{2}{*}{ Probabilidad } & \multicolumn{5}{|c|}{ Impacto } \\
\hline & Muy Bajo (0.10) & Bajo (0.25) & Medio (0.50) & Alto (0.75) & Muy Alto (1.00) \\
\hline \multicolumn{6}{|l|}{ Muy Probable (0.90) } \\
\hline \multicolumn{6}{|l|}{ Probable $(0.70)$} \\
\hline \multicolumn{6}{|l|}{ Moderado (0.50) } \\
\hline \multicolumn{6}{|l|}{ Bajo (0.30) } \\
\hline \multicolumn{6}{|l|}{ Muy Bajo (0.10) } \\
\hline Leyenda & & & & & \\
\hline & $\mathrm{Mu}$ & Bajo & Medio & Alto & Muy Alto \\
\hline
\end{tabular}

Fuente: Elaboración Propia

Tabla ํㅜ 33 Evaluación del Impacto

\begin{tabular}{|c|c|c|c|c|c|c|c|}
\hline \multicolumn{8}{|c|}{ Matriz de riesgo } \\
\hline $\mathbf{N}^{\circ}$ & Riesgo & Probabilidad & Impacto & Resultado & Estrategia & Responsable & Respuesta a Riesgo \\
\hline 1 & $\begin{array}{l}\text { Resistencia } \\
\text { al cambio }\end{array}$ & 0.7 & 1 & 0.70 & $\begin{array}{l}\text { Bondades } \\
\text { que ofrece } \\
\text { el } \\
\text { desarrollo }\end{array}$ & $\begin{array}{l}\text { Auditor } \\
\text { Senior y } \\
\text { Asistente }\end{array}$ & $\begin{array}{l}\text { Dar una charla previa a los usuarios que utilizarán la } \\
\text { solución tecnológica (antes de la ejecución del } \\
\text { desarrollo), sobre las bondades que ofrece usar una nueva } \\
\text { forma de trabajar los proyectos. Explicar, por ejemplo, de }\end{array}$ \\
\hline
\end{tabular}




\begin{tabular}{|c|c|c|c|c|c|c|c|}
\hline & & & & & $\begin{array}{l}\text { de una } \\
\text { nueva } \\
\text { forma de } \\
\text { trabajar }\end{array}$ & & $\begin{array}{l}\text { que se tendrá una base de conocimiento de la información } \\
\text { para que sean utilizadas en el caso de personas de no } \\
\text { mucha experiencia encontrar información más rápida y } \\
\text { así no tener pérdidas de tiempo en su trabajo. Otra podría } \\
\text { ser que la información estará integrada y centralizado por } \\
\text { parte del equipo de proyecto de Auditoría Interna de } \\
\text { Riesgos. }\end{array}$ \\
\hline 2 & $\begin{array}{l}\text { Sistema no } \\
\text { amigable }\end{array}$ & 0.4 & 1 & 0.40 & $\begin{array}{l}\text { Revisión } \\
\text { de diseño } \\
\text { de interfaz } \\
\text { con } \\
\text { usuario }\end{array}$ & $\begin{array}{c}\text { Gerente de } \\
\text { Proyecto, } \\
\text { Gerente de } \\
\text { Consultoría, } \\
\text { Senior y } \\
\text { Asistente }\end{array}$ & $\begin{array}{l}\text { Se propone revisar el diseño de la interface tanto con el } \\
\text { Gerente, Senior y asistente para tener un consenso de la } \\
\text { aprobación de los formularios de diseño mostrados. }\end{array}$ \\
\hline 3 & $\begin{array}{l}\text { Falta de } \\
\text { disponibilid } \\
\text { ad del } \\
\text { Gerente de } \\
\text { Consultoría } \\
\text { a las } \\
\text { reuniones }\end{array}$ & 0.30 & 0.90 & 0.27 & $\begin{array}{l}\text { Empoderar } \\
\text { al Gerente } \\
\text { de } \\
\text { Consultoría } \\
\text { para que } \\
\text { participe } \\
\text { en las } \\
\text { reuniones } \\
\text { de Sprint } \\
\text { Planning y } \\
\text { Sprint } \\
\text { Review }\end{array}$ & $\begin{array}{l}\text { Gerente de } \\
\text { Proyecto }\end{array}$ & $\begin{array}{l}\text { El Gerente de Proyecto (Scrum Master) debe empoderar } \\
\text { al Gerente de Consultoría (Product Owner) haciéndole } \\
\text { saber que es la persona más importante para que el } \\
\text { proyecto tenga éxito y que necesita que participe de los } \\
\text { Sprint Planning (priorizar y planear el nuevo Sprint en } \\
\text { base al Product Backlog creado por el Product Owner) y } \\
\text { Sprint Review (revisión del producto funcionando de } \\
\text { acuerdo al Sprint ejecutado). }\end{array}$ \\
\hline 4 & $\begin{array}{l}\text { Cambiar el } \\
\text { alcance y/o } \\
\text { requerimien }\end{array}$ & 0.25 & 1.00 & 0.25 & $\begin{array}{l}\text { Tener un } \\
\text { repositorio } \\
\text { (Product }\end{array}$ & $\begin{array}{c}\text { Gerente de } \\
\text { Consultoría }\end{array}$ & $\begin{array}{l}\text { El Gerente de consultoría (Product Owner) da la } \\
\text { aceptación formal sobre el alcance y los requerimientos } \\
\text { funcionales (User Stories o historias de usuario) que }\end{array}$ \\
\hline
\end{tabular}




\begin{tabular}{|c|c|c|c|c|c|c|c|}
\hline & $\begin{array}{l}\text { tos una vez } \\
\text { iniciado el } \\
\text { proyecto }\end{array}$ & & & & $\begin{array}{l}\text { Backlog ) } \\
\text { donde el } \\
\text { Gerente de } \\
\text { Consultoría } \\
\text { registre y } \\
\text { cambie su } \\
\text { alcance o }\end{array}$ & & $\begin{array}{l}\text { serán registrados en el Product Backlog . Luego, en los } \\
\text { eventos de Sprint Planning, se realiza un refinamiento de } \\
\text { los nuevos requerimientos existentes o creados por el } \\
\text { Gerente de Consultoría, para luego priorizar el Product } \\
\text { Backlog y crear el(los) siguiente(s) Sprint(s) por el } \\
\text { equipo de desarrollo. De esta manera, se controla que a } \\
\text { pesar que haya cambios en el ciclo de vida del proyecto, } \\
\text { se puede ir controlando los cambios dados en todo } \\
\text { momento. }\end{array}$ \\
\hline 5 & $\begin{array}{l}\text { Alta } \\
\text { rotación de } \\
\text { personal } \\
\text { bien } \\
\text { calificado }\end{array}$ & 0.20 & 1.00 & 0.20 & $\begin{array}{l}\text { Dar } \\
\text { incentivos }\end{array}$ & $\begin{array}{l}\text { Gerente } \\
\text { RRHH }\end{array}$ & $\begin{array}{l}\text { Brindar incentivos para a los miembros clave para el } \\
\text { éxito del proyecto no se vea afectado. }\end{array}$ \\
\hline 6 & $\begin{array}{l}\text { Falta de } \\
\text { disponibilid } \\
\text { ad de } \\
\text { recursos } \\
\text { para el } \\
\text { desarrollo }\end{array}$ & 0.10 & 1.00 & 0.10 & $\begin{array}{l}\text { Calendariz } \\
\text { ar recursos }\end{array}$ & $\begin{array}{l}\text { Gerente de } \\
\text { Proyecto }\end{array}$ & $\begin{array}{l}\text { Antes de comenzar con el desarrollo del proyecto, } \\
\text { realizar un calendario de los recursos que van a forma } \\
\text { parte del equipo de desarrollo del proyecto y así } \\
\text { contratarlos por el tiempo estimado según el cronograma } \\
\text { de actividades. }\end{array}$ \\
\hline 7 & $\begin{array}{l}\text { Falta de } \\
\text { pago de } \\
\text { servicio de } \\
\text { la nube para } \\
\text { el proyecto }\end{array}$ & 0.05 & 1.00 & 0.05 & $\begin{array}{l}\text { Realizar un } \\
\text { pago } \\
\text { automático } \\
\text { del servicio }\end{array}$ & $\begin{array}{l}\text { Gerente de } \\
\text { Finanzas }\end{array}$ & $\begin{array}{l}\text { Afiliar con el proveedor del servicio un pago automático } \\
\text { a fin de no tener retrasos en el pago del servicio, que } \\
\text { conlleva a perder la accesibilidad de la aplicación. }\end{array}$ \\
\hline
\end{tabular}




\begin{tabular}{|l|l|l|l|l|l|l|l|}
\hline 8 & $\begin{array}{l}\text { Falta del } \\
\text { plan de } \\
\text { pruebas }\end{array}$ & 0.04 & 1.00 & 0.04 & $\begin{array}{l}\text { Realizar } \\
\text { casos de } \\
\text { prueba de } \\
\text { los flujos } \\
\text { de trabajo }\end{array}$ & $\begin{array}{l}\text { Equipo de } \\
\text { proyecto }\end{array}$ & $\begin{array}{l}\text { El equipo de proyecto debe realizar los casos de prueba } \\
\text { correspondiente al proyecto, en base a los requerimientos } \\
\text { funcionales definidos por los interesados. Además, que } \\
\text { estos casos de prueba sean evaluados por los usuarios } \\
\text { finales para ver si salen incidentes durante las pruebas, } \\
\text { para la futura corrección. }\end{array}$ \\
\hline 9 & $\begin{array}{l}\text { Fallo de } \\
\text { conexión de } \\
\text { acceso al } \\
\text { servicio a } \\
\text { internet }\end{array}$ & 0.02 & 1.00 & 0.02 & $\begin{array}{l}\text { Tener } \\
\text { contratos } \\
\text { con } \\
\text { distintos } \\
\text { proveedore } \\
\text { sde } \\
\text { servicio }\end{array}$ & $\begin{array}{l}\text { Gerente de } \\
\text { Proyecto }\end{array}$ & $\begin{array}{l}\text { Contar con distintos proveedores de servicio de internet } \\
\text { para tener alta disponibilidad de acceso al internet y } \\
\text { poder navegar dentro del sistema de Auditoría Interna de } \\
\text { Riesgos. }\end{array}$ \\
\hline 10 & $\begin{array}{l}\text { Tareas no } \\
\text { programado } \\
\text { s }\end{array}$ & 0.10 & 0.50 & 0.05 & $\begin{array}{l}\text { Tener un } \\
\text { repositorio } \\
\text { (Product } \\
\text { Backlog }) \\
\text { donde se } \\
\text { puede } \\
\text { realizar el } \\
\text { seguimient } \\
\text { o y control } \\
\text { de todas las } \\
\text { tareas }\end{array}$ & $\begin{array}{l}\text { Gerente de } \\
\text { Consultoría }\end{array}$ & $\begin{array}{l}\text { El Gerente de Consultoría (Product Owner) tiene el } \\
\text { registro de todas las tareas o requerimientos (User Stories } \\
\text { o historias de usuario) en un repositorio llamado Product } \\
\text { Backlog . Para luego, conjuntamente con el equipo de } \\
\text { desarrollo hacer seguimiento y control de todas las tareas } \\
\text { según la priorización que se haya realizado. Por último, } \\
\text { en base a la priorización se crea los Sprints que se van a } \\
\text { ejecutar de acuerdo a iteraciones durante el ciclo de vida } \\
\text { del desarrollo del proyecto, de este modo se controla que } \\
\text { todas las tareas se desarrollen. }\end{array}$ \\
\hline
\end{tabular}

Fuente: Elaboración Propia 


\section{(4)}

\subsection{OPORTUNIDADES Y SOLUCIONES}

\subsection{ESTRATEGIA DE IMPLEMENTACIÓN Y MIGRACIÓN}

\subsection{DIRECCIÓN DE LA IMPLEMENTACIÓN ESTRATÉGICA}

Se deben considerar los siguientes puntos importantes:

- El espónsor debe describir el objetivo del alcance del proyecto para mejorar y/o automatizar el subproceso de Auditoría Interna de Riesgos y que con esta mejora se pueda reflejar en tiempo y/o dinero.

- El espónsor debe contar con el presupuesto y recursos necesarios para la realización del proyecto.

- El espónsor debe contar con un ambiente para el desarrollo del proyecto por parte del equipo y contar un servidor para realizar el despliegue del proyecto en ambientes de desarrollo, testeo y producción.

- Una de las cosas principales cosas que se debe realizar en el proyecto, es involucrar a todos los interesados clave (socio y gerentes de Auditoría Interna de Riesgos) en cada reunión, 


\section{(1)}

para considerar todos las observaciones que puede tener el proyecto, en este caso para obtener los requerimientos para crear la planificación del proyecto.

- El equipo del proyecto debe obtener todos los requerimientos por parte de los interesados clave para planificar la lista de actividades a desarrollar para utilizarlo en la planificación del proyecto.

- Se debe contar con la aprobación de cada entregable por parte de los interesados clave en cada Sprint desarrollado donde se pueda realizar el seguimiento y control del avance del proyecto.

- El equipo debe desarrollar un plan de capacitación para los usuarios finales.

\subsection{ENFOQUE DE LA SECUENCIA DE IMPLEMENTACIÓN}

Se deben considerar la siguiente secuencia:

- El Gerente de Consultoría crea el Project Charter del proyecto.

- El Gerente de Consultoría desarrolla el alcance del proyecto.

- El Gerente de Consultoría realiza la lista de requerimientos de las funcionalidades del producto a desarrollar.

- El Gerente de Proyecto incorpora recursos al proyecto de acuerdo a lo que el espónsor ofrece como recursos disponibles.

- El Development Team crea y diseña los prototipos de las interfaces del proyecto.

- El Gerente de Consultoría aprueba los prototipos del proyecto.

- EL Gerente de Consultoría y el Development Team planifican las etapas de desarrollo de acuerdo a la lista de actividades y realizan el Product Backlog que contendrá los Sprints (cada 2 semanas) del desarrollo del producto.

- El Development Team en base a la priorización de Sprints desarrolla la solución tecnológica.

- El Gerente de Proyecto y el Development Team realiza el control y seguimiento del avance del proyecto para ver si este proyecto necesita realizar acciones preventivas o correctivas. 


\section{(1)}

- El Gerente de Consultoría realiza la revisión y la aprobación del incremento del producto de cada Sprint desarrollado.

- El Development Team realiza el despliegue del proyecto en el entorno de testeo y producción.

- El Gerente de Consultoría aprueba el entregable final del proyecto. 


\section{(1)}

\subsection{ESTRUCTURA DE DESGLOSE DEL TRABAJO}

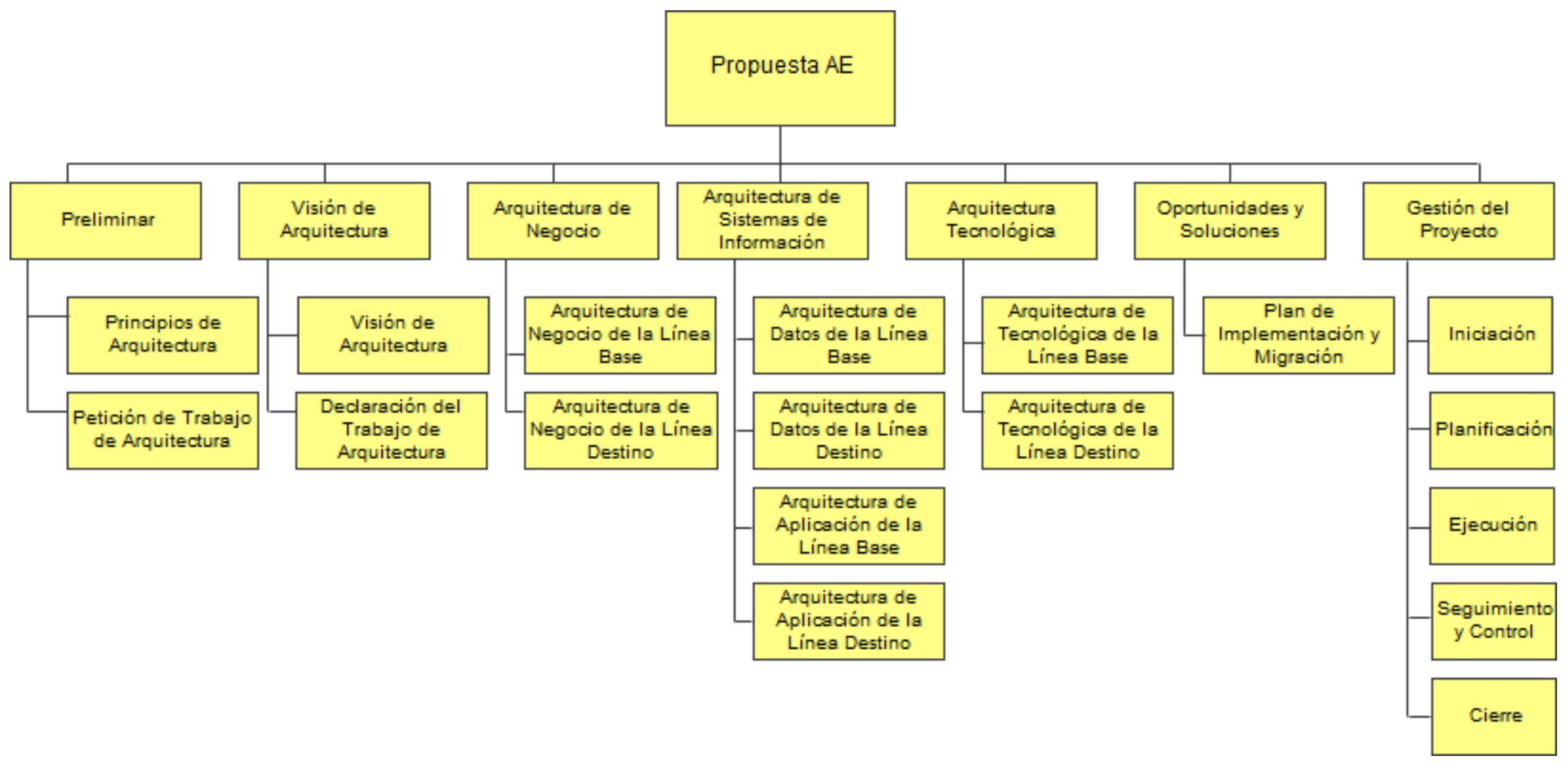

Figura $\mathrm{N}^{\circ} 24$ Estructura de Desglose del Trabajo

Fuente: Elaboración Propia 


\section{(1)}

\subsection{CUADRO DE RESUMEN DEL PLAN DE MIGRACIÓN}

Tabla N 34 Cuadro de Resumen del Plan de Migración 


\begin{tabular}{|c|c|c|c|c|c|}
\hline Brecha & Proyecto & Problema & Costos & Solución potencial & Riesgos \\
\hline $\begin{array}{l}\text { GAP 01, } \\
\text { GAP 02, } \\
\text { GAP 03, } \\
\text { GAP 04, } \\
\text { GAP 05, } \\
\text { GAP 06, } \\
\text { GAP 07, } \\
\text { GAP 08, } \\
\text { GAP 09, } \\
\text { GAP 10, } \\
\text { GAP 11, } \\
\text { GAP 12, } \\
\text { GAP 13, } \\
\text { GAP 14, } \\
\text { GAP 15, } \\
\text { GAP 16, } \\
\text { GAP 17, } \\
\text { GAP 18, } \\
\text { GAP 19, } \\
\text { GAP 20, } \\
\text { GAP 21, } \\
\text { GAP 22, } \\
\text { GAP 23, } \\
\text { GAP 24, } \\
\text { GAP 25, } \\
\text { GAP 26, } \\
\text { GAP 27, } \\
\text { GAP 28 }\end{array}$ & $\begin{array}{l}\text { Implemen } \\
\text { tación de } \\
\text { un } \\
\text { proyecto } \\
\text { de } \\
\text { Auditoría } \\
\text { Interna de } \\
\text { Riesgos }\end{array}$ & $\begin{array}{l}\text { - Registro de } \\
\text { proyectos de } \\
\text { forma } \\
\text { manual y } \\
\text { descentraliza } \\
\text { da } \\
\text { - No contar } \\
\text { con una base } \\
\text { de } \\
\text { conocimient } \\
\text { o como guía } \\
\text { para el } \\
\text { desarrollo } \\
\text { del proyecto }\end{array}$ & $\begin{array}{l}\text { - El costo } \\
\text { del } \\
\text { proyecto } \\
\text { será de } \\
\text { US\$ } \\
133,900 . \\
00\end{array}$ & $\begin{array}{l}\text { - Contar con una base } \\
\text { de conocimiento } \\
\text { como guía para el } \\
\text { trabajo de la } \\
\text { Auditoría Interna de } \\
\text { Riesgos } \\
\text { - Tener de forma } \\
\text { centralizado y } \\
\text { constante el proyecto } \\
\text { a fin de trabajarlo de } \\
\text { cualquier parte que el } \\
\text { miembro del equipo } \\
\text { se encuentre } \\
\text { El gerente puede } \\
\text { gestionar de forma } \\
\text { en tiempo real del } \\
\text { avance del proyecto } \\
\text { por parte del equipo }\end{array}$ & 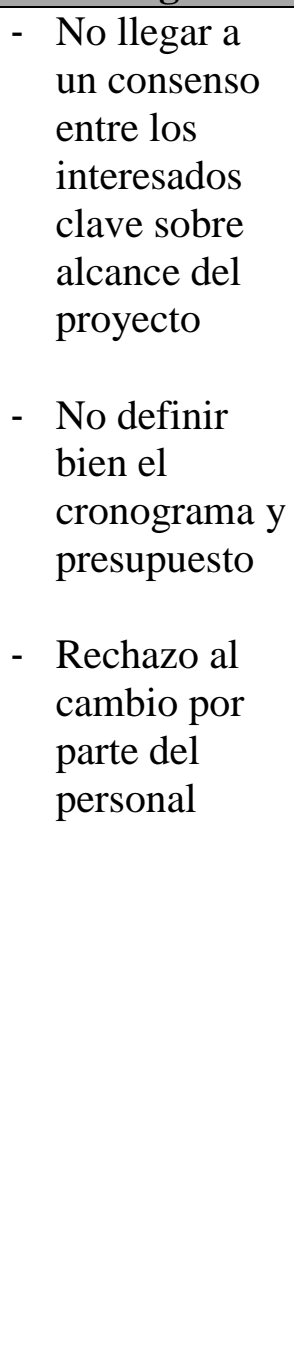 \\
\hline
\end{tabular}




\section{(4)}

\begin{tabular}{|c|c|c|c|c|c|}
\hline $\begin{array}{l}\text { GAP 29, } \\
\text { GAP 30, } \\
\text { GAP 31, }\end{array}$ & $\begin{array}{l}\text { Adquisici } \\
\text { ón de un } \\
\text { servicio } \\
\text { en la nube } \\
\text { con } \\
\text { Windows } \\
\text { Azure, } \\
\text { para un } \\
\text { proyecto } \\
\text { desarrolla } \\
\text { do con } \\
\text { Netframe } \\
\text { work } 4.5 \\
\text { y sql } 2016\end{array}$ & $\begin{array}{l}\text { En caso el } \\
\text { proyecto se } \\
\text { despliegue } \\
\text { dentro de los } \\
\text { servidores de } \\
\text { EY Global } \\
\text { (Sede Estados } \\
\text { Unidos), } \\
\text { tendría que la } \\
\text { aplicación } \\
\text { pasar un } \\
\text { tiempo } \\
\text { pruebas de de } \\
\text { auditoría que } \\
\text { será cerca de } 6 \\
\text { meses y con un } \\
\text { costo de } \$ \\
60,000.00 \\
\text { aproximadame } \\
\text { nte, que lo } \\
\text { desembolsaría } \\
\text { EY Perú }\end{array}$ & 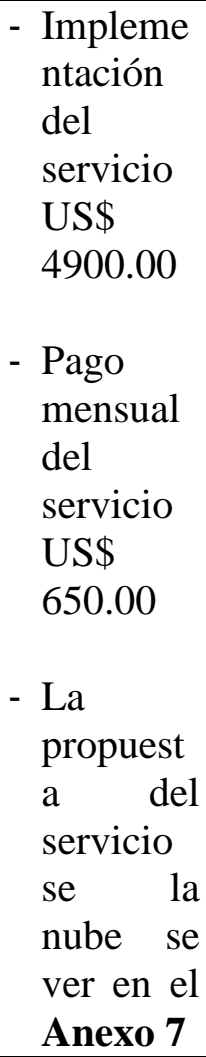 & $\begin{array}{l}\text { - No pagar a alguien por } \\
\text { realizar el soporte del } \\
\text { servidor } \\
\text { - No comprar un } \\
\text { servidor para sólo tener } \\
\text { una aplicación } \\
\text { desplegada } \\
\text { - No hacer gastos de } \\
\text { servicios de luz } \\
\text { - Tener un servicio } \\
\text { trabajando con alta } \\
\text { disponibilidad (24x7) } \\
\text { - Soporte en la seguridad } \\
\text { de la información }\end{array}$ & $\begin{array}{l}\text { - No ser dueño } \\
\text { de la } \\
\text { información } \\
\text { - Depender de } \\
\text { un servicio } \\
\text { fuera del } \\
\text { manejo de la } \\
\text { organización } \\
\text { - Pagar } \\
\text { constantemen } \\
\text { te el pago del } \\
\text { servicio }\end{array}$ \\
\hline
\end{tabular}

Fuente: Elaboración Propia

\subsection{CONCLUSIONES}

En este capítulo se han desarrollado los elementos que conforman una propuesta en base a una arquitectura empresarial mediante al arquitectura de negocio, datos, aplicaciones y tecnológica. La realización del desarrollo de la arquitectura empresarial da como resultado una solución tecnológica al subproceso de Auditoría Interna de Riesgos llama ARMEY .

Para desarrollar la propuesta, en primer lugar, se hizo un análisis de la línea base de la organización en la actualidad llamada $A S$ - IS, para luego realizar la línea base de destino $T O$ $B E$. En base a estas líneas base, se han identificado brechas de cada una de las arquitecturas, 


\section{$(1$}

para luego plantear la necesidad de desarrollar una nueva herramienta tecnológica de gestión para automatizar el proceso de trabajo de la Auditoría Interna de Riesgos.

Por último, se ha descrito el impacto de los riesgos que generaría la implementación de la presente propuesta y que estrategias se deben considerar para desarrollar de la mejor manera el proyecto. 


\section{(1)}

\section{CAPÍTULO 3. MÉTODOS ÁGILES PARA EL DESARROLLO DE SOFTWARE}

\subsection{INTRODUCCIÓN}

En el presente capítulo muestra una propuesta para utilizar un marco de trabajo ágil mediante Scrum, para el desarrollo de un proyecto de software llamado ARMY que se identificó en el capítulo 2 de la arquitectura empresarial.

Este capítulo se basa; en primer lugar, en plantear los objetivos para conocer qué beneficios se logra con el uso Scrum como forma de desarrollo de un producto tecnológico. En segundo lugar, se identifican las fortalezas y debilidades mediante un análisis interno sobre el objeto de estudio y del equipo de trabajo que conforma el proyecto mediante el uso de la herramienta FODA. En tercer lugar, se presenta un diagnóstico del grupo con la finalidad de identificar la situación actual del equipo de trabajo y los problemas que suelen tener. En cuarto lugar, se definen las dinámicas de grupos que más convienen para el bienestar del equipo de proyecto y así aprovechar las fortalezas y eliminar las debilidades. Luego, se muestra el equipo que va a conformar el proyecto, en esta parte se indica las habilidades duras y blandas que debe tener cada integrante. Posteriormente, se definen las herramientas de trabajo a utilizar. Por último, se presenta el presupuesto aplicado al proyecto de desarrollo y las conclusiones, donde se resumen los resultados de la investigación de este capítulo.

\subsection{OBJETIVOS}

Los objetivos dados al proponer un marco de trabajo ágil para el desarrollo del proyecto de Auditoría Interna de Riesgos son los siguientes:

- Realizar análisis de fortalezas y debilidades de EY.

- Establecer artefactos que se deben usar dentro del desarrollo del proyecto. 


\section{(1)}

- Obtener la flexibilidad en la planificación y gestión de proyectos de acuerde a lo que el Gerente de Consultoría quiera priorizar y lo que considere que da más valor al negocio. Con esta priorización, el Development Team podrá estar alineado a lo que desea el Gerente de Consultoría.

- Formar un equipo que tenga autonomía, responsabilidad compartida y automotivación usando para esto Scrum como marco de trabajo para alcanzar los objetivos del proyecto.

- Desarrollar por cada iteración (periodos cortos de 2 semanas) un incremento del producto de forma funcional mediante la revisión del Sprint, en la cual el Gerente de Consultoría podría dar la aprobación de lo entregado.

\subsection{IDENTIFICACIÓN DE FORTALEZAS Y DEBILIDADES}

El análisis realizado a la organización da como resultado la identificación de las fortalezas y debilidades del objeto de estudio con el fin de ofrecer estrategias que permitan brindar fortalezas y minimizar o eliminar las debilidades.

Tabla $\mathrm{N}^{\circ} 35$ Cuadro de Fortalezas

\begin{tabular}{|l|l|}
\hline Fortaleza & Descripción \\
\hline F01 - Apoyo de los socios & $\begin{array}{l}\text { Aprovechar al máximo el apoyo brindado } \\
\text { por los socios a fin de cumplir con los } \\
\text { objeticos que abarca un proyecto. }\end{array}$ \\
\hline F02 - Infraestructura tecnológica adecuada & $\begin{array}{l}\text { Aprovechar al máximo la infraestructura } \\
\text { tecnología ofrecida (hardware software) } \\
\text { para dar apoyo en primera instancia a los } \\
\text { procesos principales de la organización }\end{array}$ \\
\hline F03 - Personal capacitado & $\begin{array}{l}\text { Brindar constantes capacitaciones a fin de } \\
\text { abordar los temas que se pueden dar en cada } \\
\text { cliente. Además, se realizan capacitaciones } \\
\text { para usar nuevas herramientas en ayuda al } \\
\text { trabajo de cada miembro a fin de alinear el } \\
\text { trabajo de forma estándar en la organización. }\end{array}$ \\
\hline F04 - Personal emprendedor & $\begin{array}{l}\text { Brindar nuevas ideas de negocio para la } \\
\text { organización. En este caso, dando ideas de } \\
\text { nuevos servicios que no existen en la } \\
\text { organización hasta el momento para sus } \\
\text { clientes. }\end{array}$ \\
\hline
\end{tabular}




\section{()}

\begin{tabular}{|l|l|}
\hline F05 - Personal con perfil de liderazgo & $\begin{array}{l}\text { Los miembros de la organización pasan por } \\
\text { diferentes facetas o cargos durante su carrera } \\
\text { profesional dentro de la organización y } \\
\text { lleguen a desarrollar la habilidad para liderar } \\
\text { equipos de proyectos del cliente. }\end{array}$ \\
\hline F06 - Personal comprometido & $\begin{array}{l}\text { Los miembros de la organización se sienten } \\
\text { comprometidos en cada proyecto que se les } \\
\text { involucra, lo que hace que se identifiquen } \\
\text { con la organización y brindan de la mejor } \\
\text { manera su trabajo hacia el cliente. }\end{array}$ \\
\hline F07 - Personal experimentado & $\begin{array}{l}\text { Los miembros de la organización tienen } \\
\text { mucho conocimiento, ya que han participado } \\
\text { de varios proyectos, lo que los hacen que } \\
\text { tengan gran experiencia y puedan ayudar } \\
\text { como consultor para otros miembros con } \\
\text { menos conocimiento para el desarrollo de sus } \\
\text { proyectos. }\end{array}$ \\
\hline F08 - Clima laboral ideal & $\begin{array}{l}\text { Los líderes de los proyectos motivan de } \\
\text { forma constante a sus equipos (equipos de } \\
\text { alto desempeño) a fin de que se sientan en un } \\
\text { ambiente grato para ellos. }\end{array}$ \\
\hline F09 - Poder Adquisitivo & $\begin{array}{l}\text { Invertir en la creación o compra de nuevos } \\
\text { productos tecnológicos para brindarlos a los } \\
\text { miembros o clientes de la organización. }\end{array}$ \\
\hline el ámbito tecnológico & $\begin{array}{l}\text { Tener soporte en el uso de nuevas } \\
\text { tecnologías para automatizar los procesos de } \\
\text { trabajo de las líneas de servicios y de la } \\
\text { organización. }\end{array}$ \\
\hline
\end{tabular}

Fuente: Elaboración Propia

Tabla $N^{\circ} 36$ Cuadro de Debilidades

\begin{tabular}{|l|l|}
\hline Debilidad & Estrategia de oportunidad \\
\hline D01 - Falta de un plan estratégico de TI & $\begin{array}{l}\text { De acuerdo a la fortaleza definida en el } \\
\text { punto F01, los socios están de acuerdo del } \\
\text { uso de un plan de estratégico para cumplir } \\
\text { con los objetivos de la organización } \\
\text { mediante el uso de la tecnología }\end{array}$ \\
\hline $\begin{array}{l}\text { D02 - Falta de base de conocimientos como } \\
\text { ayuda para miembros sin experiencia en el } \\
\text { desarrollo de proyectos de los clientes }\end{array}$ & $\begin{array}{l}\text { De acuerdo a la fortaleza definida en el } \\
\text { punto F07, los miembros experimentados } \\
\text { pueden brindar su conocimiento para tomarlo } \\
\text { como una base de conocimiento y utilizarlo } \\
\text { como ayuda para los nuevos miembros de la } \\
\text { organización a fin de que puedan desarrollar } \\
\text { sus proyectos y obtener más experiencia }\end{array}$ \\
\hline
\end{tabular}




\section{(4)} mejora de procesos de trabajo dentro de las líneas de servicio que presta la organización hacia sus clientes requerimientos funcionales por parte de los subordinados y no de los interesados clave
D03 - Bajo desarrollo de aplicaciones para la

D04 - Falta de definición clara de algunos

De acuerdo a la fortaleza definida en el punto F01 y F04, los socios y los miembros de las líneas de servicio pueden tomar la decisión de realizar proyectos internos de desarrollo de aplicaciones para automatizar los diferentes procesos de trabajo que realizan los miembros de la organización para el cliente

De acuerdo a la fortaleza definida en el punto F06, los interesados clave se deben de comprometer a realizar la definición de los requerimientos a fin de crear los entregables que van a abarcar en el ciclo de vida de cada proyecto

D05 - Falta de disponibilidad de interesados clave en el desarrollo de proyectos

De acuerdo a la fortaleza definida en el punto F06, los interesados clave se deben de comprometer a tener las reuniones correspondientes (según calendario) a fin de alinear los requerimientos funcionales con el equipo del proyecto

D06 - No existe el concepto de gestión de proyectos de sistemas mediante un marco ágil con Scrum

D07 - Hay burocracia para desplegar nuevas soluciones tecnológicas en la organización por parte de EY Global (políticas internas)
De acuerdo a la fortaleza definida en el punto F03, se debe realizar capacitaciones de gestión de proyectos mediante Scrum, para concientizar a los miembros de la organización y que entiendan la forma de trabajo para el desarrollo de proyectos de sistemas tanto para la iniciación, planificación, ejecución, monitoreo y cierre.

De acuerdo a la fortaleza definida en el punto F09 y F10, se propone el uso de un servicio tercerizado (servicio en la nube de Windows llamada Azure), que ayude a desplegar los nuevos sistemas creados dentro de la organización

Fuente: Elaboración Propia

\subsection{DIAGNÓSTICO DEL GRUPO}

Actualmente, el proceso misional llamada Consultoría contiene un subproceso de trabajo llamada Auditoría de Interna de Riesgos, que realiza su trabajo de forma manual mediante el programa Excel de Microsoft. En la cual, el trabajo comienza, cuando un cliente solicita la auditoría para algún (nos) de su(s) procesos. Luego, un equipo conformado por un Gerente (Líder) y su equipo (Senior y/o Asistentes) van al cliente y realizan un taller para el 


\section{(1)}

levantamiento de requerimientos de información, entre lo que se obtienen los procesos y sus objetivos que se van a auditar. Luego, todos los que conforman el equipo de auditoria, identifican los riesgos a alto nivel (riesgos generales) que están asociados a estos procesos. Posteriormente, en una reunión se ponen a analizar los riesgos de alto nivel y se evalúan con criterios de probabilidad e impacto para saber el nivel (estos pueden ser de 3 niveles: bajo, medio y alto; 4 niveles: bajo, moderado, alto y extremo, y 5 niveles: Muy bajo, bajo, moderado, alto y extremo) con lo que el equipo tiene que trabajar según esta priorización a fin de realizar un cronograma de trabajo (plan de auditoría) para visitar al cliente y mitigar los procesos correspondiente a esta evaluación. Además de esto, se crean riesgos de bajo nivel (riesgos más al detalle) que están asociados a los riesgos de alto nivel. Estos riegos, al igual que los riesgos de alto nivel, serán evaluados en base a los criterios definidos en los riesgos evaluados inicialmente. Adicionalmente, estos riesgos contienen controles que servirán para evaluar la operatividad, para saber si un control es Efectivo (Aprobado) o No Efectivo (Fallido) y verificar si el riesgo asociado al control a variado en base a la evaluación dada inicialmente (riesgo inherente) hasta el nivel final (riesgo residual). Por último, si el control fue No Efectivo, se realizará un plan de acción para rectificar el fallo del control por parte de un responsable del cliente.

Todo el trabajo realizado por parte del equipo va siendo observado por el Gerente y este da la conformidad del trabajo que está realizando el equipo. Una vez que el trabajo es observado y aceptado, va siendo integrado en cada momento, por lo que hay pérdida de tiempo en la integración por parte del equipo y; por último, el Gerente da la aceptación formal del proyecto y se le entrega al cliente el resultado de las pruebas y el plan de acción (Las plantillas del trabajo de un proyecto de Auditoría Interna de Riesgos se ven en el Anexo 1, 2, 3, 4 y 5). Luego de esto, los archivos Excel se copian y pegan en una carpeta compartida (carpeta física) que será utilizado sólo por el área de Consultoría en un servidor local de la empresa. Esta información podría ser utilizado como base de conocimiento (base de datos con información de los proyectos terminados para ser reutilizados en otros proyectos o proyectos recurrentes). Al no contar con esa información de forma centralizada en un repositorio de datos (base de conocimiento), el proceso de trabajo de la Auditoría de Riesgos se realiza desde cero y de forma 


\section{(4)}

manual nuevamente. Esto conlleva a que haya mucha pérdida de tiempo y que no haya una automatización del trabajo para cada proyecto.

Por otro lado, en el siguiente cuadro en base a las debilidades encontradas en la organización, se identifican los problemas e impacto que se obtienen:

Tabla $\mathrm{N}^{\circ} 37$ Problema e Impacto de las Debilidades

\begin{tabular}{|c|c|}
\hline Debilidades & \\
\hline $\begin{array}{l}\text { D01 - Falta de un plan } \\
\text { estratégico de TI (PETI) }\end{array}$ & $\begin{array}{l}\text { No cuenta con un plan ni procesos de TI alineados a los } \\
\text { objetivos estratégicos de la empresa, lo que da como } \\
\text { resultado no tener claro las metas que permitan alinear los } \\
\text { objetivos del negocio con la propuesta de la arquitectura } \\
\text { empresarial }\end{array}$ \\
\hline $\begin{array}{l}\text { D02 - Falta de base de } \\
\text { conocimientos como ayuda } \\
\text { para miembros sin } \\
\text { experiencia en el desarrollo } \\
\text { de proyectos de los clientes }\end{array}$ & $\begin{array}{l}\text { - No cuenta con base de información para desarrollar } \\
\text { proyectos de Auditoría Interna de Riesgos para los } \\
\text { miembros inexpertos } \\
\text { - Horas extras en el desarrollo de proyectos de Auditoría } \\
\text { Interna de Riesgos } \\
\text { - Falta de disponibilidad de miembros expertos cuando se } \\
\text { los necesiten para ayudar a los miembros inexpertos }\end{array}$ \\
\hline $\begin{array}{l}\text { D03 - Bajo desarrollo de } \\
\text { aplicaciones para la mejora } \\
\text { de procesos de trabajo dentro } \\
\text { de las líneas de servicio que } \\
\text { presta la organización hacia } \\
\text { sus clientes }\end{array}$ & $\begin{array}{l}\text { No cuenta con área de desarrollo para la automatización de } \\
\text { procesos de trabajo de la organización, lo que da como } \\
\text { resultado a que los trabajos se sigan haciendo de forma } \\
\text { manual y haya una falta en la integración de información de } \\
\text { resultado de forma centralizada }\end{array}$ \\
\hline 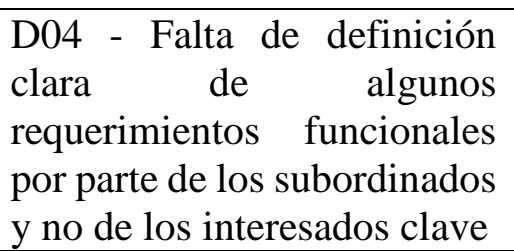 & $\begin{array}{l}\text { Los requerimientos funcionales no lo desarrollan los } \\
\text { miembros clave, lo que da como resultado que los } \\
\text { entregables no sean de acuerdo a lo esperado }\end{array}$ \\
\hline $\begin{array}{l}\text { D05 - Falta de disponibilidad } \\
\text { de interesados clave en el } \\
\text { desarrollo de proyectos }\end{array}$ & $\begin{array}{l}\text { como } \\
\text { y no } \\
\text { ve }\end{array}$ \\
\hline $\begin{array}{l}\text { D06 - No existe el concepto } \\
\text { de gestión de proyectos de } \\
\text { sistemas mediante un marco } \\
\text { ágil con Scrum }\end{array}$ & $\begin{array}{l}\text { Los interesados clave no tienen noción de cómo se lleva la } \\
\text { gestión de un proyecto de sistemas. Esto da como resultado } \\
\text { que la gestión se maneje de forma desordenada y no se } \\
\text { realice una buena planificación del alcance, tiempo y costo. }\end{array}$ \\
\hline $\begin{array}{l}\text { D07 - Hay burocracia para } \\
\text { desplegar nuevas } \\
\text { tecnoluciones } \\
\text { tecnicas } \quad \text { en la la }\end{array}$ & $\begin{array}{l}\text { La organización maneja políticas para el uso de nuevas } \\
\text { aplicaciones en sus servidores de EY Global (se realizan } \\
\text { pruebas de auditoría que duran } 6 \text { meses con un costo USD\$ }\end{array}$ \\
\hline
\end{tabular}




\section{(1)}

organización por parte de EY

Global (políticas internas)
60,000.00 que lo desembolsa EY Perú), lo que da como resultado que sea muy difícil aplicar el uso de nuevas aplicaciones para ayudar a automatizar los procesos de trabajo de la organización

Fuente: Elaboración Propia

\subsection{IDENTIFICACIÓN DE LAS DINÁMICAS PROPUESTAS}

En este punto, se identifican y proponen dinámicas que potencien las fortalezas y puedan reducir las debilidades de la organización y del equipo de trabajo. Por esta razón, se propone realizar dinámicas para desarrollar habilidades blandas, de comunicación y por último, para el desarrollo del proyecto usando un marco de trabajo mediante Scrum. A continuación se definen las siguientes dinámicas: 


\section{(4)}

Tabla Nº 38 Tabla de Dinámicas Propuestas

\begin{tabular}{|c|c|c|c|}
\hline Taller & Descripción & Objetivo & $\begin{array}{l}\text { Habilidades } \\
\text { Obtenidas }\end{array}$ \\
\hline $\begin{array}{l}\text { Taller de } \\
\text { Impro }\end{array}$ & $\begin{array}{l}\text { Este taller ofrece a la } \\
\text { persona que pueda } \\
\text { improvisar lo que } \\
\text { significa que pueda } \\
\text { atreverse, avanzar, } \\
\text { lanzarse, desarrollar la } \\
\text { confianza en uno mismo, } \\
\text { así como también en el } \\
\text { grupo de trabajo, } \\
\text { presentando una } \\
\text { información de manera } \\
\text { precisa, sencilla y clara. } \\
\text { Saber reaccionar al } \\
\text { instante, teniendo en } \\
\text { cuenta tanto las } \\
\text { informaciones } \\
\text { transmitidas por el } \\
\text { interlocutor como su } \\
\text { propia situación, siendo } \\
\text { esto un valor importante } \\
\text { para la empresa. La } \\
\text { improvisación brinda la } \\
\text { capacidad de adaptarse } \\
\text { frente a situaciones y } \\
\text { reacciones inesperadas, } \\
\text { extremas: de aquí la } \\
\text { importancia por parte del } \\
\text { colaborador de tener } \\
\text { capacidad de reacción y } \\
\text { de flexibilidad frente a } \\
\text { un cliente u otro } \\
\text { compañero de trabajo. }\end{array}$ & $\begin{array}{l}\text { Incrementar el nivel de } \\
\text { comunicación al poner al } \\
\text { integrante en diversas } \\
\text { situaciones y con ello se } \\
\text { busca fomentar la } \\
\text { escucha y mejorar la } \\
\text { comunicación } \\
\text { interpersonal. Todos los } \\
\text { integrantes del proyecto } \\
\text { deberán poseer un alto } \\
\text { nivel de comunicación } \\
\text { para establecer mejores } \\
\text { relaciones en el grupo y } \\
\text { poder convertirse equipo } \\
\text { multifuncional. }\end{array}$ & $\begin{array}{l}\text { - Desarrollar la } \\
\text { cohesión del equipo } \\
\text { - Desarrollo y mejora } \\
\text { del habla y escucha }\end{array}$ \\
\hline Coaching & $\begin{array}{l}\text { Es una disciplina } \\
\text { transformacional, en la } \\
\text { cual se utiliza el arte de } \\
\text { preguntar para } \\
\text { cuestionar y lograr así un } \\
\text { cambio en la percepción } \\
\text { que tienen los } \\
\text { participantes del mundo }\end{array}$ & $\begin{array}{l}\text { - Fomentar el espíritu } \\
\text { de equipo. Puede que } \\
\text { suene a tópico, pero en } \\
\text { algunas empresas no } \\
\text { existe el espíritu de } \\
\text { equipo. Es decir, la } \\
\text { idea de que el esfuerzo } \\
\text { conjunto es mucho }\end{array}$ & $\begin{array}{l}\text { - } \text { Desarrollo de la auto } \\
\text { motivación personal } \\
\text { - Desarrollo de } \\
\text { liderazgo } \\
\text { - Mejor fluidez de } \\
\text { comunicación } \\
\text { - Desarrollo de } \\
\text { habilidades blandas }\end{array}$ \\
\hline
\end{tabular}




\section{(1)}

\begin{tabular}{|c|c|}
\hline $\begin{array}{l}\text { o de sí mismos } \\
\text { generando } \\
\text { aprendizajes nacidos de } \\
\text { su propia interpretación } \\
\text { y por lo tanto } \\
\text { internalizados de manera } \\
\text { perdurable en el tiempo. }\end{array}$ & $\begin{array}{l}\text { más efectivo que el } \\
\text { individual. El coach } \\
\text { debe buscar estos } \\
\text { vínculos entre los } \\
\text { miembros y } \\
\text { reforzarlos. } \\
\text { - Estimular el sentido } \\
\text { de pertenencia. El } \\
\text { coaching de equipos } \\
\text { busca que los } \\
\text { miembros del grupo se } \\
\text { sientan parte de él, } \\
\text { pues de otro modo los } \\
\text { procesos carecerán de } \\
\text { compromiso. Cuando } \\
\text { el sentimiento de } \\
\text { equipo se vincula a la } \\
\text { identidad de cada } \\
\text { miembro, puede } \\
\text { hablarse de sentido de } \\
\text { pertenencia. } \\
\text { - Comunicación fluida } \\
\text { y positiva. También } \\
\text { trabaja los mensajes, } \\
\text { que son un } \\
\text { componente } \\
\text { indispensable para el } \\
\text { desempeño y la } \\
\text { productividad. Ningún } \\
\text { grupo funciona con } \\
\text { información sesgada, } \\
\text { incompleta y confusa. } \\
\text { - Gestión de los } \\
\text { errores. Un grupo } \\
\text { debe saber que los } \\
\text { errores son parte de } \\
\text { cualquier proceso. Más } \\
\text { que fallos insalvables, } \\
\text { son oportunidades } \\
\text { sobre las que es } \\
\text { necesario construir } \\
\text { algo nuevo. El coach } \\
\text { debe insistir en esta } \\
\text { idea. }\end{array}$ \\
\hline
\end{tabular}




\section{(1)}

\begin{tabular}{|c|c|c|c|}
\hline & & $\begin{array}{l}\text {-Diálogo y } \\
\text { confrontación } \\
\text { positiva. Las } \\
\text { relaciones entre los } \\
\text { miembros de un grupo } \\
\text { de trabajo suelen ser } \\
\text { complejas. De hecho, } \\
\text { se habla de que cada } \\
\text { grupo es un universo } \\
\text { en sí mismo. Las } \\
\text { diferencias y la } \\
\text { diversidad de opinión } \\
\text { forman parte del día a } \\
\text { día. Con la ayuda del } \\
\text { coaching de grupos, } \\
\text { sus integrantes deben } \\
\text { saber superarlas y } \\
\text { elaborar diálogos } \\
\text { constructivos. } \\
\text { - Liderazgo } \\
\text { situacional. Tanto si } \\
\text { el grupo es liderado } \\
\text { por alguien en } \\
\text { concreto como si no, } \\
\text { es fundamental que se } \\
\text { conozcan y asuman los } \\
\text { liderazgos pertinentes } \\
\text { en cada etapa de los } \\
\text { procesos. No existe un } \\
\text { estilo único de } \\
\text { liderazgo; existen } \\
\text { varios que pueden } \\
\text { aplicarse } \\
\text { simultáneamente o por } \\
\text { separado. }\end{array}$ & \\
\hline \begin{tabular}{|l|} 
Taller \\
Scrum
\end{tabular} & $\begin{array}{l}\text { Scrum es una marco de } \\
\text { trabajo ágil y flexible } \\
\text { para gestionar el } \\
\text { desarrollo de software, } \\
\text { cuyo principal objetivo } \\
\text { es maximizar el retorno } \\
\text { de la inversión para su } \\
\text { empresa (ROI, Return }\end{array}$ & $\begin{array}{l}\text { - El cliente se } \\
\text { entusiasma y se } \\
\text { compromete con el } \\
\text { proyecto dado que lo } \\
\text { ve crecer por cada } \\
\text { iteración. Asimismo, le } \\
\text { permite en cualquier } \\
\text { momento realinear el }\end{array}$ & $\begin{array}{l}\text { - Conocimientos } \\
\text { teóricos y prácticos } \\
\text { en el desarrollo de } \\
\text { proyectos } \\
\text { - Desarrollar equipos } \\
\text { de trabajo auto } \\
\text { organizados y de alto } \\
\text { desempeño }\end{array}$ \\
\hline
\end{tabular}




\section{(1)}

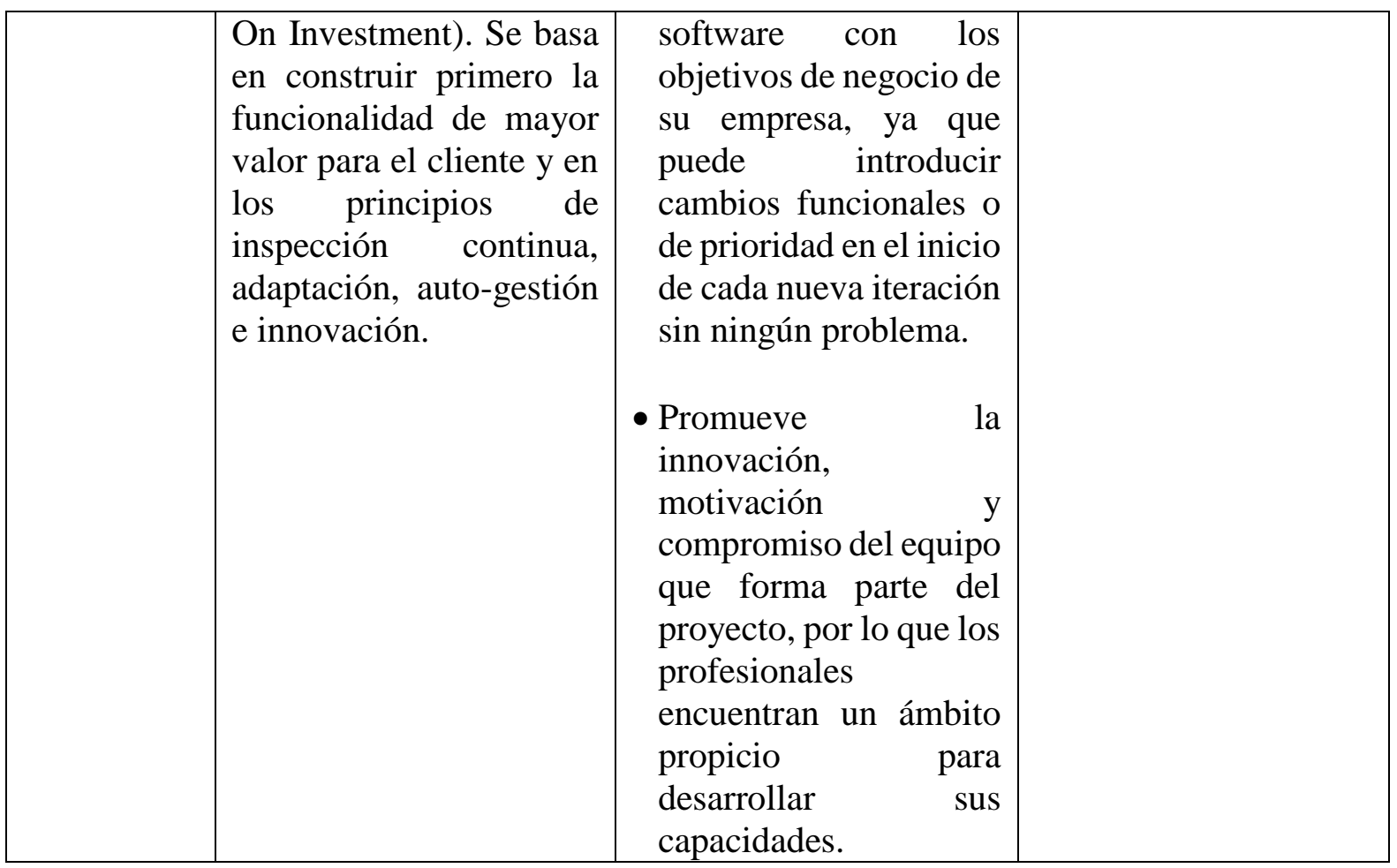

Fuente: Elaboración Propia

\subsection{DESARROLLO DE DINÁMICAS}

\section{Taller de Impro}

Según la publicación "Juegos de Improvisación” (DRAGÓN A, 2012), se definen a continuación las siguientes dinámicas del taller de Impro:

\section{a. Cuéntame un cuento... ;en 60 segundos!}

En grupos de 3 a 5, los miembros del grupo tienen 1 minuto para contar en acciones un cuento de hadas al resto de la clase. (El cuento puede ser uno sugerido por el resto de la clase y debe de ser uno conocido). El profesor hace de narrador para asegurar un buen ritmo y que los 'actores' hagan un esfuerzo para crear los personajes y contar la historia a pesar de la prisa.

\section{b. La fiesta}




\section{(1)}

Se elige un anfitrión y sale de la clase. Luego se coge a 3 de sus compañeros para hacer de invitados. Cada uno pregunta al resto de la clase “¿Quién soy?” y los alumnos van haciendo sugerencias más creativas, porque cuanto más imaginativas sea, más divertido será el ejercicio.

Por ejemplo:

- Un astronauta sufre de vértigo

- Un domador de pulgas

- Un artista borracho

El anfitrión entra y los invitados salen. De uno en uno (cada minuto), se van llamando a la puerta y empiezan a interactuar con el anfitrión, que pronto tiene que tratar con 3 invitados a la vez. Los invitados van dando pistas en su manera de comportarse cada vez más evidentes hasta que el anfitrión adivina quienes son, pero no se trata de un simple juego de adivinanzas: el énfasis debería de estar en la comedia y la improvisación.

\section{c. ¿Pero qué dices?}

Todos se sientan en círculo. El primero dice una palabra inventada, en un idioma 'extranjero' desconocido, a la persona sentada a su derecha. Esta persona se lo 'traduce' para el resto del grupo, eligiendo la primera palabra que le viene a la cabeza, pero que sea una que este de alguna manera relacionada (por sonidos o por entonación, etc.) con la palabra extranjera. Luego, dice otra palabra inventada y el juego continua.

\section{d. Coge un objetivo... iy a actuar!}

En grupos de 2 o 3, los alumnos se turnan para improvisar una escena delante del resto de la clase basado en un adjetivo (lo puede elegir el profesor o bien los demás alumnos). Tienen que presentar una escena con máxima énfasis en su adjetivo. Por ejemplo, si la palabra elegida es 'alegre', tendrán que los alumnos estar súper contentos, etc.

\section{e. Patos y vacas}




\section{(1)}

Los alumnos se colocan de pie y con los ojos cerrados. El profesor se mueve entre ellos asignando a cada uno un animal: si toca el hombro derecho, será 'vaca'; si toca el izquierdo, será 'pato'. Luego, se abren los ojos e intentan encontrarse (y agruparse) sólo con la llamada 'animal'.

\section{Coaching}

Eduardo Galeano (Galeano, 2013) nos indica a continuación las siguientes dinámicas del Coaching:

\section{a. "En una palabra" (10 -15 minutos inicialmente, luego puede alargarse más)}

Esta dinámica "rompehielos" ayuda al grupo a profundizar en sus pensamientos respecto a un tema conocido. Normalmente los participantes se maravillan de la variedad de palabras que ellos mismos han elegido.

\section{Instrucciones:}

- Formar grupos de 4-5 personas aleatoriamente (de ese modo se evita que las personas que ya se conocen se pongan juntas)

- Decir a los grupos que su tarea consiste en pensar durante un minuto qué palabra describe mejor un tema común relacionado con su trabajo. Ejemplos: cultura organizacional de la empresa, productividad del departamento, etc.

- Animar a cada grupo que comparta la palabra con el resto del grupo. Surgirá una conversación entre los participantes de cada equipo que puede dar lugar a un primer acercamiento muy interesante.

- Reunir a todos los grupos para la puesta en común de las palabras sugeridas. Para esto, lo habitual es pedir voluntarios a cada grupo: lo bueno es que como solamente son 


\section{(1)}

portavoces y no tienen que "defender" las palabras elegidas, incluso las personas más tímidas no suelen tener ningún problema en intervenir en este punto.

- Después de que todos los asistentes hayan escuchado las palabras, se formulan una serie de preguntas a los grupos sobre el tema elegido, para el que propusieron las palabras. En el ejemplo de la cultura organizacional, se les puede sondear acerca de si creen que es eficaz, si están cómodos con ella, etc.

- Luego, se ponen las reflexiones surgidas en los equipos con todos los participantes.

\section{b. "Tres momentos cumbre en tu trabajo" (60 - 90 minutos)}

Los principales beneficios de esta dinámica consisten en que los participantes aprenderán a conocer y apreciar las habilidades de sus compañeros. El objetivo de esta actividad es construir un equipo cohesionado.

\section{Instrucciones:}

- Hacer grupos de 4 personas numerándolos aleatoriamente.

- Decir a los grupos que su tarea consiste en repasar mentalmente su vida laboral y encontrar tres eventos, actividades, logros, colaboraciones o momentos especiales de reconocimiento que fueron importantes para ellos.

- Dar unos 10 minutos a cada persona para puedan pensarlo y que ordenen sus ideas antes de pedir que lo compartan con su grupo. Si alguno de los participantes es nuevo, se le puede proponer que elija momentos de su periodo de estudiante, en trabajos en prácticas o de voluntariado.

- Se le da un tiempo para comunicarlo con el resto del grupo. Lo ideal es hacer turnos: se van tomando la palabra para compartir el "primer momento", después el segundo y por 


\section{(1)}

último el tercero. De ese modo nadie acapara la conversación. Es bueno proponerles que busquen puntos que sus experiencias tienen en común.

- Decir a los grupos que elijan una sola historia de cada participante para que la cuente a todos los asistentes, si es que se sienten cómodos haciéndolo.

- Para terminar, se les debe de preguntar a los participantes cómo se han sentido al contar sus propias historias y escuchar las de los demás. Y por último, preguntar a los grupos, si creen que las historias tenían algo en común, como la temática o cómo se sintieron.

\section{c. "Preguntas divertidas" (15 - 30 minutos por pregunta)}

En la primera parte, se presenta el sistema de preguntas como forma de romper el hielo. El funcionamiento consiste en proponer una serie de interrogantes que luego los grupos tienen que contestar.

En los puntos debajo se proponen algunas preguntas que son muy divertidas y no las típicas relacionadas con la trayectoria dentro de la organización.

\section{Instrucciones:}

- Dividir a los participantes en grupos de 4 - 5 personas aleatoriamente.

- Presentar la "pregunta divertida". Algunos ejemplos de este tipo de preguntas:

- Si fueras un vegetal, ¿cuál serías?

- Si pudieras transformarte en un animal, ¿cuál elegirías y por qué?

- Si pudieses vivir en cualquier lugar y llevarte todo lo que quieres contigo (familia, pertenencias...) ¿dónde te irías?

- ¿Qué color eres y cómo te sientes? (Por ejemplo: "Soy amarillo")

- Si pudieras cambiarte el nombre, ¿cuál te pondrías?

- ¿Eres primavera, verano, otoño o invierno? ¿Por qué?

- ¿Cuál de tus pertenencias dirías que es tu objeto favorito? 


\section{$(1)$}

- Si creases un eslogan para tu vida, ¿cuál sería? (Por ejemplo: “Come, baila y ríete todo lo que puedas que la vida son dos días")

- Decir a los grupos que cada participante puede tomarse 5 minutos en pensar la respuesta y después deberán ponerlas en común dentro de su grupo. Subrayar que el propósito de la pregunta es motivar comentarios y debates.

- Tras la primera discusión, se pide voluntarios para compartir los resultados con todos los asistentes. Si ninguno se ofrece, se les puedes interpelar directamente con la pregunta: “Oye Lucía, ¿qué color eres?”

- A continuación, se les pueden exponer más preguntas.

\section{d. "El momentazo" (30 - 60 minutos, depende del número de personas)}

Por último, esta dinámica es muy indicada cuando los participantes están muy cansados o se espera que sean poco colaboradores.

En estos casos es bueno proporcionar a los asistentes las instrucciones en papel. Verlas impresas en negro sobre blanco, ayudará a los participantes a centrarse en el tema y se despejará las posibles dudas sobre la mecánica de la actividad.

\section{Instrucciones:}

- Se entrega una hoja de instrucciones a cada participante y se hacen grupos de 4-5 personas aleatoriamente.

- Se les pide que piensen en su trayectoria profesional y que escojan un momento en el que todas sus cualidades funcionaron al $100 \%$, como por ejemplo, conseguir un cliente grande, o persuadir a uno descontento para que no se fuera, o acabar un trabajo difícil.

- Decir a los grupos que la mejor elección es el primer momento que se les ha venido a la cabeza durante las explicaciones del ejercicio. Luego, se les da unos 10 minutos para que 


\section{(1)}

escojan su "momentazo", y luego se les pide que lo compartan con los miembros de su grupo.

- Se debe animar a los participantes a compartir los detalles de aquel momento especial: colores, sonidos, cómo se sintieron y cómo reaccionaron cuando se dieron cuenta de su éxito.

- Luego, dejar que hablen hasta que las conversaciones se vayan apagando poco a poco y pregunta si todo el mundo ha compartido su historia o si la primera persona todavía sigue hablando (esto es un guiño para arrancar alguna risa que otra).

- Para finalizar, se debe preguntar qué tal se han sentido al compartir su "momentazo" y escuchar las historias de los compañeros. Se puede terminar preguntando, si han encontrado temas en común en cada historia y se pide que los apunten

\section{Taller Scrum}

Se definen los siguientes eventos para la planificación y el desarrollo de una propuesta tecnológica mediante el uso del marco de trabajo con Scrum:

\section{a. Sprint Planning}

Tal como se define en la Guía para el cuerpo de conocimiento de Scrum (SBOK, 2017). Esta reunión se lleva a cabo antes del Sprint, como parte de los procesos de comprometer User Stories, identificar tareas, estimar tareas y crear el Sprint Backlog.

Adicionalmente a la información obtenida del SBOK, según la Guía Fundamental de Scrum del Agile Coach, Jerónimo Palacios (Palacios, Guía fundamental de Scrum), describe que durante esta reunión el Product Owner presenta el Product Backlog actualizado, que el Development Team se encarga de estimar, además de intentar clarificar aquellos ítems que crean necesarios. 


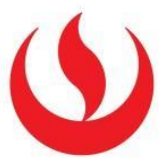

Nota:

En el Sprint Planning participa el equipo Scrum al completo, pero no los interesados clave. En el Sprint Planning se inspeccionan el Product Backlog, los acuerdos de la Retrospectiva, la capacidad y la Definition of Done y se adaptan al Sprint Backlog, al Pronóstico y al objetivo Sprint.

El Sprint Planning se divide en dos partes. En la primera parte de la reunión se trata el ¿Qué? se va a hacer en el siguiente Sprint y en la segunda parte, se discute el ¿Cómo?. La primera parte está organizada y liderada por el Product Owner y la segunda parte por el Development Team . La única labor del Scrum Master es asegurarse de que la reunión existe como parte de Scrum.

El Sprint Planning es una reunión de planificación y puede durar hasta 8 horas para Sprints de 4 semanas, pero para este proyecto será de 4 horas para un Sprint de 2 semanas, porque el Gerente de Consultoría (Product Owner) se le necesita mostrar constantemente funcionamiento de la aplicación y obtener retroalimentación. La razón del Sprint Planning es conseguir alineamiento entre negocio y desarrollo de producto en cuanto a cuáles son las prioridades.

El Product Owner presenta un Product Backlog priorizado y actualizado, además de proponer un objetivo del Sprint que de coherencia a todos los ítems seleccionados durante la reunión. Durante la primera parte, el Development Team pronostica cuantos elementos del Product Backlog cree que será capaz de terminar en el Sprint, teniendo en mente el objetivo del Sprint propuesto por el Product Owner. Una vez que existe un acuerdo entre el Product Owner y el Development Team, entonces el Development Team pasa a la segunda parte, donde se encargan de descomponer el trabajo que hayan seleccionado en tareas más pequeñas, siempre cumpliendo la regla de analizar sólo el mínimo para empezar a trabajar. 


\section{(1)}

- El Sprint Planning se compone de dos partes: Una donde se pronostica el trabajo a realizar y otra donde el Development Team se encarga de analizar y desmenuzar el trabajo en tareas, hasta donde crean necesario.

- La primera parte del Sprint Planning está liderada por el Product Owner y la segunda parte por el Development Team .

- Es responsabilidad del Scrum Master que la reunión ocurra, pero no tiene que facilitarlo ni organizarlo él mismo.

- El Development Team tiene la última palabra sobre cuanto trabajo creen que pueden completar en un sólo Sprint.

\section{¿Qué necesitamos?}

- Definition of Done

- Acuerdos de la retrospectiva

- Product Backlog

- Disponibilidad del Development Team

\section{¿Qué obtenemos?}

- Product Backlog actualizado

- Sprint Backlog

- Objetivo del Sprint

\section{Duración}

4 horas para Sprints de 2 semanas.

\section{¿Quién es el responsable?}

Primera parte: Product Owner

Segunda parte: Development Team

\section{b. Daily Scrum}




\section{(1)}

Según la Guía para el cuerpo de conocimiento de Scrum (SBOK, 2017). Es una breve reunión diaria con un tiempo de 15 minutos. El Development Team se reúne para dar un reporte sobre su progreso en el Sprint y planificar las actividades del día. La duración de la reunión es muy corta y se busca que todos los integrantes del Development Team estén presentes. Sin embargo, la reunión no se cancela o se retrasa si uno o más miembros no pueden asistir.

El Daily Scrum es organizado por el Scrum Master, donde cada miembro del Development Team brinda información en forma de respuesta a tres preguntas específicas:

- ¿Qué he hecho desde la última reunión?

- ¿Qué tengo planeado hacer antes de la siguiente reunión?

- ¿Qué impedimentos u obstáculos (si los hubiera) estoy enfrentando en la actualidad?

Adicionalmente a la información obtenida del SBOK, según la Guía Fundamental de Scrum del Agile Coach, Jerónimo Palacios (Palacios, Guía fundamental de Scrum), describe que en los Daily Scrum el Development Team debe comunicar si existe riesgo de no alcanzar la meta marcada durante el Sprint.

En Scrum existen varios Feedback Loops, pequeñas interacciones que dan la oportunidad de inspeccionar y adaptar el trabajo. Esto permite planificar riesgos y tener transparencia y visibilidad sobre el proceso.

\section{c. Sprint}

Según la Guía para el cuerpo de conocimiento de Scrum (SBOK, 2017). El Sprint es una iteración con un tiempo de una a cuatro semanas de duración durante el cual el Scrum Master guía, facilita y protege al Development Team de impedimentos tanto internos como externos durante el proceso de crear entregables. Esto ayuda a evitar una expansión de la visión más allá de su objetivo original, lo que podría afectar la meta del Sprint. Durante este tiempo, el equipo trabaja para convertir las necesidades del Backlog Priorizado del Producto en funcionalidades de productos fáciles de enviar. Para obtener los máximos beneficios de un proyecto Scrum, siempre se recomienda mantener el Sprint dentro de un Time-box de cuatro 


\section{(1)}

semanas, a menos que existan proyectos con requisitos muy estables, en los que los Sprints pueden extenderse hasta cuatro semanas.

\section{d. Sprint Review}

Tal como se define en la Guía para el cuerpo de conocimiento de Scrum (SBOK, 2017). Los miembros del equipo de Scrum y los Stakeholders relevantes participan en las reuniones de revisión del Sprint para aceptar los entregables que cumplan con los criterios de aceptación de las User Stories y rechazar los entregables no aceptables. Tales reuniones se convocan al final de cada Sprint. El Development Team demuestra los logros del Sprint, incluyendo las nuevas funcionalidades o los productos elaborados. Esto brinda una oportunidad para que el Product Owner y el(los) Stakeholder(s) inspeccionen lo que se ha completado hasta el momento y determinen si deben realizarse cambios en el proyecto o en los procesos en Sprints posteriores.

- Entregables aceptados

Los entregables que cumplen con los criterios de aceptación de las User Stories son aceptados por el Product Owner. El objetivo de un Sprint es crear e incrementar el producto, que cumplan con los criterios de aceptación definidos por el cliente y el Product Owner. Estos se consideran entregables aceptados que pudieran ser entregados al cliente y así se desea. Se mantiene una lista de entregables aceptados y se actualiza después de cada reunión de revisión del Sprint. Si un entregable no cumple con los criterios de aceptación definidos, no se considera aceptado y generalmente se llevará a un Sprint posterior para corregir cualquier problema. Esto no es muy recomendable, ya que el objetivo de cada Sprint es que los entregables cumplan con los criterios de aceptación.

- Entregables rechazados

Si los entregables no cumplen con los criterios de aceptación, tales entregables se rechazan. Las User Stories asociados a tales entregables rechazados se agregan al Backlog Priorizado del Producto para que tales entregables puedan ser considerados como parte de un Sprint posterior. 


\section{(1)}

Adicionalmente a la información obtenida del SBOK, según la Guía Fundamental de Scrum del Agile Coach, Jerónimo Palacios (Palacios, Guía fundamental de Scrum), describe que el Sprint Review no es una demo para un cliente o para los Stakeholders, o incluso para el Product Owner. No es tampoco una reunión para felicitar al Development Team. Es una reunión de trabajo, una de las más importantes, ya que sirve para marcar la estrategia de negocio.

\section{Ficha del Sprint Review}

Asistentes: Equipo Scrum (Product Owner, Scrum Master y Development Team) y Interesados

Facilitador: Product Owner

Duración: 2 horas para un Sprint de 2 semanas

\section{¿Que se inspecciona durante el Sprint Review?}

- El Incremento

- El Sprint

- El Product Backlog

\section{¿Qué se adapta durante el Sprint Review?}

El Product Backlog con las condiciones actualizadas de negocio

\section{e. Retrospectiva del Sprint}

Como se menciona en la Guía para el cuerpo de conocimiento de Scrum (SBOK, 2017), la retrospectiva del Sprint es un elemento importante del marco de trabajo de Scrum y es el último paso en un Sprint. Todos los miembros del Development Team asisten a la reunión, misma que organiza y modera el Scrum Master. Se recomienda que asista el Product Owner, aunque no es obligatorio. Un integrante del equipo se desempeña como secretario y documenta las discusiones y los elementos para acciones a futuro. Es esencial celebrar esta reunión es un entorno abierto y relajado a fin de fomentar la completa participación de todos 


\section{(1)}

los miembros del equipo. Las discusiones en la reunión de retrospectiva del Sprint abarcan tanto lo que salió mal como lo que salió bien. Los objetivos primordiales de la reunión son identificar tres elementos específicos:

- Las cosas que el equipo necesita seguir haciendo: mejores prácticas

- Las cosas que el equipo necesita empezar a hacer: mejoras en el proceso

- Las cosas que el equipo necesita dejar de hacer: problemas de proceso y embotellamiento. Estas áreas se analizan y se crea una lista de mejoras accionables aceptadas.

Adicionalmente a la información obtenida del SBOK, según la Guía Fundamental de Scrum del Agile Coach, Jerónimo Palacios (Palacios, Guía fundamental de Scrum), describe que la retrospectiva puede usar un formato común para analizar "Qué ha ido bien durante el Sprint", "Qué ha fallado" y “Qué se puede mejorar”. Este formato se puede facilitar pidiendo a los miembros del equipo Scrum que escriban post-its, para luego agruparlos y votar sobre aquellos ítems que sean más relevantes, dando a todo el mundo la oportunidad de hablar y expresar sus inquietudes.

También se utiliza el formato de retrospectiva basado en cinco fases:

- Preparar el ambiente: Un pequeño ejercicio para romper el hielo, junto con el recordatorio de la Prime Directive (Independientemente de lo que se descubra, comprenda y se crea que todos hicieron el mejor trabajo posible, dado lo que se sabía en ese momento, sus habilidades y habilidades, los recursos disponibles y la situación que se tenía hasta ese momento) se realiza el comienzo perfecto.

- Recolectar información: Durante esta fase, se utilizan actividades para intentar construir una imagen de lo que ha sido el último Sprint. Una imagen conjunta de equipo.

- Generación de ideas: Ahora el equipo intenta generar ideas para identificar acciones que ayuden a mejorar el rendimiento del equipo durante el siguiente Sprint.

- Decidir qué hacer: De las ideas generadas, se proponen acciones que puedan implementarse en el próximo Sprint. A implementar por todo el equipo. 


\section{(1)}

- Cierre: Una pequeña actividad de cierre, normalmente unida a una evaluación de la propia retrospectiva, ayudan al equipo a decidir dónde quieren ir en próximas ocasiones. Un recordatorio de la mejora continua.

\section{Ficha de la retrospectiva}

Asistentes: El equipo Scrum (Product Owner, Scrum Master y Development Team )

\section{Dueño de la reunión: Scrum Master}

Duración: 1 hora

\section{¿Qué se inspecciona durante la retrospectiva?}

- El último Sprint

- Herramientas y procesos técnicos

- Definition of Done

- Relaciones entre los miembros del equipo

- Procesos

\section{¿Que se adapta durante la retrospectiva?}

Una serie de acciones para mejorar la forma en la que el equipo trabaja.

\section{Dinámica de retrospectiva en Scrum "La línea de tiempo"}

Este proyecto usará la dinámica de línea de tiempo o Timeline, según Samuel C. (Casanova, Dinámica de retrospectiva en Scrum línea de tiempo, 2015) se puede utilizar en multitud de situaciones, pero sobre todo es útil cuando se interesa analizar un periodo temporal problemático, como por ejemplo un proyecto (aplica igual a un Sprint por ejemplo).

La dinámica tiene 5 fases y el tiempo estimado es de 1 o 2 horas, dependiendo de la longitud del periodo a analizar y del tamaño de equipo

\section{- Fase 1: Preparación preliminar (5-10 minutos)}




\section{(1)}

En esta fase se prepara el terreno para la sesión. En una pizarra o flipchart se dibuja una línea de tiempo horizontal que representará el proyecto.

Con la ayuda del equipo, se incluyen los principales hitos y eventos del proyecto. En esta fase temprana ya se pueden comenzar a identificar los hitos problemáticos y los eventos no planificados en rojo, frente a los eventos satisfactorios en verde.

\section{- Fase 2: Conseguir datos (10-20 minutos)}

Si se tienen los datos, se puede aprovechar esta fase para sacar algunos números conocidos de los Information Radiators que aporten información cuantitativa sobre el proyecto estudiado. Después se pregunta al equipo si tienen alguna otra información que ayude a entender el resultado del proyecto. Se puede hacer un recorrido en el tiempo para identificar las principales etapas del proyecto, así como los procedimientos que han entrado en juego (si se han pasado por alto alguna Definition of Done, si se han violado los límites WIP del Scrumboard, cuántos impedimentos han aflorado en las reuniones diarias de Scrum, etc...).

\section{- Fase 3: Generar conocimiento (20-40 minutos)}

En esta fase se genera un debate sobre los principales impedimentos y problemas que se han producido durante el proyecto. Al principio de esta fase siempre conviene recordar el propósito de la sesión: encontrar una medida SMART que esté al alcance del equipo y que le sirva al equipo para mejorar como equipo.

$\mathrm{Al}$ aflorar los primeros problemas, los más evidentes, se puede comenzar por marcar los que son nuevos y los que son recurrentes en el equipo.

En esta misma fase, tras los primeros problemas son útiles las herramientas Lean de la técnica de los 5 por qué o el Diagrama Ishikawa para el análisis de causa raíz. Normalmente suelen salir primero los problemas más superficiales y evidentes, y es 


\section{(1)}

necesario profundizar un poco con alguna de estas técnicas para aflorar los problemas de fondo, los que al final tienen un mayor impacto en el rendimiento.

Al finalizar esta fase se debería tener todo claro y consensuado, en un listado de los principales problemas de tratar de solucionar.

\section{- Fase 4: Decidir qué hacemos (20-40 minutos)}

Una vez identificados los problemas principales y sus causas de fondo, el equipo debe pasar a la fase creativa de la retrospectiva. En esta fase el equipo debe proponer soluciones y medidas correctivas de los principales problemas que se han identificado. Cualquier medida es bienvenida, pero se intentará focalizar al equipo a atacar sobre todo las causas raíz.

Lo normal es en una primera parte, usar técnicas como la tormenta de ideas o variantes como el Brainwriting para aflorar mayores ideas, sin juzgar ni descartar. Posteriormente, en una última parte debatir entre todos cuales son las mejores propuestas, bien por votaciones o por consenso. Se elegirá entre 1 y 2 medidas, ya que las medidas son de implementación inmediata y eso llevará más esfuerzo si son más numerosas, y además será también más sencillo evaluar si la medida es efectiva aplicando medidas de 1 en 1 en lugar de grupos de 5 medidas a la vez.

Debe quedar claro en qué va a consistir la medida adoptada por el equipo en la retrospectiva. Para ello podemos usar las $4 \mathrm{Ws:}$

El qué (What): definir muy bien qué se va a hacer.

Quién (Who): quién es el responsable de llevarla a cabo.

Cómo (hoW): el plan exacto de cómo el equipo debe adoptar la medida.

Cuándo (When): cuándo se deberá comenzar a implementar, debería ser inmediato.

Además de definir los elementos anteriores es recomendable también definir los criterios de éxito, es decir, qué indicadores vamos a mirar para comprobar si la medida ha tenido 


\section{(1)}

éxito o si no está funcionando. Para ello, se deberá especificar el indicador con el valor actual y el valor deseado una vez implementada la medida.

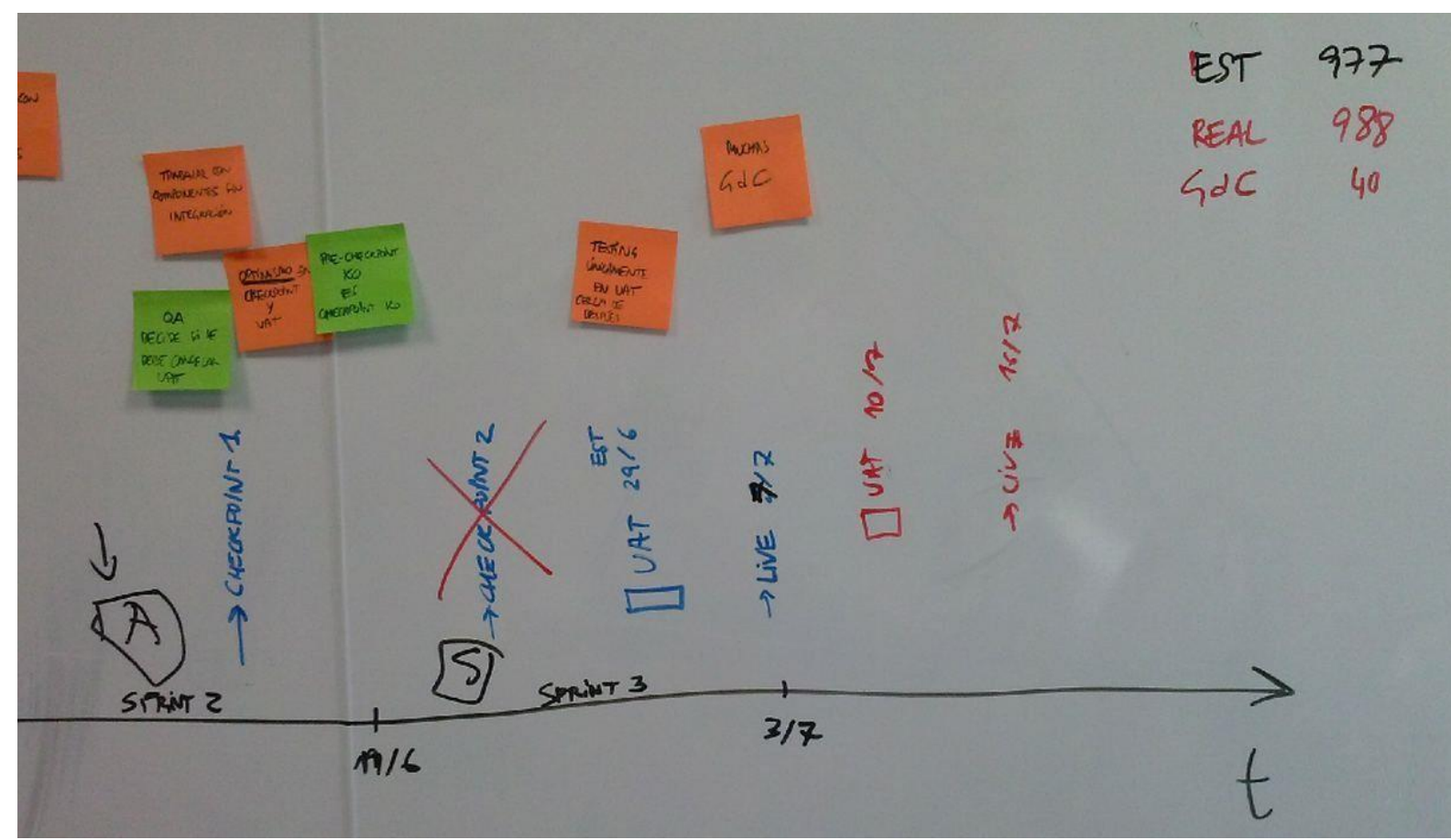

Figura $\mathrm{N}^{\circ} 25$ Dinámica de Retrospectiva

Fuente: Dinámica de Retrospectiva en Scrum Línea del Tiempo

\section{- Fase 5: Cierre (5 minutos)}

Al final de cada retrospectiva siempre conviene dejar un pequeño tiempo de margen para repasar una vez más el compromiso adquirido por el equipo y para recibir la opinión general del equipo sobre la sesión. Se puede simplemente preguntar al grupo qué les ha parecido la sesión y si la ven positiva, o también hacer una encuesta rápida para recoger las impresiones.

\subsection{PRESUPUESTO DE DINÁMICAS}

Tabla $N^{\circ} 39$ Presupuesto de Dinámicas

\begin{tabular}{|c|c|c|c|}
\hline Taller & Nro.Sesiones & Total Horas & Costo \\
\hline Taller Impro & 4 & 8 & US\$ 800.00 \\
\hline
\end{tabular}




\section{(1)}

\begin{tabular}{|l|c|c|l|}
\hline Coaching & 5 & 10 & US\$ 1100.00 \\
\hline Taller Scrum & 3 & 9 & US\$ 1300.00 \\
\hline \multicolumn{3}{|r|}{ Total } & US\$3200.00 \\
\hline
\end{tabular}

Fuente: Elaboración Propia

\subsection{COMPOSICIÓN DE LOS GRUPOS DE TRABAJO}

En este punto, se muestran los roles del equipo que conformará el proyecto (se definió un equipo de 5 miembros), basado en el marco de trabajo de Scrum. Además, se definirá las habilidades duras y blandas que deben tener cada miembro del equipo. A continuación, se definen los siguientes roles:

Tabla $N^{\circ} 40$ Rol Scrum Owner

\begin{tabular}{|l|l|}
\hline \multicolumn{1}{|c|}{ Rol } & \multicolumn{1}{|c|}{ Product Owner } \\
\hline Product Owner & $\begin{array}{l}\text { Según la guía para el cuerpo de conocimiento de Scrum (SBOK, 2017), } \\
\text { el Product Owner representa los intereses de la comunidad de } \\
\text { responsable de asegurar una comunicación clara sobre el producto y los } \\
\text { requisitos de funcionalidad del servicio con el Development Team, } \\
\text { definir los Definition of Done y asegurar que se cumplan dichos criterios. } \\
\text { En otras palabras, el Product Owner es responsable de asegurar que el } \\
\text { Development Team entregue valor. Este rol central siempre debe } \\
\text { mantener una visión dual. Debe entender y apoyar las necesidades e } \\
\text { intereses de todos los Stakeholders, al tiempo que comprende las } \\
\text { necesidades y el funcionamiento del Development Team . Puesto que el } \\
\text { Product Owner debe entender las necesidades y prioridades de los } \\
\text { Stakeholders, incluyendo los clientes y los usuarios, a este rol se le } \\
\text { conoce comúnmente como la voz del cliente. } \\
\text { A continuación, se definen las responsabilidades del rol: } \\
\bullet \text { Define el Project Vision. }\end{array}$ \\
\hline
\end{tabular}




\section{(1)}

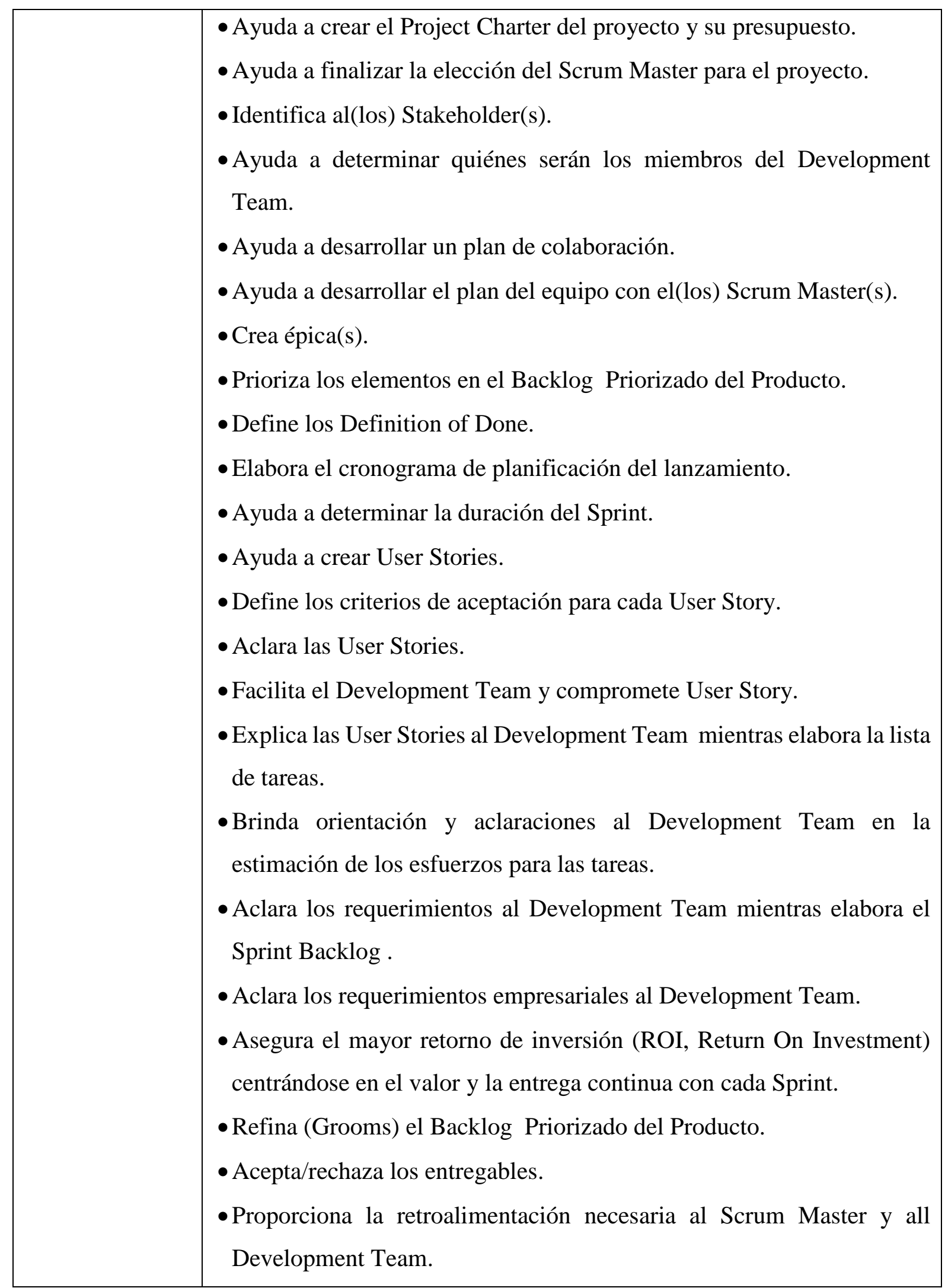




\section{()}

\begin{tabular}{|l|l|}
\hline & $\begin{array}{l}\text { • Actualiza el plan de lanzamiento y el Backlog Priorizado del Producto. } \\
\text { - Ayuda a enviar los lanzamientos del producto y se coordina con el } \\
\text { Cliente. } \\
\text { • Participa en las reuniones de retrospectiva del Sprint. }\end{array}$ \\
\hline Habilidades & $\begin{array}{l}\text { - Herramientas Office. } \\
\text { - Herramientas de gestión de proyectos (Trello y/o Asana). } \\
\text { - Conocimientos sobre las necesidades del negocio y de sus interesados } \\
\text { clave. } \\
\text { - Experiencia en definición de requisitos; así como, conocimiento de } \\
\text { técnicas y herramientas para priorizar User Stories. }\end{array}$ \\
\hline Habilidades & $\begin{array}{l}\text { Liderazgo de equipos, alta capacidad de negociación, proactivo, fluidez } \\
\text { comunicativa. }\end{array}$ \\
\hline Rlandas & 1 Gerente de Consultoría \\
\hline
\end{tabular}

Fuente: Guía para el Cuerpo de Conocimiento de Scrum - 3ra Edición

Tabla N ${ }^{\circ} 41$ Rol Scrum Master

\begin{tabular}{|l|l|}
\hline \multicolumn{1}{|c|}{ Rol } & \multicolumn{1}{|c|}{ Scrum Master } \\
\hline Scrum Master & $\begin{array}{l}\text { Según la guía para el cuerpo de conocimiento de Scrum (SBOK, 2017), } \\
\text { el Scrum Master es el "líder servicial" del Development Team y es } \\
\text { quien modera y facilita las interacciones del equipo como coach y } \\
\text { motivador del mismo. Este rol es responsable de asegurarse que el } \\
\text { Development Team tenga un ambiente de trabajo productivo } \\
\text { protegiéndolo de influencias externas, eliminando todos los obstáculos y } \\
\text { haciendo que se cumplan los principios, aspectos y procesos de Scrum. }\end{array}$ \\
$\begin{array}{l}\text { Las responsabilidades del Scrum master son : } \\
\bullet \text { Ayuda a identificar al(los) Stakeholder(s) para el proyecto. } \\
\bullet \text { Facilita la selección del Development Team . } \\
\text { equipo. } \\
\bullet \text { Garantizar que los recursos de respaldo estén disponibles para el } \\
\text { funcionamiento del proyecto sin problemas. } \\
\bullet \text { Facilitar la creación de épica(s) y prototipos (Personas). }\end{array}$ \\
\hline
\end{tabular}




\section{(1)}

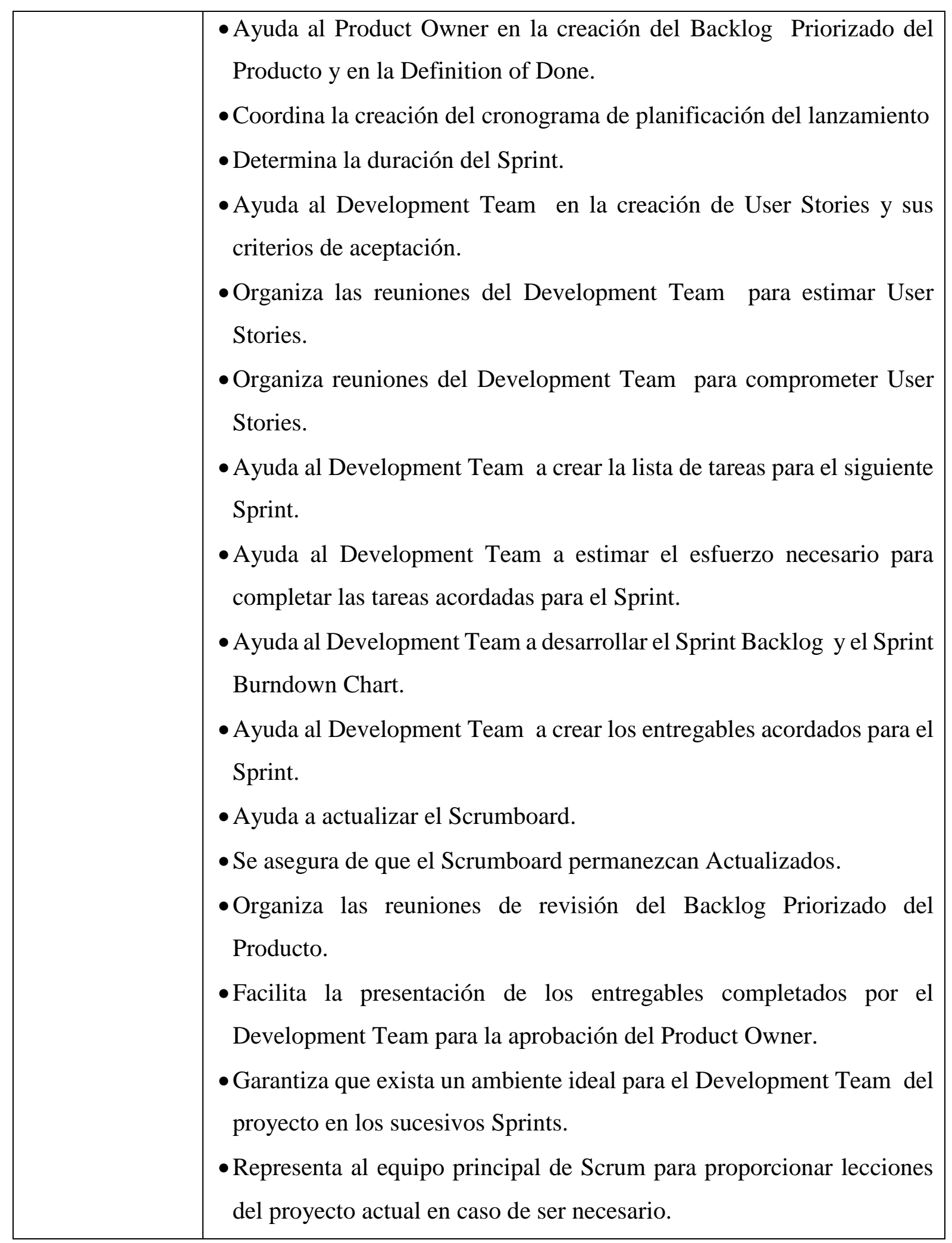




\section{()}

\begin{tabular}{|l|l|}
\hline Habilidades & $\begin{array}{l}\text { • Alto conocimiento del uso de marcos de trabajo con Scrum y ser } \\
\text { certificado como Scrum Master } \\
\bullet \text { Conocimientos en tecnología Microsoft: (SQL Server, C\#) } \\
\bullet \text { Conocimientos en herramientas de gestión de proyectos (Trello) }\end{array}$ \\
\hline $\begin{array}{l}\text { Habilidades } \\
\text { Blandas }\end{array}$ & $\begin{array}{l}\text { Liderazgo, auto motivado, comprometido, responsable, proactivo, } \\
\text { capacidad de negociación y solución de conflictos, capacidad de } \\
\text { escucha, paciencia. }\end{array}$ \\
\hline Recursos & 1 Gerente de Proyecto \\
\hline
\end{tabular}

Fuente: Guía para el Cuerpo de Conocimiento de Scrum - 3ra Edición

Tabla N ${ }^{\circ} 42$ Rol Development Team

\begin{tabular}{|l|l|}
\hline \multicolumn{1}{|c|}{ Rol } & \multicolumn{1}{c|}{ Development Team } \\
Team & $\begin{array}{l}\text { Según la guía para el cuerpo de conocimiento de Scrum (SBOK, 2017), } \\
\text { al Development Team en ocasiones se conoce como equipo de } \\
\text { desarrollo, ya que este es responsable del desarrollo del producto, } \\
\text { servicio o de cualquier otro resultado. Consiste en un grupo de personas } \\
\text { que trabajan en las User Stories en el Sprint Backlog para crear los } \\
\text { entregables del proyecto. }\end{array}$ \\
Las responsabilidades del Development Team son: \\
$\qquad \begin{array}{l}\bullet \text { Proporciona aportes para la creación del plan de colaboración y del plan } \\
\text { de desarrollo del equipo. } \\
\text { nivel) y prototipos. } \\
\bullet \text { Entiende las User Stories en el Backlog Priorizado del Producto. } \\
\bullet \text { Está de acuerdo con los demás miembros del equipo de Scrum sobre la } \\
\text { duración del Sprint. } \\
\bullet \text { Busca clarificación sobre los nuevos productos o cambios, si los hay, } \\
\text { en los productos existentes en el Backlog Priorizado del Producto. } \\
\bullet \text { Proporciona aportes al Product Owner en la creación de User Stories. } \\
\bullet \text { Estima las User Stories aprobadas por el Product Owner. } \\
\bullet \text { Compromete las User Stories a realizarse en un Sprint. }\end{array}$ \\
\hline
\end{tabular}




\section{(1)}

\begin{tabular}{|c|c|}
\hline & $\begin{array}{l}\text { - Desarrolla una lista de tareas con base en las User Stories y } \\
\text { dependencias acordadas. } \\
\text { - Estima el esfuerzo de las tareas identificadas y, de ser necesario, } \\
\text { actualiza la lista de tareas. } \\
\text { - Desarrolla el Sprint Backlog y el Sprint Burndown Chart. } \\
\text { - Elabora los entregables. } \\
\text { - Identifica riesgos y ejecuta acciones de mitigación de riesgos, si los } \\
\text { hay. } \\
\text { - Actualiza el Burndown Chart y el Scrumboard. } \\
\text { - Discute los problemas que enfrenta cada miembro y busca soluciones } \\
\text { para motivar al equipo. } \\
\text { - Presenta solicitudes de cambio, si se requieren. } \\
\text { - Participa en las reuniones de revisión del Backlog Priorizado del } \\
\text { Producto. } \\
\text { - Muestra los entregables completados al Product Owner para su } \\
\text { aprobación. } \\
\text { - Identifica oportunidades de mejora, si las hay, del Sprint actual y decide } \\
\text { si está de acuerdo sobre las posibles mejoras viables para el próximo } \\
\text { Sprint. } \\
\text { - Participa en la reunión de retrospectiva del proyecto. }\end{array}$ \\
\hline $\begin{array}{l}\text { Habilidades } \\
\text { Duras }\end{array}$ & $\begin{array}{l}\text { - Experiencia en programación: Asp.Net MVC C\# y Angular JS } \\
\text { - Conocimiento de Diseño: Html, CSS, y BootStrap. } \\
\text { - Conocimiento en gestor de base de datos: SQL Server } 2014 \\
\text { - Otros: WCF, WebServices y WindowServices }\end{array}$ \\
\hline $\begin{array}{l}\text { Habilidades } \\
\text { Blandas }\end{array}$ & Auto disciplinados, responsables, proactivos y sinceros. \\
\hline Recursos & $\begin{array}{l}\text { - } 1 \text { analista programador Senior } \\
\text { - } 2 \text { Analistas programadores Semi Seniors }\end{array}$ \\
\hline
\end{tabular}

Fuente: Guía para el Cuerpo de Conocimiento de Scrum - 3ra Edición 


\section{()}

\section{Product Owner}

+ Equipo de Desarrollo

+ Scrum Master

\section{= Equipo Scrum}

Figura $N^{\circ} 26$ Roles Scrum

Fuente: Guía Fundamental de Scrum

\subsection{PRESUPUESTO DEL EQUIPO DE TRABAJO}

Tabla N ${ }^{\circ} 43$ Presupuesto del Equipo de Trabajo

\begin{tabular}{|l|l|r|r|c|}
\hline \multicolumn{1}{|c|}{ Rol } & \multicolumn{1}{|c|}{ Recurso } & Meses & \multicolumn{1}{c|}{ Costo } & SubTotal \\
\hline Product Owner & $\begin{array}{l}\text { Gerente de } \\
\text { Consultoría }\end{array}$ & 12 & US\$ 4000.00 & US\$ 48,000.00 \\
\hline Scrum Master & $\begin{array}{l}\text { Gerente de } \\
\text { Proyecto }\end{array}$ & 12 & US\$ 2800.00 & US\$ 33,600.00 \\
\hline $\begin{array}{l}\text { Development } \\
\text { Team }\end{array}$ & $\begin{array}{l}\text { Analista } \\
\text { Programador } \\
\text { Senior }\end{array}$ & 12 & US\$ 2200.00 & US\$ 26,400.00 \\
\hline $\begin{array}{l}\text { Development } \\
\text { Team }\end{array}$ & $\begin{array}{l}\text { Analista } \\
\text { Programador } \\
\text { Semi Senior 1 }\end{array}$ & 12 & US\$ 1100.00 & US\$ 13,200.00 \\
\hline $\begin{array}{l}\text { Development } \\
\text { Team }\end{array}$ & $\begin{array}{l}\text { Analista } \\
\text { Programador } \\
\text { Semi Senior 2 }\end{array}$ & 12 & US\$ 1100.00 & US\$ 13,200.00 \\
\hline
\end{tabular}

Fuente: Elaboración Propia 


\section{(1)}

El proyecto de desarrollo durará 12 meses exactamente, ya que se han estimado talleres para las dinámicas de grupo que durará 1 semana (ver Tabla 39), para el Sprint 0 (ver Tabla 47) durará 1 semana y los 23 Sprints (ver Tabla 46) que durarán 11 meses y 2 semanas. Por esta razón, los miembros del equipo deben tener el tiempo 12 de meses en el proyecto.

\subsection{DEFINICIÓN DE LAS HERRAMIENTAS A UTILIZAR}

En esta sección se define las herramientas o artefactos que se necesitarán para realizar la propuesta tecnológica que se desarrollará en una un marco de trabajo con Scrum. En primer lugar, se definirá una visión del proyecto. Luego, se creará un Project Charter donde se colocará los objetivos y resultados deseados del proyecto, para seguir con las herramientas a utilizar.

\section{Project Vision}

Según la guía para el cuerpo de conocimiento de Scrum (SBOK, 2017). Una buena visión del proyecto explica las necesidades empresariales que el proyecto busca cumplir en vez de como habrá cumplir con la necesidad.

La declaración Project Vision Statement no debe ser demasiado específica y debe dejar espacio a la flexibilidad. Es posible que el conocimiento actual sobre el proyecto esté basado en suposiciones y cambien conforme avanza el proyecto, por lo que es importante que el Project Vision sea lo suficientemente flexible como para adaptarse a estos cambios. El Project Vision debe centrarse en el problema y no en la solución.

Tabla $\mathrm{N}^{\circ} 44$ Project Vision

\begin{tabular}{|l|}
\hline Empresa \\
\hline EY, una consultora a nivel mundial, quiere automatizar el trabajo de la Auditoría Interna de \\
Riesgos de sus clientes mediante una herramienta tecnológica \\
\hline Project Vision \\
\hline $\begin{array}{l}\text { Desarrollar una herramienta fácil de usar en el desarrollo de proyectos de Auditoría Interna } \\
\text { de Riesgos y que sea estéticamente agradable para los miembros de los equipos }\end{array}$ \\
\hline Fuente: Elaboración Propia
\end{tabular}

Fuente: Elaboración Propia 


\section{(1)}

\section{Project Charter}

Según la guía para el cuerpo de conocimiento de Scrum (SBOK, 2017). Un acta constitutiva del proyecto (conocida en inglés como Project Charter) es una declaración oficial de los objetivos y resultados deseados del proyecto. En varias organizaciones, el acta constitutiva del proyecto es el documento que autoriza el proyecto oficial y formalmente, dándole al equipo la autoridad por escrito para iniciar el proyecto (ver plantilla Project Charter Anexo 8).

Un Project Charter útil contiene tres elementos clave:

- Visión: la visión define el "Por qué" del proyecto. Este es el objetivo más elevado o el motivo de la existencia del proyecto.

- Misión: este es el "Qué" del proyecto y establece qué se hará en el proyecto para lograr su propósito superior.

- Criterios de éxito: los criterios de éxito son pruebas de gestión que describen los efectos fuera de la solución en sí.

\section{Herramientas de Scrum}

En el marco de trabajo Scrum, existen cuatro herramientas o artefactos. En este caso, artefacto se refiere a elementos físicos que se producen como resultado de la aplicación de Scrum. Los artefactos en Scrum son: El Product Backlog, el User Stories, el Sprint Backlog y el Incremento. 


\section{(}

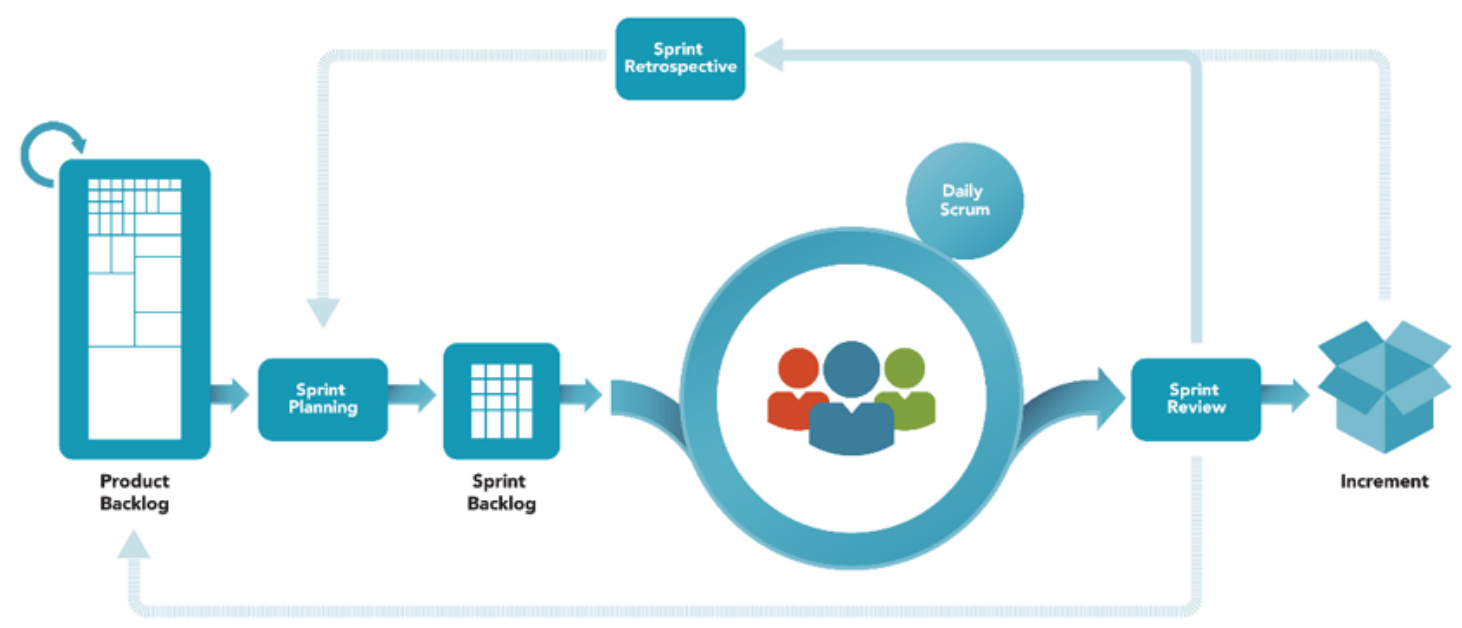

Figura $N^{\circ} 27$ Marco de Trabajo Scrum

Fuente: Guía Fundamental de Scrum

\section{a. Product Backlog}

Según la "Guía para el cuerpo de conocimiento de Scrum" (SBOK, 2017), el Product Owner desarrolla Product Backlog que contiene una lista priorizada de los requerimientos del negocio y de los proyectos escritos en forma de épicas, que son User Stories de alto nivel. El Product Backlog se basa en tres factores principales: valor, riesgo o incertidumbre y dependencias. También incluye cambios aprobados que pueden ser priorizados adecuadamente.

- Valor

Es la responsabilidad del Product Owner asegurar primero la entrega de los productos que ofrezcan el mayor valor. Incluso un producto de gran valor no puede ser parte del primer lanzamiento si hay otros productos de mayor valor que son suficientes para un primer lanzamiento.

- Riesgo e incertidumbre

Entre mayor incertidumbre exista, más riesgoso es el proyecto. Por lo tanto, es importante que se le dé mayor prioridad a los productos de mayor riesgo en el Product Backlog . Los 


\section{(1)}

productos que llevan un mayor nivel de riesgo también requerirán acciones de mitigación de riesgos. Tratar con riesgos al principio del proyecto no garantiza que el proyecto tenga éxito, pero sí mejorará la capacidad del equipo para hacer frente a los riesgos.

\section{- Dependencias}

Generalmente no es posible crear un Product Backlog donde no existan dependencias entre las User Stories. Los requerimientos funcionales a menudo dependen de otros requerimientos funcionales incluso los no-funcionales. Estas dependencias pueden afectar la forma en que se priorizan las User Stories en el Product Backlog. Dos de las formas más comunes para resolver las dependencias son dividir un sola User Story en varias partes o combinar User Stories interdependientes.

\section{b. User Stories}

Según la guía para el cuerpo de conocimiento de Scrum (SBOK, 2017). Los User Stories se apegan a una estructura específica predefinida y son una forma simple de documentar los requerimientos y funcionalidades que desea el usuario final. Un User Story incluye tres elementos sobre el requerimiento: ¿Quién? ¿Qué? y ¿Por qué?; los requerimientos expresados en los User Stories son oraciones breves, sencillas y fáciles de entender. El formato estándar predefinido da como resultado en una comunicación mejorada entre los Stakeholders, así como en mejores estimaciones por parte del equipo. Algunas User Stories tal vez sean demasiado extensas como para poderse manejar dentro un solo Sprint. A estas amplias User Stories generalmente se les llama épicas.

Una vez que las épicas surgen en el Backlog Priorizado del Producto para completarse en otro Sprint, se fragmentan aún más en User Stories.

Adicionalmente a la información obtenida del SBOK, según la Guía Fundamental de Scrum del Agile Coach, Jerónimo Palacios (Palacios, Guía fundamental de Scrum), describe que para obtener el máximo valor de un User Story, es necesario expresarlas desde el punto de vista del usuario. Intentar expresar una tarea técnica como un User Story puede llevarnos a 


\section{$(1$}

relaciones absurdas del tipo: Como desarrollador, quiero descargar el entorno de desarrollo para poder desarrollar.

Como se puede comprobar, el valor que se obtiene es mínimo. Otro punto a tener en cuenta en las User Stories es que tienen tres elementos importantes: La Tarjeta donde se expresa la User Story, una Conversación acerca de qué va la User Story y la Confirmación de que todo el mundo ha entendido el valor (listado de User Stories del proyecto, ver Tabla 45).

\section{Priorizar el Product Backlog mediante Bussiness Value \& Stories Point}

Según la publicación (Global Logic, 2016) se puede afirmar lo siguiente:

Esta técnica propone priorizar las User Stories basándose en factores como el esfuerzo y la opinión del Product Owner, del cliente y del Development Team, o incluso combinándolas. El Business Value es un valor númerico asignada a cada User Story donde a más alto el valor, mayor valor para el cliente.

Entonces una manera de priorizar el Backlog sería utilizando el Business Value de las User Stories. Sin embargo, llevarlo a cabo de manera "aislada" puede traer problemas.

Uno de ellos radica en que el cliente muchas veces se deja llevar por detalles superfluos y esto puede llevar a dejar de lado funcionalidad realmente importante.

Otro problema es que no se considera el esfuerzo que lleva implementar cada User Story. Esto último puede resolverse con Story Points, que son valores numéricos que introduce el equipo de desarrollo estimando el esfuerzo que le llevará desarrollar cada User Story (se realiza mediante el uso de la técnica de Planning Poker). Luego, para priorizar el Backlog es utilizando el cociente BusinessValue/StoryPoints. Es decir, dar lo que de mayor importancia para el usuario. Para ilustrar esta técnica, se adoptará al Product Backlog del desarrollo del proyecto con valores de cartas de $0,1,2,3,5,8,13$ y 20 (ver tabla 46). 
Tabla $N^{\circ} 45$ Lista de User Stories del Sistema de Auditoría Interna de Riesgos

\begin{tabular}{|c|c|c|c|c|c|}
\hline Código & Rol & Título & User Story & Pruebas de Aceptación & Dependencia \\
\hline HU001 & $\begin{array}{l}\text { Gerente de } \\
\text { Consultoría/ } \\
\text { Product } \\
\text { Owner }\end{array}$ & Cliente & $\begin{array}{l}\text { Quiero poder registrar un cliente de una } \\
\text { determinada industria donde puede indicar su GFIS } \\
\text { (código interno numérico), país de procedencia }\end{array}$ & $\begin{array}{l}\text { - Debe introducir todos los datos correctos y } \\
\text { comprobar que se seleccione la industria y que } \\
\text { no se creen dos clientes con el mismo GFIS }\end{array}$ & \\
\hline HU002 & $\begin{array}{l}\text { Gerente de } \\
\text { Consultoría/ } \\
\text { Product } \\
\text { Owner }\end{array}$ & $\begin{array}{l}\text { Proyect } \\
\text { o }\end{array}$ & $\begin{array}{l}\text { Quiero que cualquier usuario de la aplicación pueda } \\
\text { crear un proyecto de un cliente donde se puede } \\
\text { indicar el Engagement (código del proyecto), } \\
\text { nombre y las fechas que se va a trabajar }\end{array}$ & $\begin{array}{l}\text { - Debe introducir todos los datos correctos y } \\
\text { comprobar que las fechas de inicio y fin se } \\
\text { sean validados y que no se creen dos proyectos } \\
\text { con el mismo Engagement }\end{array}$ & \\
\hline HU003 & $\begin{array}{l}\text { Gerente de } \\
\text { Consultoría/ } \\
\text { Product } \\
\text { Owner }\end{array}$ & $\begin{array}{l}\text { Persona } \\
1 \mathrm{EY}\end{array}$ & $\begin{array}{l}\text { Quiero que el usuario que creo el proyecto pueda } \\
\text { crear un equipo (conformado por Gerente, Senior } \\
\text { y/o asistentes) y que sólo estos tengan acceso al } \\
\text { proyecto }\end{array}$ & $\begin{array}{l}\text { - Debe crear el equipo sólo el usuario que creo } \\
\text { el proyecto } \\
\text { - Sólo el personal asignado como equipo puede } \\
\text { desarrollar el proyecto }\end{array}$ & \\
\hline HU004 & $\begin{array}{l}\text { Gerente de } \\
\text { Consultoría/ } \\
\text { Product } \\
\text { Owner }\end{array}$ & $\begin{array}{l}\text { Persona } \\
1 \\
\text { Cliente }\end{array}$ & $\begin{array}{l}\text { Quiero que el usuario que tiene acceso al proyecto } \\
\text { pueda registrar al personal del cliente que ayudarán } \\
\text { al desarrollo del mismo. Lo datos que se registrarán } \\
\text { por parte del cliente será su nombre, correo y cargo } \\
\text { que desempeña en su organización }\end{array}$ & $\begin{array}{l}\text { - No debe cargase dos veces la misma persona } \\
\text { - Introducir y validar todos los datos } \\
\text { correctamente }\end{array}$ & \\
\hline HU005 & $\begin{array}{l}\text { Gerente de } \\
\text { Consultoría/ } \\
\text { Product } \\
\text { Owner }\end{array}$ & $\begin{array}{l}\text { Criterio } \\
\mathrm{S} \quad \text { del } \\
\text { proceso }\end{array}$ & $\begin{array}{l}\text { Quiero que el usuario que tiene acceso al proyecto } \\
\text { pueda crear criterios de procesos sólo para un } \\
\text { determinado proyecto. Además, se muestre } \\
\text { información referencial de criterios ya definidos } \\
\text { como ayuda a los usuarios }\end{array}$ & $\begin{array}{l}\text { - No debe registrar dos criterios con el mismo } \\
\text { nombre } \\
\text { - Debe registrar por lo menos un criterio }\end{array}$ & \\
\hline HU006 & $\begin{array}{l}\text { Gerente de } \\
\text { Consultoría/ }\end{array}$ & $\begin{array}{l}\text { Proceso } \\
\mathrm{s} \quad \text { del }\end{array}$ & $\begin{array}{l}\text { Quiero que el usuario que tiene acceso proyecto } \\
\text { pueda identificar y crear los procesos de un } \\
\text { proyecto de acuerdo a una base de conocimiento }\end{array}$ & $\begin{array}{l}\text { - Poder ver una base de conocimiento de los } \\
\text { procesos por la industria del cliente }\end{array}$ & \\
\hline
\end{tabular}




\begin{tabular}{|c|c|c|c|c|c|}
\hline & $\begin{array}{l}\text { Product } \\
\text { Owner }\end{array}$ & $\begin{array}{l}\text { proyect } \\
\text { o }\end{array}$ & $\begin{array}{l}\text { que se hará de la industria del cliente. } \\
\text { Adicionalmente, quiero ingresar nuevos procesos si } \\
\text { se necesita o modificar los que se me muestran de } \\
\text { forma predeterminada. }\end{array}$ & $\begin{array}{l}\text { - Codificar automáticamente el código del } \\
\text { proceso (tres primeros caracteres del proceso } \\
+ \text { correlativo, ejemplo proceso llamado } \\
\text { logística = LOG001) } \\
\text { - No cargarse dos procesos con el mismo } \\
\text { nombre } \\
\text { - Ver reflejado la estructura de procesos } \\
\text { definida para el proyecto }\end{array}$ & \\
\hline HU007 & $\begin{array}{l}\text { Gerente de } \\
\text { Consultoría/ } \\
\text { Product } \\
\text { Owner }\end{array}$ & $\begin{array}{l}\text { Objetiv } \\
\text { os del } \\
\text { proyect } \\
\text { o }\end{array}$ & $\begin{array}{l}\text { Quiero que el usuario que tiene acceso al proyecto } \\
\text { pueda crear objetivos estratégicos para el proyecto. } \\
\text { Además, debe mostrar objetivos estratégicos } \\
\text { referenciales como ayuda al usuario. }\end{array}$ & $\begin{array}{l}\text { - No puede crear dos objetivos con el mismo } \\
\text { nombre } \\
\text { - Debe crear por lo menos un objetivo } \\
\text { estratégico }\end{array}$ & \\
\hline HU008 & $\begin{array}{l}\text { Gerente de } \\
\text { Consultoría/ } \\
\text { Product } \\
\text { Owner }\end{array}$ & $\begin{array}{l}\text { Asociar } \\
\text { objetiv } \\
\text { os a } \\
\text { proceso } \\
\text { S }\end{array}$ & $\begin{array}{l}\text { Quiero que el usuario que tiene acceso al proyecto } \\
\text { pueda mediante una matriz asociar objetivos } \\
\text { estratégicos a los procesos definidos de un } \\
\text { proyecto. }\end{array}$ & $\begin{array}{l}\text { - No debe asociar dos veces el objetivo } \\
\text { estratégico a un determinado proceso } \\
\text { - Debe tener por lo menos un objetivo } \\
\text { estratégico asociado el proceso }\end{array}$ & $\begin{array}{l}\text { HU002, } \\
\text { HU006, } \\
\text { HU007 }\end{array}$ \\
\hline HU009 & $\begin{array}{l}\text { Gerente de } \\
\text { Consultoría/ } \\
\text { Product } \\
\text { Owner }\end{array}$ & $\begin{array}{l}\text { Config } \\
\text { urar } \\
\text { mapa } \\
\text { de } \\
\text { riesgos }\end{array}$ & $\begin{array}{l}\text { Quiero que el usuario que tiene acceso al proyecto } \\
\text { pueda configurar y registrar un mapa de riesgos de } \\
\text { acuerdo a una matriz definida para un proyecto } \\
(3 \times 3=\text { bajo, moderado, alto } ; 4 \times 4=\text { bajo, moderado, } \\
\text { alto y extremo o } 5 \times 5=\text { más bajo, bajo, moderado, } \\
\text { alto y extremo) }\end{array}$ & $\begin{array}{l}\text { - Debe por defecto seleccionado la matriz de } \\
3 \times 3 \\
\text { - El cuadrante seleccionado debe ser igual o } \\
\text { mayor al nivel del cuadrante que está debajo } \\
\text { de este }\end{array}$ & \\
\hline HU010 & $\begin{array}{l}\text { Gerente de } \\
\text { Consultoría/ } \\
\text { Product } \\
\text { Owner }\end{array}$ & $\begin{array}{l}\text { Criterio } \\
\mathrm{s} \quad \text { de } \\
\text { riesgos }\end{array}$ & $\begin{array}{l}\text { Quiero que el usuario que tiene acceso al proyecto } \\
\text { pueda identificar y crear criterios de riesgos (se } \\
\text { crearán criterios por el tipo de matriz } 3 \times 3,4 \times 4 \text { o } \\
5 \times 5 \text { ) de un proyecto de forma predeterminado de }\end{array}$ & $\begin{array}{l}\text { - No tener dos criterios de riesgos iguales } \\
\text { - Introducir todos los datos y comprobar que se } \\
\text { seleccione si la categoría del criterio es de }\end{array}$ & \\
\hline
\end{tabular}




\begin{tabular}{|c|c|c|c|c|c|}
\hline & & & $\begin{array}{l}\text { acuerdo a una base de conocimiento por industria } \\
\text { del cliente. Estos criterios serán de categoría de } \\
\text { probabilidad e impacto que serán de tipo } \\
\text { cuantitativo y/o cualitativo. Adicionalmente, } \\
\text { quiero ingresar nuevos criterios si se requiere o } \\
\text { actualizar con lo que se me muestran de forma } \\
\text { predeterminada. }\end{array}$ & $\begin{array}{l}\text { Probabilidad o Impacto y seleccione el tipo si } \\
\text { es Cuantitativo o Cualitativo }\end{array}$ & \\
\hline HU011 & $\begin{array}{l}\text { Gerente de } \\
\text { Consultoría/ } \\
\text { Product } \\
\text { Owner }\end{array}$ & $\begin{array}{l}\text { Categor } \\
\text { 1́as de } \\
\text { riesgo }\end{array}$ & $\begin{array}{l}\text { Quiero que el usuario que tiene acceso al proyecto } \\
\text { pueda crear categorías de riesgos. Se puede } \\
\text { introducir el nombre de la categoría que } \\
\text { pertenecerán a los riesgos de alto nivel del proyecto }\end{array}$ & $\begin{array}{l}\text { - No se puede crear dos veces la misma } \\
\text { categoría } \\
\text { - Se debe crear por lo menos una categoría de } \\
\text { riesgos }\end{array}$ & \\
\hline HU012 & $\begin{array}{l}\text { Gerente de } \\
\text { Consultoría/ } \\
\text { Product } \\
\text { Owner }\end{array}$ & $\begin{array}{l}\text { Riesgos } \\
\text { de alto } \\
\text { nivel }\end{array}$ & $\begin{array}{l}\text { Quiero que el usuario que tiene acceso al proyecto } \\
\text { pueda identificar y crear riesgos de alto nivel en un } \\
\text { proyecto de acuerdo a una base de conocimiento } \\
\text { por industria del cliente. Adicionalmente, quiero } \\
\text { ingresar nuevos riesgos o modificar los que se } \\
\text { muestran como base de conocimiento. }\end{array}$ & $\begin{array}{l}\text { - Ver la base de conocimiento cargada de } \\
\text { riesgos de alto nivel por industria para } \\
\text { identificar cuáles serán usados en un proyecto } \\
\text { - No ingresar dos riesgos iguales } \\
\text { - Poder registrar, editar o eliminar los riesgos }\end{array}$ & \\
\hline HU013 & $\begin{array}{l}\text { Gerente de } \\
\text { Consultoría/ } \\
\text { Product } \\
\text { Owner }\end{array}$ & $\begin{array}{l}\text { Asociar } \\
\text { categorí } \\
\text { a a } \\
\text { riesgo }\end{array}$ & $\begin{array}{l}\text { Quiero que el usuario que tiene acceso al proyecto } \\
\text { pueda mediante una matriz asociar una o más } \\
\text { categorías a uno o varios riesgos de alto nivel }\end{array}$ & $\begin{array}{l}\text { - Debe asociar por lo menos una categoría al } \\
\text { riesgo } \\
\text { - Debe asociar de una o varias categorías }\end{array}$ & $\begin{array}{l}\text { HU002, } \\
\text { HU008, } \\
\text { HU009 }\end{array}$ \\
\hline HU014 & $\begin{array}{l}\text { Gerente de } \\
\text { Consultoría/ } \\
\text { Product } \\
\text { Owner }\end{array}$ & $\begin{array}{l}\text { Evaluar } \\
\text { riesgos } \\
\text { de alto } \\
\text { nivel }\end{array}$ & $\begin{array}{l}\text { Quiero que el usuario que tiene acceso al proyecto } \\
\text { pueda evaluar los riesgos de alto nivel de acuerdo a } \\
\text { los criterios de probabilidad e impacto definidos de } \\
\text { forma cualitativos y/o cuantitativos. Los riegos } \\
\text { pueden ser evaluados por uno o varios criterios, } \\
\text { tanto para probabilidad e impacto. Además, los }\end{array}$ & $\begin{array}{l}\text { - La suma de porcentaje de criterios debe ser } \\
100 \% \text { para evaluar la probabilidad e impacto } \\
\text { - Debe evaluar la probabilidad e impacto, para } \\
\text { que pueda salir la severidad }\end{array}$ & \\
\hline
\end{tabular}




\begin{tabular}{|c|c|c|c|c|c|}
\hline & & & $\begin{array}{l}\text { criterios tendrán un porcentaje de peso (mayor } 0 \% \text { ) } \\
\text { que deben sumar hasta } 100 \% \text {. Por último, la } \\
\text { evaluación de la probabilidad e impacto dará como } \\
\text { resultado la severidad del riesgo. }\end{array}$ & & \\
\hline HU015 & $\begin{array}{l}\text { Gerente de } \\
\text { Consultoría/ } \\
\text { Product } \\
\text { Owner }\end{array}$ & $\begin{array}{l}\text { Mapa } \\
\text { de } \\
\text { riesgos }\end{array}$ & $\begin{array}{l}\text { Quiero que el usuario que tiene acceso al proyecto } \\
\text { pueda ver los riesgos dentro del mapa de riesgos } \\
\text { para ver en que cuadrante se encuentra y cuál es la } \\
\text { severidad obtenida }(3 \times 3=\text { bajo, moderado, alto } \\
; 4 \times 4=\text { bajo, moderado, alto y extremo o } 5 \times 5=\text { más } \\
\text { bajo, bajo, moderado, alto y extremo) }\end{array}$ & $\begin{array}{l}\text { Debe evaluar los criterios de alto nivel para } \\
\text { mostrar los puntos de los riesgos en el mapa de } \\
\text { riesgos }\end{array}$ & \\
\hline HU016 & $\begin{array}{l}\text { Gerente de } \\
\text { Consultoría/ } \\
\text { Product } \\
\text { Owner }\end{array}$ & $\begin{array}{l}\text { Asociar } \\
\text { riesgo a } \\
\text { proceso }\end{array}$ & $\begin{array}{l}\text { Quiero que el usuario que tiene acceso al proyecto } \\
\text { pueda mediante una matriz asociar los riesgos de } \\
\text { alto nivel a los procesos }\end{array}$ & $\begin{array}{l}\text { - El proceso puede estar asociado a uno o más } \\
\text { riesgos } \\
\text { - El proceso debe tener por lo menos un riesgo }\end{array}$ & $\begin{array}{l}\text { HU002, } \\
\text { HU006, } \\
\text { HU012 }\end{array}$ \\
\hline HU017 & $\begin{array}{l}\text { Gerente de } \\
\text { Consultoría/ } \\
\text { Product } \\
\text { Owner }\end{array}$ & $\begin{array}{l}\text { Evaluar } \\
\text { los } \\
\text { proceso } \\
\text { s }\end{array}$ & $\begin{array}{l}\text { Quiero que el usuario que tiene acceso al proyecto } \\
\text { pueda evaluar y priorizar los procesos de acuerdo } \\
\text { al ponderado de la probabilidad e impacto } \\
\text { obtenidos de los evaluación de riesgos y sobre la } \\
\text { evaluación de los criterios de los procesos }\end{array}$ & $\begin{array}{l}\text { - Debe colocar un porcentaje en el peso de } \\
\text { riesgos y criterios de procesos que sumen } \\
100 \% \\
\text { - El valor que se ponen por cada criterio a cada } \\
\text { proceso será de acuerdo a la matriz que se haya } \\
\text { seleccionado ( } 3 \times 3=1 \text { bajo, } 2 \text { moderado y } 3 \\
\text { alto; } 4 \times 4=1 \text { bajo, } 2 \text { moderado, } 3 \text { alto y } 4 \\
\text { extremo; y } 5 \times 5=1 \text { más bajo, } 2 \text { bajo, } 3 \\
\text { moderado, } 4 \text { alto y } 5 \text { extremo) }\end{array}$ & \\
\hline HU018 & $\begin{array}{l}\text { Gerente de } \\
\text { Consultoría/ }\end{array}$ & $\begin{array}{l}\text { Prioriza } \\
\mathrm{r} \quad \text { los }\end{array}$ & $\begin{array}{l}\text { Quiero que el usuario que tiene acceso al proyecto } \\
\text { pueda ver los procesos priorizados. Luego, pueda } \\
\text { crear las visitas de acuerdo a una fecha de inicio y }\end{array}$ & $\begin{array}{l}\text { - Introducir todos los datos y comprobar que las } \\
\text { fechas de inicio y fin sean validadas }\end{array}$ & \\
\hline
\end{tabular}




\begin{tabular}{|c|c|c|c|c|}
\hline & $\begin{array}{l}\text { Product } \\
\text { Owner }\end{array}$ & $\begin{array}{l}\text { proceso } \\
\mathrm{S}\end{array}$ & $\begin{array}{l}\text { fin para los procesos que serán auditados. Estas } \\
\text { visitas crearán el plan de auditoría del proyecto }\end{array}$ & $\begin{array}{l}\text { - Debe crear por lo menos una visita para crear } \\
\text { el plan de auditoría }\end{array}$ \\
\hline HU019 & $\begin{array}{l}\text { Gerente de } \\
\text { Consultoría/ } \\
\text { Product } \\
\text { Owner }\end{array}$ & $\begin{array}{l}\text { Plan de } \\
\text { auditorí } \\
\text { a }\end{array}$ & $\begin{array}{l}\text { Quiero que el usuario que tiene acceso al proyecto } \\
\text { pueda crear y gestionar el plan de auditoría (tipo } \\
\text { cronograma de trabajo) en base a los procesos } \\
\text { priorizados donde se le asignarán a cada proceso } \\
\text { los miembros del equipo y las fechas de visitas. } \\
\text { Además, se podrán crear actividades, por ejemplo, } \\
\text { KickOff, reuniones, etc. Como parte del plan de } \\
\text { auditoría. }\end{array}$ & $\begin{array}{l}\text { - Debe seleccionar por lo menos un responsable } \\
\text { (personal de EY) para trabajar el proceso } \\
\text { - No necesariamente se deben crear actividades } \\
\text { en el proyecto }\end{array}$ \\
\hline HU020 & $\begin{array}{l}\text { Gerente de } \\
\text { Consultoría/ } \\
\text { Product } \\
\text { Owner }\end{array}$ & $\begin{array}{l}\text { Riesgo } \\
\text { de Bajo } \\
\text { nivel }\end{array}$ & $\begin{array}{l}\text { Quiero que el usuario que tiene acceso al proyecto } \\
\text { pueda seleccionar la visita y ver el proceso en la } \\
\text { cual es responsable y luego, pueda identificar y } \\
\text { crear riesgos de bajo nivel asociados a los riesgos } \\
\text { de alto nivel de acuerdo a una base de conocimiento } \\
\text { por industria del cliente. Adicionalmente, quiero } \\
\text { ingresar nuevos riesgos o modificar los que se } \\
\text { muestran como base de conocimiento. }\end{array}$ & $\begin{array}{l}\text { - Debe poder ver la base conocimiento de } \\
\text { riesgos de bajo nivel por industria para } \\
\text { identificar cuáles serán usados en un proyecto } \\
\text { - No debe ingresar dos riesgos iguales } \\
\text { - El riesgo de bajo nivel debe estar asociado a } \\
\text { un riesgo de alto nivel } \\
\text { - El riesgo puede estar asociado a uno o más } \\
\text { controles }\end{array}$ \\
\hline HU021 & $\begin{array}{l}\text { Gerente de } \\
\text { Consultoría/ } \\
\text { Product } \\
\text { Owner }\end{array}$ & $\begin{array}{l}\text { Control } \\
\text { es }\end{array}$ & $\begin{array}{l}\text { Quiero que el usuario que tiene acceso al proyecto } \\
\text { pueda seleccionar la visita y ver el proceso en la } \\
\text { cual es responsable y luego, pueda identificar y } \\
\text { crear controles de riesgo de bajo nivel de acuerdo a } \\
\text { una base de conocimiento por industria del cliente }\end{array}$ & $\begin{array}{l}\text { - Debe poder ver la base de conocimiento de } \\
\text { controles por industria para identificar cuáles } \\
\text { serán usados en el proyecto } \\
\text { - No ingresar dos controles iguales } \\
\text { - El control puede estar asociado a uno o más } \\
\text { riesgos }\end{array}$ \\
\hline
\end{tabular}




\begin{tabular}{|c|c|c|c|c|}
\hline HU022 & $\begin{array}{l}\text { Gerente de } \\
\text { Consultoría/ } \\
\text { Product } \\
\text { Owner }\end{array}$ & $\begin{array}{l}\text { Evaluar } \\
\text { riesgos } \\
\text { de bajo } \\
\text { nivel }\end{array}$ & $\begin{array}{l}\text { Quiero que el usuario que tiene acceso al proyecto } \\
\text { pueda evaluar los riesgos de bajo nivel de acuerdo } \\
\text { a los criterios de probabilidad e impacto definidos } \\
\text { de forma cualitativos y/o cuantitativos. Los riegos } \\
\text { pueden ser evaluados por uno o varios criterios, } \\
\text { tanto para probabilidad e impacto. Además, los } \\
\text { criterios tendrán un porcentaje de peso (mayor 0\%) } \\
\text { que deben sumar hasta } 100 \% \text {. Por último, la } \\
\text { evaluación de la probabilidad e impacto dará como } \\
\text { resultado la severidad del riesgo. }\end{array}$ & $\begin{array}{l}\text { - La suma de porcentaje de criterios debe ser } \\
100 \% \text { para evaluar la probabilidad e impacto } \\
\text { - Debe evaluar la probabilidad e impacto, para } \\
\text { que pueda salir la severidad }\end{array}$ \\
\hline HU023 & $\begin{array}{l}\text { Gerente de } \\
\text { Consultoría/ } \\
\text { Product } \\
\text { Owner }\end{array}$ & $\begin{array}{l}\text { Diseño } \\
\text { de } \\
\text { control } \\
\text { es }\end{array}$ & $\begin{array}{l}\text { Quiero que el usuario que tiene acceso al proyecto } \\
\text { pueda evaluar el diseño de un control, colocando } \\
\text { los atributos que le corresponda, para luego, sean } \\
\text { evaluados en la operatividad de controles (en caso } \\
\text { el control este con resultado Efectivo) }\end{array}$ & $\begin{array}{l}\text { - Poder decidir si el control es Efectivo o No } \\
\text { Efectivo para que luego sea usado en la } \\
\text { operatividad (en caso sea Efectivo) } \\
\text { - Debe introducir todos los datos y validar todos } \\
\text { los atributos de los controles }\end{array}$ \\
\hline HU024 & $\begin{array}{l}\text { Gerente de } \\
\text { Consultoría/ } \\
\text { Product } \\
\text { Owner }\end{array}$ & $\begin{array}{l}\text { Operati } \\
\text { vidad } \\
\text { de } \\
\text { control } \\
\text { es }\end{array}$ & $\begin{array}{l}\text { Quiero que el usuario que tiene acceso al proyecto } \\
\text { pueda evaluar la operatividad de controles para ver } \\
\text { si el riesgo inherente a cambiado, obteniendo el } \\
\text { riesgo residual que se verá una vez finalizada la } \\
\text { evaluación del control }\end{array}$ & $\begin{array}{l}\text { - Ver los controles que han pasado del diseño de } \\
\text { controles (controles con resultado Efectivo) } \\
\text { - Poder evaluar la operatividad del control si es } \\
\text { Efectivo o No Efectivo } \\
\text { - Debe introducir todos los datos y comprobar si } \\
\text { al Seleccionar el riesgo Residual si ha } \\
\text { cambiado con la evaluación del control }\end{array}$ \\
\hline HU025 & $\begin{array}{l}\text { Gerente de } \\
\text { Consultoría/ } \\
\text { Product } \\
\text { Owner }\end{array}$ & $\begin{array}{l}\text { Plan de } \\
\text { acción }\end{array}$ & $\begin{array}{l}\text { Quiero que el usuario que tiene acceso al proyecto } \\
\text { pueda crear un plan de acción por cada control que } \\
\text { haya obtenido como resultado No Efectivo, en la } \\
\text { cual se asigne a un responsable que tome acciones } \\
\text { correctivas para eliminar la falla del control. }\end{array}$ & $\begin{array}{l}\text { - Ver los controles que han dado como resultado } \\
\text { No Efectivo, ya sea desde la evaluación del } \\
\text { diseño u operatividad del control }\end{array}$ \\
\hline
\end{tabular}




\begin{tabular}{|c|c|c|c|c|c|}
\hline & & & $\begin{array}{l}\text { Además, se le asigna el supervisor de dicho } \\
\text { responsable para que haga el seguimiento del } \\
\text { responsable del control a fin de que este cumpla con } \\
\text { su trabajo en la solución del incidente. }\end{array}$ & $\begin{array}{l}\text { - Poder asignar un responsable y un plan de } \\
\text { acción para el control de acuerdo a una fecha } \\
\text { de implementación } \\
\text { - Poder hacer el seguimiento del plan de acción } \\
\text { por parte del supervisor del responsable }\end{array}$ & \\
\hline HU026 & $\begin{array}{l}\text { Gerente de } \\
\text { Consultoría/ } \\
\text { Product } \\
\text { Owner }\end{array}$ & $\begin{array}{l}\text { Servici } \\
\text { o de } \\
\text { notifica } \\
\text { ción de } \\
\text { plan de } \\
\text { acción }\end{array}$ & $\begin{array}{l}\text { Quiero tener un servicio de mensajería instantánea } \\
\text { (por correo corporativo), en la cual se le envié al } \\
\text { responsable notificaciones del control que se le ha } \\
\text { asignado hasta que sea solucionado. } \\
\text { Adicionalmente, al supervisor se le muestre un } \\
\text { resumen de los estados de los controles por } \\
\text { responsable }\end{array}$ & $\begin{array}{l}\text { - Debe tener por lo menos un plan de acción de } \\
\text { los controles con resultado No Efectivo }\end{array}$ & HU025 \\
\hline HU027 & $\begin{array}{l}\text { Gerente de } \\
\text { Consultoría/ } \\
\text { Product } \\
\text { Owner }\end{array}$ & $\begin{array}{l}\text { Reporte } \\
\text { de } \\
\text { resultad } \\
\text { o de } \\
\text { operati } \\
\text { vidad }\end{array}$ & $\begin{array}{l}\text { Quiero poder obtener reportes del resultado final de } \\
\text { la operatividad de los controles evaluados por parte } \\
\text { del equipo de proyecto. Para que el cliente pueda } \\
\text { ver el resultado de la auditoría realizada a su } \\
\text { organización. }\end{array}$ & $\begin{array}{l}\text { - Ver el resultado final de la operatividad de los } \\
\text { controles } \\
\text { - Debe mostrar información del proyecto si el } \\
\text { usuario es miembro del equipo } \\
\text { - Debe filtrar la información por fecha de inicio } \\
\text { y fin del proyecto, periodo y/o cliente }\end{array}$ & HU024 \\
\hline HU028 & $\begin{array}{l}\text { Gerente de } \\
\text { Consultoría/ } \\
\text { Product } \\
\text { Owner }\end{array}$ & $\begin{array}{l}\text { Reporte } \\
\text { de plan } \\
\text { de } \\
\text { acción }\end{array}$ & $\begin{array}{l}\text { Quiero poder obtener un reporte de los planes de } \\
\text { acción de los controles que ha definido el equipo de } \\
\text { proyecto para realizar el seguimiento si han tomado } \\
\text { las acciones correctivas pertinentes sobre los } \\
\text { controles con incidencias }\end{array}$ & $\begin{array}{l}\text { - Ver el plan de acción para realizar un } \\
\text { seguimiento de las correcciones a resolver } \\
\text { para cada control con resultado No Efectivo } \\
\text { - Debe mostrar información del proyecto si el } \\
\text { usuario es miembro del equipo } \\
\text { - Debe filtrar la información por fecha de inicio } \\
\text { y fin del proyecto, periodo y/o cliente }\end{array}$ & HU025 \\
\hline
\end{tabular}




\begin{tabular}{|c|c|c|c|c|}
\hline HU029 & $\begin{array}{l}\text { Gerente de } \\
\text { Consultoría/ } \\
\text { Product } \\
\text { Owner }\end{array}$ & $\begin{array}{l}\text { Admini } \\
\text { strar } \\
\text { usuario } \\
\text { s }\end{array}$ & $\begin{array}{l}\text { Quiero que haya un administrador que cree las } \\
\text { cuenta de los usuarios que tendrán acceso a la } \\
\text { aplicación }\end{array}$ & $\begin{array}{l}\text { - Debe incluir todos los datos, comprobar y } \\
\text { validar la información correspondiente como } \\
\text { correo, si existe el mismo usuario }\end{array}$ \\
\hline
\end{tabular}

Elaboración: Fuente Propia

En esta lista no se está colocando de forma dependiente todos los User Stories, ya que se desea poder priorizar dando mayor valor a lo que el

Product Owner considere importante.

Tabla $N^{\circ} 46$ Product Backlog Priorizado del Sistema de Auditoría Interna

\begin{tabular}{|c|c|c|c|c|c|c|c|}
\hline Código & Título & User Story & Dependencia & $\begin{array}{c}\text { Business } \\
\text { Value }\end{array}$ & Story Points & Cociente & Nro Sprint \\
\hline HU001 & Cliente & $\begin{array}{l}\text { Quiero poder registrar un cliente de una } \\
\text { determinada industria donde puede indicar } \\
\text { su GFIS (código interno numérico), país de } \\
\text { procedencia }\end{array}$ & & 5 & 2 & 2.50 & 1 \\
\hline HU002 & Proyecto & $\begin{array}{l}\text { Quiero que cualquier usuario de la } \\
\text { aplicación pueda crear un proyecto de un } \\
\text { cliente donde se puede indicar el } \\
\text { Engagement (código del proyecto), nombre } \\
\text { y las fechas que se va a trabajar }\end{array}$ & & 5 & 2 & 2.50 & 1 \\
\hline HU003 & Personal EY & $\begin{array}{l}\text { Quiero que el usuario que creo el proyecto } \\
\text { pueda crear un equipo (conformado por } \\
\text { Gerente, Senior y/o asistentes) y que sólo } \\
\text { estos tengan acceso al proyecto }\end{array}$ & & 2 & 2 & 1.00 & 19 \\
\hline
\end{tabular}




\section{$(1$}

\begin{tabular}{|c|c|c|c|c|c|c|}
\hline HU004 & $\begin{array}{l}\text { Personal } \\
\text { Cliente }\end{array}$ & $\begin{array}{l}\text { Quiero que el usuario que tiene acceso al } \\
\text { proyecto pueda registrar al personal del } \\
\text { cliente que ayudarán al desarrollo del } \\
\text { mismo. Lo datos que se registrarán por parte } \\
\text { del cliente será su nombre, correo y cargo } \\
\text { que desempeña en su organización }\end{array}$ & 2 & 2 & 1.00 & 18 \\
\hline HU005 & $\begin{array}{l}\text { Criterios del } \\
\text { proceso }\end{array}$ & $\begin{array}{l}\text { Quiero que el usuario que tiene acceso al } \\
\text { proyecto pueda crear criterios de procesos } \\
\text { sólo para un determinado proyecto. Además, } \\
\text { se muestre información referencial de } \\
\text { criterios ya definidos como ayuda a los } \\
\text { usuarios }\end{array}$ & 3 & 2 & 1.50 & 13 \\
\hline HU006 & $\begin{array}{l}\text { Procesos del } \\
\text { proyecto }\end{array}$ & $\begin{array}{l}\text { Quiero que el usuario que tiene acceso } \\
\text { proyecto pueda identificar y crear los } \\
\text { procesos de un proyecto de acuerdo a una } \\
\text { base de conocimiento que se hará de la } \\
\text { industria del cliente. Adicionalmente, quiero } \\
\text { ingresar nuevos procesos si se necesita o } \\
\text { modificar los que se me muestran de forma } \\
\text { predeterminada. }\end{array}$ & 13 & 5 & 2.60 & 1 \\
\hline HU007 & $\begin{array}{l}\text { Objetivos del } \\
\text { proyecto }\end{array}$ & $\begin{array}{l}\text { Quiero que el usuario que tiene acceso al } \\
\text { proyecto pueda crear objetivos estratégicos } \\
\text { para el proyecto. Además, debe mostrar } \\
\text { objetivos estratégicos referenciales como } \\
\text { ayuda al usuario. }\end{array}$ & 2 & 2 & 1.00 & 19 \\
\hline
\end{tabular}




\section{$(1)$}

\begin{tabular}{|c|c|c|c|c|c|c|c|}
\hline HU008 & $\begin{array}{l}\text { Asociar } \\
\text { objetivos a } \\
\text { procesos }\end{array}$ & $\begin{array}{l}\text { Quiero que el usuario que tiene acceso al } \\
\text { proyecto pueda mediante una matriz asociar } \\
\text { objetivos estratégicos a los procesos } \\
\text { definidos de un proyecto. }\end{array}$ & $\begin{array}{l}\text { HU002, } \\
\text { HU006, } \\
\text { HU007 }\end{array}$ & 1 & 1 & 1.00 & 19 \\
\hline HU009 & $\begin{array}{l}\text { Configurar } \\
\text { mapa de } \\
\text { riesgos }\end{array}$ & $\begin{array}{l}\text { Quiero que el usuario que tiene acceso al } \\
\text { proyecto pueda configurar y registrar un } \\
\text { mapa de riesgos de acuerdo a una matriz } \\
\text { definida para un proyecto ( } 3 \times 3=\text { bajo, } \\
\text { moderado, alto ; } 4 \times 4=\text { bajo, moderado, alto } \\
\text { y extremo o } 5 \times 5=\text { más bajo, bajo, } \\
\text { moderado, alto y extremo) }\end{array}$ & & 13 & 20 & 0.65 & 20,21 \\
\hline HU010 & $\begin{array}{l}\text { Criterios de } \\
\text { riesgos }\end{array}$ & $\begin{array}{l}\text { Quiero que el usuario que tiene acceso al } \\
\text { proyecto pueda identificar y crear criterios } \\
\text { de riesgos (se crearán criterios por el tipo de } \\
\text { matriz } 3 \times 3,4 \times 4 \text { o } 5 \times 5 \text { ) de un proyecto de } \\
\text { forma predeterminado de acuerdo a una base } \\
\text { de conocimiento por industria del cliente. } \\
\text { Estos criterios serán de categoría de } \\
\text { probabilidad e impacto que serán de tipo } \\
\text { cuantitativo y/o cualitativo. Adicionalmente, } \\
\text { quiero ingresar nuevos criterios si se } \\
\text { requiere o actualizar con lo que se me } \\
\text { muestran de } 0.13 \text { forma predeterminada. }\end{array}$ & & 5 & 8 & 0.63 & 22 \\
\hline HU011 & $\begin{array}{l}\text { Categorías de } \\
\text { riesgo }\end{array}$ & $\begin{array}{l}\text { Quiero que el usuario que tiene acceso al } \\
\text { proyecto pueda crear categorías de riesgos. } \\
\text { Se puede introducir el nombre de la } \\
\text { categoría que pertenecerán a los riesgos de } \\
\text { alto nivel del proyecto }\end{array}$ & & 3 & 2 & 1.50 & 13 \\
\hline
\end{tabular}




\begin{tabular}{|c|c|c|c|c|c|c|c|}
\hline HU012 & $\begin{array}{l}\text { Riesgos de } \\
\text { alto nivel }\end{array}$ & $\begin{array}{l}\text { Quiero que el usuario que tiene acceso al } \\
\text { proyecto pueda identificar y crear riesgos de } \\
\text { alto nivel en un proyecto de acuerdo a una } \\
\text { base de conocimiento por industria del } \\
\text { cliente. Adicionalmente, quiero ingresar } \\
\text { nuevos riesgos o modificar los que se } \\
\text { muestran como base de conocimiento. }\end{array}$ & & 13 & 8 & 1.63 & 3 \\
\hline HU013 & $\begin{array}{l}\text { Asociar } \\
\text { categoría a } \\
\text { riesgo }\end{array}$ & $\begin{array}{l}\text { Quiero que el usuario que tiene acceso al } \\
\text { proyecto pueda mediante una matriz asociar } \\
\text { una o más categorías a uno o varios riesgos } \\
\text { de alto nivel }\end{array}$ & $\begin{array}{l}\text { HU002, } \\
\text { HU008, } \\
\text { HU009 }\end{array}$ & 1 & 1 & 1.00 & 15 \\
\hline HU014 & $\begin{array}{l}\text { Evaluar } \\
\text { riesgos de } \\
\text { alto nivel }\end{array}$ & $\begin{array}{l}\text { Quiero que el usuario que tiene acceso al } \\
\text { proyecto pueda evaluar los riesgos de alto } \\
\text { nivel de acuerdo a los criterios de } \\
\text { probabilidad e impacto definidos de forma } \\
\text { cualitativo y/o cuantitativo. Los riegos } \\
\text { pueden ser evaluados por uno o varios } \\
\text { criterios, tanto para probabilidad e impacto. } \\
\text { Además, los criterios tendrán un porcentaje } \\
\text { de peso (mayor 0\%) que deben sumar hasta } \\
100 \% \text {. Por último, la evaluación de la } \\
\text { probabilidad e impacto dará como resultado } \\
\text { la severidad del riesgo. }\end{array}$ & & 13 & 8 & 1.63 & 4 \\
\hline HU015 & $\begin{array}{l}\text { Mapa de } \\
\text { riesgos }\end{array}$ & $\begin{array}{l}\text { Quiero que el usuario que tiene acceso al } \\
\text { proyecto pueda ver los riesgos dentro del } \\
\text { mapa de riesgos para ver en que cuadrante } \\
\text { se encuentra y cuál es la severidad obtenida } \\
\text { (3x3 = bajo, moderado, alto } ; 4 \times 4=\text { bajo, }\end{array}$ & & 13 & 13 & 1.00 & 17 \\
\hline
\end{tabular}




\begin{tabular}{|c|c|c|c|c|c|c|c|}
\hline & & $\begin{array}{l}\text { moderado, alto y extremo o } 5 \times 5=\text { más bajo, } \\
\text { bajo, moderado, alto y extremo) }\end{array}$ & & & & & \\
\hline HU016 & $\begin{array}{l}\text { Asociar } \\
\text { riesgo a } \\
\text { proceso }\end{array}$ & $\begin{array}{l}\text { Quiero que el usuario que tiene acceso al } \\
\text { proyecto pueda mediante una matriz asociar } \\
\text { los riesgos de alto nivel a los procesos }\end{array}$ & $\begin{array}{l}\text { HU002, } \\
\text { HU006, } \\
\text { HU012 }\end{array}$ & 2 & 3 & 0.67 & 20 \\
\hline HU017 & $\begin{array}{l}\text { Evaluar los } \\
\text { procesos }\end{array}$ & $\begin{array}{l}\text { Quiero que el usuario que tiene acceso al } \\
\text { proyecto pueda evaluar y priorizar los } \\
\text { procesos de acuerdo al ponderado de la } \\
\text { probabilidad e impacto obtenidos de los } \\
\text { evaluación de riesgos y sobre la evaluación } \\
\text { de los criterios de los procesos }\end{array}$ & & 5 & 8 & 0.63 & 22 \\
\hline HU018 & $\begin{array}{l}\text { Priorizar los } \\
\text { procesos }\end{array}$ & $\begin{array}{l}\text { Quiero que el usuario que tiene acceso al } \\
\text { proyecto pueda ver los procesos priorizados. } \\
\text { Luego, pueda crear las visitas de acuerdo a } \\
\text { una fecha de inicio y fin para los procesos } \\
\text { que serán auditados. Estas visitas crearán el } \\
\text { plan de auditoría del proyecto }\end{array}$ & & 5 & 5 & 1.00 & 18 \\
\hline HU019 & $\begin{array}{l}\text { Plan de } \\
\text { auditoría }\end{array}$ & $\begin{array}{l}\text { Quiero que el usuario que tiene acceso al } \\
\text { proyecto pueda crear y gestionar el plan de } \\
\text { auditoría (tipo cronograma de trabajo) en } \\
\text { base a los procesos priorizados donde se le } \\
\text { asignarán a cada proceso los miembros del } \\
\text { equipo y las fechas de visitas. Además, se } \\
\text { podrán crear actividades, por ejemplo, }\end{array}$ & & 20 & 20 & 1.00 & 14,15 \\
\hline
\end{tabular}




\begin{tabular}{|c|c|c|c|c|c|c|}
\hline & & $\begin{array}{l}\text { KickOff, reuniones, etc. Como parte del } \\
\text { plan de auditoría. }\end{array}$ & & & & \\
\hline HU020 & $\begin{array}{l}\text { Riesgo de } \\
\text { Bajo nivel }\end{array}$ & $\begin{array}{l}\text { Quiero que el usuario que tiene acceso al } \\
\text { proyecto pueda seleccionar la visita y ver el } \\
\text { proceso en la cual es responsable y luego, } \\
\text { pueda identificar y crear riesgos de bajo } \\
\text { nivel asociados a los riesgos de alto nivel de } \\
\text { acuerdo a una base de conocimiento por } \\
\text { industria del cliente. Adicionalmente, quiero } \\
\text { ingresar nuevos riesgos o modificar los que } \\
\text { se muestran como base de conocimiento. }\end{array}$ & 20 & 13 & 1.54 & 7 \\
\hline HU021 & Controles & $\begin{array}{l}\text { Quiero que el usuario que tiene acceso al } \\
\text { proyecto pueda seleccionar la visita y ver el } \\
\text { proceso en la cual es responsable y luego, } \\
\text { pueda identificar y crear controles de riesgo } \\
\text { de bajo nivel de acuerdo a una } 5 \text { base de } \\
\text { conocimiento por industria del cliente }\end{array}$ & 20 & 13 & 1.54 & 8 \\
\hline HU022 & $\begin{array}{l}\text { Evaluar } \\
\text { riesgos de } \\
\text { bajo nivel }\end{array}$ & $\begin{array}{l}\text { Quiero que el usuario que tiene acceso al } \\
\text { proyecto pueda evaluar los riesgos de bajo } \\
\text { nivel de acuerdo a los criterios de } \\
\text { probabilidad e impacto definido de forma } \\
\text { cualitativo y/o cuantitativo. Los riegos } \\
\text { pueden ser evaluados por uno o varios } \\
\text { criterios, tanto para probabilidad e impacto. } \\
\text { Además, los criterios tendrán un porcentaje } \\
\text { de peso (mayor 0\%) que deben sumar hasta } \\
100 \% \text {. Por último, la evaluación de la }\end{array}$ & 13 & 8 & 1.63 & 5 \\
\hline
\end{tabular}




\begin{tabular}{|c|c|c|c|c|c|c|c|}
\hline & & $\begin{array}{l}\text { probabilidad e impacto dará como resultado } \\
\text { la severidad del riesgo. }\end{array}$ & & & & & \\
\hline HU023 & \begin{tabular}{ll|} 
Diseño & $\mathrm{de}$ \\
controles &
\end{tabular} & $\begin{array}{l}\text { Quiero que el usuario que tiene acceso al } \\
\text { proyecto pueda evaluar el diseño de un } \\
\text { control, colocando los atributos que le } \\
\text { corresponda, para luego, sean evaluados en la } \\
\text { operatividad de controles (en caso el control } \\
\text { este con resultado Efectivo) }\end{array}$ & & 20 & 13 & 1.54 & 9,10 \\
\hline HU024 & $\begin{array}{l}\text { Operatividad } \\
\text { de controles }\end{array}$ & $\begin{array}{l}\text { Quiero que el usuario que tiene acceso al } \\
\text { proyecto pueda evaluar la operatividad de } \\
\text { controles para ver si el riesgo inherente a } \\
\text { cambiado, obteniendo el riesgo residual que } \\
\text { se verá una vez finalizada la evaluación del } \\
\text { control }\end{array}$ & & 20 & 13 & 1.54 & 11,12 \\
\hline HU025 & $\begin{array}{ll}\text { Plan } & \text { de } \\
\text { acción } & \end{array}$ & $\begin{array}{l}\text { Quiero que el usuario que tiene acceso al } \\
\text { proyecto pueda crear un plan de acción por } \\
\text { cada control que haya obtenido como } \\
\text { resultado No Efectivo, en la cual se asigne a } \\
\text { un responsable que tome acciones correctivas } \\
\text { para eliminar la falla del control. Además, se } \\
\text { le asigna el supervisor de dicho responsable } \\
\text { para que haga el seguimiento del responsable } \\
\text { del control a fin de que este cumpla con su } \\
\text { trabajo en la solución del incidente. }\end{array}$ & & 20 & 8 & 2.50 & 2 \\
\hline HU026 & $\begin{array}{l}\text { Servicio de } \\
\text { notificación }\end{array}$ & $\begin{array}{l}\text { Quiero tener un servicio de mensajería } \\
\text { instantánea (por correo corporativo), en la } \\
\text { cual se le envié al responsable notificaciones }\end{array}$ & HU025 & 8 & 20 & 1.00 & 16 \\
\hline
\end{tabular}




\begin{tabular}{|c|c|c|c|c|c|c|c|}
\hline & $\begin{array}{l}\text { de plan de } \\
\text { acción }\end{array}$ & $\begin{array}{l}\text { del control que se le ha asignado hasta que } \\
\text { sea solucionado. Adicionalmente, al } \\
\text { supervisor se le muestre un resumen de los } \\
\text { estados de los controles por responsable }\end{array}$ & & & & & \\
\hline HU027 & $\begin{array}{l}\text { Reporte de } \\
\text { resultado de } \\
\text { operatividad }\end{array}$ & $\begin{array}{l}\text { Quiero poder obtener reportes del resultado } \\
\text { final de la operatividad de los controles } \\
\text { evaluados por parte del equipo de proyecto. } \\
\text { Para que el cliente pueda ver el resultado de } \\
\text { la auditoría realizada a su organización. }\end{array}$ & HU024 & 8 & 5 & 1.60 & 6 \\
\hline HU028 & $\begin{array}{ll}\text { Reporte } & \text { de } \\
\text { plan } & \text { de } \\
\text { acción } & \end{array}$ & $\begin{array}{l}\text { Quiero poder obtener un reporte de los planes } \\
\text { de acción de los controles que ha definido el } \\
\text { equipo de proyecto para realizar el } \\
\text { seguimiento si han tomado las acciones } \\
\text { correctivas pertinentes sobre los controles } \\
\text { con incidencias }\end{array}$ & HU025 & 8 & 5 & 1.60 & 6 \\
\hline HU029 & $\begin{array}{l}\text { Administrar } \\
\text { usuarios }\end{array}$ & $\begin{array}{l}\text { Quiero que haya un administrador que cree } \\
\text { las cuenta de los usuarios que tendrán acceso } \\
\text { a la aplicación }\end{array}$ & & 5 & 8 & 0.63 & 23 \\
\hline
\end{tabular}

Fuente: Elaboración propia

De acuerdo al resultado de cocientes, el Development Team priorizará los User Stories HU001, HU002 y HU006, para realizar el Sprint 1, ya que dan mayor valor para el Product Owner y que implican un menor esfuerzo para el Development Team . Luego de esto, seguirán los otros User Stories para los siguientes Sprints que en total en el cuadro son 23 Sprints por desarrollar. Es importante notar que estos valores no son fijos y se pueden actualizar al terminar cada Sprint. 


\section{(1)}

\section{c. Sprint Backlog}

Según la "Guía para el cuerpo de conocimiento de Scrum” (SBOK, 2017). La lista de tareas que llevará a cabo el Development Team en el siguiente Sprint se denomina Sprint Backlog . Es común que el Sprint Backlog esté representado en un Scrumboard o tablero de tareas, el cual proporciona una constante representación visual del estado de los User Stories en el Backlog. En el Sprint Backlog también se incluye cualquier riesgo asociado a las tareas. Cualquier actividad de mitigación de riesgos para atender los riesgos identificados también se incluirían como tareas en el Sprint Backlog. Una vez que el Development Team finaliza y se compromete al Sprint Backlog, no se deben agregar nuevas User Stories; sin embargo, las tareas que pudieron haberse pasado por alto o ignoradas de las User Stories comprometidas pudieran ser agregadas. Si durante un Sprint surgen nuevos requerimientos, estos serán agregados al Backlog Priorizado del Producto e incluidos en un futuro Sprint.

Adicionalmente a la información obtenida del SBOK, según la Guía Fundamental de Scrum del Agile Coach, Jerónimo Palacios (Palacios, Guía fundamental de Scrum), describe que este artefacto es un elemento para visualizar el trabajo del Sprint y está gestionado por el Development Team . Su propósito es mantener la transparencia dentro del desarrollo.

El Sprint Backlog proporciona una visión del trabajo a realizar durante el Sprint actual. Está gestionado por el Development Team, que se encarga de mantenerlo actualizado y transparente durante toda la iteración, especialmente a través de los Daily Scrums.

Después del Sprint Planning, el Development Team obtiene una lista de elementos en los que van a trabajar durante un Sprint. Estos elementos normalmente se deshacen en tareas técnicas más pequeñas. Facilitan la implementación de los mismos en un Incremento de software terminado.

El Sprint Backlog permite visualizar todo el trabajo pendiente durante un Sprint. Así, se pueden ver aquellos elementos que aún no han empezado a desarrollarse, aquellos que sí y quienes están trabajando en los mismos y aquellos que están esperando a desplegarse o están completamente terminados. 


\section{4}

Este artefacto permite entender cuál es la evolución del trabajo durante el Sprint así como hacer un análisis de riesgos. Dado que cada Sprint tiene una meta específica (permitir que se pueda evaluar la operatividad de los controles de un proyecto de Auditoría Interna de Riesgos) y hay elementos seleccionados del Product Backlog que tienen más o menos valor, el Sprint Backlog permite analizar hasta donde se ha cumplido el objetivo y que se podría eliminar. Así maximizamos el retorno de la inversión en desarrollo.

Hay diferentes maneras de visualizar el Sprint Backlog. Desde el uso de herramientas electrónicas (Trello entre otras) hasta una hoja de cálculo. Dado que el objetivo del Sprint Backlog es favorecer la adaptación y transparencia, el uso de una pizarra con columnas es uno de los más adecuados, al menos hasta que el equipo de desarrollo es suficientemente maduro como para poder lanzarse al uso de otra herramienta.

A continuación sección se mostrará la visualización del Sprint 0 (es aquel Sprint en que se organiza el trabajo, se estudian requisitos iniciales, conceptualizaciones arquitectónicas iniciales, se dejan listos los puestos de trabajo, la planificación inicial, y todo lo que se necesita para iniciar el proyecto).

Tabla $N^{\circ} 47$ Sprint 0

\begin{tabular}{|l|l|l|l|}
\hline \multicolumn{4}{|c|}{ SPRINT 0 } \\
\hline Objetivo & $\begin{array}{l}\text { Preparar previamente las siguientes } \\
\text { desarrollar la aplicación }\end{array}$ \\
\hline Calendario & $08 / 01 / 2018-12 / 01 / 2018$ \\
\hline Actividad & Equipo & Duración Inicial & Duración Final \\
\hline $\begin{array}{l}\text { Configurar entorno } \\
\text { de desarrollo }\end{array}$ & DT & $08 / 01 / 2018$ 3:00 PM & $08 / 01 / 2018$ 6:00 PM \\
\hline $\begin{array}{l}\text { Crear User Stories - } \\
\text { Parte 1 }\end{array}$ & PO,SM,DT & $\begin{array}{l}09 / 01 / 2018 \\
\text { AM }\end{array}$ & $09 / 01 / 2018$ 16:00 PM \\
\hline $\begin{array}{l}\text { Crear User Stories - } \\
\text { Parte 2 }\end{array}$ & PO,SM,DT & $\begin{array}{l}10 / 01 / 2018 \\
\text { AM 10:00 }\end{array}$ & $10 / 01 / 2018$ 16:00 PM \\
\hline $\begin{array}{l}\text { Crear y priorizar el } \\
\text { Product Backlog }\end{array}$ & PO,SM,DT & $11 / 01 / 2018$ 9:00 AM & $11 / 01 / 2018$ 6:00 PM \\
\hline $\begin{array}{l}\text { Sprint Planning del } \\
\text { Sprint 1 }\end{array}$ & PO,SM,DT & $12 / 01 / 2018$ 9:00 AM & $12 / 01 / 2018$ 1:00 PM \\
\hline
\end{tabular}




\section{(4)}

$\mathbf{P O}=$ Product Owner $\quad$ SM=Scrum Master $\quad$ DT $=$ Development Team

Fuente: Elaboración Propia

Por último, luego de realizar el Sprint 0 se puede ejecutar los Sprints planificados para el

desarrollo del proyecto. A continuación, se muestra el Sprint 1 como primer iteración para

el Product Owner.

Tabla $N^{\circ} 48$ Sprint 1

\begin{tabular}{|l|l|}
\hline \multicolumn{2}{|c|}{ SPRINT 1 } \\
\hline Objetivo & Brindar un avance funcional de las User Stories listadas \\
\hline \multirow{3}{*}{ User } & HU001 - Cliente (2.50) \\
\cline { 2 - 2 } & HU002 - Proyecto (2.50) \\
\cline { 2 - 2 } Calendario & HU006 - Proceso del Proyecto (2.60) \\
\cline { 2 - 2 } & Iteración Sprint: 2 semanas \\
\cline { 2 - 2 } & Periodo de Sprint: $15 / 01 / 2018-29 / 01 / 2018$ \\
\cline { 2 - 2 } & Daily Scrum: 9:00 AM - 9:15 AM en la sala del equipo \\
\hline & Sprint Review: 29/01/2018, 11:00 AM - 1:00 PM en la sala del equipo \\
\hline \multirow{3}{*}{ Equipo } & Sprint Planning: 29/01/2018, 4:00 PM - 6:00 PM para el Sprint 2 \\
\cline { 2 - 2 } & Product Owner \\
\cline { 2 - 2 } & Scrum Master \\
\cline { 2 - 2 } & Development Team \\
\hline
\end{tabular}

Fuente: Elaboración Propia

\section{d. Incremento}

Según la Guía Fundamental de Scrum del Agile Coach, Jerónimo Palacios (Palacios, Guía fundamental de Scrum). El Incremento es la suma de todas las tareas, casos de uso, User Stories y cualquier elemento que se haya desarrollado durante el Sprint y que será puesto a disposición del usuario final en forma de software al final del mismo.

Un incremento es el resultado del Sprint. Es una pieza de Software, acorde con los elementos seleccionados durante el Sprint Planning del Sprint Backlog que aporta un valor de negocio al producto que se está desarrollando. 


\section{(1)}

Construir software de manera ágil se basa en hacerlo de manera iterativa e incremental. Mediante las iteraciones, se asegura que todo el ciclo de vida del software: Planificación, diseño, desarrollo, testeo y entrega ocurre cada 4 semanas o menos (en este proyecto será de 2 semanas). Por supuesto, no se puede construir toda la funcionalidad que se quiere en sólo 2 semanas y se tiene que buscar la manera de ir entregando los componentes necesarios justo a tiempo.

A través de un desarrollo incremental, primero se realizarán las características principales y luego se añadirán más, re factorizando y permitiendo tanto una arquitectura como un diseño emergente.

El desarrollo incremental es uno de los pilares principales de cualquier iniciativa ágil, y tiene una ventaja principal. Esta permite una adaptación rápida a las condiciones cambiantes del mercado y del producto. Por ejemplo, si se descubre que lo diseñado no es lo que el cliente busca, en la segunda o tercera iteración, se habrá reducido el riesgo y aumentará el retorno de la inversión.

Un desarrollo de este tipo choca con la mentalidad tradicional de desarrollo en fases, y es probablemente el hito que marca el cambio de una empresa de un modelo tradicional a un modelo ágil. No importan los roles, reuniones o artefactos en marcha puesto que, sin un incremento de Software terminado al final de cada Sprint no hay posibilidad de ser ágil.

\section{e. Artefactos Adicionales}

Aunque existen otros artefactos que se pueden utilizar en Scrum, el marco de trabajo sólo necesita los cuatro expuestos anteriormente. Sin embargo, hay otro que es llamado Definition of Done, es necesario para asegurar la calidad cuando se sigue Scrum.

\section{Definition of Done}

Según la guía para el cuerpo de conocimiento de Scrum (SBOK, 2017), hay una diferencia clave entre los "criterios de terminado" y los "criterios de aceptación". Mientras que los criterios de aceptación son únicos en los User Stories individuales, los criterios de terminado 


\section{(1)}

son una serie de reglas aplicables a todas las User Stories en un determinado Sprint. Los criterios de terminado o Definition of Done pueden incluir cualquiera de los siguientes:

- Fueron revisados por otros miembros del equipo.

- Completaron la prueba de unidad de la User Story.

- Conclusión de las pruebas de garantía de calidad.

- Conclusión de toda la documentación relacionada a la User Story.

- Se corrigieron todos los problemas.

- Demostración satisfactoria a los Stakeholders y/o representantes empresariales.

Al igual que con los criterios de aceptación, se deben cumplir todas las condiciones de los criterios de terminado para que la User Story se considere terminada. El Development Team debe utilizar una checklist (o lista de verificación) de los criterios de terminado generales para garantizar que una tarea está terminada y de que el resultado cumpla con la con la definición de terminado (DoD, por sus siglas en inglés). Es importante contar con una clara definición de terminado, ya que ayuda a eliminar la ambigüedad y permite al equipo apegarse a las normas de calidad requeridas. La definición de terminado típicamente la determina y la documenta el Scrum Guidance Body.

Los registros y datos necesarios para cumplir con los requisitos de documentación del proyecto se pueden generar a medida que el equipo procede a través de Sprints y lanzamientos. La inclusión de actividades tales como reuniones de revisión y la redacción de documentos de diseño pueden ayudar a asegurar el cumplimiento de las normas de calidad internas y externas. Los principios básicos de Scrum, tales como iteraciones cortas, la construcción gradual, la participación del cliente, la adaptación a las nuevas necesidades y el constante ajuste de tiempo y costo en el proyecto seguirán siendo aplicables.

\section{Monitorizando el progreso del Sprint}

Según el Agile Coach, Jerónimo Palacios (Palacios, Guía fundamental de Scrum), el monitoreo del progreso del Sprint es una práctica bastante utilizada en equipos Scrum. Es una práctica del equipo de desarrollo que les permite ser transparentes acerca de la situación del trabajo 


\section{(1)}

reflejado en el Sprint Backlog y decidir si es necesario adaptar. En el caso de que así fuera, es el Development Team el responsable de hablar con el Product Owner para que sea él o ella quien decida cuál es el trabajo de más valor del Sprint.

Una de las técnicas utilizadas es el panel de tareas o Taskboard, mediante la cual se puede visualizar el estado actual del avance de cada Sprint, conteniendo principalmente el nombre de los integrantes identificados con un color, las actividades que se están realizando y el estado actual de cada tarea establecida.

El objetivo es tener un estado de las actividades que se están realizando en el Sprint. Para esto, se implementará un espacio dentro de una sala que tendrá una pizarra que permita formar un tablero Scrum, donde se irá colocando las actividades que se irán realizando.

Esta tabla se divide en tres columnas que representan el estado de la tarea:

- Por hacer

- Haciendo

- Terminado 


\section{(1)}

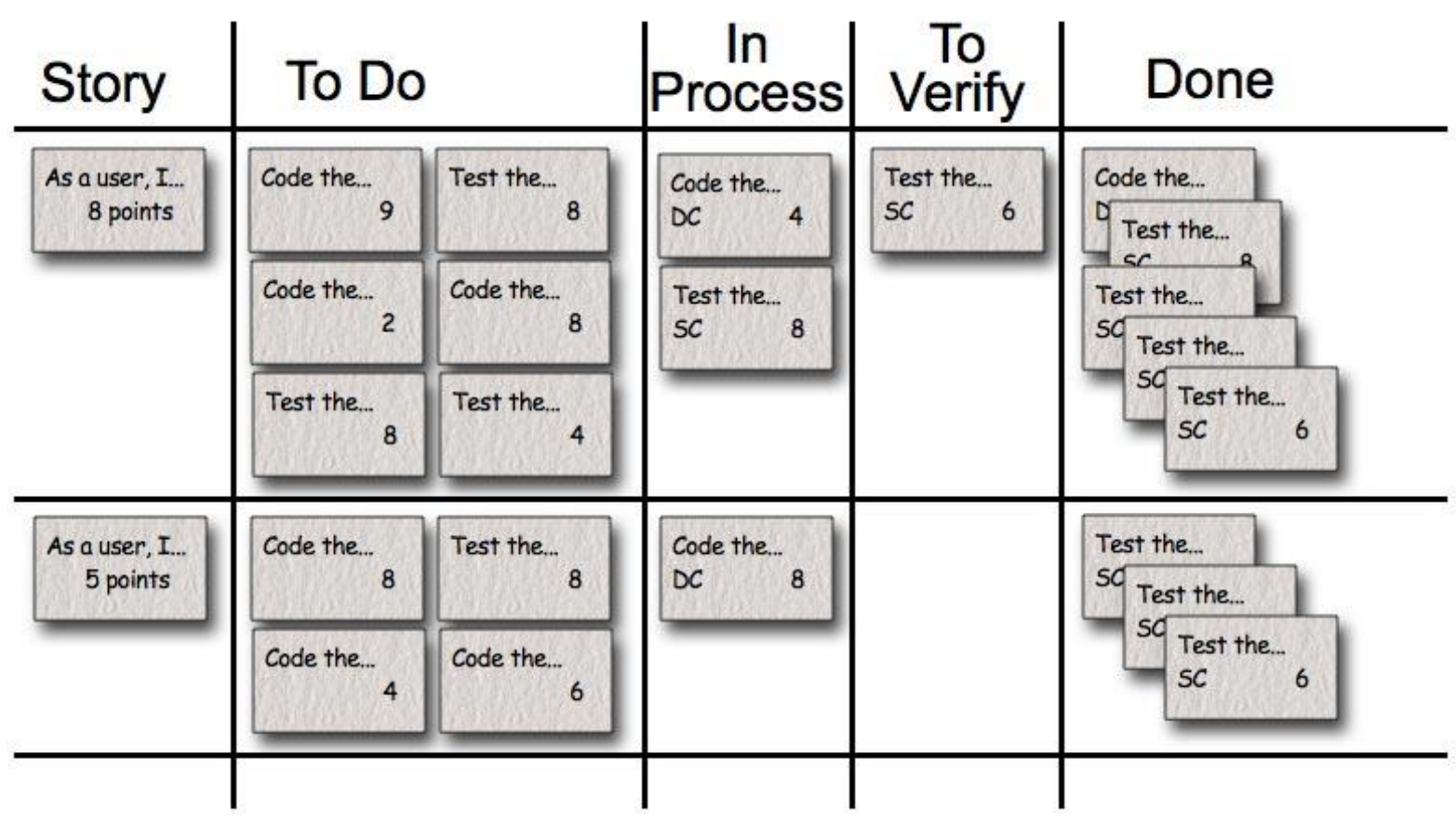

Figura $\mathrm{N}^{\circ} 28$ Tablero de Tareas Scrum

Fuente: Mountain Goat Software

Otra de las técnicas frecuentemente utilizadas es la del Sprint Burndown. En un diagrama se fijan los días del Sprint en el eje de abcisas, mientras que en el eje de ordenadas se refleja la suma del trabajo por hacer. Se hace un seguimiento diario del trabajo pendiente y el burndown va reflejando el trabajo restante a lo largo del tiempo.

Claves:

- La duración del Sprint se mantiene fija.

- No hay espacios entre Sprints, cuando acaba uno, empieza el siguiente.

- Permite mantener el ritmo.

- Sirve a la transparencia 


\section{$(1$}

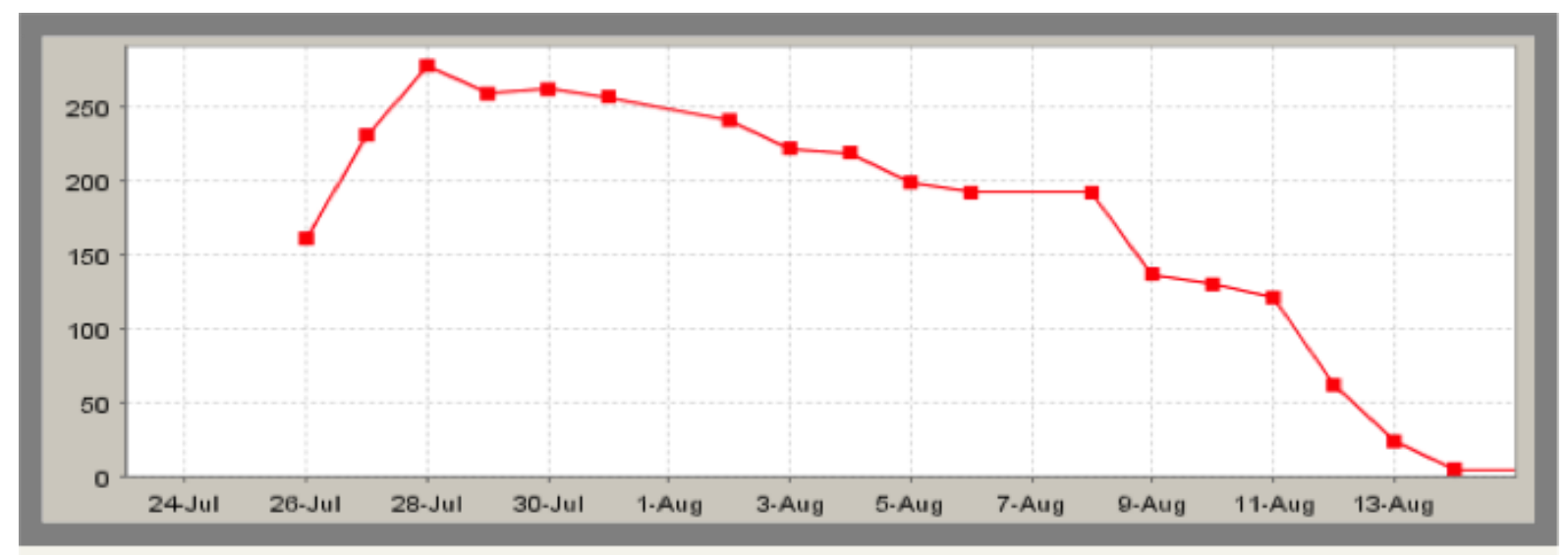

Figura $\mathrm{N}^{\circ} 29$ Diagrama Burndown

Fuente: Guía Fundamental de Scrum

\section{Estimación Ágil con la Técnica Planning Poker}

Según Samuel Casanova (Casanova, Estimación ágil con la técnica Planning Poker, 2016) indica lo siguiente, que es cierto que tener una estimación, aunque sea a alto nivel será útil para tomar mejores decisiones a la hora de ordenar y priorizar el Backlog. Por ejemplo, si se tiene la User Story A y B, y la User Story A aporta valor 100 con esfuerzo 100 y la User Story B aporta valor 90 pero esfuerzo 10, seguramente sea más interesante hacer primero B antes que A.

\section{La estimación ágil}

En la estimación ágil se persigue los siguientes objetivos:

- Tener diferentes puntos de vista. Está claro que 7 pares de ojos ven más que uno. En la estimación ágil busca la democracia, que todo el mundo participe y diga la suya. Si hay discusión mejor, ya que de lo que se trata es de avanzar todo lo posible los problemas y tenerlos en cuenta desde el inicio. No debería haber personas con una voz y voto más fuertes que los demás. 


\section{(1)}

- Detectar posibles tareas ocultas y posibles obstáculos. La sesión de estimación es una de las primeras oportunidades de detectar riesgos que pueden comenzar a tratarse para que no se conviertan en impedimentos.

- Tener una visión compartida de la que se viene encima. Es muy útil haber participado en las estimaciones para después hacer las planificaciones. Si se conoce el tamaño de las User Stories y tareas es mucho más sencillo comprometerte con un plan de trabajo que si las estimaciones te vienen "impuestas".

- Tener estimaciones más realistas (no más precisas). La idea es que entre todos los números que salgan sea lo más cercano a la realidad posible. Para ello, se necesita eliminar la presión contractual, esto es, dejar margen para equivocarse y evitar así introducir buffers "inconscientes" por si acaso. Lo que se busca es el realismo, no precisión, es decir, se quiere saber si un User Story será 3 o 5 días, si se dice que tardará 26,5 horas, se puede tener la duda de que se haya hecho un buen ejercicio de estimación.

\section{$\checkmark \quad$ Planning Poker}

La técnica que se usará para este proyecto es una de las más efectivas y conocidas del mundo ágil para estimar. Se trata de una dinámica ágil en la que se reúne el equipo con una baraja de Poker modificada y se hacen rondas de estimación con ayuda de estas cartas. 


\section{(1)}
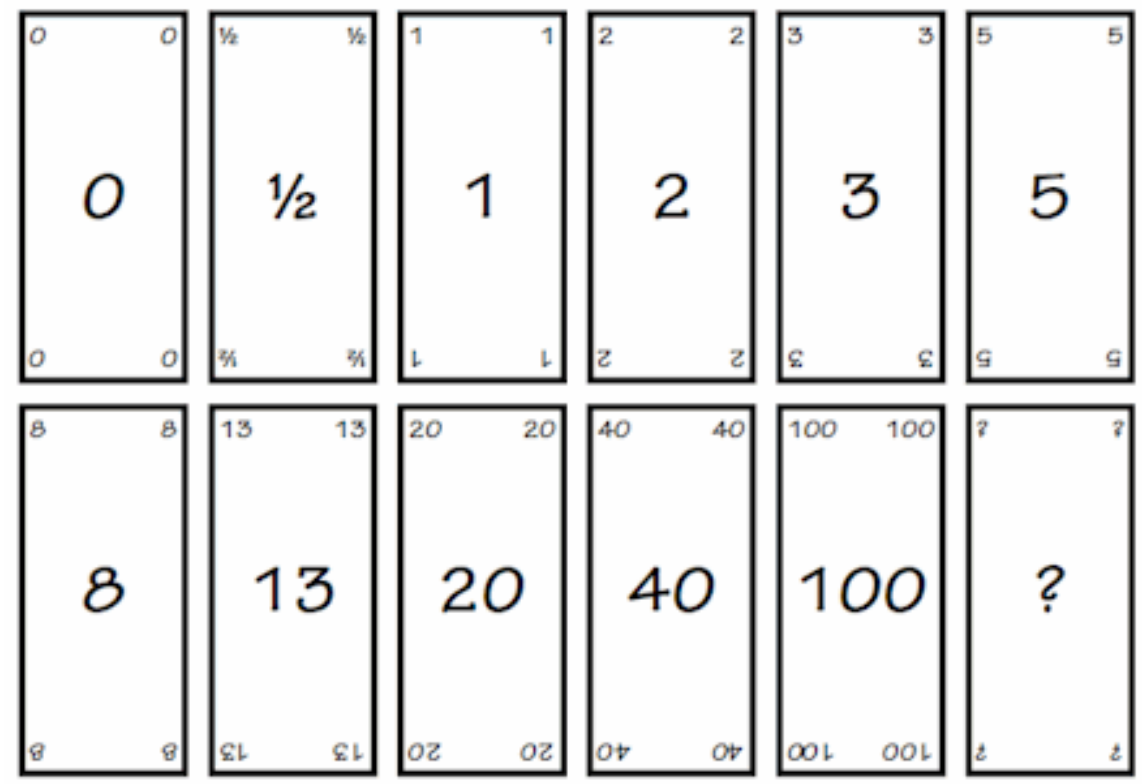

Figura $\mathrm{N}^{\circ} 30$ Barajas Planning Poker

Fuente: Agile Planning Poker (JM, 2010)

\section{$\checkmark \quad$ Material necesario}

Para una sesión de estimación ágil será necesario que cada participante tenga una baraja de Planning Poker. Se puede descargar e imprimir una baraja desde internet, pero también se puede utilizar una app móvil, en caso todo el equipo tenga un teléfono, aunque le quita algo de glamour a la sesión.

En cada baraja hay una pseudo-secuencia de Fibonacci modificada. Las cartas tendrán los siguientes valores: 0,1/2, 1, 2, 3, 5, 20, 40, 100,? e infinito. El cero significa que el User Story ya está hecha o no requiere ningún esfuerzo, el interrogante significa que falta información para estimar ese User Story o tarea y el infinito es que es demasiado grande y se tiene que descomponer en más pequeñas. Podría haber una carta adicional que tenga el símbolo de una taza de café, que significa que se necesita un descanso de la sesión de estimación.

\section{$\checkmark \quad$ Trabajo previo}




\section{(1)}

Además del material, antes de iniciar la sesión se tendrá que tener claro en qué unidades se va estimar. Es posible que para estimaciones de alto nivel o de épicas o User Story, se prefiera estimar en semanas ideales, mientras que para User Stories más pequeñas y tareas de bajo nivel se prefiera estimar en días ideales. Un día ideal es el trabajo que consigue una persona en un día, en el que no tiene interrupciones de ningún tipo y todo le sale a la primera. También es posible que se decida estimar en una medida relativa como puntos Story Points. En cualquier caso, lo importante es que todos sepan en qué medida se estima.

También será importante que todos sepan qué se incluye y qué no en la estimación, si se incluye alguna documentación, tests unitarios, tests de integración y cualquier otra cosa que forme parte del desarrollo.

\section{$\checkmark \quad$ Dinámica de la sesión}

Una vez que se tiene el material, es necesario tener una sesión que contenga la siguiente dinámica:

- Todo el equipo "se encierra" para estimar, y todos conocen lo que se va a estimar. Si hay gente que no está al tanto de lo que se va a estimar en la sesión, debe comenzar con una explicación y una sesión de preguntas para despejar cualquier duda sobre los User Stories que se van a estimar.

- Una por una se leen y se discuten los User Stories. Una vez que todo el equipo tiene claro en qué consiste cada uno, eligen una carta en función del esfuerzo que requerirá esa User Story. No es posible seleccionar un valor no incluido en la baraja sólo se estima lo que después se desarrolla (ni el Scrum Master ni el Product Owner estiman, sólo resuelven dudas).

- Si no hay consenso (lo normal con más de 2 participantes) se abre la discusión. No muy larga, por ejemplo, se puede hacer que explique su elección el que tiene la puntuación más baja y más alta. Se repite la estimación nuevamente en busca de 


\section{(1)}

consenso. Si no se consigue a la segunda se vuelve a discutir. A la tercera si no hay consenso se escoge o bien la media o bien el máximo (mejor el máximo).

Al final de la sesión el resultado es una estimación consensuada y validada por todo el equipo para cada una de las User Stories o tareas seleccionadas. Si se trabaja con Sprints lo habitual es estimar a alto nivel cuando los elementos entran en el Backlog, y nuevamente cuando se realiza el Sprint planning o Backlog grooming si se hace por separado para estimar las tareas a bajo nivel.

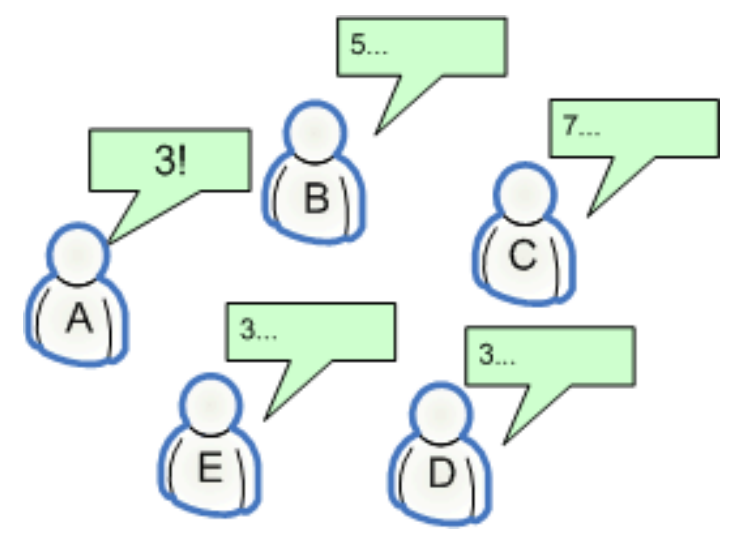

Figura $\mathrm{N}^{\circ} 31$ Dinámica de Planning Poker

Fuente: Planning poker - ¿Cómo planificar un Sprint en Scrum? (Romeu, 2014)

\section{$\checkmark \quad$ ¿Cuál es el resultado de un planning poker?}

El resultado de un Planning Poker debe ser que junto a cada User Story debe aparecer un número que indique el esfuerzo necesario para terminar esa tarea. Todo el equipo ha participado, todo el mundo conoce el alcance de cada User Story y todos están de acuerdo en el trabajo a realizar.

Ese número se deberá actualizar cada día en el Daily Meeting, indicando el esfuerzo restante para terminar la tarea en curso. No se debe de olvidar que durante el Daily Meeting se actualice el gráfico de Burndown. 


\section{(1)}

Además, tras el Planning Poker, si se realiza al final de cada Sprint, es buena idea planificar las User Stories que entran en el siguiente Sprint. En el fondo estamos planificando.

\section{$\checkmark$ Conclusión sobre la estimación}

Si bien es cierto que la estimación de tareas de desarrollo de software es una ciencia infusa, es posible mejorar notablemente la calidad de las estimaciones con técnicas como Planning Poker. ¿Por qué funciona Planning Poker? Porque unifica la opinión de varios expertos en lugar de depender de uno, ayuda a identificar más riesgos más pronto, define una visión única del trabajo por hacer, y obliga a defender las estimaciones dadas ante los compañeros.

\subsection{CONCLUSIONES}

Al realizar un análisis de la organización se ha comprobado que se pueden aprovechar las debilidades que se dan en la actualidad, para posteriormente convertirlas en oportunidades. En este caso, se pueden identificar y visualizar los problemas que tiene la organización Ernst and Young por la falta de conocimientos sobre gestión de proyectos y aprovechar y capacitar sobre el uso de un marco de trabajo ágil para trabajar en la gestión de proyectos de sistemas. Por lo que, al no contar con este conocimiento se dificulta la comunicación entre el Gerente de Consultoría (Product Owner) y el equipo de TI (Gerente de Proyecto y equipo de desarrollo). Por esta razón, se debería tomar acciones correctivas que ayuden a solucionarlos, en este caso, realizar talleres de capacitación para el uso de Scrum como marco de trabajo. La cual brindará al equipo de proyecto (conformado por Gerente de Consultoría, Gerente de Proyecto y equipo de desarrollo) un nuevo conocimiento, que ayude a mejorar el desempeño del proyecto y dándole al Gerente de Consultoría, mediante iteraciones (Sprints), un producto que le de valor al negocio alineado a los objetivos de la organización. 


\section{(1)}

En conclusión, al optar por el uso de un marco de trabajo mediante Scrum, se pueden obtener los siguientes resultados:

\section{- Cumplimento de expectativas:}

El Gerente de Consultoría (Product Owner) de la empresa EY puede establecer sus expectativas indicando el valor que le aporta cada requisito mediante Business Value/Story Points, el equipo las estimas y con esta información el Product Owner establece su prioridad. De manera regular, en la presentación del Sprint el Product Owner comprueba que efectivamente los requisitos se han cumplido y transmite el feedback al equipo.

- Flexibilidad a cambios: El equipo de TI de la empresa EY al estar capacitado en el marco de trabajo Scrum tendra alta capacidad de reacción ante los cambios de requerimientos generados por necesidades del cliente o evoluciones del mercado. El marco de trabajo está diseñada para adaptarse a los cambios de requerimientos que conllevan los proyectos complejos.

- Reducción del Time to Market: El Gerente de Consultoría (Product Owner) puede empezar a utilizar las funcionalidades más importantes del proyecto antes de que esté finalizado por completo.

- Mayor calidad del software: El uso de un marco trabajo ágil y la necesidad de obtener una versión funcional después de cada iteración, ayuda a la obtención de un software de calidad.

- Mayor productividad: Se consigue entre otras razones, gracias a la eliminación de la burocracia y a la motivación del equipo que proporciona el hecho de que sean autónomos para organizarse. 
- Maximiza el retorno de la inversión (ROI): Producción de software únicamente con las prestaciones que aportan mayor valor de negocio gracias a la priorización por retorno de inversión.

- Predicciones de tiempos: Mediante Scrum se conoce la velocidad media del equipo por Sprint (los llamados Story Points), con lo que consecuentemente, es posible estimar fácilmente para cuando se dispondrá de una determinada funcionalidad que todavía está en el Backlog .

- Reducción de riesgos: El hecho de llevar a cabo las funcionalidades de más valor en primer lugar y de conocer la velocidad con que el equipo avanza en el proyecto, permite despejar riesgos eficazmente de manera anticipada. 


\section{(1)}

\section{CAPÍTULO 4: ESTRUCTURA PROPUESTA}

\subsection{INTRODUCCIÓN}

En este capítulo se presenta la propuesta final para la organización EY, en la cual se muestra una propuesta para el desarrollo de un sistema del subproceso "Auditoría Interna de Riesgos", la cual está alineada a los objetivos estratégicos definidos por la organización. Por esta razón, se realiza un resumen de la situación actual, la problemática de la situación actual, el objetivo de la propuesta, sus beneficios, la evaluación de riesgos de la propuesta, así como la evaluación financiera de la propuesta, el cronograma de la elaboración de la propuesta de forma tentativa, estructura de desglose de la solución propuesta (entregables) y el marco de trabajo integral, que inicia desde la selección del subproceso "Auditoría Interna de Riesgos", para obtener la identificación de problemática; para luego, realizar el análisis e identificación de las brechas y dar una propuesta en el marco de una Arquitectura Empresarial para finalizar con el desarrollo de una aplicación a fin de cumplir con los objetivos estratégicos de la organización. Por último, se dará las conclusiones y recomendaciones respectivas sobre el trabajo realizado.

\subsection{SITUACIÓN ACTUAL}

Actualmente, el proceso misional llamada Consultoría contiene un subproceso de trabajo llamada Auditoría de Interna de Riesgos, que realiza su trabajo de forma manual mediante el programa Excel de Microsoft. En la cual, el trabajo comienza, cuando un cliente solicita la auditoría para algún (nos) de su(s) procesos. Luego, un equipo conformado por un Gerente (Líder) y su equipo (Senior y/o Asistentes) van al cliente y realizan un taller para el levantamiento de requerimientos de información, entre lo que se obtienen los procesos y sus objetivos que se van a auditar. Luego, todos los que conforman el equipo de auditoria, identifican los riesgos a alto nivel (riesgos generales) que están asociados a estos procesos. Posteriormente, en una reunión se ponen a analizar los riesgos de alto nivel y se evalúan con criterios de probabilidad e impacto para saber el nivel (estos pueden ser de 3 niveles: bajo, medio y alto; 4 niveles: bajo, moderado, alto y extremo, y 5 niveles: Muy bajo, bajo, moderado, 


\section{$(1)$}

alto y extremo) con lo que el equipo tiene que trabajar según esta priorización a fin de realizar un cronograma de trabajo (plan de auditoría) para visitar al cliente y mitigar los procesos correspondiente a esta evaluación. Además de esto, se crean riesgos de bajo nivel (riesgos más al detalle) que están asociados a los riesgos de alto nivel. Estos riegos, al igual que los riesgos de alto nivel, serán evaluados en base a los criterios definidos en los riesgos evaluados inicialmente. Adicionalmente, estos riesgos contienen controles que servirán para evaluar la operatividad, para saber si un control es Efectivo (Aprobado) o No Efectivo (Fallido) y verificar si el riesgo asociado al control a variado en base a la evaluación dada inicialmente (riesgo inherente) hasta el nivel final (riesgo residual). Por último, si el control fue No Efectivo, se realizará un plan de acción para rectificar el fallo del control por parte de un responsable del cliente.

Todo el trabajo realizado por parte del equipo va siendo observado por el Gerente y este da la conformidad del trabajo que está realizando el equipo. Una vez que el trabajo es observado y aceptado, va siendo integrado en cada momento, una vez terminado este trabajo, el Gerente da la aceptación formal del proyecto y se le entrega al cliente el resultado de las pruebas y el plan de acción. Luego de esto, los archivos Excel se copian y pegan en una carpeta compartida del área de Consultoría (carpeta física) en un servidor local de la empresa, para utilizarlos cuando se necesiten.

\subsection{PROBLEMÁTICA DE LA SITUACION ACTUAL}

En base a la situación actual se identificaron los siguientes problemas:

- Al no contar con una base de conocimiento como son proyectos pasados como también procesos, riesgos y controles predefinidos por industria (datos cargados en el sistema), como ayuda en el desarrollo del trabajo de proyectos. Este problema da como resultado, que el auditor genere horas extras de trabajo, por no contar con esta información en el momento que se necesite. Además, que el auditor constantemente tenga que consultar con expertos (los cuales a veces no se encuentran disponibles por diferentes actividades que 


\section{(1)}

realizan como: reuniones con clientes o estar enfocados en otros proyectos) para obtener la información necesaria y poder cerrar sus proyectos.

- Desarrollar e integrar el trabajo de forma manual por cada miembro del equipo perdiendo horas hombre de trabajo.

- El gerente no visualiza en tiempo real el avance del equipo y no puede dar la retroalimentación necesario (todo se hace de forma presencial con el equipo).

- La descentralización de la información mediante archivos esparcidos en una carpeta física compartida en el servidor como base de conocimiento para futuros proyectos.

\subsection{OBJETIVO DE LA PROPUESTA}

El objetivo es automatizar la gestión del trabajo de la Auditoría Interna de Riesgos de los procesos del cliente, en donde un equipo pueda trabajar sus proyectos de forma centralizada, integrando y obteniendo información en base a los conocimientos obtenidos de las experiencias de los equipos en cada proyecto por industria, que se les haya involucrado. Además, de contar con una base de conocimiento como guía para el desarrollo del proyecto, para los miembros del equipo.

\subsubsection{OBJETIVO ESPECÍFICOS DE LA PROPUESTA}

- Realizar el análisis de la situación actual del proceso desarrollo de software desde el punto de vista de la arquitectura empresarial.

- Proponer una arquitectura empresarial que permita identificar las oportunidades de mejora mediante el análisis de brechas de las Arquitecturas de la Línea Base y Destino.

- Proponer y desarrollar una solución tecnológica que permita reducir las brechas encontradas, las cuales impiden el cumplimiento de los objetivos estratégicos asociados al proceso de negocio. 


\section{(1)}

- Proponer un marco de trabajo para el desarrollo de la solución tecnológica mediante el uso de SCRUM.

- Proponer dinámicas y/o talleres de trabajo en equipo, ya que el Gerente de Consultoría (Product Owner) no cuenta con experiencia en la gestión de proyectos de sistema, al igual que el equipo de desarrollo (Development Team ), que no tiene experiencia al usar un marco ágil para el desarrollo de proyectos; por ello, se necesita llevar un taller de Scrum. Aparte de esto, todos los miembros que conforman el equipo necesitan mejorar sus habilidades blandas y su nivel de comunicación (Coaching y Taller Impro), ya que un equipo Scrum necesita contar con esas habilidades para que los proyectos puedan tener éxito. Por este motivo, estas dinámicas y/o talleres ayudarán a potenciar las fortalezas y eliminar las debilidades del equipo de proyectos.

- Construir un equipo de trabajo con las habilidades adecuados (dinámicas y/o talleres) y que se potencie el trabajo entre el equipo. Además, se busca que estos tengan el compromiso de auto gestionar el modo en que se realizará el trabajo del desarrollo de la solución tecnológica mediante las herramientas que ofrece Scrum y que mediante dinámicas de Daily Scrum y Retrospectivas llegar a mayores niveles de motivación y autogestión.

\subsection{BENEFICIOS DE LA PROPUESTA}

En esta sección se muestra el sustento de los beneficios Tangibles e Intangibles que da como beneficio la realización de este proyecto. Estos se detallan a continuación:

\subsubsection{BENEFICIOS TANGIBLES}

Tabla $N^{\circ} 49$ Beneficios Tangibles

\begin{tabular}{|l|l|}
\hline \multicolumn{1}{|c|}{ Beneficio } & \multicolumn{1}{c|}{ Sustento } \\
\hline $\begin{array}{l}\text { Minimizar el tiempo de trabajo de } \\
\text { Auditoría Interna de Riesgos de un } \\
\text { proyecto entre 25\% hasta 30\%. }\end{array}$ & $\begin{array}{l}\text { Al ingresar un nuevo miembro a la organización } \\
\text { (Asistente), este es insertado a un proyecto con un } \\
\text { Gerente y Senior. Este asistente al no contar con } \\
\text { experiencia necesita constante retroalimentación, } \\
\text { por ejemplo, sobre la identificación de riesgos y }\end{array}$ \\
\hline
\end{tabular}




\begin{tabular}{|c|c|}
\hline & $\begin{array}{l}\text { controles por cada proceso del proyecto. Esto hace } \\
\text { que dependan de sus superiores como guías para el } \\
\text { desarrollo de su trabajo. Esto causa perdida de } \\
\text { tiempo, ya que el Asistente consumo horas hombre } \\
\text { de los Gerentes y/o Seniors, ya que no cuentan con } \\
\text { una base de conocimiento como guía, como por } \\
\text { ejemplo proyectos anteriores para la misma } \\
\text { industria o contar con riesgos y controles } \\
\text { predefinidos para agilizar el trabajo del proyecto. } \\
\text { Aparte de esto, el trabajo realizado por los miembros } \\
\text { del equipo se realizada de forma manual, no estando } \\
\text { la información del proyecto de forma consolidada en } \\
\text { todo momento, para que pueda ser supervisada por } \\
\text { parte del Gerente. Por esta razón, se considera la } \\
\text { realización de un proyecto de Auditoría Interna de } \\
\text { Riesgos para automatizar el trabajo de los proyectos } \\
\text { del cliente. }\end{array}$ \\
\hline $\begin{array}{l}\text { Aumentar en } 1.5 \% \text { los ingresos en el } \\
\text { primer año, para la línea de servicio } \\
\text { de consultoría, vendiendo la base de } \\
\text { conocimiento por industria a los } \\
\text { clientes. }\end{array}$ & $\begin{array}{l}\text { Constantemente los clientes preguntan a los } \\
\text { Gerentes y Socios de EY si cuentan con una } \\
\text { herramienta de Auditoría Interna de Riesgos, ya que } \\
\text { tienen sus propios auditores internos y no tienen una } \\
\text { manera en realizar sus proyectos de forma } \\
\text { automatizada. Esto daría una oportunidad de ofrecer } \\
\text { este producto como un ingreso más a Consultoría, } \\
\text { donde se podría contratar el servicio por periodos de } \\
\text { tiempo entre } 3 \text { meses hasta } 1 \text { año. El } 1.5 \% \text { de } \\
\text { ingresos se manifiesta de acuerdo a las ventas que se } \\
\text { realizarán del servicio comparando al último año de } \\
\text { ingresos que fue de USD } \$ 20,000,000.00 \text { en la línea } \\
\text { de servicio de Consultoría, por lo que se obtendría } \\
\text { un monto de USD } \$ 300,000.00 \text {. }\end{array}$ \\
\hline $\begin{array}{l}\text { Brindar una base de conocimiento } \\
\text { informativa } 24 \times 7 \text { (información } \\
\text { cargada) de los procesos, riesgos y } \\
\text { controles que se utilizarán como } \\
\text { ayuda para el desarrollo de proyectos, } \\
\text { ya que no se necesitaría utilizar las } \\
\text { horas hombre de un experto (Gerente } \\
\text { y/o Senior) para la retroalimentación } \\
\text { de la identificación de riesgos y } \\
\text { controles. Además de esto, contar con } \\
\text { proyectos guraros para } \\
\text { anteriormente, como guía } \\
\text { trabajar otros proyectos (realizar } \\
\text { réplicas de información para }\end{array}$ & $\begin{array}{l}\text { Los nuevos integrantes de la organización } \\
\text { (Asistentes) en base a su falta de experiencia, } \\
\text { constantemente necesitan ser supervisados y deben } \\
\text { tener talleres con los miembros más experimentados } \\
\text { (Gerente y/o Senior) para tener retroalimentación de } \\
\text { cómo se debe desarrollar un proyecto de Auditoría } \\
\text { Interna de Riesgos (identificar riesgos y controles y, } \\
\text { la manera de evaluarlos). El problema aquí es que } \\
\text { no siempre los miembros más experimentados están } \\
\text { disponibles; por esta razón, los asistentes tienen que } \\
\text { esperar a recibir retroalimentación y esto genera } \\
\text { horas adicionales de trabajo. Además de esto, la } \\
\text { integración de los avances por parte del equipo se } \\
\text { realiza una vez que los Senior y Asistentes }\end{array}$ \\
\hline
\end{tabular}




\section{(}

desarrollar proyectos recurrentes $\mathrm{u}$ otros proyectos) por parte del equipo de Auditoría Interna de Riesgos; alineándose al objetivo estratégico de optimizar costos y mejor márgenes, ya que reduciría las horas hombre.

Automatizar el desarrollo del trabajo de la Auditoría Interna de Riesgos mejorando la organización y productividad en el procesamiento de la información. consoliden la información (de forma manual) dando un reporte de resultados de los controles auditados (mediante un archivo Excel) para los procesos del cliente. Esta información no se encuentra centralizado en todo momento, para la aceptación formal del entregable por parte del Gerente.

Actualmente, los equipos de auditoría interna de riesgos de EY, no cuenta con un sistema que los organice y tengan mejor acceso a un estándar de información (procesos, riesgos y controles predefinidos) para el desarrollo del trabajo de los proyectos que se realizan para cada cliente, el trabajo se hace de forma manual mediante el uso de una herramienta Office llamada Excel. Por otro lado, los clientes comentan que no cuentan con una herramienta tecnológica para el desarrollo, de la mejor manera, de la Auditoría Interna de Riesgos por sus auditores. Por lo que el desarrollo de esta propuesta de desarrollo, haría que se les pueda ofrecer una herramienta para la automatización del proceso del trabajo que realiza tanto el personal de EY como del cliente de.

Fuente: Elaboración Propia

\subsubsection{BENEFICIOS INTANGIBLES}

Tabla $\mathrm{N}^{\circ} 50$ Beneficios Intangibles

\begin{tabular}{|l|l|}
\hline \multicolumn{1}{|c|}{ Beneficio } & \multicolumn{1}{|c|}{ Sustento } \\
\hline Empoderar a los clientes & $\begin{array}{l}\text { Al brindar una solución tecnológica para los } \\
\text { clientes. Estos verían a la organización EY no sólo } \\
\text { como alguien que les brinda el servicio de } \\
\text { consultoría, sino que pensarán que siempre está el } \\
\text { apoyo para la mejora de su organización, haciendo } \\
\text { que EY y el cliente tengan un lazo fuerte y } \\
\text { cooperativo. }\end{array}$ \\
\hline $\begin{array}{l}\text { Dar mayor valor a la marca en el } \\
\text { concepto de líder de consultaría }\end{array}$ & $\begin{array}{l}\text { El desarrollo de esta nueva solución propuesta hará } \\
\text { que EY cuenta con una ventaja frente a sus } \\
\text { competidores, ya que al ofrecer un nuevo servicio de } \\
\text { su propia marca, hará que los clientes se fidelicen } \\
\text { con la organización. }\end{array}$ \\
\hline $\begin{array}{l}\text { Ser el primero a quien el cliente tenga } \\
\text { que consultar en la toma de decisión }\end{array}$ & $\begin{array}{l}\text { El desarrollo de la propuesta tecnológica hará que el } \\
\text { cliente vea a EY como el mejor consultor para sus }\end{array}$ \\
\hline
\end{tabular}




\begin{tabular}{|l|l|}
\hline & problemas, ya que esta solución satisface las \\
necesidades de los clientes en el proceso de trabajo \\
de la Auditoría Interna de Riesgos. Esto abrirá más \\
puertas para futuras soluciones tecnológicas, lo que \\
será beneficioso para EY económicamente.
\end{tabular}

Fuente: Elaboración Propia 


\section{$(4)$}

\subsection{EVALUACIÓN DE RIESGOS DE LA PROPUESTA}

En esta sección de la misma manera que se ve en el Capítulo 2 en el punto de EVALUACIÓN DEL IMPACTO se ven los siguientes riesgos identificados. La idea es evaluar en base a la probabilidad e impacto los riesgos identificados para obtener un resultado de acuerdo a su complejidad e incertidumbre. Para luego, controlar en mayor medida (mediante la Respuesta al Riesgo, Ver Tabla 52) aquellos que puedan causar mayor problema y que puedan afectar significativamente el proyecto.

Tabla $N^{\circ} 51$ Mapa de Riesgos de Probabilidad e Impacto

\begin{tabular}{|c|c|c|c|c|c|}
\hline \multirow{2}{*}{ Probabilidad } & \multicolumn{5}{|c|}{ Impacto } \\
\hline & Muy Bajo (0.10) & Bajo (0.25) & Medio $(0.50)$ & Alto $(0.75)$ & Muy Alto (1.00) \\
\hline \multicolumn{6}{|l|}{ Muy Probable $(0.90)$} \\
\hline \multicolumn{6}{|l|}{ Probable $(0.70)$} \\
\hline \multicolumn{6}{|l|}{ Moderado $(0.50)$} \\
\hline \multicolumn{6}{|l|}{ Bajo $(0.30)$} \\
\hline \multicolumn{6}{|l|}{ Muy Bajo (0.10) } \\
\hline \multicolumn{6}{|l|}{ Leyenda } \\
\hline & $\mathrm{Mu}$ & Bajo & Medio & Alto & Muy Alto \\
\hline
\end{tabular}

Fuente: Elaboración Propia

Tabla N ${ }^{\circ} 52$ Evaluación de Riesgos de la Propuesta 


\begin{tabular}{|c|c|c|c|c|c|c|c|}
\hline $\mathbf{N}^{\circ}$ & Riesgo & Probabilidad & Impacto & Resultado & Estrategia & Responsable & Respuesta al Riesgo \\
\hline 1 & $\begin{array}{l}\text { Resistencia } \\
\text { al cambio }\end{array}$ & 0.7 & 1 & 0.70 & $\begin{array}{l}\text { Bondades } \\
\text { que ofrece } \\
\text { el } \\
\text { desarrollo } \\
\text { de una } \\
\text { nueva } \\
\text { forma de } \\
\text { trabajar }\end{array}$ & $\begin{array}{l}\text { Auditor } \\
\text { Senior y } \\
\text { Asistente }\end{array}$ & $\begin{array}{l}\text { Dar una charla previa a los usuarios que utilizarán la } \\
\text { solución tecnológica (antes de la ejecución del } \\
\text { desarrollo), sobre las bondades que ofrece usar una } \\
\text { nueva forma de trabajar los proyectos. Explicar por } \\
\text { ejemplo, de que se tendrá una base de conocimiento de } \\
\text { la información para que sean utilizadas en el caso de } \\
\text { personas de no mucha experiencia encontrar } \\
\text { información más rápida y así no tener pérdidas de } \\
\text { tiempo en su trabajo. Otra podría ser que la información } \\
\text { estará integrada y centralizado por parte del equipo de } \\
\text { proyecto de Auditoría Interna de Riesgos. }\end{array}$ \\
\hline 2 & $\begin{array}{l}\text { Sistema no } \\
\text { amigable }\end{array}$ & 0.4 & 1 & 0.40 & $\begin{array}{l}\text { Revisión } \\
\text { de diseño } \\
\text { de interfaz } \\
\text { con } \\
\text { Product } \\
\text { Owner }\end{array}$ & $\begin{array}{c}\text { Gerente de } \\
\text { Proyecto, } \\
\text { Gerente de } \\
\text { Consultoría, } \\
\text { Senior y } \\
\text { Asistente }\end{array}$ & $\begin{array}{l}\text { Se propone revisar el diseño de la interface tanto con el } \\
\text { Gerente, Senior y asistente para tener un consenso de la } \\
\text { aprobación de los formularios de diseño mostrados. }\end{array}$ \\
\hline 3 & $\begin{array}{l}\text { Falta de } \\
\text { disponibilid } \\
\text { ad del } \\
\text { Gerente de } \\
\text { Consultoría } \\
\text { a las } \\
\text { reuniones }\end{array}$ & 0.30 & 0.90 & 0.27 & $\begin{array}{l}\text { Empodera } \\
\mathrm{r} \text { al } \\
\text { Gerente de } \\
\text { Consultorí } \\
\text { a para que } \\
\text { participe } \\
\text { en las } \\
\text { reuniones } \\
\text { de Sprint }\end{array}$ & $\begin{array}{l}\text { Gerente de } \\
\text { Proyecto }\end{array}$ & $\begin{array}{l}\text { El Gerente de Proyecto (Scrum Master) debe empoderar } \\
\text { al Gerente de Consultoría (Product Owner) haciéndole } \\
\text { saber que es la persona más importante para que el } \\
\text { proyecto tenga éxito y que necesita que participe de los } \\
\text { Sprint Planning (priorizar y planear el nuevo Sprint en } \\
\text { base al Product Backlog creado por el Product Owner) } \\
\text { y Sprint Review (revisión del producto funcionando de } \\
\text { acuerdo al Sprint ejecutado). }\end{array}$ \\
\hline
\end{tabular}




\begin{tabular}{|c|c|c|c|c|c|c|c|}
\hline & & & & & $\begin{array}{l}\text { Planning y } \\
\text { Sprint } \\
\text { Review }\end{array}$ & & \\
\hline 4 & $\begin{array}{l}\text { Cambiar el } \\
\text { alcance y/o } \\
\text { requerimien } \\
\text { tos una vez } \\
\text { iniciado el } \\
\text { proyecto }\end{array}$ & 0.25 & 1.00 & 0.25 & $\begin{array}{l}\text { Tener un } \\
\text { repositorio } \\
\text { (Product } \\
\text { Backlog ) } \\
\text { donde el } \\
\text { Gerente de } \\
\text { Consultorí } \\
\text { a registre } \\
\text { y cambie } \\
\text { su alcance } \\
\text { o } \\
\text { requerimie } \\
\text { nto en } \\
\text { todo } \\
\text { momento }\end{array}$ & $\begin{array}{l}\text { Gerente de } \\
\text { Consultoría }\end{array}$ & $\begin{array}{l}\text { El Gerente de consultoría (Product Owner) da la } \\
\text { aceptación formal sobre el alcance y los requerimientos } \\
\text { funcionales (User Stories o historias de usuario) que } \\
\text { serán registrados en el Product Backlog. Luego, en los } \\
\text { eventos de Sprint Planning, se realiza un refinamiento } \\
\text { de los nuevos requerimientos existentes o creados por } \\
\text { el Gerente de Consultoría, para luego priorizar el } \\
\text { Product Backlog y crear el(los) siguiente(s) Sprint(s) } \\
\text { por el equipo de desarrollo. De esta manera, se controla } \\
\text { que a pesar que haya cambios en el ciclo de vida del } \\
\text { proyecto, se puede ir controlando los cambios dados en } \\
\text { todo momento. }\end{array}$ \\
\hline 5 & $\begin{array}{l}\text { Alta } \\
\text { rotación de } \\
\text { personal } \\
\text { bien } \\
\text { calificado }\end{array}$ & 0.20 & 1.00 & 0.20 & $\begin{array}{l}\text { Dar } \\
\text { incentivos }\end{array}$ & $\begin{array}{l}\text { Gerente } \\
\text { RRHH }\end{array}$ & $\begin{array}{l}\text { Brindar incentivos para a los miembros clave para el } \\
\text { éxito del proyecto no se vea afectado. }\end{array}$ \\
\hline 6 & $\begin{array}{l}\text { Falta de } \\
\text { disponibilid } \\
\text { ad } \\
\text { recursos }\end{array}$ & 0.10 & 1.00 & 0.10 & $\begin{array}{l}\text { Calendariz } \\
\text { ar recursos }\end{array}$ & $\begin{array}{l}\text { Gerente de } \\
\text { Proyecto }\end{array}$ & $\begin{array}{l}\text { Antes de comenzar con el desarrollo del proyecto, } \\
\text { realizar un calendario de los recursos que van a forma } \\
\text { parte del equipo de desarrollo del proyecto y así }\end{array}$ \\
\hline
\end{tabular}




\begin{tabular}{|c|c|c|c|c|c|c|c|}
\hline & $\begin{array}{l}\text { para el } \\
\text { desarrollo }\end{array}$ & & & & & & $\begin{array}{l}\text { contratarlos por el tiempo estimado según el } \\
\text { cronograma de actividades. }\end{array}$ \\
\hline 7 & $\begin{array}{l}\text { Falta de } \\
\text { pago de } \\
\text { servicio de } \\
\text { la nube para } \\
\text { el proyecto }\end{array}$ & 0.05 & 1.00 & 0.05 & $\begin{array}{l}\text { Realizar } \\
\text { un pago } \\
\text { automátic } \\
\text { o del } \\
\text { servicio }\end{array}$ & $\begin{array}{l}\text { Gerente de } \\
\text { Finanzas }\end{array}$ & $\begin{array}{l}\text { Afiliar con el proveedor del servicio un pago } \\
\text { automático a fin de no tener retrasos en el pago del } \\
\text { servicio, que conlleva a perder la accesibilidad de la } \\
\text { aplicación. }\end{array}$ \\
\hline 8 & $\begin{array}{lr}\text { Falta } & \text { del } \\
\text { plan } & \text { de } \\
\text { pruebas } & \end{array}$ & 0.04 & 1.00 & 0.04 & $\begin{array}{l}\text { Realizar } \\
\text { casos de } \\
\text { prueba de } \\
\text { los flujos } \\
\text { de trabajo }\end{array}$ & $\begin{array}{l}\text { Equipo de } \\
\text { proyecto }\end{array}$ & $\begin{array}{l}\text { El equipo de proyecto debe realizar los casos de prueba } \\
\text { correspondiente al proyecto, en base a los } \\
\text { requerimientos funcionales definidos por los } \\
\text { interesados. Además, que estos casos de prueba sean } \\
\text { evaluados por los usuarios finales para ver si salen } \\
\text { incidentes durante las pruebas, para la futura } \\
\text { corrección. }\end{array}$ \\
\hline 9 & $\begin{array}{l}\text { Fallo de } \\
\text { conexión de } \\
\text { acceso al } \\
\text { servicio a } \\
\text { internet }\end{array}$ & 0.02 & 1.00 & 0.02 & $\begin{array}{l}\text { Tener } \\
\text { contratos } \\
\text { con } \\
\text { distintos } \\
\text { proveedor } \\
\text { es de } \\
\text { servicio }\end{array}$ & $\begin{array}{l}\text { Gerente de } \\
\text { Proyecto }\end{array}$ & $\begin{array}{l}\text { Contar con distintos proveedores de servicio de internet } \\
\text { para tener alta disponibilidad de acceso al internet y } \\
\text { poder navegar dentro del sistema de Auditoría Interna } \\
\text { de Riesgos }\end{array}$ \\
\hline 10 & $\begin{array}{l}\text { Tareas no } \\
\text { programada } \\
\mathrm{S}\end{array}$ & 0.10 & 0.50 & 0.05 & $\begin{array}{l}\text { Tener un } \\
\text { repositorio } \\
\text { (Product } \\
\text { Backlog ) } \\
\text { donde se } \\
\text { puede }\end{array}$ & $\begin{array}{l}\text { Gerente de } \\
\text { Consultoría }\end{array}$ & $\begin{array}{l}\text { El Gerente de Consultoría (Product Owner) tiene el } \\
\text { registro de todas las tareas o requerimientos (User } \\
\text { Stories o historias de usuario) en un repositorio llamado } \\
\text { Product Backlog. Para luego, conjuntamente con el } \\
\text { equipo de desarrollo hacer seguimiento y control de } \\
\text { todas las tareas según la priorización que se haya }\end{array}$ \\
\hline
\end{tabular}




\section{$(\varphi)$}

\begin{tabular}{|l|l|l|l|}
\hline & & & \\
& & & \\
\end{tabular}

realizar el

seguimient

o y control

de todas

Fuente: Elaboración Propia

las tareas

realizado. Por último, en base a la priorización se crea los Sprints que se van a ejecutar de acuerdo a iteraciones durante el ciclo de vida del desarrollo del proyecto, de este modo se controla que todas las tareas se desarrollen. 


\section{()}

\subsection{EVALUACIÓN FINANCIERA DE LA PROPUESTA}

Tabla Nº 53 Evaluación Financiera de la Propuesta

\begin{tabular}{|l|r|r|r|r|}
\hline Año & $\mathbf{0}$ & $\mathbf{1}$ & $\mathbf{2}$ & $\mathbf{3}$ \\
\hline INGRESOS & & & & \\
\hline Venta Servicio Peru & $\$ 0.00$ & $\$ 300,000.00$ & $\$ 300,000.00$ & $\$ 300,000.00$ \\
\hline Venta Servicio Otros Países & & & $\$ 500,000.00$ & $\$ 800,000.00$ \\
\hline TOTAL INGRESOS & $\$ 0.00$ & $\$ 300,000.00$ & $\$ 800,000.00$ & $\$ 1,100,000.00$ \\
\hline EGRESOS & & & & \\
\hline Configurar Azure por Certero SAC & $\$ 4,900.00$ & & & \\
\hline Pago Anual de la Nube Azure & $\$ 7,800.00$ & $\$ 7,800.00$ & $\$ 7,800.00$ & \\
\hline Recursos & $\$ 121,200.00$ & & & \\
\hline $\begin{array}{l}\text { Reservas de contingencia (10\% del } \\
\text { gasto de Recursos) }\end{array}$ & $\$ 12,120.00$ & & & \\
\hline Taller impro & $\$ 800.00$ & & & \\
\hline Coaching & $\$ 1,100.00$ & & & \\
\hline Taller Scrum & $\$ 1,300.00$ & & & \\
\hline Capacitación de ARMEY & $\$ 4,500.00$ & & $\$ 9,500.00$ \\
\hline Video Promocional & $\$ 70,000.00$ & & & \\
\hline TOTAL EGRESOS & $\$ 232,720.00$ & $\$ 7,800.00$ & $\$ 17,300.00$ & \\
\hline FLUJO EFECTIVO & $-\$ 232,720.00$ & $\$ 292,200.00$ & $\$ 782,700.00$ & $\$ 1,080,700.00$ \\
\hline FLUJO ACUMULADO & $-\$ 232,720.00$ & $\$ 59,480.00$ & $\$ 842,180.00$ & $\$ 1,922,880.00$ \\
\hline
\end{tabular}

Fuente: Elaboración Propia

Tabla N 54 VAN y TIR de la Propuesta Financiera

\begin{tabular}{|l|r|}
\hline$\%$ Tasa Descuento & $10 \%$ \\
\hline VAN (Valor Actual Neto) & $\$ 1,491,721.77$ \\
\hline TIR (Tasa Interna de Retorno) & $194 \%$ \\
\hline
\end{tabular}

Fuente: Elaboración Propia

Como resultado de la evaluación, se demuestra que el proyecto tiene una tasa interna de retorno (TIR), según la proyección de sólo 3 años, la cual será de 194\%. Como se aprecia, esta proyección representa una gran oportunidad de inversión en un proyecto que puede brindarle la oportunidad de incrementar las ventas (de gastar USD $\$ 232,720.00$ a ganar USD\$ 1,491,721.77 en sólo 3 años) y mejorar el desempeño del trabajo tanto para la organización como para el cliente, con lo que aparte de incrementar las ventas para la organización, se 


\section{(1)}

contará con una herramienta con la marca registrada de EY, la cual el cliente se sentirá más aun identificado con la marca.

\subsection{EVALUACIÓN DE MINIMIZAR EL TIEMPO DE TRABAJO SEGÚN LA PROPUESTA}

Se ha tomado como muestra para este ejemplo un proyecto de Auditoría Interna de Riesgos que tiene un tiempo de 48 horas de trabajo (1 semana). A continuación, se muestra un cuadro con la comparación de realizar un trabajo de forma manual (trabajo que se realiza actualmente) versus lo que se quiere automatizar con el uso del sistema llamado ARMEY.

Tabla N ${ }^{\circ} 55$ Horas Trabajadas de Forma Manual VS Automatizada

\begin{tabular}{|l|r|r|}
\hline \multirow{2}{*}{\multicolumn{1}{|c}{ Actividades }} & \multicolumn{2}{c|}{ Horas Trabajadas } \\
\cline { 2 - 3 } & \multicolumn{1}{c|}{ Manual } & \multicolumn{1}{c|}{ Automatizado } \\
\hline Identificar Riesgos Alto Nivel & 2.00 & 1.30 \\
\hline Evaluar Riesgos de Alto Nivel & 1.00 & 0.65 \\
\hline Diseñar HeatMap Riesgos Alto Nivel & 1.00 & 0.00 \\
\hline Identificar Riesgos Bajo Nivel & 4.00 & 2.60 \\
\hline Evaluar Riesgos de Bajo Nivel & 3.00 & 1.95 \\
\hline Diseñar HeatMap Riesgos Bajo Nivel & 2.00 & 0.00 \\
\hline Diseñar Plan de Auditoría & 2.50 & 1.50 \\
\hline Identificar Controles & 5.00 & 3.25 \\
\hline Diseño de Control & 1.50 & 1.00 \\
\hline Operatividad Control & 4.00 & 3.25 \\
\hline Integrar Información & 2.00 & 0.00 \\
\hline Trabajo de Campo & 20.00 & 20.00 \\
\hline Total Horas Trabajo & $\mathbf{4 8 . 0 0}$ & $\mathbf{3 5 . 5 0}$ \\
\hline
\end{tabular}

Fuente: Elaboración Propia

Tabla N ${ }^{\circ} 56$ Porcentaje Trabajo Minimizado

\begin{tabular}{|l|r|}
\hline Horas Trabajadas & \\
\hline Total Horas Manual & 48.00 \\
\hline Total Horas Automatizado & 35.50 \\
\hline Porcentaje Trabajo Minimizado & $\mathbf{2 6 . 0 4}$ \\
\hline
\end{tabular}




\section{(1)}

Fuente: Elaboración Propia

Al realizar el análisis en el cuadro de las actividades que se realizaron de forma manual versus las que se realizaron de forma automatizada usando una herramienta como ARMEY se puede verificar que se puede llegar a minimizar el trabajo de un proyecto en $26.04 \%$ haciendo que el desempeño del equipo de trabajo mejore notablemente.

\subsection{CRONOGRAMA DE LA PROPUESTA}

En esta sección se muestra los dos cronogramas tentativos para la propuesta. El primero, servirá para desarrollar la propuesta de la Arquitectura Empresarial obteniendo las brechas en base a la Arquitectura de la Línea base y la Destino. El segundo, servirá para realizar el desarrollo propio de la propuesta de un Sistema de Auditoría Interna de Riesgos, para alinear los objetivos de la organización y reducir sus brechas obtenidas en el primer cronograma, la cual contendrá las 5 fases de desarrollo como son: Iniciación, Planificación, Ejecución Seguimiento y Control, y Cierre. Todas estas fases se desarrollarán usando el marco de trabajo Scrum dando así, un producto incremental por cada Sprint (cada 2 semanas) al Product Owner hasta la realización de todo el producto funcionando en su totalidad.

\section{Cronograma Tentativo Arquitectura Empresarial}




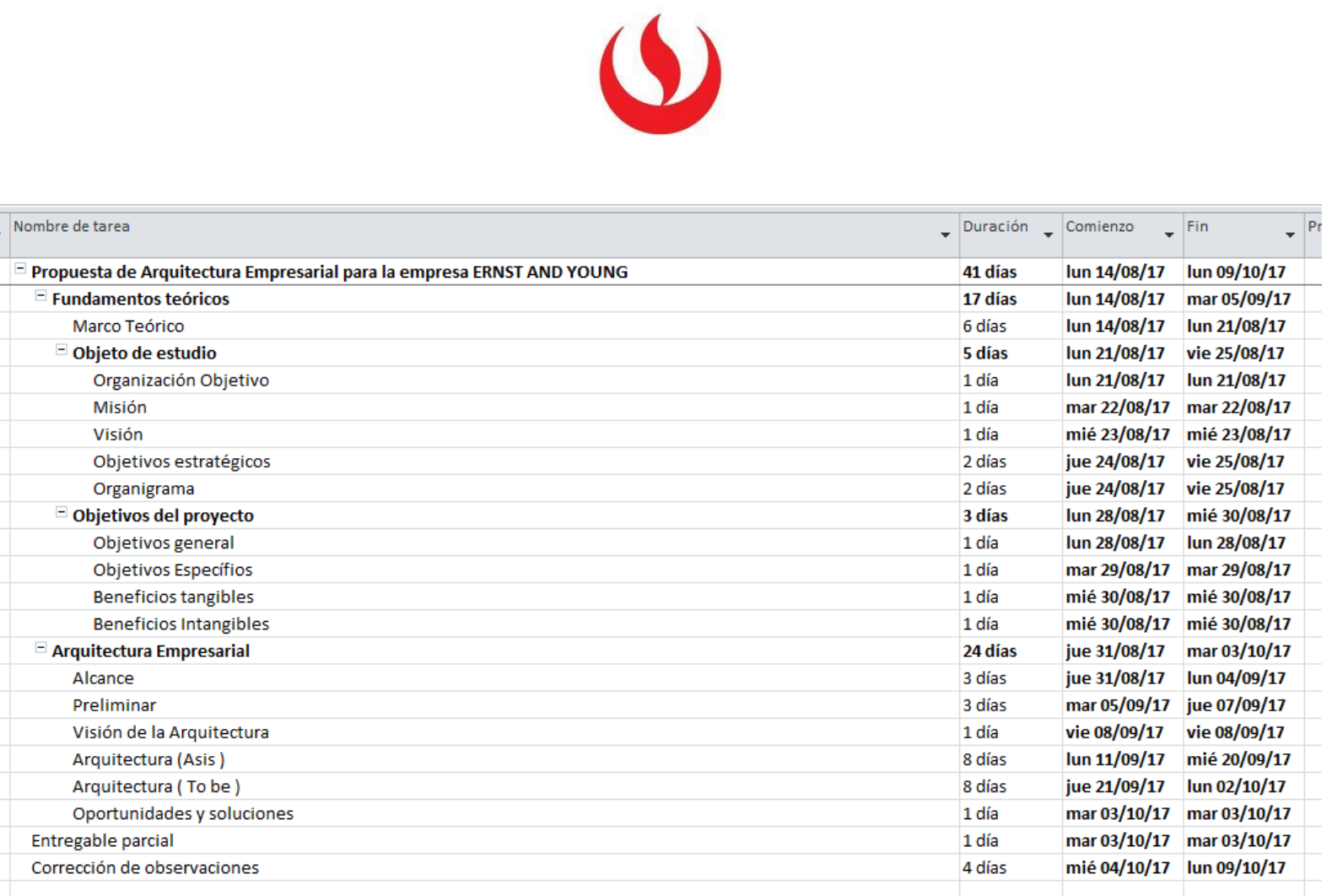

Figura $\mathrm{N}^{\circ} 32$ Cronograma Tentativo Arquitectura Empresarial

Fuente: Elaboración Propia 
$\underline{\text { Cronograma Tentativo Gestión de Proyecto }}$

\begin{tabular}{|c|c|c|c|c|c|c|}
\hline 7 & Nombre de tarea & $\checkmark$ & Duración & Comienzo & Fin & Prec \\
\hline & - Gestión de Proyecto : Proyecto de Auditoria Interna de Riesgos & & 262 días & mié 3/01/18 & jue $3 / 01 / 19$ & \\
\hline & - Iniciación & & 3 días & mié 3/01/18 & vie $5 / 01 / 18$ & \\
\hline & Formar equipo Scrum & & 2 días & mié 3/01/18 & jue $4 / 01 / 18$ & \\
\hline & - KickOff del proyecto & & 2 días & jue $4 / 01 / 18$ & vie $5 / 01 / 18$ & \\
\hline & Crear project vision & & 2 días & jue 4/01/18 & vie $5 / 01 / 18$ & \\
\hline & Project Charter & & 1 día & vie $5 / 01 / 18$ & vie $5 / 01 / 18$ & \\
\hline & - Planificación & & 247 días & lun $8 / 01 / 18$ & $\operatorname{mar} 18 / 12 / 18$ & \\
\hline & - Sprint 0 & & 5 días & Iun $8 / 01 / 18$ & vie $12 / 01 / 18$ & \\
\hline & Configurar el entorno de desarrollo & & 1 día & Iun $8 / 01 / 18$ & Iun $8 / 01 / 18$ & \\
\hline & Crear User Stories & & 2 días & $\operatorname{mar} 9 / 01 / 18$ & mié 10/01/18 & \\
\hline & Crear y priorizar el Product Backlog & & 1 día & jue $11 / 01 / 18$ & jue $11 / 01 / 18$ & \\
\hline & Sprint Planning del Sprint 1 & & 1 día & vie $12 / 01 / 18$ & vie $12 / 01 / 18$ & \\
\hline & Sprint Planning del Sprint 2 & & 1 día & Iun $29 / 01 / 18$ & Iun $29 / 01 / 18$ & \\
\hline & Sprint Planning del Sprint 3 & & 1 día & $\operatorname{mar} 13 / 02 / 18$ & $\operatorname{mar} 13 / 02 / 18$ & \\
\hline & Sprint Planning del Sprint 4 & & 1 día & mié 28/02/18 & mié $28 / 02 / 18$ & \\
\hline & Sprint Planning del Sprint 5 & & 1 día & jue $15 / 03 / 18$ & jue $15 / 03 / 18$ & \\
\hline & Sprint Planning del Sprint 6 & & 1 día & vie $30 / 03 / 18$ & vie $30 / 03 / 18$ & \\
\hline & Sprint Planning del Sprint 7 & & 1 día & Iun $16 / 04 / 18$ & Iun $16 / 04 / 18$ & \\
\hline & Sprint Planning del Sprint 8 & & 1 día & $\operatorname{mar} 1 / 05 / 18$ & $\operatorname{mar} 1 / 05 / 18$ & \\
\hline & Sprint Planning del Sprint 9 & & 1 día & mié 16/05/18 & mié 16/05/18 & \\
\hline & Sprint Planning del Sprint 10 & & 1 día & jue 31/05/18 & jue 31/05/18 & \\
\hline & Sprint Planning del Sprint 11 & & 1 día & vie $15 / 06 / 18$ & vie $15 / 06 / 18$ & \\
\hline & Sprint Planning del Sprint 12 & & 1 día & Iun $2 / 07 / 18$ & Iun $2 / 07 / 18$ & \\
\hline & Sprint Planning del Sprint 13 & & 1 día & $\operatorname{mar} 17 / 07 / 18$ & $\operatorname{mar} 17 / 07 / 18$ & \\
\hline & Sprint Planning del Sprint 14 & & 1 día & mié $1 / 08 / 18$ & mié $1 / 08 / 18$ & \\
\hline & Sprint Planning del Sprint 15 & & 1 día & jue $16 / 08 / 18$ & jue $16 / 08 / 18$ & \\
\hline & Sprint Planning del Sprint 16 & & 1 día & vie $31 / 08 / 18$ & vie $31 / 08 / 18$ & \\
\hline & Sprint Planning del Sprint 17 & & 1 día & Iun $17 / 09 / 18$ & Iun $17 / 09 / 18$ & \\
\hline & Sprint Planning del Sprint 18 & & 1 día & $\operatorname{mar} 2 / 10 / 18$ & $\operatorname{mar} 2 / 10 / 18$ & \\
\hline & Sprint Planning del Sprint 19 & & 1 día & mié 17/10/18 & mié 17/10/18 & \\
\hline & Sprint Planning del Sprint 20 & & 1 día & jue $1 / 11 / 18$ & jue $1 / 11 / 18$ & \\
\hline & Sprint Planning del Sprint 21 & & 1 día & vie $16 / 11 / 18$ & vie $16 / 11 / 18$ & \\
\hline & Sprint Planning del Sprint 22 & & 1 día & Iun $3 / 12 / 18$ & Iun $3 / 12 / 18$ & \\
\hline & Sprint Planning del Sprint 23 & & 1 día & $\operatorname{mar} 18 / 12 / 18$ & $\operatorname{mar} 18 / 12 / 18$ & \\
\hline & - Ejecución & & 253 días & Iun $15 / 01 / 18$ & mié 2/01/19 & \\
\hline & - Sprint 1 & & 11 días & Iun $15 / 01 / 18$ & Iun $29 / 01 / 18$ & \\
\hline & Cliente & & 4 días & Iun $15 / 01 / 18$ & jue $18 / 01 / 18$ & \\
\hline & Proyecto & & 4 días & jue $18 / 01 / 18$ & $\operatorname{mar} 23 / 01 / 18$ & \\
\hline
\end{tabular}




\section{(}

\begin{tabular}{|c|c|c|c|c|c|c|}
\hline \multirow[t]{2}{*}{ 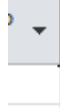 } & Nombre de tarea & $\checkmark$ & Duración & Comienzo & Fin & $\mathrm{Pr}$ \\
\hline & Procesos del proyecto & & 5 días & $\operatorname{mar} 23 / 01 / 18$ & Iun $29 / 01 / 18$ & \\
\hline & - Sprint 2 & & 11 días & $\operatorname{mar} 30 / 01 / 18$ & $\operatorname{mar} 13 / 02 / 18$ & \\
\hline & Plan de acción & & 11 días & $\operatorname{mar} 30 / 01 / 18$ & $\operatorname{mar} 13 / 02 / 18$ & \\
\hline & - Sprint 3 & & 11 días & mié 14/02/18 & mié 28/02/18 & \\
\hline & Riesgos de alto nivel & & 11 días & mié 14/02/18 & mié 28/02/18 & \\
\hline & - Sprint 4 & & 11 días & jue $1 / 03 / 18$ & jue $15 / 03 / 18$ & \\
\hline & Evaluar riesgos de alto nivel & & 11 días & jue $1 / 03 / 18$ & jue $15 / 03 / 18$ & \\
\hline & - Sprint 5 & & 11 días & vie $16 / 03 / 18$ & vie $30 / 03 / 18$ & \\
\hline & Evaluar riesgos de bajo nivel & & 11 días & vie $16 / 03 / 18$ & vie $30 / 03 / 18$ & \\
\hline & - Sprint 6 & & 11 días & Iun $2 / 04 / 18$ & Iun $16 / 04 / 18$ & \\
\hline & Reporte de resultado de operatividad & & 8 días & Iun $2 / 04 / 18$ & mié 11/04/18 & \\
\hline & Reporte de plan de acción & & 4 días & mié 11/04/18 & Iun $16 / 04 / 18$ & \\
\hline & - Sprint 7 & & 11 días & $\operatorname{mar} 17 / 04 / 18$ & $\operatorname{mar} 1 / 05 / 18$ & \\
\hline & Riesgo de bajo nivel & & 11 días & $\operatorname{mar} 17 / 04 / 18$ & $\operatorname{mar} 1 / 05 / 18$ & \\
\hline & - Sprint 8 & & 11 días & mié 2/05/18 & mié 16/05/18 & \\
\hline & Controles & & 11 días & mié 2/05/18 & mié 16/05/18 & \\
\hline & - Sprint 9 & & 11 días & jue $17 / 05 / 18$ & jue $31 / 05 / 18$ & \\
\hline & Diseño de controles & & 11 días & jue $17 / 05 / 18$ & jue $31 / 05 / 18$ & \\
\hline & - Sprint 10 & & 11 días & vie $1 / 06 / 18$ & vie $15 / 06 / 18$ & \\
\hline & Diseño de controles & & 11 días & vie $1 / 06 / 18$ & vie $15 / 06 / 18$ & \\
\hline & - Sprint 11 & & 11 días & Iun $18 / 06 / 18$ & lun $2 / 07 / 18$ & \\
\hline & Operatividad de controles & & 11 días & Iun $18 / 06 / 18$ & Iun $2 / 07 / 18$ & \\
\hline & - Sprint 12 & & 11 días & $\operatorname{mar} 3 / 07 / 18$ & $\operatorname{mar} 17 / 07 / 18$ & \\
\hline & Operatividad de controles & & 11 días & $\operatorname{mar} 3 / 07 / 18$ & $\operatorname{mar} 17 / 07 / 18$ & \\
\hline & - Sprint 13 & & 11 días & mié 18/07/18 & mié 1/08/18 & \\
\hline & Categorías de riesgos & & 11 días & mié 18/07/18 & mié $1 / 08 / 18$ & \\
\hline & - Sprint 14 & & 11 días & jue $2 / 08 / 18$ & jue $16 / 08 / 18$ & \\
\hline & Plan de auditoria & & 11 días & jue $2 / 08 / 18$ & jue $16 / 08 / 18$ & \\
\hline & - Sprint 15 & & 11 días & vie $17 / 08 / 18$ & vie $31 / 08 / 18$ & \\
\hline & Plan de auditoria & & 11 días & vie $17 / 08 / 18$ & vie $31 / 08 / 18$ & \\
\hline & - Sprint 16 & & 11 días & lun $3 / 09 / 18$ & Iun $17 / 09 / 18$ & \\
\hline & Servicio de notificación de plan de acción & & 11 días & lun $3 / 09 / 18$ & Iun $17 / 09 / 18$ & \\
\hline & - Sprint 17 & & 11 días & $\operatorname{mar} 18 / 09 / 18$ & $\operatorname{mar} 2 / 10 / 18$ & \\
\hline & Mapa de riesgos & & 11 días & $\operatorname{mar} 18 / 09 / 18$ & $\operatorname{mar} 2 / 10 / 18$ & \\
\hline & - Sprint 18 & & 11 días & mié $3 / 10 / 18$ & mié 17/10/18 & \\
\hline & Priorizar los procesos & & 11 días & mié $3 / 10 / 18$ & mié 17/10/18 & \\
\hline & - Sprint 19 & & 11 días & jue $18 / 10 / 18$ & jue $1 / 11 / 18$ & \\
\hline & Personal EY & & 4 días & jue $18 / 10 / 18$ & $\operatorname{mar} 23 / 10 / 18$ & \\
\hline
\end{tabular}




\begin{tabular}{|c|c|c|c|c|c|c|}
\hline$\checkmark$ & Nombre de tarea & $\checkmark$ & Duración . & Comienzo & Fin & Prec \\
\hline & Objetivos de proceso & & 4 días & $\operatorname{mar} 23 / 10 / 18$ & vie $26 / 10 / 18$ & \\
\hline & Asociar objetivos a procesos & & 5 días & vie $26 / 10 / 18$ & jue $1 / 11 / 18$ & \\
\hline & - Sprint 20 & & 11 días & vie $2 / 11 / 18$ & vie $16 / 11 / 18$ & \\
\hline & Configurar mapa de riesgos & & 11 días & vie $2 / 11 / 18$ & vie $16 / 11 / 18$ & \\
\hline & - Sprint 21 & & 11 días & Iun $19 / 11 / 18$ & Iun $3 / 12 / 18$ & \\
\hline & Configurar mapa de riesgos & & 11 días & lun $19 / 11 / 18$ & Iun $3 / 12 / 18$ & \\
\hline & - Sprint 22 & & 11 días & $\operatorname{mar} 4 / 12 / 18$ & $\operatorname{mar} 18 / 12 / 18$ & \\
\hline & Criterios de riesgos & & 7 días & $\operatorname{mar} 4 / 12 / 18$ & mié 12/12/18 & \\
\hline & Evaluar los procesos & & 5 días & mié 12/12/18 & $\operatorname{mar} 18 / 12 / 18$ & \\
\hline & - Sprint 23 & & 11 días & mié 19/12/18 & mié 2/01/19 & \\
\hline & Administrar usuarios & & 11 días & mié 19/12/18 & mié 2/01/19 & \\
\hline & - Seguimiento y Control & & 243 días & Iun $29 / 01 / 18$ & mié 2/01/19 & \\
\hline & Sprint Review 1 & & 1 día & Iun $29 / 01 / 18$ & Iun $29 / 01 / 18$ & \\
\hline & Retrospectiva del Sprint 1 & & 1 día & lun $29 / 01 / 18$ & Iun $29 / 01 / 18$ & \\
\hline & Sprint Review 2 & & 1 día & $\operatorname{mar} 13 / 02 / 18$ & $\operatorname{mar} 13 / 02 / 18$ & \\
\hline & Retrospectiva del Sprint 2 & & 1 día & $\operatorname{mar} 13 / 02 / 18$ & $\operatorname{mar} 13 / 02 / 18$ & \\
\hline & Sprint Review 3 & & 1 día & mié 28/02/18 & mié 28/02/18 & \\
\hline & Retrospectiva del Sprint 3 & & 1 día & mié 28/02/18 & mié 28/02/18 & \\
\hline & Sprint Review 4 & & 1 día & jue $15 / 03 / 18$ & jue $15 / 03 / 18$ & \\
\hline & Retrospectiva del Sprint 4 & & 1 día & jue $15 / 03 / 18$ & jue $15 / 03 / 18$ & \\
\hline & Sprint Review 5 & & 1 día & vie 30/03/18 & vie 30/03/18 & \\
\hline & Retrospectiva del Sprint 5 & & 1 día & vie 30/03/18 & vie 30/03/18 & \\
\hline & Sprint Review 6 & & 1 día & Iun $16 / 04 / 18$ & lun $16 / 04 / 18$ & \\
\hline & Retrospectiva del Sprint 6 & & 1 día & Iun $16 / 04 / 18$ & Iun $16 / 04 / 18$ & \\
\hline & Sprint Review 7 & & 1 día & $\operatorname{mar} 1 / 05 / 18$ & $\operatorname{mar} 1 / 05 / 18$ & \\
\hline & Retrospectiva del Sprint 7 & & 1 día & $\operatorname{mar} 1 / 05 / 18$ & $\operatorname{mar} 1 / 05 / 18$ & \\
\hline & Sprint Review 8 & & 1 día & mié 16/05/18 & mié 16/05/18 & \\
\hline & Retrospectiva del Sprint 8 & & 1 día & mié 16/05/18 & mié 16/05/18 & \\
\hline & Sprint Review 9 & & 1 día & jue 31/05/18 & jue 31/05/18 & \\
\hline & Retrospectiva del Sprint 9 & & 1 día & jue 31/05/18 & jue $31 / 05 / 18$ & \\
\hline & Sprint Review 10 & & 1 día & vie $15 / 06 / 18$ & vie $15 / 06 / 18$ & \\
\hline & Retrospectiva del Sprint 10 & & 1 día & vie $15 / 06 / 18$ & vie $15 / 06 / 18$ & \\
\hline & Sprint Review 11 & & 1 día & Iun $2 / 07 / 18$ & Iun $2 / 07 / 18$ & \\
\hline & Retrospectiva del Sprint 11 & & 1 día & Iun $2 / 07 / 18$ & Iun $2 / 07 / 18$ & \\
\hline & Sprint Review 12 & & 1 día & $\operatorname{mar} 17 / 07 / 18$ & $\operatorname{mar} 17 / 07 / 18$ & \\
\hline & Retrospectiva del Sprint 12 & & 1 día & $\operatorname{mar} 17 / 07 / 18$ & $\operatorname{mar} 17 / 07 / 18$ & \\
\hline & Sprint Review 13 & & 1 día & mié 1/08/18 & mié 1/08/18 & \\
\hline & Retrospectiva del Sprint 13 & & 1 día & mié 1/08/18 & mié 1/08/18 & \\
\hline
\end{tabular}




\begin{tabular}{|c|c|c|c|c|c|}
\hline Nombre de tarea & 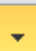 & Duración & Comienzo & Fin & Prec \\
\hline Sprint Review 14 & & 1 día & jue $16 / 08 / 18$ & jue $16 / 08 / 18$ & \\
\hline Retrospectiva del Sprint 14 & & 1 día & jue $16 / 08 / 18$ & jue $16 / 08 / 18$ & \\
\hline Sprint Review 15 & & 1 día & vie $31 / 08 / 18$ & vie $31 / 08 / 18$ & \\
\hline Retrospectiva del Sprint 15 & & 1 día & vie $31 / 08 / 18$ & vie $31 / 08 / 18$ & \\
\hline Sprint Review 16 & & 1 día & Iun $17 / 09 / 18$ & Iun $17 / 09 / 18$ & \\
\hline Retrospectiva del Sprint 16 & & 1 día & Iun $17 / 09 / 18$ & Iun $17 / 09 / 18$ & \\
\hline Sprint Review 17 & & 1 día & $\operatorname{mar} 2 / 10 / 18$ & $\operatorname{mar} 2 / 10 / 18$ & \\
\hline Retrospectiva del Sprint 17 & & 1 día & $\operatorname{mar} 2 / 10 / 18$ & $\operatorname{mar} 2 / 10 / 18$ & \\
\hline Sprint Review 18 & & 1 día & mié 17/10/18 & mié 17/10/18 & \\
\hline Retrospectiva del Sprint 18 & & 1 día & mié 17/10/18 & mié 17/10/18 & \\
\hline Sprint Review 19 & & 1 día & jue $1 / 11 / 18$ & jue $1 / 11 / 18$ & \\
\hline Retrospectiva del Sprint 19 & & 1 día & jue $1 / 11 / 18$ & jue $1 / 11 / 18$ & \\
\hline Sprint Review 20 & & 1 día & vie $16 / 11 / 18$ & vie $16 / 11 / 18$ & \\
\hline Retrospectiva del Sprint 20 & & 1 día & vie $16 / 11 / 18$ & vie $16 / 11 / 18$ & \\
\hline Sprint Review 21 & & 1 día & Iun $3 / 12 / 18$ & Iun $3 / 12 / 18$ & \\
\hline Retrospectiva del Sprint 21 & & 1 día & Iun $3 / 12 / 18$ & Iun $3 / 12 / 18$ & \\
\hline Sprint Review 22 & & 1 día & $\operatorname{mar} 18 / 12 / 18$ & $\operatorname{mar} 18 / 12 / 18$ & \\
\hline Retrospectiva del Sprint 22 & & 1 día & $\operatorname{mar} 18 / 12 / 18$ & $\operatorname{mar} 18 / 12 / 18$ & \\
\hline Sprint Review 23 & & 1 día & mié 2/01/19 & mié 2/01/19 & \\
\hline - Cierre & & 1 día & jue $3 / 01 / 19$ & jue $3 / 01 / 19$ & \\
\hline Retrospectiva del proyecto & & 1 día & jue $3 / 01 / 19$ & jue $3 / 01 / 19$ & \\
\hline Entrega Producto Final & & 1 día & jue $3 / 01 / 19$ & jue $3 / 01 / 19$ & \\
\hline
\end{tabular}

Figura $N^{\circ} 33$ Cronograma Tentativo Gestión de Proyecto

Fuente: Elaboración Propia 


\section{(1)}

\subsection{ESTRUCTURA DE DESGLOSE DE LA PROPUESTA}

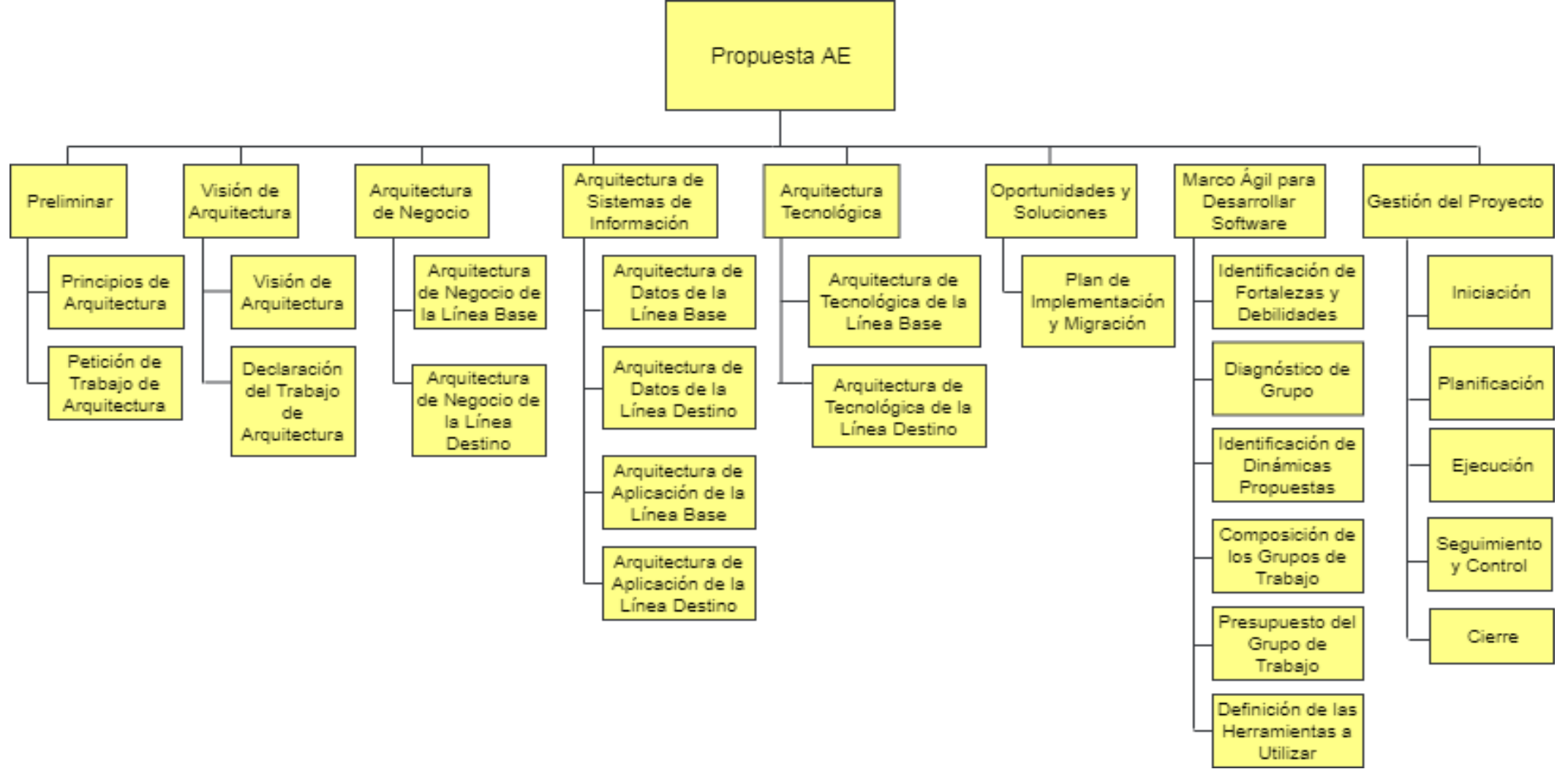

Figura $\mathrm{N}^{\circ} 34$ Estructura de Desglose de la Propuesta de Arquitectura Empresarial

Fuente: Elaboración Propia 


\section{(1)}

\subsection{MARCO INTEGRAL DE LA PROPUESTA}
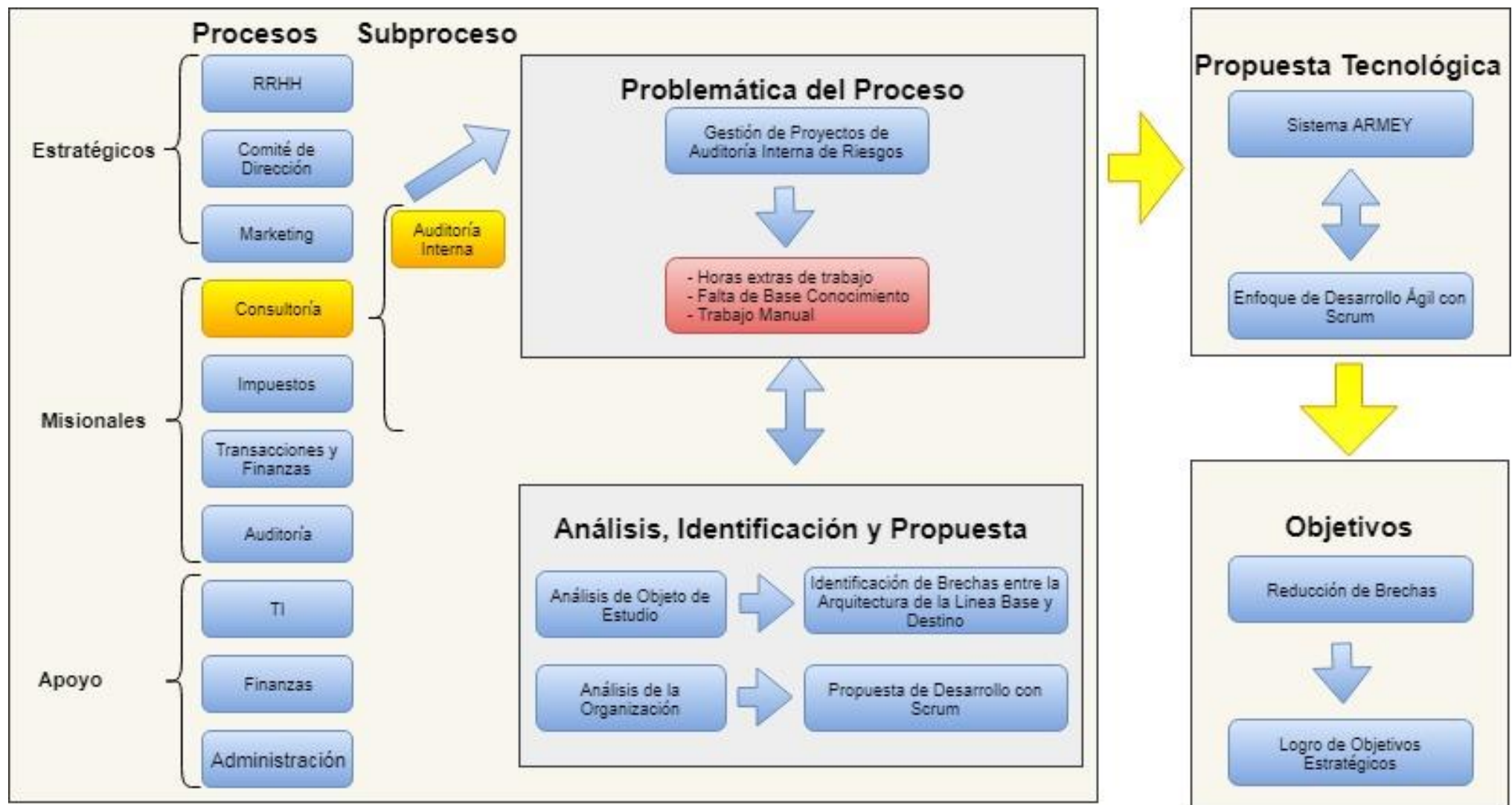

Figura $\mathrm{N}^{\circ} 35$ Marco Integral del Proyecto

Fuente: Elaboración Propia 


\section{(1)}

El marco integral muestra el objeto de estudio de la propuesta tecnológica sobre el subproceso de Auditoría Interna de Riesgos, en la cual se ve como este subproceso en base a la problemática que tiene y utilizando una Arquitectura Empresarial se puede analizar e identificar las brechas dadas entre una Arquitectura de la Línea Base y la Destino, dando así una solución sobre estas. Luego, se realizará un análisis de la organización a fin de desarrollar un proceso de trabajo mediante el uso de una marco de trabajo ágil usando Scrum, para desarrollar un proyecto tecnológico y que esta se aliene a los objetivos estratégicos de la organización ofreciendo beneficios tangibles y no intangibles. 


\section{(1)}

\section{CONCLUSIONES}

Se han llegado a las siguientes conclusiones:

- El trabajo manual causa un problema a los equipos de auditoría del subproceso de la Auditoría Interna de Riegos de la organización EY; por esta razón, se consideró el uso de un marco de referencia de arquitectura mediante TOGAF. En base a este marco, se ha podido realizar el análisis de la situación actual del sub proceso de la Auditoría Interna de Riesgos en donde en base a un análisis se han identificado las brechas de la arquitectura de la línea base contra la de destino, con lo cual se propone el uso una arquitectura empresarial para esta solución.

- Al obtener las brechas tanto de negocio, aplicación, base de datos y arquitectura; además de los riesgos y su impacto dentro del subproceso de la Auditoría Interna de Riesgos, se puede realizar un resumen del plan de migración que ayudará a mitigar mediante soluciones potenciales los riesgos dados y ayudará a la problemática que aqueja al proceso en proyectos del cliente. Adicionalmente, el costo del plan de migración del desarrollo de la propuesta y la configuración e implementación del desarrollo en un servicio en la nube (Azure).

- La gestión de la solución tecnológica se realizará con Scrum. Este marco de trabajo, es la mejor solución para conseguir resultados en plazos más cortos que los que se obtienen usando metodologías tradicionales como son el caso las de tipo cascada, ya que en da valor al negocio en la medida que se logran resultados en un tiempos cortos, haciendo que sea atractivo para el cliente.

- Se tiene que optar por crear un equipo de proyecto que sea cohesivo y auto disciplinado en el uso de Scrum. Además, el equipo debe tener habilidades técnicas, de comunicación y una 
habilidad empática (habilidades blandas). En caso estas habilidades no existan los miembros dentro del equipo, se les deberá capacitar mediante talleres de Scrum, Coaching y/o Impro.

- A partir del desarrollo de una herramienta tecnológica bajo los lineamientos de la arquitectura empresarial, alineados al proceso de negocio y sus objetivos; se puede lograr que la organización pueda tener mayores beneficios tanto cualitativamente, en términos de ingresos y mejora del tiempo del proceso de trabajo de proyectos de Auditoría Interna de Riesgos, como también de forma cuantitativa en términos de empoderar clientes, dar valor a la marca y ser de cara al cliente como su primer opción en servicio de consultoría.

- Por último, se considera que la realización del proyecto en base a la propuesta de la arquitectura empresarial, puede tener una gran proyección dentro de la empresa y que al implementarse se obtendrían un mejor desempeño en el proceso de trabajo de la Auditoría Interna de Riesgos. Además, al aplicar propuestas de este tipo dentro de la organización permitirá analizar, validar, construir y mantener sistemas de información altamente competitivos y una gestión más eficiente del área de TI. Posteriormente, TI podría llegar a ser un área estratégica de la organización. 


\section{(1)}

\section{RECOMENDACIONES}

Se tienen las siguientes consideraciones:

- Se recomienda que los interesados clave dentro del proyecto cuenten con capacitaciones en la gestión de proyectos de sistemas, ya que no al no contar con la experiencia de trabajar en estos tipos de proyectos puede tener dificultad en el desarrollo de la propuesta de la arquitectura empresarial con el área de TI.

- Se recomienda que el equipo de proyecto, en caso no cuente con conocimiento de utilizar un marco de trabajo ágil con SCRUM. Estos se han capacitados en talleres prácticos donde pueden desarrollar sus habilidades como un equipo cohesivo y auto disciplinado.

- Se recomienda que en cada Retrospectiva luego del Sprint Review se cree un documento de lecciones aprendidas como apoyo de dudas o consultas para futuros proyectos de desarrollo o en sí para el próximo Sprint.

- Se recomienda que los socios o gerentes de cada proceso vean al área de TI como un aliado estratégico, ya que esta área puede ayudar a desarrollar productos y/o servicios para la mejora de sus procesos. En este caso, automatizando el trabajo dentro de la organización haciendo que puedan cumplir con sus metas u objetivos. 


\section{(1)}

\section{GLOSARIO DE TÉRMINOS}

- Backlog Priorizado del Producto

El Backlog Priorizado del Producto es un solo documento de requisitos que define el alcance del proyecto, proporcionando una lista de prioridades de las características del producto o servicio a ser entregado por el proyecto.

- $\quad$ Effort Estimated Task List

La llama Effort Estimated Task List (lista de tareas del esfuerzo estimado) es una lista de tareas asociadas con las User Stories incluidas en un Sprint. Típicamente la precisión de las estimaciones varía dependiendo de las habilidades del equipo. El esfuerzo estimado se expresa en términos de los criterios de estimación acordados por el equipo. El Equipo Scrum utiliza la Effort Estimated Task List durante las reuniones de Sprint Planning a fin de crear el Sprint Backlog. Se utiliza también para determinar cuándo el equipo necesita reducir su compromiso o asumir User Stories adicionales durante el Sprint Planning.

- Épica(s)

Las épicas se escriben en las etapas iniciales del proyecto, cuando la mayoría de las User Stories son funcionalidades de alto nivel o descripciones de productos que están ampliamente definidas. Las épicas son User Stories grandes, sin refinar en el Backlog Priorizado del Producto. Una vez que estas épicas aparecen en el Backlog Priorizado del Producto para completarse en el próximo Sprint, se convierten en User Stories más pequeñas. Estas User Stories más pequeñas son generalmente funcionalidades simples, cortas y fáciles de implementar, o bloques de tareas que deben completarse en un Sprint.

\section{- Marco de trabajo:}




\section{(1)}

Un marco de trabajo o framework es un marco de referencia que corresponde a los componentes especiales que actúan como base para la estructuración y ensamble de componentes en construcciones más complejas.

\section{- User Stories comprometidas}

El Equipo Scrum se compromete a un subconjunto de User Stories estimadas que consideran que se pueden completar en el siguiente Sprint con base en la velocidad. Las User Stories comprometidas se seleccionarán siempre según las prioridades definidas por el Product Owner.

\section{- Kick off}

Se define el kick off del proyecto como la reunión que da el inicio formal al proyecto. Debido a la importancia de esta reunión para encarrilar correctamente el proyecto, es muy conveniente disponer de una lista de control del kick off del proyecto, de tal forma que se estandarice y se verifique que este hito se lleva a cabo con toda la información necesaria.

\section{- Metodología:}

Hace referencia al conjunto de procedimientos racionales utilizados para alcanzar una gama de objetivos que rigen en una investigación científica, una exposición doctrinal o tareas que requieran habilidades o conocimientos. La metodología es una de las etapas específicas de un trabajo o proyecto que parte de una posición teórica y conduce una selección de técnicas concretas o métodos

\section{- Scrum:}

Scrum es un marco de trabajo en el que se aplican de manera regular un conjunto de buenas prácticas para trabajar colaborativamente en equipo, y obtener el mejor resultado posible de un proyecto. Estas prácticas se apoyan unas a otras y su selección tiene origen en un estudio de la manera de trabajar de equipos altamente productivos.

\section{- Product Owner:}




\section{(1)}

Como se describe en la Guía de Scrum, el Product Owner es responsable de maximizar el valor del producto y el trabajo del equipo de desarrollo. La forma en que se hace esto puede variar ampliamente entre las organizaciones, los equipos Scrum y los individuos. El Product Owner es la única persona responsable de administrar el Backlog de Producto.

\section{- Scrum Master:}

También llamado facilitador de proyectos, es la figura que lidera los equipos en la gestión ágil de proyectos. Su misión es que los equipos de trabajo alcancen sus objetivos hasta llegar a la fase de Sprint final, eliminando cualquier dificultad que puedan encontrar en el camino.

\section{- Scrum Guidance Body (SGB)}

Es un rol opcional, que generalmente consiste en un conjunto de documentos y/o un grupo de expertos que normalmente están involucrados en la definición de los objetivos relacionados con la calidad, las regulaciones gubernamentales, la seguridad y otros parámetros claves de la organización. El SGB guía el trabajo llevado a cabo por el Product Owner, el Scrum Master y el Development Team.

\section{- Scrumboard}

En Scrum, la transparencia proviene de las herramientas visiblemente abiertas tales como el Scrumboard, donde se muestra el avance del equipo. El equipo utiliza un Scrumboard para planificar y dar seguimiento al progreso durante cada Sprint. El tablero contiene cuatro columnas para indicar el progreso de las tareas estimadas para el Sprint: una columna "por hacer" para las tareas que aún no se inician; una columna "en progreso" para las tareas que ya iniciaron, pero no se han concluido; una columna "en prueba" para las tareas concluidas pero que están en proceso de evaluación y una columna de "terminado" para las tareas que se han concluido y evaluado satisfactoriamente. Al principio de cada Sprint, todas las tareas se colocan en la columna "por hacer" y avanzan según su progreso.

\section{- Sprint Backlog}




\section{(1)}

El equipo principal de Scrum lleva a cabo reuniones de planificación del Sprint donde el grupo elabora un Sprint Backlog que contiene todas las tareas a completarse en el Sprint.

\section{- Software:}

Equipamiento lógico o soporte lógico de un sistema informático, comprende el conjunto de los componentes lógicos necesarios que hacen posible la realización de tareas específicas, en contraposición a los componentes físicos, que son llamados hardware.

\section{- Call Center:}

Es un centro de llamadas telefónicas, un sistema de administración y gestión que se realiza a través de un solo canal, el telefónico, y cuya principal actividad es la recepción o emisión de información, la cual se realiza de manera rápida y concisa con una atención exclusiva entre el usuario/ciudadano y tele operador.

\section{- Data Analytics:}

Plataformas digitales que permitan conectar a compradores con vendedores ya sea de productos o servicios.

\section{- Outsourcing:}

Es el proceso económico empresarial en el que una sociedad mercantil transfiere los recursos y las responsabilidades referentes al cumplimiento de ciertas tareas a una sociedad externa, empresa de gestión o subcontratista, que precisamente se dedica a la prestación de diferentes servicios especializados.

- Azure

Es el servicio de construcción de aplicaciones en la nube ofrecido por la compañía Microsoft.

\section{- Roadmap}




\section{(1)}

Es una planificación del desarrollo de un software con los objetivos a corto y largo plazo, y posiblemente incluyendo unos plazos aproximados de consecución de cada uno de estos objetivos.

\section{- Information Radiators}

Podemos definir los information radiators como una serie de información colocada estratégicamente en un lugar de paso para que cualquiera que pase cerca del equipo pueda ver en un vistazo la situación de su trabajo sin preguntar al equipo directamente. El objetivo es aumentar la comunicación sin necesidad de aumentar el trabajo del equipo ni las interrupciones.

El ejemplo típico de information radiator en Scrum es el Burndown Chart, que refleja el progreso de trabajo planificado en el Sprint o en el proyecto versus el tiempo que tenemos para completarlo.

\section{- WIP}

Trabajo en curso (acrónimo: WIP) o en proceso de inventario incluye el conjunto en general de los elementos pendientes de los productos en un proceso de producción. Estos elementos no se han completado, pero ya sea simplemente ser fabricados o esperando en una cola para su procesamiento posterior o en una memoria buffer.

- Lean

Este modelo es crear máximo valor posible, desde el punto de vista del cliente, con el menor consumo posible de recursos (es decir ajustados), usando el conocimiento y habilidades de la gente que realiza el trabajo.

\section{- Diagrama Ishikawa}

Es una representación gráfica que por su estructura también se llama diagrama de pescado, este consiste en una representación sencilla en la que puede verse una especie de espina central, que es una línea en el plano horizontal, representando un problema a analizar, que se escribe en la cabeza del pescado. 


\section{(}

\section{- Brainwriting}

Es una técnica creativa que provee una forma eficaz y simple para recolectar ideas innovadoras de un grupo de personas de cómo resolver un problema, desarrollar un proyecto o mejorar una situación existente.

\section{- Pair Programming}

Se basa en que dos programadores trabajan juntos en un solo ordenador. Uno de ellos desarrolla mientras que el otro ayuda y revisa el código del compañero.

\section{- Trello}

Es una herramienta gestión de tareas que permite el trabajo de forma colaborativa mediante tableros (board) compuestos de columnas (llamadas listas) que representan distintos estados. Se basa en el método Kanban para gestión de proyectos, con tarjetas que viajan por diferentes listas en función de su estado.

\section{- Extreme Programming}

Es una metodología de desarrollo de la ingeniería de software formulada por Kent Beck, autor del primer libro sobre la materia, Extreme Programming Explained: Embrace Change (1999). Es el más destacado de los procesos ágiles de desarrollo de software. Al igual que éstos, la programación extrema se diferencia de las metodologías tradicionales principalmente en que pone más énfasis en la adaptabilidad que en la previsibilidad.

\section{- Standup Meeting}

Stand-up Meeting es una reunión del equipo organizada a diario para presentar una actualización de estado a todos los miembros de un equipo de desarrollo. Esta actualización de estado en tiempo real plantea posibles problemas y sincroniza los esfuerzos para eliminar los problemas desafiantes y lentos. Los Stand-up Meeting son más comunes en un proceso de desarrollo ágil como Scrum, pero también se pueden extender a cualquier metodología en desarrollo. 


\section{()}

- Time-boxing

El Time-boxing es la fijación de breves periodos para hacer el trabajo. Si el trabajo realizado queda incompleto al final del time-box, este se asigna a un nuevo time-box. El asignar bloques de tiempo fijo proporciona la estructura necesaria para los proyectos Scrum, los cuales tienen un elemento de incertidumbre, son dinámicos por naturaleza y propensos a cambios frecuentes.

\section{- Project Charter}

Un acta constitutiva del proyecto (conocida en inglés como Project Charter) es una declaración oficial de los objetivos y resultados deseados del proyecto. En varias organizaciones, el acta constitutiva del proyecto es el documento que autoriza el proyecto oficial y formalmente, dándole al equipo la autoridad por escrito para iniciar el proyecto.

\section{- Sprint Burndown Chart}

El Sprint Burndown Chart es una gráfica que muestra la cantidad de trabajo pendiente en el actual sprint.

\section{- Stakeholder(s)}

Stakeholder es un término colectivo que incluye a clientes, usuarios y patrocinadores que interactúan frecuentemente con el Product Owner, con el Scrum Master y con el Equipo Scrum para brindar opiniones y facilitar la creación del producto del proyecto, servicio u otros resultados. 


\section{(}

\section{SIGLARIO}

- $\quad$ EY (Ernst and Young)

Empresa líder de servicios de consultoría, auditoria, impuestos y Transacciones y Finanzas a nivel mundial.

- $\quad$ ADM (Métodos de Desarrollo de Arquitectura)

Es el método definido por TOGAF para el desarrollo de una arquitectura empresarial, este puede ser ajustado y personalizado según las necesidades propias de la organización y una vez definido se utiliza para gestionar la ejecución de las actividades de desarrollo de la arquitectura.

- $\mathbf{A E}$ (Arquitectura Empresarial)

“Arquitectura Empresarial es el proceso de trasladar una visión y estrategia de negocio en un cambio efectivo, comunicando las capacidades actuales y repensando los principios y los modelos que describen el estado futuro de la empresa y facilitan su evolución." (Gartner 2015).

- ASIS (Arquitectura Base)

Ayuda a generar un alineamiento y entendimiento entre las distintas áreas y locaciones de la empresa en cuanto a cómo efectivamente se ejecuta el proceso de negocios. A menudo en las organizaciones grandes muchos ejecutivos y usuarios claves no tienen la visión completa de cada uno de los pasos y detalles de la operación del proceso de negocios. La documentación del As-Is ayuda a generar claridad respecto a cómo se ejecutan las cosas y cuáles son los desalineamientos.

\section{- ROADMAP}




\section{(1)}

El roadmap (hoja de ruta) es el término que se utiliza para definir el documento en el que se detalla la planificación en el desarrollo de un proyecto. Aunque se utiliza con mayor frecuencia en proyectos relacionados con el desarrollo de un software, el término puede usarse en cualquier área de desarrollo.

\section{- ROI}

El índice de retorno sobre la inversión (ROI por sus siglas en inglés) es un indicador financiero que mide la rentabilidad de una inversión, es decir, la relación que existe entre la utilidad neta o la ganancia obtenida, y la inversión.

- SI (Sistema de Información)

Un sistema de información se puede definir técnicamente como un conjunto de componentes relacionados que recolectan (o recuperan), procesan, almacenan y distribuyen información para apoyar la toma de decisiones y el control en una organización.

\section{- TIC}

TIC es la abreviatura para referirse a las Tecnologías de la información y la comunicación. Las TIC son un conjunto de tecnologías desarrolladas para una información y comunicación más eficiente.

Las TIC son compuestas por las tecnologías que se definen como productos innovadores donde la ciencia y la ingeniería trabajan en conjunto para desarrollar aparatos que resuelven problemas del día a día.

- TI (Tecnología de Información)

Es la aplicación de ordenadores y equipos de telecomunicación para almacenar, recuperar, transmitir y manipular datos, con frecuencia utilizado en el contexto de los negocios u otras empresas.

- TOGAF (Esquema de Arquitectura del Open Group) 


\section{(1)}

Es marco de trabajo de Arquitectura Empresarial que proporciona un enfoque para el diseño, planificación, implementación y gobierno de una arquitectura empresarial de información.

- COSO (Committee of Espónsor ing Organizations of the Treadway Commission)

Es un documento que contiene las principales directivas para la implantación, gestión y control de un sistema de control.

- SOX (Sarbanes-Oxley)

Es una ley de Estados Unidos también conocida como la Ley de Reforma de la Contabilidad Pública de Empresas y de Protección al Inversionista.

- $\quad$ ERM (Enterprise Risk Management)

La Gestión Integral de Riesgos forma parte de las buenas prácticas de gestión empresarial y es un proceso que permite tratar eficazmente la incertidumbre, identificando riesgos y oportunidades, y optimizando la capacidad de generar valor.

- COBIT (Control Objectives for Information and related Technology)

Es un modelo para auditar la gestión y control de los sistemas de información y tecnología, orientado a todos los sectores de una organización, es decir, administradores IT, usuarios y por supuesto, los auditores involucrados en el proceso.

- $\quad$ NIIF - IFRS (International Financial Reporting Standards)

Son estándares técnicos contables adoptadas por el IASB, institución privada con sede en Londres.

- ERP (Enterprise Relationship Management)

Los sistemas de planificación de recursos empresariales.

- CRM (Customer Relationship Management) 
Describe el conjunto de los sistemas informáticos, basados en la web o en un software, que ayudan a las empresas a organizar la información que servirá para desarrollar acciones de marketing, ventas y servicio al cliente.

- $\quad$ SCM (Supply Chain Management)

Consiste en el seguimiento de los materiales, la información y las finanzas durante el proceso que va del proveedor al fabricante, al mayorista, al minorista, y al consumidor.

- BI (Business Intelligence)

Es la habilidad para transformar los datos en información, y la información en conocimiento, de forma que se pueda optimizar el proceso de toma de decisiones en los negocios. 


\section{(1)}

\section{REFERENCIAS BIBLIOGRÁFICAS}

ARES, J. (3 de Febrero de 2014). Una visión general del ciclo ADM de TOGAF. Recuperado el 15 de Septiembre de 2017, de Una visión general del ciclo ADM de TOGAF: https://www.netmind.es/knowledge-center/vision-general-del-ciclo-architecturedevelopment-method-adm-de-togaf-33/

Bara, M. (13 de Abril de 2015). Las 5 etapas en los "Sprints" de un desarrollo Scrum. Recuperado el 8 de Octubre de 2017, de Las 5 etapas en los "Sprints" de un desarrollo Scrum: https://www.obs-edu.com/int/blog-investigacion/project-management/las-5etapas-en-los-sprints-de-un-desarrollo-scrum

Canós, J. H. (12 de Noviembre de 2003). Métodologías Ágiles en el Desarrollo de Software. Recuperado el 16 de Septiembre de 2017, de Métodologías Ágiles en el Desarrollo de Software: http://issi.dsic.upv.es/archives/f-1069167248521/actas.pdf

Casanova, S. (1 de Octubre de 2015). Dinámica de retrospectiva en Scrum línea de tiempo. Recuperado el 15 de Octubre de 2017, de Dinámica de retrospectiva en Scrum línea de tiempo: https://samuelcasanova.com/2015/10/dinamica-de-retrospectiva-en-scrumlinea-de-tiempo/

Casanova, S. (01 de Enero de 2016). Estimación ágil con la técnica Planning Poker. Obtenido de Estimación ágil con la técnica Planning Poker: https://samuelcasanova.com/2016/01/estimacion-agil-con-la-tecnica-planning-poker/

DIGITAL, J. P. (17 de Enero de 2017). https://jeronimopalacios.com/scrum/. Recuperado el 15 de Ocyubre de 2017, de https://jeronimopalacios.com/scrum/: https://jeronimopalacios.com/page/3/

DRAGÓN A. (24 de Febrero de 2012). Juegos para la improvisación. Recuperado el 5 de Octubre de 2017, de Juegos para la improvisación.

Ernst \& Young. (15 de Septiembre de 2017). Dos personas. Una visión. Recuperado el 15 de Septiembre de 2017, de Dos personas. Una visión.: http://www.ey.com/pe/es/aboutus/our-people-and-culture/our-history

ESPOL, B. (1 de Septiembre de 2010). SCRUM, METODOLOGÍA DE DESARROLLO DE SOLFTWARE ÁGIL. Obtenido de SCRUM, METODOLOGÍA DE DESARROLLO 


\section{$(1)$}

DE SOLFTWARE ÁGIL: http://blog.espol.edu.ec/elpoli/scrum-metodologia-dedesarrollo-de-solftware-agil/

EY Vision. (15 de Enero de 2013). Our vision,values and impact. Recuperado el 20 de Septiembre de 2017, de Our vision,values and impact: http://www.ey.com/Publication/vwLUAssets/Our_vision,_values_and_impact:_UN_ Global_Compact_2013/\$FILE/Our\%20vision,\%20values\%20and\%20impact\%20\%20UN\%20Global\%20Compact\%202013.pdf

Galeano, E. (25 de Abril de 2013). 10 dinámicas y actividades de team building para "romper el hielo”. Recuperado el 3 de Octubre de 2017, de 10 dinámicas y actividades de team building para "romper el hielo": http://utopia-consultores.com/10-dinamicas-yactividades-de-team-building-para-romper-el-hielo-segunda-parte/

Global Logic. (26 de Octubre de 2016). Cómo priorizar el backlog en Metodologías Ágiles. Recuperado el 16 de Octubre de 2017, de Cómo priorizar el backlog en Metodologías Ágiles: https://www.globallogic.com/latam/gl_news/como-priorizar-el-backlog-enmetodologias-agiles/

INTRODUCTION TO AUDITING. (s.f.). INTRODUCTION TO AUDITING. Obtenido de INTRODUCTION

http://archive.mu.ac.in/myweb_test/study\%20TYBCom\%20Accountancy\%20Auditin g-II.pdf

JM, G. (17 de Octubre de 2010). Poker de planificación ágil. Recuperado el 15 de Octubre de Septiembre, de Poker de planificación ágil: https://www.garethjmsaunders.co.uk/2010/04/17/agile-planning-poker/

Mejía, M. I. (2 de Diciembre de 2013). El camino hacia un gobierno integrado. Recuperado el 15 de Septiembre de 2017, de El camino hacia un gobierno integrado: http://www.mintic.gov.co/gestionti/615/articles-5322_Revista_pdf.pdf

Molano, A. (27 de Enero de 2015). Colombia Digital. Recuperado el 15 de Septiembre de 2017, de Colombia Digital: https://colombiadigital.net/actualidad/articulosinformativos/item/8123-que-es-arquitectura-empresarial.html

ORTIZ, E. J. (1 de Diciembre de 2010). Arquitectura Empresarial: Un Nuevo reto Para Las Empresas De Hoy. Recuperado el 18 de Septiembre de 2017, de Arquitectura Empresarial: Un Nuevo reto Para Las Empresas De Hoy: 
http://www.academia.edu/15157112/ARQUITECTURA_EMPRESARIAL_UN_NUE VO

Palacios, J. (17 de Enero de Guía fundamental de Scrum). https://jeronimopalacios.com/scrum/. Recuperado el 15 de Ocyubre de 2017, de Guía fundamental de Scrum: https://jeronimopalacios.com/scrum/

Romeu, A. (9 de Septiembre de 2014). Planning poker - ¿Cómo planificar un sprint en Scrum? - Obtenido de Planning poker - ¿Cómo planificar un sprint en Scrum? : http://albertoromeu.com/scrum-planning-poker/

SBOK. (2017). A Guide to the Scrum Body Of Knowledge (SBOK ${ }^{\mathrm{TM} G u i d e)}-3 r d$ Edition. Arizona: Scrum Study.

SBOK, G. (2017). A Guide to the Scrum Body Of Knowledge (SBOK ${ }^{\mathrm{TM}}$ Guide) - 3rd Edition. Arizona: Scrum Study.

Slideshare. (11 de Junio de 2014). Metodología SCRUM . Obtenido de Metodología SCRUM : https://es.slideshare.net/carmen1589/metodologia-scrum-35728388

The open group. (2 de Diciembre de 2011). TOGAF® VERSIÓN 9.1. Recuperado el 15 de Septiembre de 2017, de TOGAF® VERSIÓN 9.1: https://publications.opengroup.org/g116

Velázquez, A. (4 de Agosto de 2006). Un Método para definir la Arquitectura de Procesos. Recuperado el 18 de Septiembre de 2017, de Un Método para definir la Arquitectura de

Procesos:

https://pdfs.semanticscholar.org/1fb9/d129523eec8b33eab860378a06e732885c83.pdf

Zachman. (1987). A Framework for Information Systems Architecture,IBM Systems Journal.

En J. Zachman, A Framework for Information Systems Architecture,IBM Systems Journal (págs. 26,3). 


\section{ANEXOS}

Anexo 1 - Matriz de Probabilidad e Impacto de EY

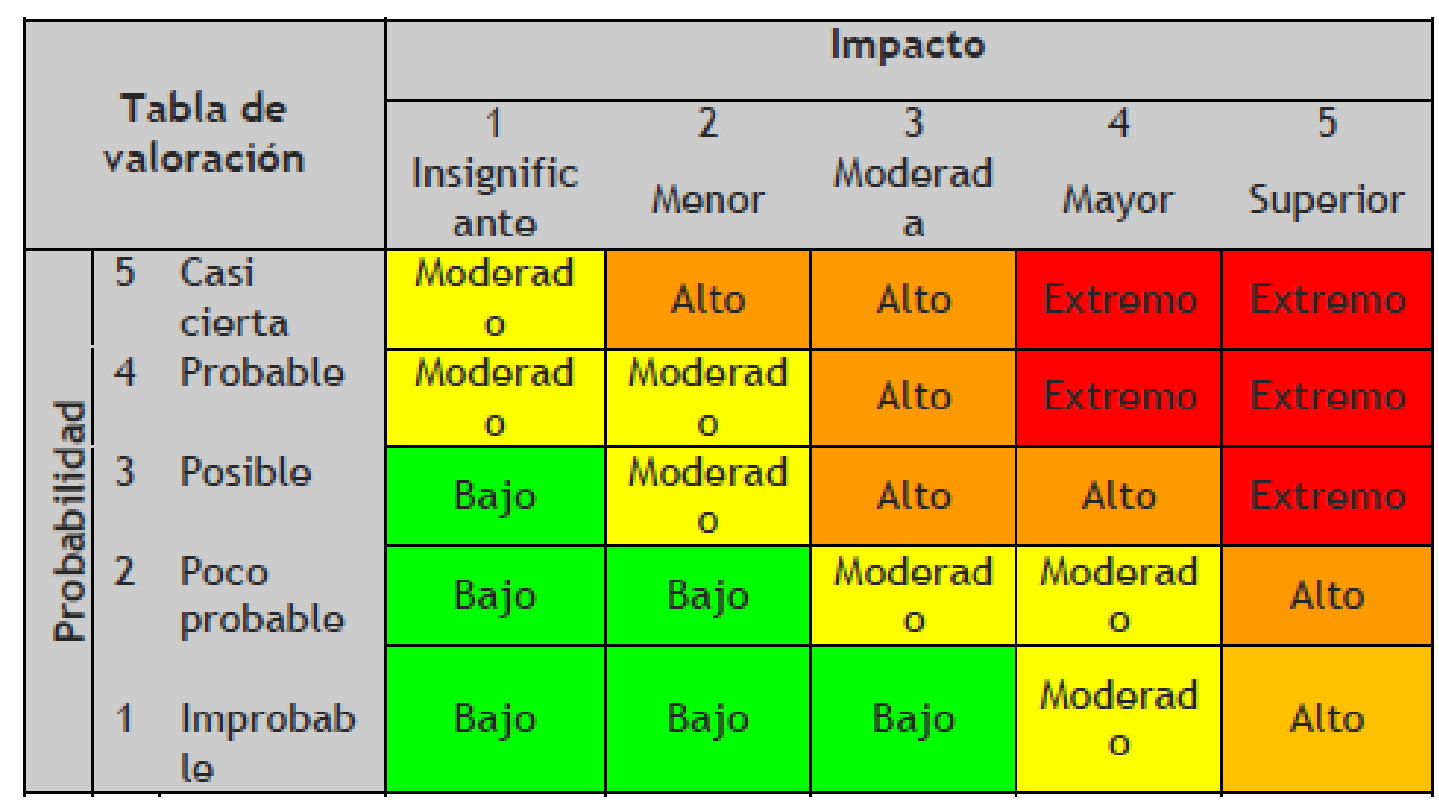




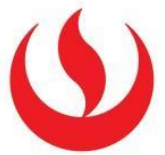

Anexo 2 - Valores de Probabilidad del Riesgo

\section{Probabilidad $^{3}$ :}

\begin{tabular}{|l|l|l|c|}
\hline Rango & Posibilidad de ocurrencia & $\begin{array}{c}\text { Frecuencia del } \\
\text { evento }\end{array}$ & Valor \\
\hline Improbable & Ocurrencia excepcional & $\begin{array}{l}\text { Menos de una vez } \\
\text { en cinco años }\end{array}$ & 1 \\
\hline Poco probable & $\begin{array}{l}\text { Poca posibilidad de } \\
\text { ocurrencia }\end{array}$ & $\begin{array}{l}\text { Al menos una vez } \\
\text { en cinco años }\end{array}$ & 2 \\
\hline Posible & Posible ocurrencia & $\begin{array}{l}\text { Al menos una vez } \\
\text { en dos años }\end{array}$ & 3 \\
\hline Probable & $\begin{array}{l}\text { Debería ocurrir en pocas } \\
\text { circunstancias }\end{array}$ & $\begin{array}{l}\text { Al menos una vez } \\
\text { en un año }\end{array}$ & 4 \\
\hline Casi cierto & $\begin{array}{l}\text { Debería ocurrir en muchas } \\
\text { circunstancias }\end{array}$ & $\begin{array}{l}\text { Al menos 5 veces } \\
\text { en un año }\end{array}$ & 5 \\
\hline
\end{tabular}




\section{Anexo 3 - Valores de Impacto del Riesgo}

Impacto $^{4}$ :

\begin{tabular}{|l|l|c|c|}
\hline Rango & \multicolumn{1}{|c|}{ Descripción } & Económico S/. & Valor \\
\hline Insignificante & $\begin{array}{l}\text { El riesgo tiene un efecto } \\
\text { nulo o pequeño en el } \\
\text { desarrollo del proceso. } \\
\text { Incremento hasta el 10\% de } \\
\text { reclamos fundados de } \\
\text { cliente con periodicidad } \\
\text { anual. } \\
\begin{array}{l}\text { Multas hasta 4 UIT' en un } \\
\text { periodo anual. }\end{array}\end{array}$ & 1 \\
\hline Menor & $\begin{array}{l}\text { El desarrollo del proceso } \\
\text { sufre un daño menor. } \\
\text { Incremento del 11\% al 20\% } \\
\text { de reclamos fundados de } \\
\text { cliente con periodicidad }\end{array}$ & 50,000 & 2 \\
\hline
\end{tabular}




\section{(}

\begin{tabular}{|l|l|l|l|}
\hline & $\begin{array}{l}\text { anual. } \\
\text { Multas desde 5 UIT hasta 14 } \\
\text { UIT en un periodo anual. }\end{array}$ & \\
\hline Moderada & $\begin{array}{l}\text { El desarrollo del proceso } \\
\text { sufre un deterioro } \\
\text { dificultando o retrasando su } \\
\text { cumplimionto. } \\
\text { Incremento del 21\% al 30\% } \\
\text { de reclamos fundados de } \\
\text { cliente con periodicidad } \\
\text { anual } \\
\text { Multas desde 15 UIT hasta 27 } \\
\text { UIT en un periodo anual }\end{array}$ & 100,000 & 3 \\
\hline Mayor & $\begin{array}{l}\text { El desarrollo del proceso es } \\
\text { afectado significativamente. } \\
\text { Incremento del 31\% al 50\% } \\
\text { de reclamos fundados de } \\
\text { cliente con periodicidad } \\
\text { anual. } \\
\text { Multas desde 28 UIT hasta 68 } \\
\text { UIT en un periodo anual. }\end{array}$ & \\
\hline Superior & $\begin{array}{l}\text { El desarrollo del proceso es } \\
\text { dañado gravemente. } \\
\text { Incremento mayor al 50\% de } \\
\text { reclamos fundados de } \\
\text { cliente con periodicidad } \\
\text { anual. } \\
\text { Multas mayores a 68 UIT on } \\
\text { un periodo anual. }\end{array}$ & \\
\hline
\end{tabular}

(*) UIT: Unidad Impositiva Tributaria. 


\section{(1)}

Anexo 4 - Tabla de Valoración de Controles

\begin{tabular}{|c|c|c|c|c|}
\hline & Clasificacion & Descripcion & Valores & Ponderación \\
\hline \multirow{3}{*}{$\begin{array}{l}\frac{\pi}{\pi} \\
\frac{\pi}{0} \\
\frac{1}{3} \\
0 \\
0 \\
0\end{array}$} & Preventivo (Pv) & $\begin{array}{l}\text { Controles claves que actúan antes o al } \\
\text { inicio de un proceso }\end{array}$ & $100 \%$ & \multirow{3}{*}{$40 \%$} \\
\hline & Detectivo (Dt) & $\begin{array}{l}\text { Controles claves que actúan durante el } \\
\text { proceso y que permiten corregir las } \\
\text { deficiencias. }\end{array}$ & $60 \%$ & \\
\hline & Correctivo $(\mathrm{Cr})$ & $\begin{array}{l}\text { Controles claves que solo actúan una vez } \\
\text { que el proceso ha terminado }\end{array}$ & $20 \%$ & \\
\hline \multirow{3}{*}{ 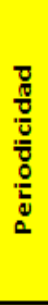 } & Permanente (Pe) & $\begin{array}{l}\text { Controles claves aplicados durante el } \\
\text { proceso, es decir en cada operación }\end{array}$ & $100 \%$ & \multirow{3}{*}{$25 \%$} \\
\hline & Periódico (Pd) & $\begin{array}{l}\text { Controles claves aplicados en forma } \\
\text { constante sólo cuando ha transcurrido un } \\
\text { período especifico de tiempo }\end{array}$ & $60 \%$ & \\
\hline & Ocasional (Oc) & $\begin{array}{l}\text { Controles claves que se aplican en forma } \\
\text { ocasional en un proceso }\end{array}$ & $20 \%$ & \\
\hline \multirow{4}{*}{ 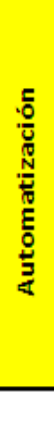 } & $100 \%$ Automatizado (At) & $\begin{array}{l}\text { Controles claves incorporados en los } \\
\text { sistemas informatizados }\end{array}$ & $100 \%$ & \multirow{3}{*}{$35 \%$} \\
\hline & Semi-automatizada (Sa) & $\begin{array}{l}\text { Controles claves incorporados en el } \\
\text { proceso, cuya aplicación es parcialmente } \\
\text { desarrollada mediante sistemas } \\
\text { informatizados }\end{array}$ & $60 \%$ & \\
\hline & Manual (Ma) & $\begin{array}{l}\text { Controles claves incorporados en el } \\
\text { proceso, cuya aplicación no considera el } \\
\text { uso de sistemas informatizados }\end{array}$ & $20 \%$ & \\
\hline & & \multicolumn{2}{|l|}{ Puntaje Máximo } & $100 \%$ \\
\hline
\end{tabular}




\section{Anexo 5 - Resultado de Operatividad de Controles}

\begin{tabular}{|c|c|c|c|c|c|c|c|c|c|c|c|c|c|}
\hline \multirow{3}{*}{$\begin{array}{c}\text { Código } \\
\text { de } \\
\text { Riesgo }\end{array}$} & \multirow{3}{*}{ Evento de Riesgo } & \multirow{3}{*}{ Causa del evento de riesgo } & \multicolumn{6}{|c|}{$\begin{array}{l}\text { Riesgo Absoluto } \\
\text { (NRA) }\end{array}$} & \multicolumn{3}{|c|}{ Control } & \multicolumn{2}{|c|}{$\begin{array}{l}\text { Evaluación } \\
\text { Controle }\end{array}$} \\
\hline & & & 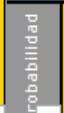 & Sustento probabilidad & 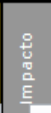 & Sustento impacto & 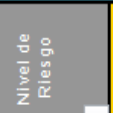 & $\begin{array}{c}\text { Pédida esperada } \\
\text { (inherente) }\end{array}$ & Código control & Descripción del Control & \begin{tabular}{|l|} 
Respons bile \\
Principal del Controul
\end{tabular} & 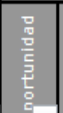 & $\frac{\square}{\square}$ \\
\hline & & & के & 7 & 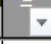 & $\checkmark$ & $2-7$ & $\checkmark$ & $\nabla$ & $\nabla$ & $\checkmark$ & 界 & is \\
\hline \multirow[t]{4}{*}{ R01 } & \multirow[t]{4}{*}{\begin{tabular}{|l|} 
Que se exponga al Banco a \\
pérdias económicas y/o sanciones \\
por reclamos de clientes, debido a \\
la información errada sobre el \\
producto o sus beneficicios.
\end{tabular}} & $\begin{array}{l}\text { La presión de cumplimiento de } \\
\text { metas, podría llevar a que ell } \\
\text { Ejecutivo de Negocios comunique } \\
\text { |ccaracteŕsticas o b benficios } \\
\text { inexistentes acerca del producto. }\end{array}$ & \multirow{2}{*}{\begin{tabular}{|l|l} 
& \\
$e$ \\
en \\
\end{tabular}} & \multirow[t]{2}{*}{ 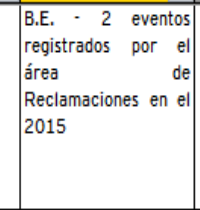 } & \multirow[t]{2}{*}{1} & \multirow[t]{2}{*}{$\left|\begin{array}{l}\text { Impacto menor a } \\
15 \text { mil soles }\end{array}\right|$} & \multirow[t]{2}{*}{ B } & \multirow[t]{2}{*}{15,000} & \multirow[t]{2}{*}{ C1 } & \multirow[t]{2}{*}{$\begin{array}{l}\text { Cada vez que el Ejecutivo de Negocios visita a un cliente para } \\
\text { informarle acerca de las características y beneficios del } \\
\text { producto; el Ejecutivo de Negocios Leasing asiste, a fin de } \\
\text { ressaldar y verificar que la información proporcioinada al } \\
\text { ciente es correcta. }\end{array}$} & \multirow[t]{2}{*}{\begin{tabular}{|l} 
Ejecutivo de \\
Negocios Leasing
\end{tabular}} & \multirow[t]{2}{*}{$\mathrm{Pv}$} & \multirow[t]{2}{*}{$\mathrm{Pe}$} \\
\hline & & $\begin{array}{l}\begin{array}{l}\text { Desconocimiento del producto por } \\
\text { parte del Ejecutivo de Negocios. }\end{array} \\
\end{array}$ & & & & & & & & & & & \\
\hline & & 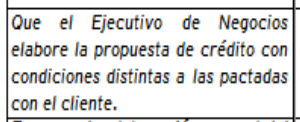 & 3 & 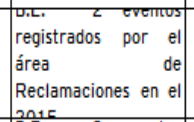 & 1 & $\begin{array}{l}\text { Impacto menor a } \\
15 \text { mil soles }\end{array}$ & B & & c2 & $\begin{array}{l}\text { Cada vez que el Ejecutivo de Negocios elabora una propuesta } \\
\text { de crédito; a través del sistema Coreview, el Ejecutivo de } \\
\text { Negocios Leasing verifica que las condiciones del crédito se } \\
\text { encuentren conforme. }\end{array}$ & $\begin{array}{l}\text { Ejecutivo de } \\
\text { Negocios Leasing }\end{array}$ & Pv & $\mathrm{Pe}$ \\
\hline & & $\begin{array}{l}\text { Error en la elaboración manual del } \\
\text { cronograma, debido a a una } \\
\text { incorrecta digitación de información } \\
\text { o falta de capacitación del personal } \\
\text { eiecuttor. }\end{array}$ & 3 & $\mid \begin{array}{lrr}\text { B.E. } & 2 & \text { eventos } \\
\text { registrados } & \text { por } & \text { el } \\
\text { área } & & \text { de } \\
\text { Reclamaciones } & \text { en el } \\
2015 & & \end{array}$ & 1 & $\begin{array}{l}\text { Impacto menor a } \\
15 \text { mil soles }\end{array}$ & B & & C3 & $\begin{array}{l}\text { Cada vez que el Ejecutivo de Negocios Leasing elabora el } \\
\text { cronograma en base a las condiciones establecidas en la } \\
\text { propuesta, el Jefe Comercial revisa el cronograma, a fin de } \\
\text { dar su conformidad. }\end{array}$ & Jefe Comercial & $\mathrm{Pv}$ & $\mathrm{Pe}$ \\
\hline \multirow[t]{2}{*}{ R02 } & \multirow[t]{2}{*}{$\begin{array}{l}\text { Que se exponga al Banco a una } \\
\text { pérdida económica por aprobar y } \\
\text { desembolsar un crédito a un } \\
\text { cliente, bajo criterios incorrectos } \\
\text { debiodo a información } \\
\text { desactualizzada, errónea y/o falsa. }\end{array}$} & $\begin{array}{l}\text { Falta de revisión critica por parte } \\
\text { del Asistente / Analista de Riesgos, } \\
\text { con respocto a la información } \\
\text { sustento de evaluación. }\end{array}$ & 5 & $\left|\begin{array}{l}\text { B.E. - } 23 \text { clientes han } \\
\text { pasado } \\
\text { recuperaciociones en el } \\
\text { útimo año }\end{array}\right|$ & 5 & $\begin{array}{l}\text { B.E.- } \\
\text { Monto promedio de } \\
\text { Leasing: \$3.5 MM } \\
\text { Monto de } 23 \text { cliente } \\
\text { en recuperaciones: } \\
\text { \$4.307MM }\end{array}$ & E & $11,830,000$ & C4 & $\begin{array}{l}\text { Cada vez que el Asistente de Riesgos recepciona la propuesta } \\
\text { de crédito, verifica a través del check list, que contenga la } \\
\text { documentación correspondiente y además, se encuentre } \\
\text { vigente, completo y firmado; además, corrobora que Ia } \\
\text { información registrada en el sistema IBS se encuentre } \\
\text { correcta. En caso los documentos sustento de la propuesta no } \\
\text { se encuentren conforme, solicita al Ejecutivo de Negocios } \\
\text { mediante mail, con copia al Asistente de Negocios y Analista } \\
\text { de Riesgos, regularizar los documentos indicados. }\end{array}$ & Asistente de Riesgos & $\mathrm{Pv}$ & $\mathrm{Pe}$ \\
\hline & & $\begin{array}{l}\text { Falta de capacitación del Analista } \\
\text { de Riesgos, con respecto a la } \\
\text { evallarión a realizar }\end{array}$ & 5 & $\left|\begin{array}{lr}\text { B.E. }-23 \text { clientes han } \\
\text { pasado } & a \\
\text { recuperacioines en el }\end{array}\right|$ & 5 & $\begin{array}{l}\text { B.E.- } \\
\text { Monto promedio de } \\
\text { Ieasinn } ₫ 35 \mathrm{MM}\end{array}$ & $\mathrm{E}$ & 187,261 & C5 & 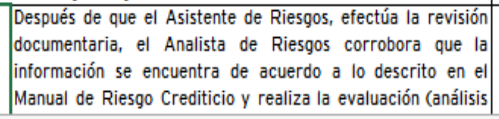 & Analista de Riesgos & $\mathrm{Pv}$ & $\mathrm{Pe}$ \\
\hline$\ldots$ & Resumen riesgos BE Leasing & Ig Matriz Riesgos - BE Car & ampos & Tabla de valores & & 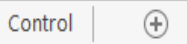 & & & & & & & \\
\hline
\end{tabular}




\section{(1)}

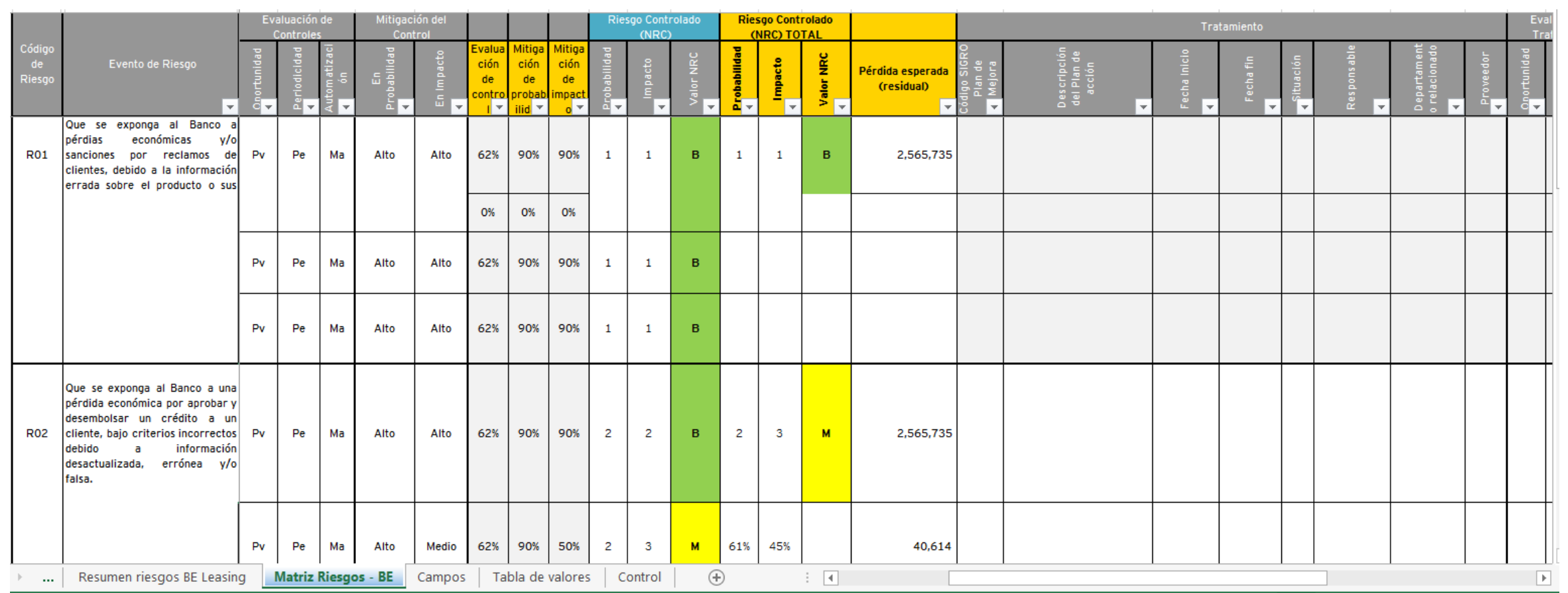




\section{Anexo 6 - Plantilla de Solicitud de Control de Cambio}

FORMULARIO CONTROL DE CAMBIOS

\begin{tabular}{|c|c|c|}
\hline & AÑO : 2011 & FOLIO : \\
\hline \multirow{2}{*}{\multicolumn{3}{|c|}{ Fecha de la Solicitud }} \\
\hline & & \\
\hline \multicolumn{3}{|l|}{ Nombre Solicitante } \\
\hline \multicolumn{3}{|l|}{ Sección o Unidad } \\
\hline \multicolumn{3}{|l|}{ Rut } \\
\hline \multicolumn{3}{|l|}{ Cargo } \\
\hline \multicolumn{3}{|l|}{ Fono/Anexo } \\
\hline \multicolumn{3}{|l|}{ E-Mail } \\
\hline \multicolumn{3}{|l|}{ Responsable Producción } \\
\hline \multicolumn{3}{|l|}{ Servicio o Proyecto } \\
\hline Responsable Sala de Operaciones & & \\
\hline Responsable del Cambio & & \\
\hline
\end{tabular}

\begin{tabular}{|l|}
\hline 2. Tipo de Cambio \\
\hline 5 Cambio Programado \\
\hline Cambio no programado \\
\hline
\end{tabular}

\begin{tabular}{|l|}
\hline 3. Objetivo del Cambio \\
\hline
\end{tabular}

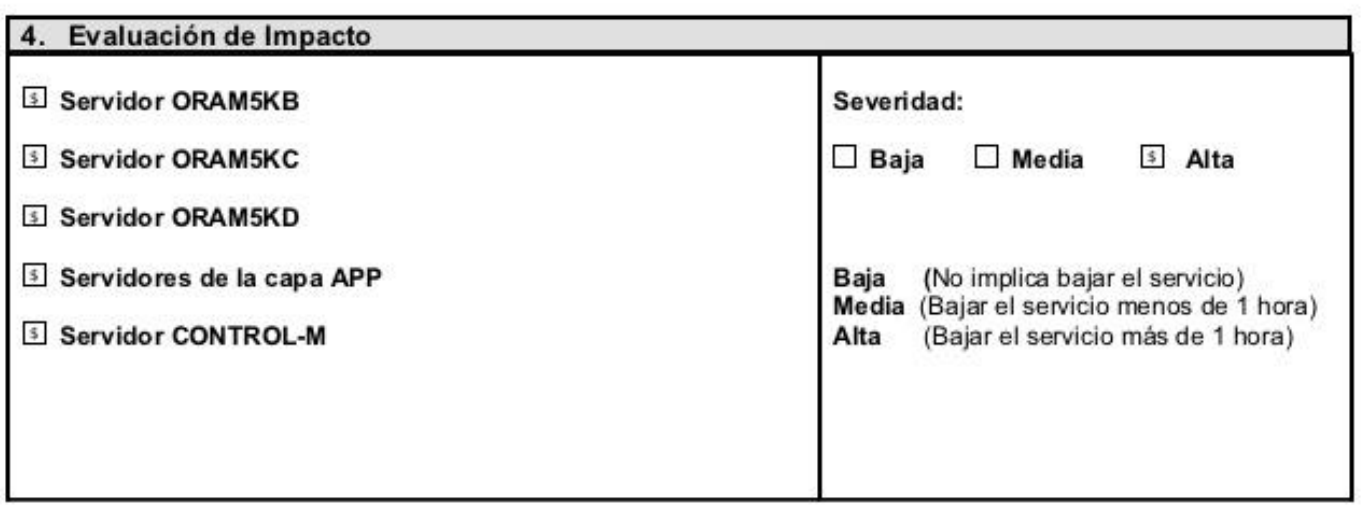




\section{(1)}

\section{Anexo 7 - Propuesta de Compra Servicio Azure}

Sr.

Andree Galdos

Ernst \& Young - Perú

Presente. -

Estimado Andres,

De acuerdo a su solicitud me es grato remitirle nuestra propuesta económica respecto al siguiente servicio:

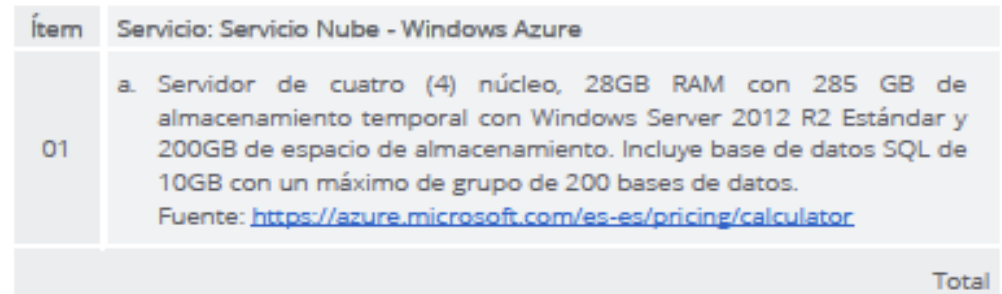

Ítem Servicio: Implementación de servidor y servicio Windows Azure

a. Configuración de Windows Azure

01 b. Implementación y habilitación de servidor

c. Informe y capacitación de dos (2) horas

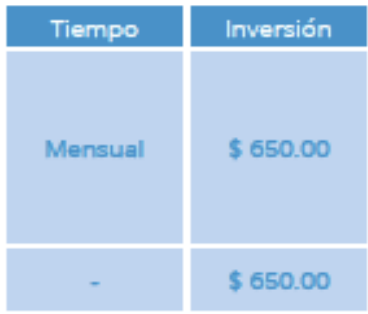

\begin{tabular}{|c|c|}
\hline Tiempo & Inversión \\
\hline 2 Semanas & $\$ 4,900.00$ \\
\hline 2 Semanas & $\$ 4,900.00$ \\
\hline
\end{tabular}

\section{Consideraciones generales:}

1. Los trabajos se iniciarán luego de la recepción de nuestra factura

2. Garantía por servicios: Dos (2) meses.

3. Forma de pago: $50 \%$ al inicio, $50 \%$ al final.

4. Precio: expresado en dólares americanos, no incluye I.G.V.

Sin otro particular, quedamos a sus órdenes para cualquier consulta adicional.

Agustín Combe

-Gerente Soluciones Tecnológicas
Martín Súnico

Gerente Comercial 


\section{(}

\section{Anexo 8 - Agile Project Charter}

\section{Agile Project Charter}

\begin{tabular}{|l|l|}
\hline General Project Information \\
\hline Project Name & \\
\hline Project Champion & \\
\hline Project Sponsor & \\
\hline Project Manager & \\
\hline Stakeholders & \\
\hline Expected Start Date & \\
\hline Expected Completion Date & \\
\hline
\end{tabular}

\section{Project Details}

Mission

Vision

Scope

Success Metrics

Date: Date: 